U.S. Department

of Transportation

National Highway

Traffic Safety

Administration

DOT HS 811518

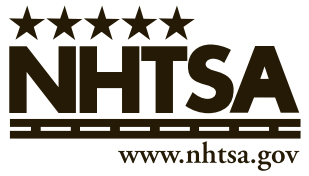

September 2011

\title{
Evaluation of Teen Seat Belt Demonstration Projects in Colorado and Nevada
}




\section{DISCLAIMER}

This publication is distributed by the U.S. Department of Transportation, National Highway Traffic Safety Administration, in the interest of information exchange. The opinions, findings, and conclusions expressed in this publication are those of the authors and not necessarily those of the Department of Transportation or the National Highway Traffic Safety Administration. The United States Government assumes no liability for its contents or use thereof. If trade names, manufacturers' names, or specific products are mentioned, it is because they are considered essential

to the object of the publication and should not be construed as an endorsement. The United States Government does not endorse products or manufacturers. 
Technical Report Documentation Page

\begin{tabular}{|c|c|c|c|}
\hline $\begin{array}{l}\text { 1. Report No. } \\
\text { DOT HS } 811518\end{array}$ & 2. Government Accession No. & \multicolumn{2}{|c|}{ 3. Recipients' Catalog No. } \\
\hline \multirow{2}{*}{\multicolumn{2}{|c|}{$\begin{array}{l}\text { 4. Title and Subtitle } \\
\text { Evaluation of Teen Seat Belt Demonstration Projects } \\
\text { in Colorado and Nevada }\end{array}$}} & \multicolumn{2}{|c|}{$\begin{array}{l}\text { 5. Report Date } \\
\text { September } 2011\end{array}$} \\
\hline & & \multicolumn{2}{|c|}{ 6. Performing Organization Code NTI-132 } \\
\hline \multicolumn{2}{|c|}{$\begin{array}{l}\text { 7. Author(s) } \\
\text { J. Nichols, E. Haire, M. Solomon, P. Ellison-Potter, } \\
\text { and L. Cosgrove }\end{array}$} & \multicolumn{2}{|c|}{ 8. Performing Organization Report No. } \\
\hline \multirow{2}{*}{\multicolumn{2}{|c|}{$\begin{array}{l}\text { 9. Performing Organization Name and Address } \\
\text { Preusser Research Group, Inc. } \\
7100 \text { Main Street } \\
\text { Trumbull, CT } 06611\end{array}$}} & \multicolumn{2}{|c|}{ 10. Work Unit No. (TRAIS)n code } \\
\hline & & \multicolumn{2}{|c|}{$\begin{array}{l}\text { 11. Contract of Grant No. } \\
\text { DTNH22-05-D-15043, Task Order } 0010\end{array}$} \\
\hline \multirow{2}{*}{\multicolumn{2}{|c|}{$\begin{array}{l}\text { 12. Sponsoring Agency Name and Address } \\
\text { National Highway Traffic Safety Administration } \\
\text { U.S. Department of Transportation } \\
1200 \text { New Jersey Avenue SE. } \\
\text { Washington, DC } 20590\end{array}$}} & \multicolumn{2}{|c|}{$\begin{array}{l}\text { 13. Type of Report and Period Covered } \\
\text { NHTSA Technical Report } \\
\text { Final Report } \\
\text { June 1, } 2007 \text { - May 31, } 2009\end{array}$} \\
\hline & & \multicolumn{2}{|c|}{ 14. Sponsoring Agency Code } \\
\hline \multicolumn{4}{|c|}{$\begin{array}{l}\text { 15.Supplementary Notes } \\
\text { Patty Ellison-Potter, Ph.D., served as the NHTSA Contracting Officer's Technical Representative for this } \\
\text { study. }\end{array}$} \\
\hline \multicolumn{4}{|c|}{$\begin{array}{l}\text { 16. Abstract } \\
\text { Colorado and Nevada initiated multiwave Teen Seat Belt Demonstration Projects in October } 2007 \text {. Four } \\
\text { waves of paid media and law enforcement activity were conducted over the next year. Three of these waves } \\
\text { were conducted independently of statewide Click It or Ticket (CIOT) mobilizations, and one wave was con- } \\
\text { ducted immediately prior to the May } 2008 \text { CIOT effort. Program data indicate that these were "strong" pro- } \\
\text { grams, and awareness surveys indicated that media efforts and law enforcement agencies successfully im- } \\
\text { pacted the target population of teens } 16 \text { to } 20 \text { years old. Baseline use rates were substantially higher in Ne- } \\
\text { vada than in Colorado; and, in Nevada, baselines were higher among college students than among high } \\
\text { school students. Teen seat belt use increased significantly in both States. Overall gains of } 5 \text { percentage } \\
\text { points in Colorado and } 8 \text { points in Nevada were substantial, particularly given that both States have second- } \\
\text { ary enforcement laws and low fine levels ( } \$ 20 \text { in Colorado; } \$ 25 \text { in Nevada). It is likely that greater gains } \\
\text { could be made with passage of a primary law upgrade and/or an increase in fine levels in either or both of } \\
\text { these States. }\end{array}$} \\
\hline \multicolumn{2}{|c|}{$\begin{array}{l}\text { 17. Key Words } \\
\text { Novice driver, Young driver, Teen driver, Occupant } \\
\text { Protection, Click It Or Ticket, Teen Seat Belt Dem- } \\
\text { onstration, Teen Seat Belt Use, Colorado Seat Belt } \\
\text { Demonstration, Nevada Seat Belt Demonstration, } \\
\text { Teen crash }\end{array}$} & \multicolumn{2}{|c|}{$\begin{array}{l}\text { 18. Distribution Statement } \\
\text { Document is available to the public from the } \\
\text { National Technical Information Service } \\
\text { www.ntis.gov }\end{array}$} \\
\hline $\begin{array}{l}\text { 19. Security Classif. (of this report) } \\
\text { Unclassified }\end{array}$ & $\begin{array}{l}\text { 20. Security Classif. (of this page) } \\
\text { Unclassified }\end{array}$ & $\begin{array}{l}\text { 21. No of Pages } \\
128\end{array}$ & 22. Price \\
\hline
\end{tabular}




\section{Executive Summary}

\section{Program Design}

The Teen Seat Belt Demonstration Projects described in this report were implemented in Colorado and Nevada from September 2007 to September 2008. They were based on a Special Traffic Enforcement Program (STEP) model in which publicity and enforcement activity are implemented according to a defined schedule. The program begins with outreach to involve State and local organizations and earned media to obtain news coverage. Next, a paid media campaign is implemented, followed by actual law enforcement. The paid media phase usually lasts for one full week, overlapping with one or two weeks of enforcement. Observational and awareness surveys are conducted at baseline (before outreach and earned media begin) and immediately after enforcement ends. When such a program is conducted in conjunction with a Click It or Ticket (CIOT) mobilization, each component is extended by one or two weeks.

\section{Program Schedule}

The Teen Seat Belt Demonstration Projects involved four waves of sTEP or high-visibility enforcement (HVE) program activity, one of which was implemented in conjunction with the May 2008 CIOT mobilization. Colorado and Nevada implemented these four waves according to slightly different schedules throughout 2007-2008. Surveys were conducted at baseline and after each program wave to measure changes in teen awareness of the program and changes in teen seat belt use rates.

\section{Targeted Areas}

The targeted areas were major population centers of each State including: the Colorado SpringsPueblo, Denver, and Grand Junction-Montrose media markets in Colorado; and the Las Vegas and Reno-Sparks media markets in Nevada. Virtually the entire population of both States was covered by these media markets, although enforcement was focused more in metropolitan areas.

\section{Program Message}

CIOT was the primary branding for the teen program, just as it is for statewide CIOT mobilizations. In addition, the paid advertising component of the program included enforcement-related ads for radio and for television that carried an "Out of Nowhere" theme, designed to send a message to teens that, if they are not buckled up, policeman can appear out of nowhere to give them tickets.

\section{Program Activity}

Outreach and Earned Media Outreach to the news media and various partner organizations resulted in scores of news stories and events associated with each program wave, usually in conjunction with news events or news releases just prior to each enforcement period. In Colorado, there was an average of about 60 television news stories and 50 print or Web stories associated 
with each wave (earned media). In Nevada, there was an average of about 30 television and 11 print or Web stories associated with each wave, but the greatest number of these articles and stories was associated with the first program wave.

Paid Media In addition to earned media, an average of $\$ 195,878$ was spent on paid media during each wave in Colorado and about $\$ 122,356$ was spent per wave in Nevada. Total expenditures for four waves of activity were $\$ 783,510$ in Colorado and $\$ 489,422$ in Nevada. Relative to the total population, Colorado spent a total of $\$ 0.16$ per capita over the entire year, an average of $\$ 0.04$ per wave. Nevada spent about $\$ 0.19$ per capita over all four waves, an average of about $\$ 0.05$ per wave. Looking only at the teen population age 16 to 20 , however, overall expenditures were about $\$ 2.45$ per capita in Colorado ( $\$ 0.61$ per wave) and $\$ 3.20$ per capita in Nevada ( $\$ 0.80$ per wave). These paid media efforts resulted in an average of more than 2,000 radio and television ads aired during each program wave, many times the number of earned media stories. In terms of gross rating points (GRPs), these ads resulted in just over 600 GRPs per wave in Colorado and 525 GRPs per wave in Nevada. Both averages indicate "strong" to "very strong" media programs. Television was the primary medium used by both States.

Enforcement The Colorado State Patrol and more than 40 local enforcement agencies in 11 populous counties participated in the Colorado teen program. These counties accounted for about $73 \%$ of the total population of the State. In Nevada, the Highway Patrol and local agencies in four counties participated in the program, covering more than $90 \%$ of the population of the State.

Each wave involved the use of enforcement zones and/or saturation patrols in areas and during times when teens were most likely to be driving (e.g., in areas near high schools or colleges). Overtime grants, agency and officer recognition programs, and incentives (usually equipment incentives) were used to encourage agency participation in the program.

On average, about 13 citations per 10,000 teens were issued for seat belt violations during each program period in each State. The highest citation rates were during Wave 4 of the Colorado program and during Wave 3 of the Nevada program, both of which preceded statewide CIOT mobilizations. Another measure of enforcement examined was the teen percentage of all tickets issued for seat belt violations. A high percentage was indicative of a program that was more heavily focused on teens because of the times and locations where enforcement was conducted. With regard to this measure, Nevada had the most concentrated program, with an average of $23 \%$ of seat belt tickets issued to teens, compared with $11 \%$ in Colorado. In both States, the teen percentage of total citations was much higher than the teen percentage of the driving population. These indices suggested that officers were able to focus their enforcement efforts in a way that affected unbuckled teens to a greater extent than traditional approaches used in the past.

\section{Outcomes: Changes in Teen Awareness}

The Colorado and Nevada Highway Safety Offices collected public awareness data. Two direct measures of media and enforcement activities were teen awareness of seat belt messages and teen awareness of special efforts by police to enforce seat belt laws. In addition, teen perceptions 
regarding the likelihood that they would be stopped and ticketed if they did not buckle up were measured, although this index has been highly variable in past demonstration projects.

The figures below show changes in these key indices from baseline through Wave 4. In Colorado, there was a 17-percentage-point increase in teen awareness of seat belt messages; a 20percentage-point increase in awareness of special police enforcement; and a 6-percentage-point increase in the perception that it would be very likely or certain that they would be stopped and ticketed if they did not buckle up. In Nevada increases in these measures were 17, 12, and 2 percentage points, respectively. Perceived risk of a ticket was highest after Wave 1 in both States.

Results of Key Awareness Indices in Colorado, by Wave

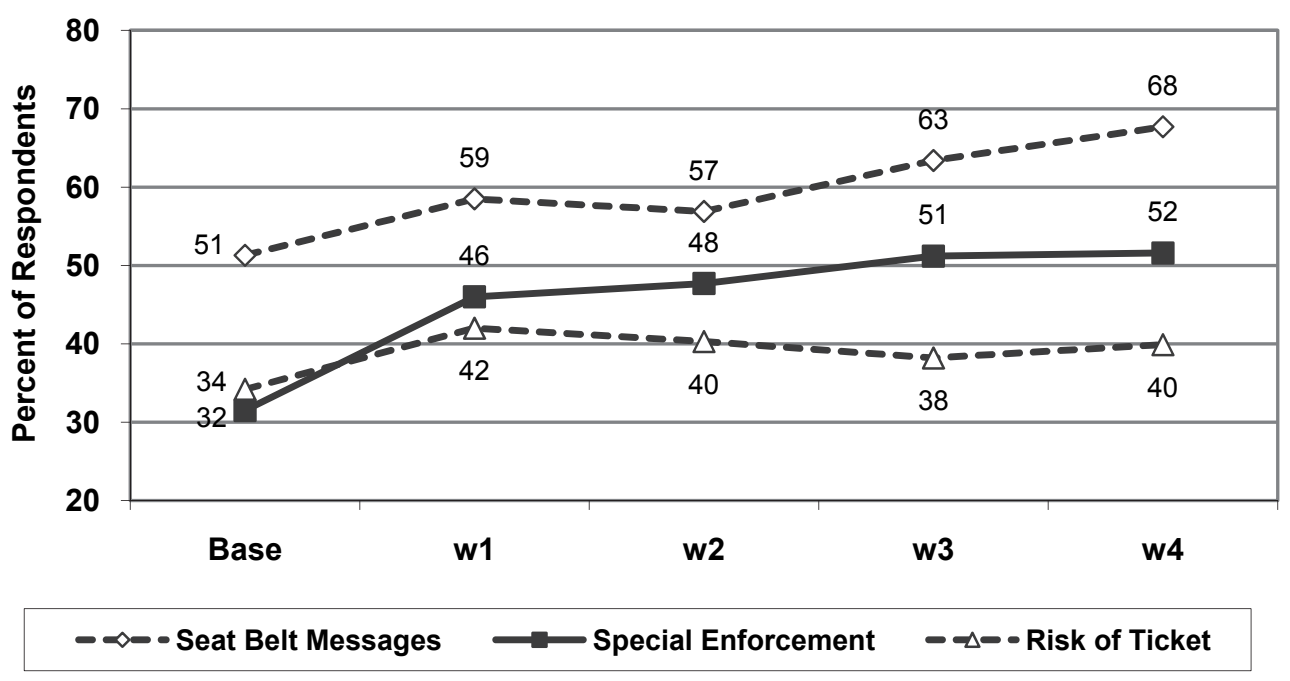

Results of Key Awareness Indices in Nevada, by Wave

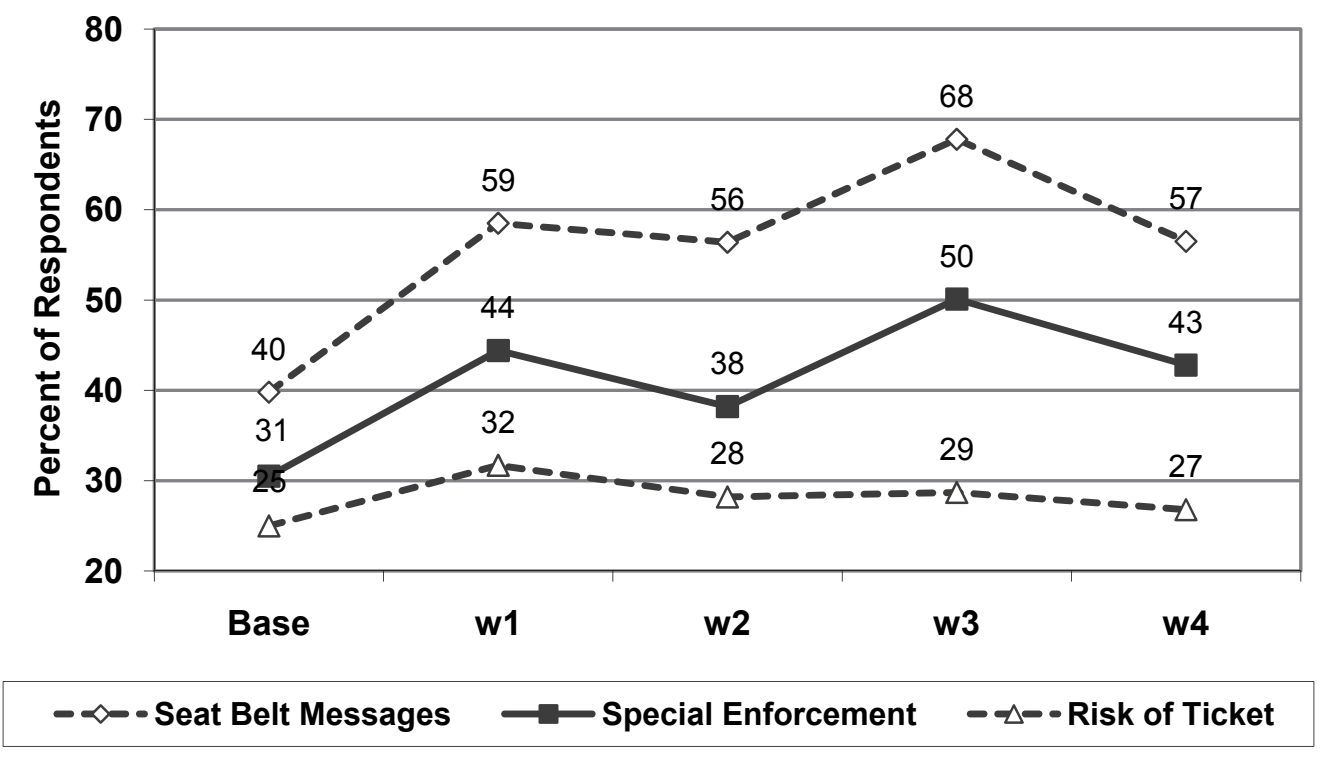


Sources of Information There were several sources of seat belt information. Paid media focused on television, radio, theater screens, and the Internet; but other media were in play as well, including newspaper stories, billboards, posters, and brochures. With regard to seat belt messages, television was by far the most frequent source of information for teens, followed by radio, billboards, and newspapers. Other sources, including enforcement itself, the Web, posters, theater ads, or brochures were reported less frequently.

With regard to where they were when they received general seat belt messages, most teens reported seeing or hearing them while at home, followed by on the roadway or at school (with slight variations between Colorado and Nevada). Interestingly, teens most frequently reported being made aware of special efforts by police to enforce seat belt laws when they were at school, followed by at home, and while driving, in that order. Very few teens reported hearing about seat belts or enforcement while at work or in social or recreational settings.

\section{Outcomes: Changes in Teen Seat Belt Use}

Although the teen seat belt programs implemented in Colorado and Nevada were similar, there were some important differences regarding changes in seat belt use: overall, by school type, among drivers and passengers, and by vehicle type.

Teen Seat Belt Use Rates in Colorado and Nevada, by Wave

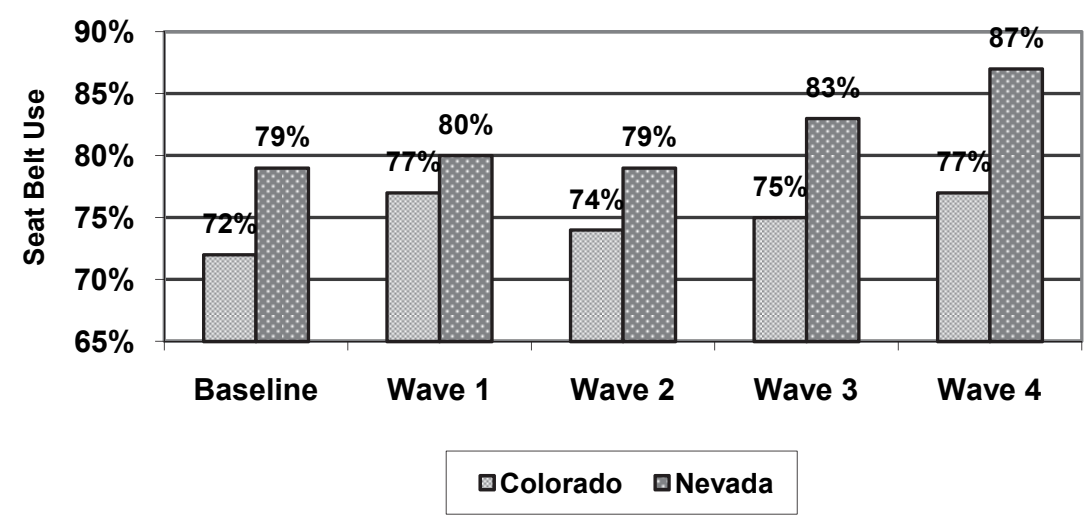

Summary of Teen Seat Belt Use Rates and Change in Colorado and Nevada, by Wave

\begin{tabular}{|c|c|c|c|c|c|}
\hline State & B & w1 & w2 & w3 & w4 \\
\hline \multicolumn{6}{|c|}{ Observed Use Rate } \\
\hline Colorado & $72.0 \%$ & $76.7 \%$ & $73.8 \%$ & $74.9 \%$ & $77.0 \%$ \\
\hline Nevada & $79.4 \%$ & $79.8 \%$ & $78.9 \%$ & $83.3 \%$ & $87.0 \%$ \\
\hline \multicolumn{6}{|c|}{ Wave-to-Wave Change (percentage points) } \\
\hline Colorado & \multirow[b]{2}{*}{$\mathrm{n} / \mathrm{a}$} & $+4.7^{*}$ & $-2.9^{*}$ & +1.1 & +2.1 \\
\hline Nevada & & +0.4 & -0.9 & $+4.4^{*}$ & $+3.7^{*}$ \\
\hline \multicolumn{6}{|c|}{ Cumulative Change Relative to Baseline } \\
\hline Colorado & \multirow[b]{2}{*}{$\mathrm{n} / \mathrm{a}$} & $+4.7^{*}$ & $+2.5^{*}$ & $+2.6^{*}$ & $+5.0^{*}$ \\
\hline Nevada & & +0.4 & -0.5 & $+3.9^{*}$ & $+7.6^{*}$ \\
\hline
\end{tabular}


Baseline teen belt use was higher in Nevada than in Colorado (79\% versus $72 \%)$. In spite of the higher baseline in Nevada, use increased more in that State ( +8 points) than in Colorado $(+5$ points). There was a significant initial impact associated with Wave 1 in Colorado ( +5 points), but not in Nevada ( +1 point). Use declined significantly at Wave 2 in Colorado ( -3 points), which was conducted immediately following the winter holiday for most schools. While a significant decline did not appear in the overall Nevada rate (-1 point), use did decline at college and non-school sites in the Reno area. Modest increases in use were associated with waves 3 and 4 (March and May) in Colorado, bringing teen seat belt use to its previous high of $77 \%(+5$ points) achieved immediately after Wave 1 . In Nevada, by contrast, the first significant seat belt use increases of 8 points combined were associated with waves 3 and 4 (May and September). In both States, the highest use rates were recorded immediately after Wave 4. With regard to wave-to wave changes, the greatest single wave gain in Colorado was associated with Wave 1, followed by Wave 4 . In Nevada, the greatest gain was associated with Wave $3(+4.4$ points), followed by Wave 4 ( +3.7 points).

High Schools Versus Colleges Seat belt use among younger teens was observed primarily at high schools, and use among older teens was observed primarily at colleges. Again, baseline rates in Nevada were higher than in Colorado. Baselines at Nevada colleges were substantially higher than at Nevada high schools; but, in Colorado, there was very little difference between high school and college baseline rates. In general, impact associated with the program was greater at high schools than at colleges. This was the case in both States, with increases at Colorado high schools occurring at Wave 1 and Wave 4 and increases at Nevada high schools occurring at Wave 3 and Wave 4, essentially the same pattern as for overall rates in both States.

Use among college students did not increase significantly in Nevada but did increase by approximately 4 percentage points in Colorado. These increases were significant at Wave 3. In spite of the increases in Colorado, use among college students in that State remained about 11 points lower than in Nevada.

Drivers Versus Passengers Drivers had higher seat belt use rates than passengers in both States. In Nevada, teen passengers appear to have been affected more than teen drivers by the teen program ( +10 points and +6 points, respectively). In Colorado, overall use increased by about 5 percentage points among both drivers and passengers.

Changes by Vehicle Type Use among occupants of all vehicles increased at some point during the program. In Nevada, overall use in cars increased by about 8 points; use in pickup trucks increased by about 7 points; and use in vans and SUVs (combined) increased by about 6 points. All of these increases were relative to baseline levels.

In Colorado, use in cars increased by about 5 points and use in pickups increased by about 3 points over all four waves of the program. At baseline, seat belt use was higher in vans than in any other vehicle type, and increases (through Wave 3) were greater than for other vehicle type (+10 points). However, there was a large and significant decline in use among van occupants at Wave 4 (May 2008), leaving use at about 4 points over baseline. Use in SUVs increased more gradually, also reaching about 4 points over baseline at Wave 4. 
Seat Belt Use Among Teens Killed in Fatal Crashes The unbuckled percentage of teens 16 to 20 years old killed in Colorado increased from 2005 to 2006; declined in 2007, from $70 \%$ to $64 \%$; and declined again in 2008 , from $64 \%$ to $56 \%$. Due to the small numbers involved, however, these declines were not statistically significant, neither alone nor combined. In Nevada, the unbuckled percentage of teen victims increased from 2005 through 2006; remained at that level (69\%) through 2007; then declined by 10 percentage points in 2008. Here again, with small numbers involved, this substantial decline was not statistically significant. These trends suggest that there may have been an impact on belt use among teens killed in crashes in both States.

\section{Unbelted Percentage of Teen Fatalities in Colorado and Nevada, 2003-2008 Source: FARS}

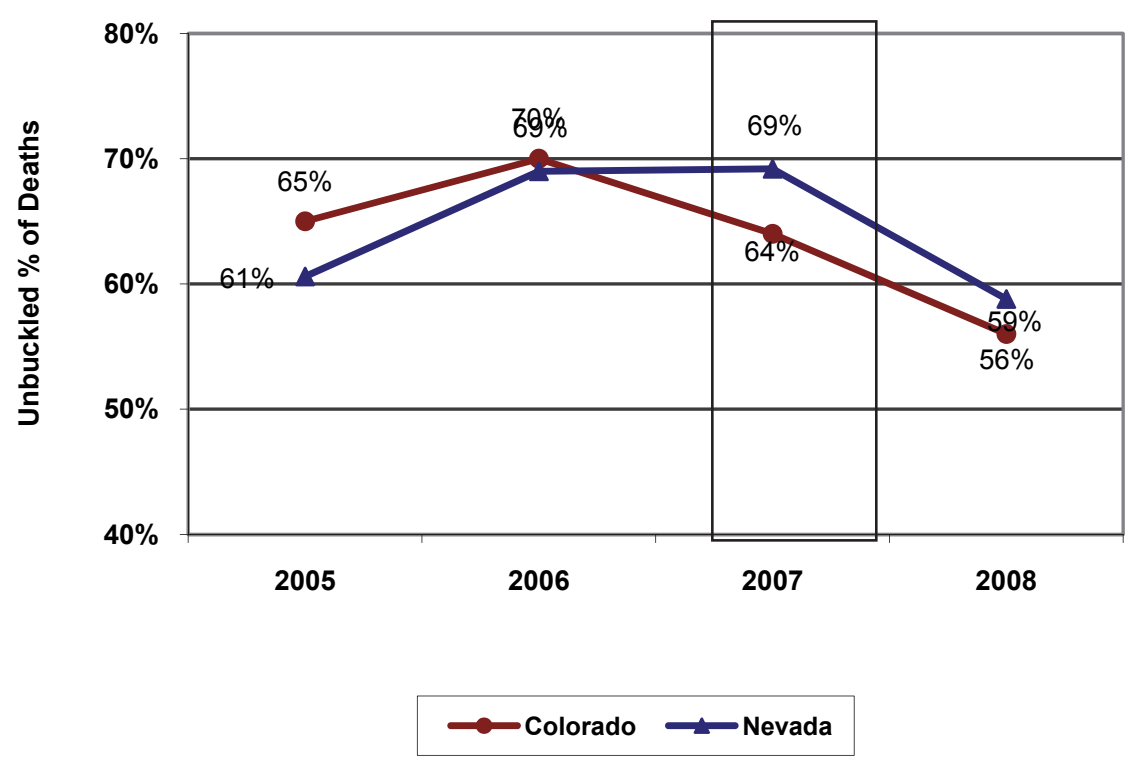

Summary In summary, the teen demonstration projects implemented in Colorado and Nevada were "strong" programs and teen seat belt use increased significantly in both States. The largest increases were among occupants of vans (at Wave 3 in Colorado), followed by occupants of cars and pickups (at Wave 4 in Nevada). The first and last program waves appeared to have the greatest impact in Colorado; the last two waves had the greatest impact in Nevada. Generally speaking, use at high schools (among younger teens) increased more than use at colleges (among older teens). Baseline use rates were substantially higher in Nevada than in Colorado and, in Nevada, baselines were higher among college students than among high school students.

The overall gains of 5 percentage points in Colorado and 8 points in Nevada were substantial, particularly given that both States have secondary enforcement laws and low fine levels (\$20 in Colorado; $\$ 25$ in Nevada). It is likely that greater gains could be made with passage of a primary law upgrade and/or an increase in fine levels in either or both of these States. 


\section{Table of Contents}

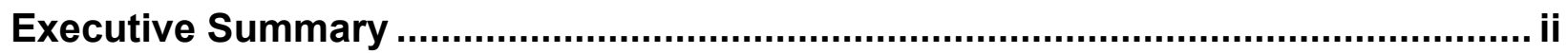

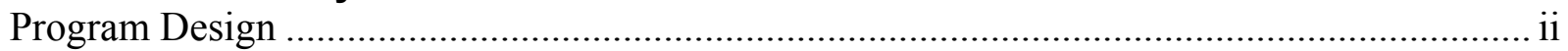

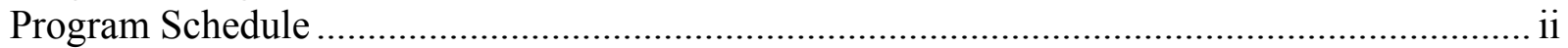

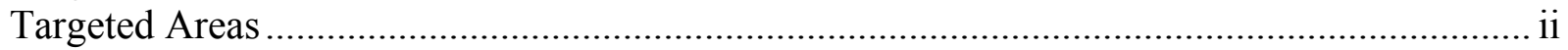

Program Message .......................................................................................................... ii

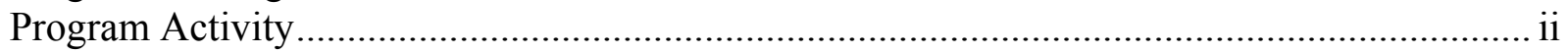

Outcomes: Changes in Teen Awareness ..............................................................................iii

Outcomes: Changes in Teen Seat Belt Use.......................................................................

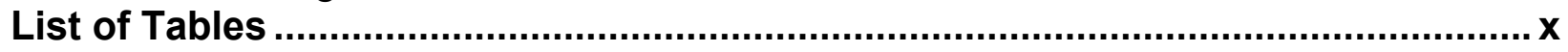

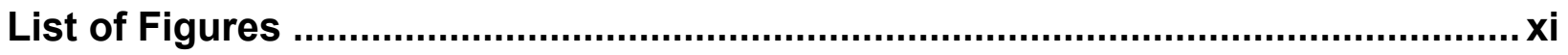

1. Introduction

1.1. Problem Identification ......................................................................................... 1

1.2. The Teen Seat Belt Demonstration Projects ...................................................................... 1

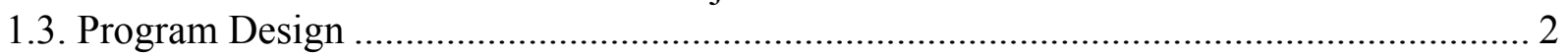

1.3.1. Special Traffic Enforcement Program (sTEP) Model ............................................... 2

1.3.2. Design for a Teen Demonstration Project with Four Emphasis Periods ....................... 3

1.3.3. Targeted Program Areas ..................................................................................... 4

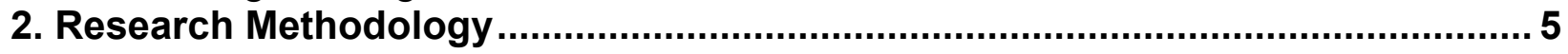

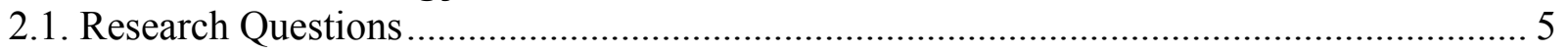

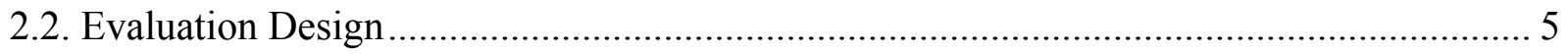

2.2.1. Seat Belt Observation Surveys....................................................................... 5

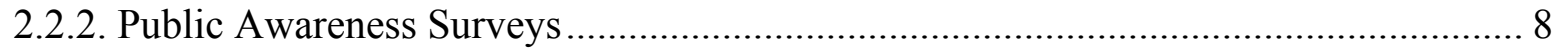

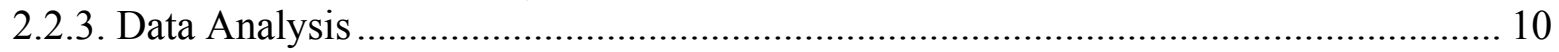

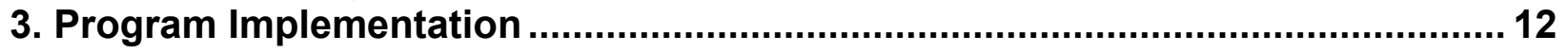

3.1. Implementation Schedules .................................................................................... 12

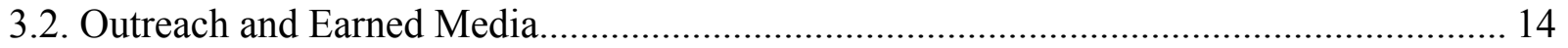

3.2.1. Defining Outreach and Earned Media ........................................................................ 14

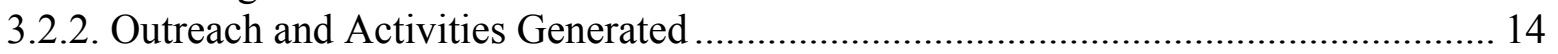

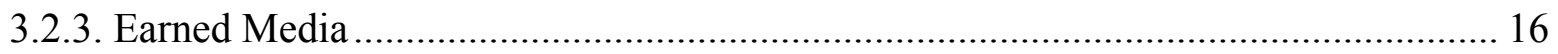

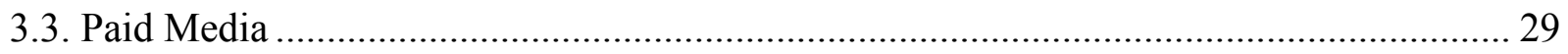

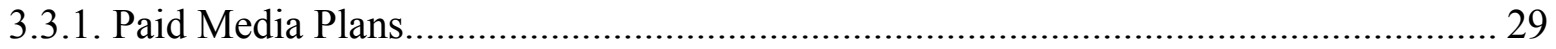

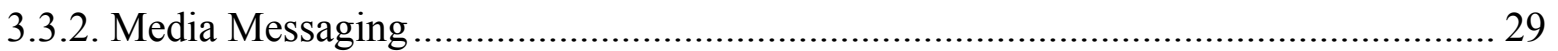

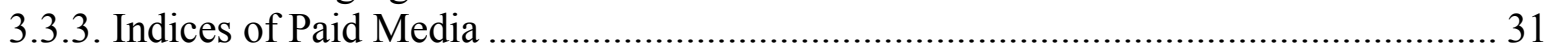

3.3.4. Markets, Counties, and Population Sizes.................................................................. 31

3.3.5. Paid Media Expenditures in Colorado and Nevada ................................................... 32

3.3.6. Paid Media Allocations by Medium in Colorado and Nevada ................................... 33

3.3.7. Number of Television and Radio Advertisements Aired............................................. 34

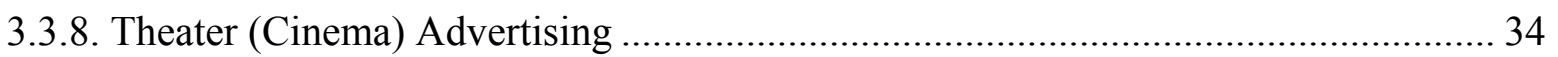

3.3.9. Alternative Media: Online Gaming and Yahoo/AOL Advertising............................. 35

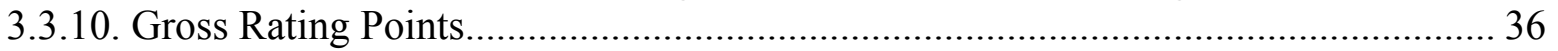

3.3.11. May 2008 Statewide Click or Ticket Media Campaigns .......................................... 38

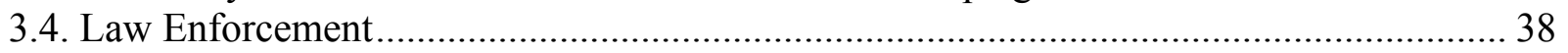

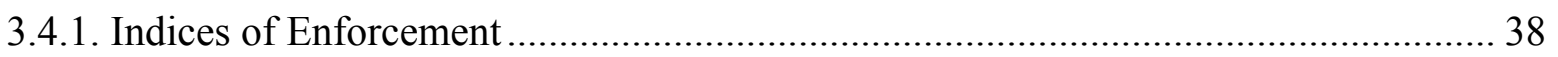

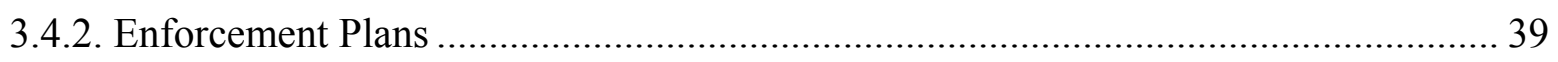

3.4.3. Implementation of the Enforcement Programs ......................................................... 41 


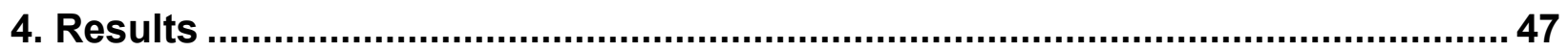

4.1. Awareness of Media and Law Enforcement Activity ..................................................... 47

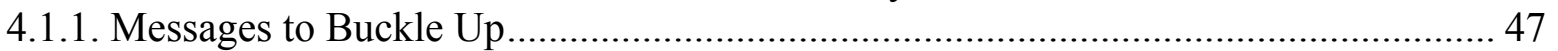

4.1.2. Enforcement Related Questions............................................................................... 55

4.1.3. Comparison of Colorado and Nevada Awareness Results ............................................ 61

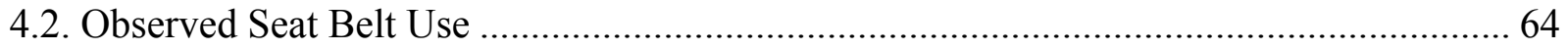

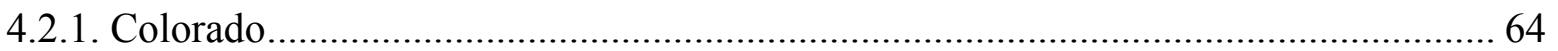

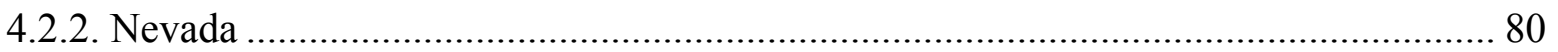

4.2.3. A Comparison of Colorado and Nevada Results ................................................... 90

4.2.4. Seat Belt Use Among Teens Killed in Fatal Crashes ............................................... 95

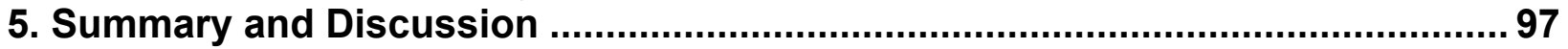

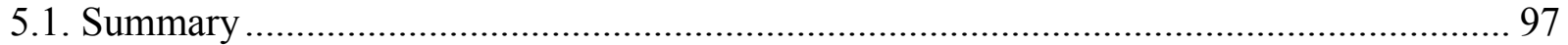

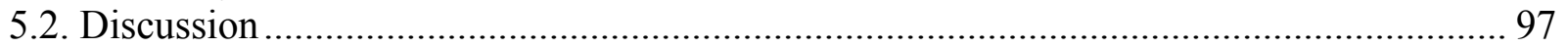

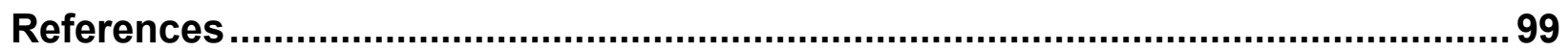

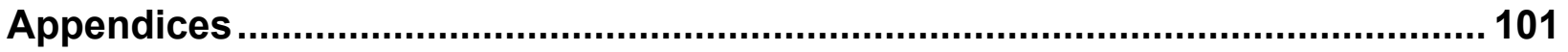




\section{List of Tables}

Table 1. Colorado Awareness Survey Frequencies by Site ..................................................................

Table 2. Nevada Awareness Survey Frequencies by Site ................................................................ 10

Table 3. Teen Seat Belt Demonstration Projects and Evaluation Schedule.......................................... 13

Table 4. Summary of Earned Media Activity in Colorado .....................................................................24

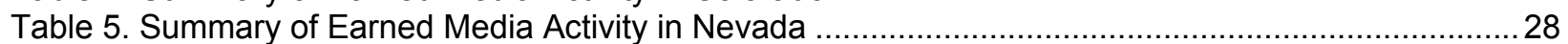

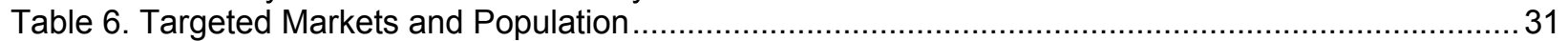

Table 7. Paid Media Expenditures in the Teen Belt Demonstration .................................................... 32

Table 8. Funding Allocations by Medium, by State and Wave ......................................................... 34

Table 9. TV and Radio Ads, Total Number and Percentage of Total (purchased + added value ads) .......34

Table 10. Cinema Expenditures and Exposures in the Teen Demonstration Project................................ 35

Table 11. Online Expenditures and Impressions in the Teen Demonstration Project .............................. 35

Table 12. Television Gross Rating Points by State and Wave ............................................................ 36

Table 13. Counties, Population, Agencies, and Enforcement Hours Planned for .................................... 39

Table 14. Counties, Population, Agencies, and Enforcement Hours Planned for ...................................40

Table 15. Indices of Enforcement Activity, Colorado Teen Demonstration .......................................... 41

Table 16. Indices of Enforcement Activity, Nevada Teen Demonstration Project ................................... 44

Table 17. Awareness of Teen Seat Belt Messages and Recognition of Click It or Ticket in Colorado ...... 48

Table 18. Awareness of Teen-Related Seat Belt Messages and Recognition of CIOT in Nevada ............52

Table 19. Perceptions and Awareness Related to Seat Belt Enforcement in Colorado ...........................56

Table 20. Perceptions and Awareness Related to Seat Belt Enforcement in Colorado ..........................59

Table 21. Colorado Teen Seat Belt Observation Frequencies, Driver and Passenger Combined.............64

Table 22. Results of Binary Logistic Regression of Seat Belt Use Data in Colorado ...............................65

Table 23. Colorado Teen Seat Belt Use Near High Schools, Changes in the Odds of Use, ...................67

Table 24. Colorado Teen Seat Belt Use Near High Schools in the Denver Metro Area, ..........................68

Table 25. Colorado Teen Seat Belt Use Near Colorado Springs/Pueblo High Schools, .........................69

Table 26. Colorado Teen Seat Belt Use Near High Schools in North Central Colorado, ......................... 71

Table 27. Colorado Teen Seat Belt Use Near Grand Junction/Mesa County High Schools,

Changes in the Odds of Use Relative to Baseline After Each Program Wave ….................... 72

Table 28. Colorado Teen Seat Belt Use Near Colleges and Universities by Occupant Type, .................. 74

Table 29. Colorado Teen Seat Belt Use in Passenger Vehicles, ..................................................... 77

Table 30. Summary of Teen Seat Belt Use Rate and Change in Colorado by Vehicle Type....................78

Table 31. Nevada Teen Seat Belt Observation Frequencies, by Wave and Subgroup ........................... 81

Table 32. Results of Binary Logistic Regression of Teen Seat Belt Use Data in Nevada ......................... 82

Table 33. Teen Seat Belt Use Percentages, Odds of Use, and Odds Ratios Relative to Baseline

Levels near High Schools, College/University, and Non-School Locations............................. 85

Table 34. Teen Seat Belt Use Percentages, Odds of Use, and Odds Ratios ....................................... 86

Table 35. Teen Seat Belt Use Percentages, Odds of Use, and Odds Ratios Relative to .......................... 89

Table 36. Summary of Nevada Teen Seat Belt Use Rates and Change, by Vehicle Type .......................90

Table 37. Summary of Teen Seat Belt Use Rates and Change in Colorado and Nevada, by Wave .........91 


\section{List of Figures}

Figure 1. Components and Timing of a Typical HVE Program .......................................................... 3

Figure 2. Multiwave Teen Demonstration Projects and Measurement Periods....................................... 12

Figure 3. Distribution of Web/Print and Television Stories in Colorado, Wave 1 ................................... 18

Figure 4. Distribution of Web/Print and Television Stories in Colorado, Wave 2 ..................................20

Figure 5. Distribution of Web/Print and Television Stories in Colorado, Wave 3.................................... 21

Figure 6. Distribution of Web/Print and Television Stories in Colorado, Wave 4 ...................................23

Figure 7. Distribution of Web/Print and Television Stories in Nevada, Wave 1 .......................................25

Figure 8. Distribution of Web/Print and Television Stories in Nevada, Wave 2 ......................................26

Figure 9. Distribution of Web/Print and Television Stories in Nevada, Wave 3...................................2 27

Figure 10. Distribution of Web/Print and Television Stories in Nevada, Wave 4 ..................................2 27

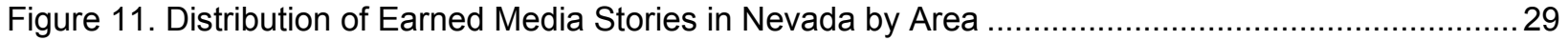

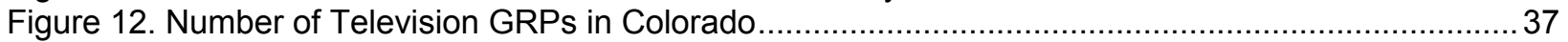

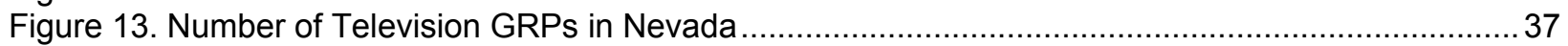

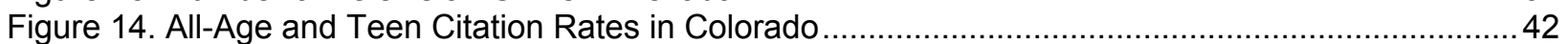

Figure 15. Teen Percent of Seat Belt Citations and Teen Percentage of Population in Colorado ............. 43

Figure 16. All-Age and Teen Citation Rates in Nevada ................................................................. 45

Figure 17. Teen Percentage of Seat Belt Citations and Teen Percentage of Population in Nevada ......... 45

Figure 18. Awareness of Teen Seat Belt Messages and of CIOT Program and Message in Colorado..... 49

Figure 19. Sources of Awareness for Teen-Related Seat Belt Messages, Baseline Levels and Change

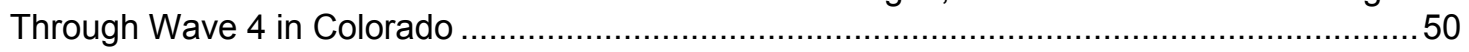

Figure 20. Locations of Teen-Related Seat Belt Messages, Baseline Levels and .................................50

Figure 21. Awareness of Teen Seat Belt Messages and CIOT in Nevada...........................................5 53

Figure 22. Sources of Awareness for Teen Seat Belt Messages, ....................................................5 54

Figure 23. Self-Reported Locations of Teen-Related Seat Belt Messages, Baseline Levels and Change

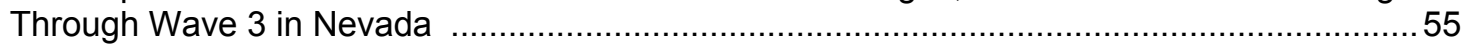

Figure 24. Perceived Strictness of Enforcement, Awareness of Special Police Efforts, and ...................57

Figure 25. Self-Reported Locations of Enforcement Messages, Baseline Levels and.............................58

Figure 26. Perceived Strictness of Enforcement, Awareness of Special Police Efforts, and ....................60

Figure 27. Self-Reported Locations of Enforcement-Related Messages, Baseline Levels and Change

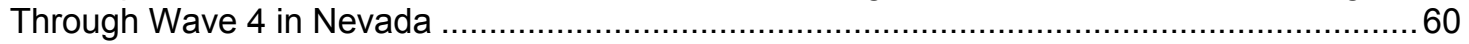

Figure 28. Results of Key Awareness Indices in Colorado, by Wave.................................................. 61

Figure 29. Results of Key Awareness Indices in Nevada, by Wave ....................................................... 61

Figure 30. Awareness of Seat Belt Messages in Colorado and Nevada, by Wave .................................6 62

Figure 31. Awareness of Special Enforcement Efforts, by Wave in Colorado and Nevada .....................63

Figure 32. Perceived Risk of Receiving a Ticket in Colorado and Nevada ............................................63

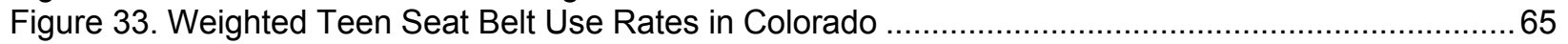

Figure 34. Teen Seat Belt Use Rates Near High Schools in Colorado, ...........................................6 66

Figure 35. Colorado Teen Seat Belt Use Rates Near Denver Metro Area High School Sites, By Occupant

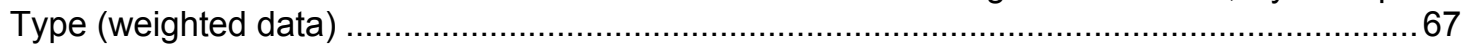

Figure 36. Colorado Teen Seat Belt Use Rates Near Colorado Springs/Pueblo High Schools, by Occupant Type (weighted data)....

Figure 37. Colorado Teen Seat Belt Use Rates Near North Central Colorado High Schools, By Occupant Type (weighted data) ...................................................................................... 70

Figure 38. Colorado Teen Seat Belt Use Rates Near Grand Junction/Mesa County High Schools, by

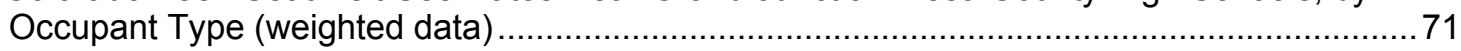

Figure 39. Percentage-Point Increases in Colorado Teen Seat Belt Use, ........................................ 72

Figure 40. Overall Seat Belt Use Rates of Colorado Teens, ......................................................... 73

Figure 41. Colorado Teen Seat Belt Use Rates Near Colleges or Universities, ...................................74

Figure 42. Colorado Teen Seat Belt Use Rates, High Schools ....................................................... 75

Figure 43. Increases in Colorado Teen Seat Belt Use Relative to Baseline Levels ............................... 76

Figure 44. Colorado Teen Seat Belt Use Rates in Cars and Pickup Trucks ..........................................76

Figure 45. Results of the Colorado Statewide Teen Seat Belt Surveys, .......................................... 79

Figure 46. Nevada Teen Seat Belt Use Rates (weighted data) ........................................................ 82 
Figure 47. Nevada Teen Driver and Passenger Seat Belt Use, by Wave ............................................ 83

Figure 48. Nevada Teen Seat Belt Use Rates Near High School, .................................................... 84

Figure 49. Change in Teen Seat Belt Use at High School and College Sites in Nevada .......................... 84

Figure 50. Overall Teen Seat Belt Use Rates in the Reno and Las Vegas Areas.................................... 86

Figure 51. Teen Seat Belt Use Rate at High School, College, and Non-School Sites in Reno Area ......... 87

Figure 52. Teen Seat Belt Use Rates at High School, College, and Non-School Sites in Las Vegas ....... 88

Figure 53. Nevada Teen Seat Belt Use Rates by Vehicle Type, All 30 Sites .......................................... 88

Figure 54. Teen Seat Belt Use Rates in Colorado and Nevada, by Wave ..........................................91

Figure 55. Teen Seat Belt Use Rates Near High School and College/University Sites in Colorado and Nevada

Figure 56. Teen Seat Belt Use Rates Among Teen Drivers and Passengers in Colorado and Nevada, by Wave

Figure 57. Teen Seat Belt Use Rates Among Occupants of Cars and Pickup Trucks in Colorado and Nevada, by Wave.

Figure 58. Teen Seat Belt Use Rates Among Occupants of Vans and SUVs in Colorado and Nevada, by Wave

Figure 59. Unbelted Percentage of Teen Fatalities in Colorado and Nevada, 2005-2008. 


\section{Introduction}

\subsection{Problem Identification}

Teens have higher fatality and injury rates in motor vehicle crashes than any other age group. In $2006,6.4 \%$ of all licensed drivers were 15 to 20 years old (13.0 million out of 202.8 million). Yet this cohort represented $12.9 \%$ of all drivers who were involved in fatal crashes regardless of mortality (7,463 out of 57,695 involved). The 15- to 20-year-old drivers who died in these fatal crashes numbered 3,490, making motor vehicle crashes the number one cause of death for this age group (NHTSA, March 2008).

The general immaturity, inexperience, and underdeveloped hazard-recognition skills of young drivers have been well documented (Williams 2006). Additional risk factors that contribute to teen driver crashes include: driving at night (Lin \& Fearn, 2003); alcohol impairment (Williams, 2003); transporting other teen passengers (Lin \& Fearn, 2003, Williams, 2003); cell phone use (NHTSA, July 2007); speeding; and lack of seat belt use (Hedlund, Shults, \& Compton, 2003). Observational surveys have indicated that teenagers' seat belt use is among the lowest of any age group (Williams \& Shabanova, 2002), with males and passengers showing even lower belt use within the teen subpopulation (Williams et al., 2003). In 2007, 61\% of the 16- to 20-year-old passenger vehicle occupants who were killed in crashes were unrestrained (NHTSA, 2007). Unrestrained fatalities for this age group were 60 and 61\% in 2008 and 2009, respectively (NHTSA, 2009, 2010).

\subsection{The Teen Seat Belt Demonstration Projects}

The Teen Seat Belt Demonstration Projects described in this report were implemented in Colorado and Nevada in 2007. They were the first statewide efforts to target seat belt use among teen occupants of passenger vehicles. From the start, it was recognized that securing adequate police participation and pairing such enforcement with effectively targeted publicity would be two essential components of the programs. From an evaluation standpoint, there was an emphasis placed on measuring program intensity, teen awareness of enforcement and media messages, and seat belt use among teens after each phase of the programs.

Prior to implementing these programs, NHTSA had several years of experience with implementing and evaluating seat belt demonstration programs targeting special populations (e.g., Buckle Up in Your Truck campaign, and the Rural Demonstration Project). In addition, a NHTSAsponsored examination of teen belt use research suggested that the strategies that have been effective at increasing seat belt use among adults were also likely to be the most effective strategies for increasing use among teens (NHTSA, 2005, November). These approaches included upgrading to primary seat belt laws and highly-publicized enforcement of seat belt laws, such as Click it or Ticket (CIOT) programs. In this initial teen demonstration project, NHTSA chose to provide support for two State-level campaigns that emphasized high-visibility enforcement, earned and paid media, as well as outreach tailored toward teens. In addition, NHTSA proposed that these campaigns follow a multiwave design, similar to that of the Next Generation Click It 
or Ticket program model, which includes a May CIOT mobilization, but also adds three waves of program activity within approximately a 12-month period.

A solicitation for these Teen Seat Belt Demonstration Projects was sent to NHTSA's Regional offices to share with their States. The solicitation included various criteria, including:

- willingness and capacity to participate in a large-scale demonstration program and contribute the adequate funding, staffing, and support to carry out the functions related to the project;

- participation in the CIOT May Mobilizations as well as three additional high-visibility enforcement periods;

- use of the CIOT slogan as the primary message delivered by the program; and

- inclusion of the four key elements of a CIOT mobilization-earned media, paid media, highvisibility enforcement, and evaluation.

States that were in one of the top 10 media markets were not eligible for the program, due to the high cost of purchasing television and radio advertisements in those markets. Of the remaining States, several indicated interest and were reviewed by NHTSA. All agreed to the criteria listed above. The two final candidate States also had the following characteristics:

- $\quad$ higher teen fatality rates than the national average;

- elevated percentages of unbuckled teen occupants in fatal crashes;

- $\quad$ strong graduated driver licensing (GDL) laws;

- affordable media markets;

- $\quad$ strong law enforcement partnerships and programs; and

- established community outreach networks.

Based on these attributes, the States of Colorado and Nevada were selected to implement Teen Seat Belt Demonstration Projects. The specific objectives of these projects were: (1) to increase seat belt use among teen motor vehicle occupants, as measured by observational seat belt surveys; and (2) to increase the perception among teen motor vehicle occupants that they are likely to get a ticket if they are unbelted, as measured by awareness surveys of enforcement and media.

\subsection{Program Design}

\subsubsection{Special Traffic Enforcement Program (sTEP) Model}

The program design is based on the $S T E P$ model in which publicity and enforcement activity are implemented according to a defined schedule. The program begins with outreach to involve State and local organizations and earned media to obtain news coverage. Next, a paid media campaign is implemented, followed by actual enforcement. The paid media phase usually lasts for one full week, overlapping with one or two weeks of enforcement. Observational and awareness surveys are conducted at baseline point before outreach and earned media begin and then immediately after enforcement ends. When such a program is conducted in conjunction with a CIOT mobilization, each component is extended by one or two weeks. During the CIOT period, both media and enforcement focused less on the targeted teen group than during the special demonstration period. Each of these programs (i.e., sTEP, special demonstration, CIOT mobili- 
zation) is an HVE program. Figure 1 shows a typical wave of activity in an HVE program such as this.

Figure 1. Components and Timing of a Typical HVE Program

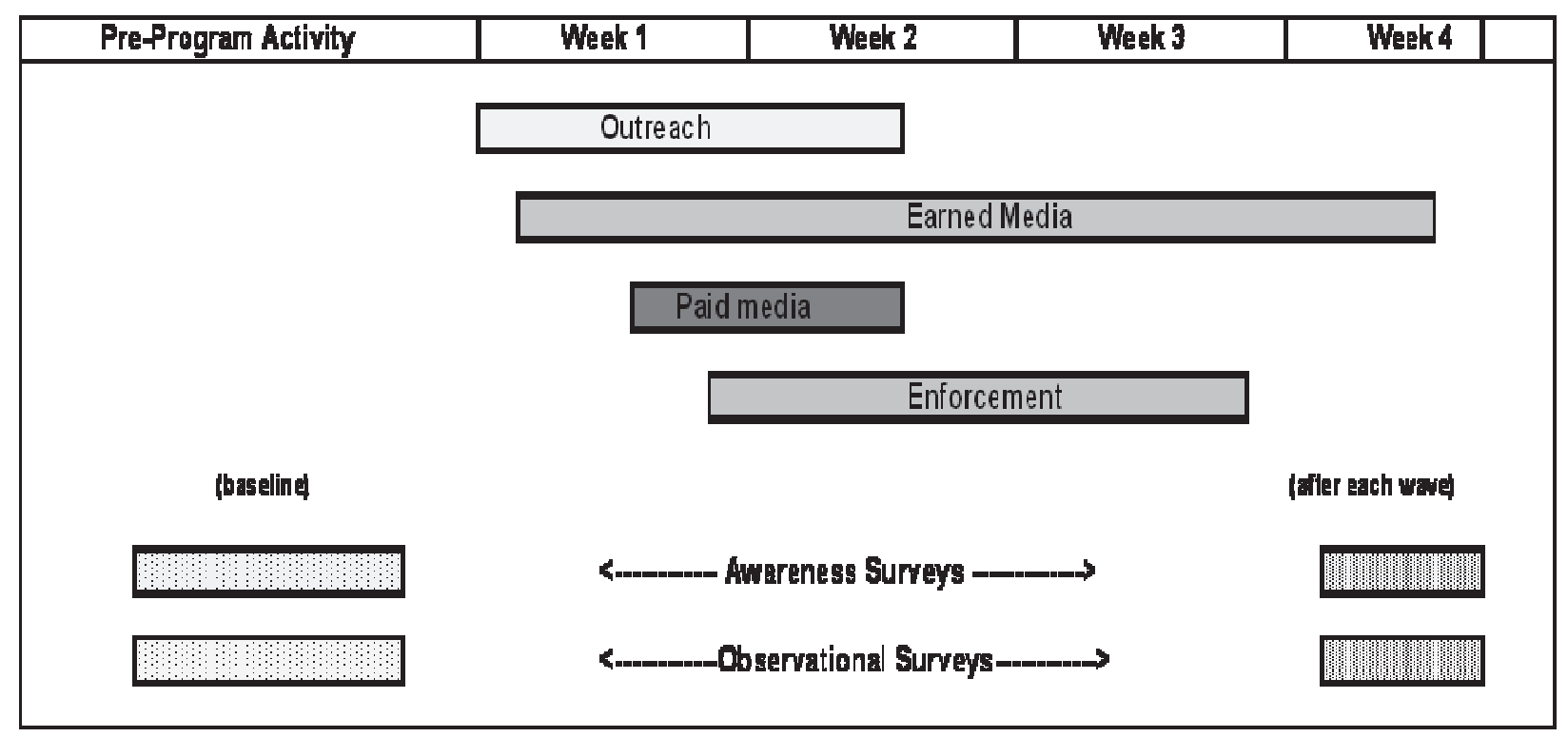

\subsubsection{Design for a Teen Demonstration Project with Four Emphasis Periods}

The Teen Seat Belt Demonstration Projects involved four waves of sTEP or HVE program activity, one of which was implemented in conjunction with the May (2008) CIOT mobilization. Colorado and Nevada implemented these four waves according to slightly different schedules. Those program schedules (W1 to W4), along with the general timing of observational and awareness surveys (Baseline to W4) are described more completely in the Implementation Section (see Figure 2). 


\subsubsection{Targeted Program Areas}

The areas targeted for the Colorado and Nevada Teen Demonstration Projects were the major population centers of each State. In Colorado, the program targeted the Colorado SpringsPueblo, Grand Junction-Montrose and Denver media markets, with an estimated 1.8 million households and about 320,000 teen residents 16 to 20 years old. In Nevada, the program targeted the Las Vegas and Reno-Sparks media markets, with approximately 812,000 households and about 153,000 teens 16 to 20 . Virtually the entire population of both States was covered by the media markets included in the publicity component of the program, although enforcement was focused primarily in the metropolitan areas served by these markets. (See Appendices A and B for DMA maps.) 


\section{Research Methodology}

\subsection{Research Questions}

The purpose of this evaluation was to scientifically determine the effects of two teen seat belt campaigns in Colorado and Nevada, with the following research questions in mind:

- How does observed teen belt use change before, during, and after implementation of a teen seat belt campaign?

- How do teen attitudes toward belt use and self-reported belt behavior change before, during, and after implementation of a teen seat belt campaign?

- How do older teens (18 to 20 years old) differ from younger teens (16 and 17) in regard to seat belt use, public awareness of teen belt use, knowledge of their State's seat belt and GDL laws, and perceptions toward teen belt use in general, before, during, and after implementation of the seat belt campaign?

\subsection{Evaluation Design}

The evaluation design included both process and impact evaluation components. Process evaluation included monitoring of program activities such as outreach; media placement, expenditures, and messages; and enforcement activities and citation levels. Participating law enforcement agencies and media contractors collected and delivered enforcement and media activity data. These data are provided in the Program Implementation section of this report. Impact evaluation consisted primarily of measuring changes in teen awareness of program efforts and changes in seat belt use. These changes were measured via public awareness and observational surveys, each conducted at baseline and after each of four waves of program activity. PRG collaborated with State evaluators to design observation and awareness surveys. PRG developed the evaluation designs, and worked with these evaluators to develop survey sampling plans, instruments, and procedures; PRG coordinated the data collection procedures, collected and input the data into a suitable database, and performed all analyses. The procedures for conducting observational and awareness surveys are described below.

\subsubsection{Seat Belt Observation Surveys}

Observational surveys involve direct observations of seat belt use among drivers and front seat outboard passengers of passenger vehicles (i.e., passenger cars, SUVs, light trucks, and vans). They require a sampling plan; selection of observation sites; defined procedures for conducting observations; training in such procedures; and collection, input, organization, and analysis of use data. For full statewide surveys, NHTSA has developed uniform criteria to ensure a representative sample of statewide seat belt use. These criteria can be found in 23 CFR, Part 1340, of the U.S. Code. Such surveys are relatively expensive to conduct and they usually require several weeks of observations to complete. As a result, evaluations that include multiple waves of surveys often make use of mini-surveys, which may involve a sub-sample of sites from the statewide probability sample. These mini-surveys usually consist of 30-50 sites, each of which is surveyed during each wave of data collection. They follow the same observation procedures used in the statewide survey and, to the extent possible, they follow the same time schedule each 
time the survey is conducted (i.e., sites are observed on same days and at same times in all survey waves). Such surveys do not provide a statistically representative sample of the targeted area. But, to the extent that these surveys are conducted uniformly from wave to wave, they provide a reliable and valid index of change from one time period to another.

For observations involving special populations (such as teenagers), sites are selected where such people frequently travel or congregate. With regard to teens, such locations include roads and intersections within one or two blocks of high schools, colleges, or universities; near retail locations such as shopping malls or movie theaters; or wherever teens congregate. With regard to school observations, perhaps the best time to conduct such surveys is in the morning because that is when the largest number of students can be observed within a narrow time period (i.e., 40 to 60 minutes prior to the start of school). Afternoon dismissals are often characterized by more dispersed travel times due to extracurricular activities. Special events (e.g., sports and other events) usually cannot be used for multiwave surveys because of the need for duplication of survey venues, times, and procedures.

For this teen demonstration, there were no suitable locations within either State to serve as control areas. That is because the media markets used for media component of the program (three markets in Colorado and two markets in Nevada) covered the entire State. ${ }^{1}$ Thus, all observational and awareness surveys were conducted in the targeted program areas. As indicated, there were four program activity periods in each State (shown as W1 to W4 in Figure 2). Surveys were conducted at baseline (i.e., prior to any program activity) and after each wave of activity. Thus, the basic design for this evaluation called for five waves of surveys in each State (shown as baseline and w1 to w4 in Figure 2). In both States, PRG worked with subcontractors who were already experienced in observing seat belt use in that they had been involved in conducting statewide seat belt surveys for the State. PRG collaborated with these contractors to select sites, determine observational procedures, and ensure training of all observers in these procedures. Due to past and ongoing efforts in the States, however, these two States used somewhat different protocols for conducting their teen observational surveys. These procedures are described below.

\subsubsection{Colorado}

The Safety and Traffic Engineering Branch of the Colorado Department of Transportation (CDOT) serves as the focal point for highway safety in Colorado and, as such, was the grantee for the Colorado Teen Seat Belt Demonstration Project. The evaluation contractor for CDOT is the Institute of Transportation Management (ITM) of the Colorado State University (CSU), which has conducted statewide seat belt surveys for CDOT for several years. In addition, to conducting traditional statewide seat belt surveys covering occupants of all ages, ITM/CSU has been conducting statewide observational surveys specifically to measure teen seat belt use since 2004. ${ }^{2}$ These surveys involve observations conducted over a two-week period at approximately 200 sites in 17 counties across the State. Observations are conducted by retired Colorado State Highway Patrol officers who observe each site twice (once in each week), for 40 minutes each.

\footnotetext{
${ }^{1}$ In addition, the programs covered all or nearly all of the State. PRG also explored using Arizona or Utah as control areas, but, for a variety of reasons, neither provided an acceptable alternative.

${ }^{2}$ Teen seat belt surveys were conducted in 2004, 2005, 2007, 2008, and 2009. No survey was conducted in 2006.
} 
Drivers and front-seat outboard passengers 16 to 19 years old, riding in passenger vehicles, are observed at road intersections or parking lot entrances/exits of selected high schools, community colleges, State colleges, and universities. The sampling design for this statewide survey is a multistage probability-based sample, based on population and vehicle miles traveled. Observations are collected during daylight hours, usually during April. ${ }^{3}$ These surveys provided an opportunity to measure longer term trends in teen seat belt use in Colorado and to relate such trends to the implementation of the Teen Demonstration Project.

NHTSA, however, sought a wave-to-wave evaluation that would measure impact associated with each wave of program activity. Because budget limitations did not permit conducting awareness and observational surveys before and after each activity period, PRG developed a modified wave-to-wave evaluation that was similar to the annual CIOT evaluation design. In this approach, a single baseline for awareness and teen seat belt use was established prior to any program activity and post-program surveys were conducted following completion of each program wave. Such a design provided a measure of cumulative change in seat belt use from baseline to each of the four post-program periods and it provided a measure of incremental change from post-program to post-program for each program wave. It did not provide a measurement of the impact of each wave from immediate pre-wave levels.

In Colorado, the five waves of measurement (baseline, w1, w2, w3, and w4) were completed by means of five mini-surveys. The data for two of these mini-surveys were derived from annual statewide teen surveys conducted in April 2007 and April 2008; data for the remaining three mini-surveys were obtained by conducting additional surveys at these 33 sites. Thus, for baseline and post-Wave 3 observations, the data were extracted from the full statewide survey database and for Waves 1, 2, and 4, additional mini-surveys were conducted at these 33 sites. In the three additional surveys, as in the full teen surveys, retired Colorado State Highway Patrol officers observed each site twice (once each week) for 40 minutes and the sites were located near high schools, community colleges, State colleges, and universities. Survey procedures were consistent with the cohort observed in full statewide surveys. Mini-survey observations commenced the weekday after enforcement ceased ${ }^{4}$ and continued over the course of two weeks. Eighty-five percent of all teen observations were made during morning hours. All others were made during after school or during evening hours. The general timing of these mini-surveys, relative to program periods is shown in Figure 2. The actual start and completion dates of these surveys are provided in Table 3.

Colorado surveyors recorded observations on an occupant level. Upon identification of a teen occupant, they recorded that occupant's belt use, sex, seating location (driver or passenger), and vehicle type. They then collapsed these occupant-level data into 32 distinct categories in the format of "Belt Use-Sex-Occupant Type-Vehicle." For example, "Belted-Male-Driver-Car" was a single category type and "Unbelted-Male-Driver-Car" was another. Only belt use of teenagers was observed and recorded. An example of the Colorado observation form is shown in Appen$\operatorname{dix}$ C.

\footnotetext{
${ }^{3}$ The months of these surveys were November 2004, September 2005, and April 2007, 2008, and 2009.

${ }^{4}$ The spring semester in some Colorado schools ended in early May. The observation schedule was modified to capture occupants at these sites while school was still in session-during the week of enforcement and the week immediately after enforcement ceased.
} 


\subsubsection{Nevada}

The Nevada Office of Traffic Safety (OTS) is the focal point for highway traffic safety in Nevada and, as such, was the grantee for the Nevada Teen Demonstration Project. Nevada's statewide seat belt surveys are conducted for the Nevada OTS by the University of Nevada, Las Vegas (UNLV). Although UNLV had much prior experience conducting statewide seat belt surveys, no prior surveys of teen seat belt use had been conducted in Nevada. PRG worked with UNLV and with the University of Nevada, Reno (UNR), to develop a sampling plan and observation procedures for observing seat belt use among teens. The final sampling plan included observations made at a total of 30 sites during each measurement wave (i.e., baseline through w4). Eighteen of these sites were in the Las Vegas metro area and 12 were in the Reno/Sparks metro area. A baseline measurement was taken prior to program activity. The post-wave observations commenced the weekday after enforcement activity ceased for each wave and continued for five days, with extra time allotted for days of poor weather and visibility.

Survey sites included a combination of academic locations (high schools and colleges) and social locations such as shopping malls, cinemas, and skate parks. The surveyors made $52 \%$ of all observations in the morning and $48 \%$ in the afternoons, scheduled around daily school start and release schedules. Observation periods were 60 minutes long and were made of drivers and frontseat outboard passengers of passenger vehicles. However, in Nevada, all front-seat occupants were observed, and based on these observations, occupants were put in one of three age categories - under 16, 16 to 20, and over 20. The general timing of these mini-surveys, relative to program periods is shown in Figure 2. The actual start and completion dates of these surveys are provided in table 3 .

Nevada observers collected vehicle-level records of belt use. They randomly selected a vehicle for observation and then recorded belt use for the driver and front seat outboard passenger in that vehicle, regardless of estimated age. This approach maintained the integrity of each variable observed within each vehicle in a format of "Vehicle: driver (sex, belt use), passenger (sex, belt use)." Appendix D provides an example of the Nevada field observation form.

\subsubsection{Public Awareness Surveys}

PRG and the State evaluators developed public awareness survey protocols to measure selfreported driving behaviors and belt use, perceptions regarding media and law enforcement activity, attitudes regarding law enforcement, knowledge of seat belt and GDL laws, and teen-reported seat belt enforcement by parents. These data were collected from teens 16 to 20 years old during approximately the same time period that observations surveys were conducted (i.e., at baseline and after each program period). Appendices $\mathrm{E}$ and $\mathrm{F}$ provide copies of these awareness surveys for each State. As with the observation data, there were differences between State protocols used for collecting awareness data. The protocols are described below. 


\subsubsection{Colorado}

The CDOT conducted awareness surveys at 7 licensing centers of the Division of Motor Vehicles (DMV) across the State. These centers, listed in Table 1, included Colorado Springs, Denver (2 centers), Fort Collins, Greeley, Grand Junction, and Pueblo. One-page questionnaires (see Appendix E) were given to teen visitors to these centers who were asked to voluntarily complete them while waiting for services. Baseline surveys were conducted in April 2007, just prior to the start of the statewide teen observational survey. Post-program surveys were conducted immediately following the completion of enforcement activity (for the teen program) in October 2007, and in January, March, and May 2008, prior to the end of the school year at most high schools, but also prior to the end of the CIOT phase of the program. As with observation surveys, the general timing of DMV surveys, relative to program periods, is shown in Figure 2. The actual start and completion dates of these surveys are shown in Table 3.

Table 1 shows the number and percentage of total surveys completed, by wave and by site.

Table 1. Colorado Awareness Survey Frequencies by Site

\begin{tabular}{|l|c|c|c|c|c|c|c|}
\hline Site & & $\begin{array}{c}\text { Baseline } \\
\text { April 2007 }\end{array}$ & $\begin{array}{c}\text { Post } \\
\text { Wave 1 } \\
\text { Oct 2007 }\end{array}$ & $\begin{array}{c}\text { Post } \\
\text { Wave 2 } \\
\text { Jan 2008 }\end{array}$ & $\begin{array}{c}\text { Post } \\
\text { Wave 3 } \\
\text { March 2008 }\end{array}$ & $\begin{array}{c}\text { Post } \\
\text { Wave 4 } \\
\text { May 2008 }\end{array}$ & Total \\
\hline Colorado Springs & $\mathbf{n}$ & $\mathbf{1 2 8}$ & $\mathbf{1 8 2}$ & $\mathbf{1 6 8}$ & $\mathbf{2 4 6}$ & $\mathbf{1 3 3}$ & $\mathbf{8 5 7}$ \\
\hline & $\%$ & $21.6 \%$ & $23.2 \%$ & $18.0 \%$ & $23.6 \%$ & $13.9 \%$ & $19.9 \%$ \\
\hline Denver-Athmar & $\mathbf{n}$ & $\mathbf{6 2}$ & $\mathbf{1 1 4}$ & $\mathbf{1 2 1}$ & $\mathbf{1 2 7}$ & $\mathbf{1 7 4}$ & $\mathbf{5 9 8}$ \\
\hline & $\%$ & $10.4 \%$ & $14.5 \%$ & $12.9 \%$ & $12.2 \%$ & $18.2 \%$ & $13.9 \%$ \\
\hline Denver-Northglenn & $\mathbf{n}$ & $\mathbf{8 4}$ & $\mathbf{1 6 5}$ & $\mathbf{1 6 8}$ & $\mathbf{1 7 3}$ & $\mathbf{1 9 7}$ & $\mathbf{7 8 7}$ \\
\hline & $\%$ & $14.1 \%$ & $21.0 \%$ & $18.0 \%$ & $16.6 \%$ & $20.6 \%$ & $18.2 \%$ \\
\hline Fort Collins & $\mathbf{n}$ & $\mathbf{7 8}$ & $\mathbf{7 1}$ & $\mathbf{1 4 6}$ & $\mathbf{1 4 6}$ & $\mathbf{1 5 7}$ & $\mathbf{5 9 8}$ \\
\hline & $\%$ & $13.1 \%$ & $9.0 \%$ & $15.6 \%$ & $14.0 \%$ & $16.4 \%$ & $13.9 \%$ \\
\hline Greeley & $\mathbf{n}$ & $\mathbf{1 0 6}$ & $\mathbf{1 3 7}$ & $\mathbf{1 4 5}$ & $\mathbf{1 6 3}$ & $\mathbf{1 0 4}$ & $\mathbf{6 5 5}$ \\
\hline & $\%$ & $17.9 \%$ & $17.4 \%$ & $15.5 \%$ & $15.7 \%$ & $10.9 \%$ & $15.2 \%$ \\
\hline Grand Junction & $\mathbf{n}$ & $\mathbf{8 0}$ & $\mathbf{3 2}$ & $\mathbf{8 2}$ & $\mathbf{8 4}$ & $\mathbf{1 1 0}$ & $\mathbf{3 8 8}$ \\
\hline & $\%$ & $13.5 \%$ & $4.1 \%$ & $8.8 \%$ & $8.1 \%$ & $11.5 \%$ & $9.0 \%$ \\
\hline Pueblo & $\mathbf{n}$ & $\mathbf{5 6}$ & $\mathbf{8 5}$ & $\mathbf{1 0 6}$ & $\mathbf{1 0 2}$ & $\mathbf{8 2}$ & $\mathbf{4 3 1}$ \\
\hline & $\%$ & $9.4 \%$ & $10.8 \%$ & $11.3 \%$ & $9.8 \%$ & $8.6 \%$ & $10.0 \%$ \\
\hline Total & $\mathbf{n}$ & $\mathbf{5 9 4}$ & $\mathbf{7 8 6}$ & $\mathbf{9 3 6}$ & $\mathbf{1 , 0 4 1}$ & $\mathbf{9 5 7}$ & $\mathbf{4 . 3 1 4}$ \\
\hline & $\%$ & $100 \%$ & $100 \%$ & $100 \%$ & $100 \%$ & $100 \%$ & $100 \%$ \\
\hline
\end{tabular}

\subsubsection{Nevada}

The Nevada Office of Traffic Safety collected voluntary surveys at several participating high schools and universities. The surveys were similar to the one-page questionnaires used in the Colorado DMVs (see Appendix F).

Baseline surveys were conducted in April 2007; post-wave surveys were collected beginning on the weekday immediately after each wave of enforcement activity associated with the teen program was completed - in November 2007 and in January, May, and September 2008. Again, the 
general timing of these awareness surveys, relative to program periods is shown in Figure 2 . The actual start and completion dates of these surveys are provided in Table 3.

Survey collection frequencies are presented in Table 2. Six high schools and two universities collected surveys, but there was considerable variation in site participation and survey volume across the five measurement periods. Shaded areas in Table 2 highlight the periods and locations for which no surveys were taken. The first post-program high school surveys (w1) were collected only in Reno due to administrative delays in the Clark County School District (Las Vegas). This issue was resolved by start of the second post-program measurement period (w2); but, for a variety of reasons, some schools still were not able to participate during each period. Despite these variations, respondent demographics (i.e., sex, race, ethnicity, and self-reported annual miles driven) were relatively stable across measurement waves. The stability of these characteristics across time provided some level of confidence regarding the validity of the overall responses as an index of change.

Table 2. Nevada Awareness Survey Frequencies by Site

\begin{tabular}{|l|c|c|c|c|c|c|c|}
\hline \multirow{2}{*}{ Site } & & $\begin{array}{c}\text { Baseline } \\
\text { April 2007 }\end{array}$ & $\begin{array}{c}\mathbf{w 1} \\
\text { Nov 2007 }\end{array}$ & $\begin{array}{c}\mathbf{w 2} \\
\text { Jan 2008 }\end{array}$ & $\begin{array}{c}\text { w3 } \\
\text { May 2008 }\end{array}$ & $\begin{array}{c}\text { w4 } \\
\text { Sep 2008 }\end{array}$ & Total \\
\hline \multirow{2}{*}{ UN-Reno } & $\mathbf{n}$ & $\mathbf{2 7}$ & $\mathbf{7 2}$ & $\mathbf{4 6}$ & $\mathbf{3 5}$ & $\mathbf{4 3}$ & $\mathbf{2 2 3}$ \\
& $\%$ & $3.3 \%$ & $21.7 \%$ & $4.7 \%$ & $4.6 \%$ & $6.1 \%$ & $6.2 \%$ \\
\hline \multirow{2}{*}{ 1 High School, Reno } & $\mathbf{n}$ & $\mathbf{1 6 9}$ & $\mathbf{1 1 5}$ & $\mathbf{1 3 7}$ & $\mathbf{1 0 6}$ & $\mathbf{6 2}$ & $\mathbf{5 8 9}$ \\
& $\%$ & $20.5 \%$ & $34.6 \%$ & $13.9 \%$ & $13.8 \%$ & $8.8 \%$ & $16.3 \%$ \\
\hline \multirow{2}{*}{ 2 High School, Reno } & $\mathbf{n}$ & - & $\mathbf{1 4 5}$ & $\mathbf{2 6 8}$ & $\mathbf{2 0 7}$ & $\mathbf{1 8 4}$ & $\mathbf{8 0 4}$ \\
& $\%$ & & $43.7 \%$ & $27.2 \%$ & $27.0 \%$ & $26.1 \%$ & $22.3 \%$ \\
\hline \multirow{2}{*}{ 1 High School, Las Vegas } & $\mathbf{n}$ & $\mathbf{2 1 4}$ & - & $\mathbf{1 4 4}$ & $\mathbf{1 3 2}$ & $\mathbf{1 6 3}$ & $\mathbf{6 5 3}$ \\
& $\%$ & $25.9 \%$ & & $14.6 \%$ & $17.2 \%$ & $23.2 \%$ & $18.1 \%$ \\
\hline \multirow{2}{*}{ 2 High School, Las Vegas } & $\mathbf{n}$ & $\mathbf{1 5 5}$ & - & $\mathbf{1 5 1}$ & - & $\mathbf{2 7}$ & $\mathbf{3 3 3}$ \\
\cline { 2 - 9 } & $\%$ & $18.8 \%$ & & $15.3 \%$ & & $3.8 \%$ & $9.2 \%$ \\
\hline \multirow{2}{*}{3 High School, Las Vegas } & $\mathbf{n}$ & - & - & $\mathbf{2 0 1}$ & $\mathbf{2 2 2}$ & $\mathbf{2 2 5}$ & $\mathbf{6 4 8}$ \\
\cline { 2 - 8 } & $\%$ & & & $20.4 \%$ & $29.0 \%$ & $32.0 \%$ & $17.9 \%$ \\
\hline \multirow{2}{*}{4 High School, Las Vegas } & $\mathbf{n}$ & $\mathbf{1 2 9}$ & - & - & - & - & $\mathbf{1 2 9}$ \\
& $\%$ & $15.6 \%$ & & & & & $3.6 \%$ \\
\hline \multirow{2}{*}{ UNLV } & $\mathbf{n}$ & $\mathbf{1 3 2}$ & - & $\mathbf{3 8}$ & $\mathbf{6 4}$ & - & $\mathbf{2 3 4}$ \\
& $\%$ & $16.0 \%$ & & $3.9 \%$ & $8.4 \%$ & & $6.5 \%$ \\
\hline \multirow{2}{*}{ Total } & $\mathbf{n}$ & $\mathbf{8 2 6}$ & $\mathbf{3 3 2}$ & $\mathbf{9 8 5}$ & $\mathbf{7 6 6}$ & $\mathbf{7 0 4}$ & $\mathbf{3 , 6 1 3}$ \\
& $\%$ & $100 \%$ & $100 \%$ & $100 \%$ & $100 \%$ & $100 \%$ & $100 \%$ \\
\hline
\end{tabular}

\subsubsection{Data Analysis}

All observational and awareness survey data were audited to an error rate of less than 1\%. All use rate calculations excluded people for which use was unknown, thus providing binomial distributions (used/not used) for various dichotomous variables (e.g., baseline versus w1; male versus female, etc.). For the overall analysis in each State, the use rate obtained at each site within a particular wave was weighted by the average number of observations for all sites within that wave. This was done to allow each site to contribute equally to the overall use rate index. These weighted data were then analyzed by means of logistic regression to determine use rates at each 
measurement period and to test the significance of changes in use after each wave, relative to baseline.

For sub-group analyses and comparisons, the raw use rate at each site was weighted by the average number of observations, within each subgroup being compared, within each wave. For example, for the calculation of use rates in Las Vegas and in Reno, raw use rates for each observation site within Las Vegas and within Reno, were weighted (within each measurement wave) by the average number of observations for that sub-group, for that wave. This weighting was done so that large-volume sites would not be over-represented in the overall index of seat belt use. In addition to calculation of use rates (i.e., number observed with [shoulder] belt fastened $\div$ total number for which [shoulder belt] use was known), analyses of seat belt use data consisted of the construction of two-by-two tables of use/non-use frequencies and, from these tables, the odds of seat belt use, odds ratios (i.e., changes in the odds from one period to another), and 95\% confidence intervals for these odds ratios were calculated.

The results of awareness surveys conducted at high schools and DMV licensing centers were not weighted prior to analysis. Raw data were entered into contingency tables and chi squares were calculated for each dichotomous category of responses being compared (e.g., "aware of special police efforts" versus "not aware of special police efforts" for any two time periods being compared (w4 versus w3, w4 versus baseline, etc.). As with the odds ratio analyses, the level set for rejecting a null hypothesis of no difference between groups was $\mathrm{p} \leq 0.05$. 


\section{Program Implementation}

\subsection{Implementation Schedules}

Figure 1, in the Introduction Section of this report, provides an example of the timing of various program components in a typical HVE program wave and Figure 2 (shown below) provides a visual regarding the timing of the four waves of activity in Colorado and Nevada. Table 3, shown below, provides the actual start and completion dates for each program (and survey) component, for each wave of activity in Colorado and Nevada. Each program wave begins with outreach and earned media, followed by paid media and actual high-visibility law enforcement. In nearly all cases, the completion of enforcement was followed immediately by observation and awareness surveys. There were two exceptions. In Colorado, the post-Wave 3 statewide observational survey was conducted approximately four weeks after Wave 3 enforcement ended, and the post-Wave 4 mini-observational survey was conducted while enforcement was ongoing in order to precede the end of the school year. In this section, we focus on the nature of the implementation data and the characteristics of the four program waves.

Figure 2. Multiwave Teen Demonstration Projects and Measurement Periods

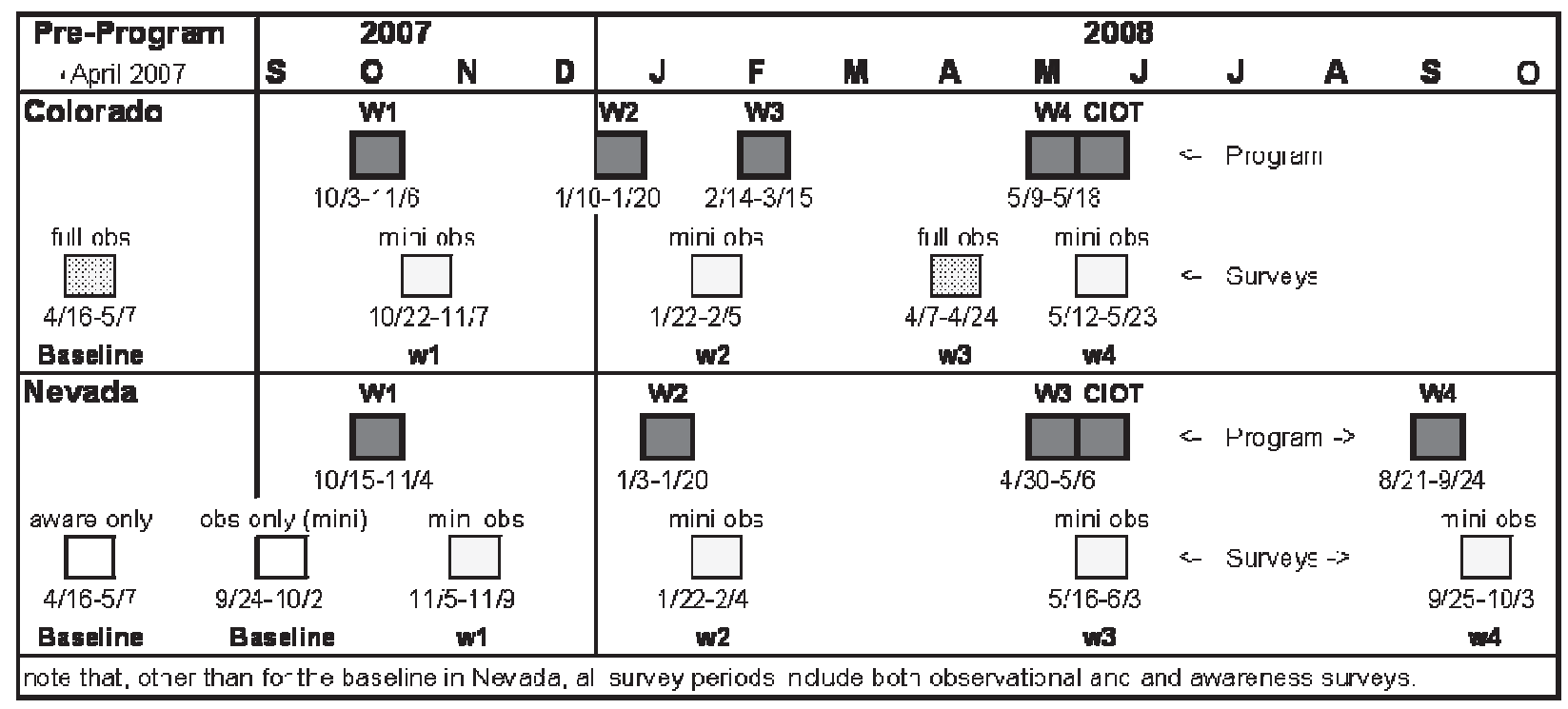


Table 3. Teen Seat Belt Demonstration Projects and Evaluation Schedule

\begin{tabular}{|c|c|c|c|c|c|}
\hline Component & Baseline & Wave 1 & Wave 2 & Wave 3 & Wave 4 \\
\hline \multicolumn{5}{|c|}{ Colorado } \\
\hline Outreach & - & $10 / 01-10 / 21$ & $12 / 31-1 / 20$ & $2 / 18-3 / 09$ & $5 / 01-5 / 18$ \\
\hline Earned Media & - & $10 / 03-11 / 06$ & $1 / 10-1 / 24$ & $2 / 14-3 / 15$ & $5 / 12-6 / 06$ \\
\hline Paid Media & - & $10 / 12-10 / 18$ & $1 / 11-1 / 17$ & $2 / 29-3 / 06$ & $5 / 09-5 / 15$ \\
\hline Enforcement & - & $10 / 15-10 / 21$ & $1 / 14-1 / 20$ & $3 / 03-3 / 09$ & $5 / 12-5 / 18$ \\
\hline Awareness & $4 / 16-4 / 20$ & $10 / 22-10 / 26$ & $1 / 22-1 / 28$ & $3 / 10-3 / 14$ & $5 / 19-5 / 23$ \\
\hline Observation & $4 / 23-5 / 07^{*}$ & $10 / 22-11 / 07$ & $1 / 22-2 / 05$ & $4 / 07-4 / 24^{*}$ & $5 / 12-5 / 23$ \\
\hline \multicolumn{5}{|c|}{ Nevada } \\
\hline Outreach & - & $10 / 15-10 / 25$ & $1 / 08-1 / 18$ & $4 / 17-5 / 28$ & $9 / 10-9 / 24$ \\
\hline Earned Media & - & $10 / 16-11 / 09$ & $1 / 06-1 / 16$ & $4 / 29-5 / 31$ & $8 / 21-9 / 17$ \\
\hline Paid Media & - & $10 / 19-10 / 25$ & $1 / 03-1 / 09$ & $4 / 30-5 / 06$ & $9 / 08-9 / 14$ \\
\hline Enforcement & - & $10 / 20-11 / 04$ & $1 / 04-1 / 20$ & $5 / 01-5 / 15$ & $9 / 10-9 / 24$ \\
\hline Awareness & $4 / 16-5 / 07$ & $11 / 05-11 / 09$ & $1 / 22-2 / 06$ & $5 / 19-6 / 03$ & $9 / 25-10 / 03$ \\
\hline Observation & $9 / 24-10 / 02$ & $11 / 05-11 / 09$ & $1 / 22-1 / 31$ & $5 / 16-5 / 23$ & $9 / 25-10 / 01$ \\
\hline * Colorado Baseline and Wave 3 observation data were extracted from CDOT's annual statewide youth seat belt survey. \\
\hline
\end{tabular}




\subsection{Outreach and Earned Media}

\subsubsection{Defining Outreach and Earned Media}

Outreach refers to efforts to engage other organizations and groups to achieve mutually beneficial objectives in a demonstration program such as this. It is measured in various ways, such as numbers of organizations contacted, numbers of organizations participating, specific programs or activities initiated by various organizations, etc.

Earned media refers to the generation of news articles and stories in the various media and in other awareness-producing activities, such as promotional events, educational programs, demonstrations, etc. The generation of news stories, which is the key component of earned media, results from a very specific form of outreach that focuses on the news media itself. It is often measured in terms of number of news stories printed or aired, number of events gaining media coverage (e.g., community kick-off events), number of media (or participating organizations) present at media events, etc. With emerging use of Internet advertising, number of impressions is also being reported and documented. ${ }^{5}$

Outreach and earned media are important components of any HVE program to increase seat belt use. Consistently, awareness surveys have shown that a substantial portion of the information that respondents read, see, or hear about HVE comes from news stories. Outreach can not only help create earned media, it can add to its credibility. Messages for teens to buckle up that come from various partners can reinforce and provide verification of messages that come from the media (and vice versa). Some examples include messages from schools, employers, and other organizations to their students, employees, members, and affiliates. Unfortunately, the strength of earned media and outreach is difficult to assess, in part due to a combination of incomplete and variable reporting of events, stories, and contacts made. In these projects, however, the States made substantial efforts to generate outreach and earned media and to document the results by contracting with media monitoring services.

\subsubsection{Outreach and Activities Generated}

\subsubsection{Colorado}

CDOT awarded mini-grants to several local coalitions and other organizations to conduct community-based activities to educate the public about seat belt use and enforcement activities in their communities. Some of the organizations CDOT engaged in the process were the Center for Transportation Safety (Commerce City); CH2MHILL (Englewood); Crossroads Turning Points, Inc. (Pueblo); Drive Smart Evergreen/Conifer (Evergreen); Fort Lupton Injury Free Coalition

\footnotetext{
${ }^{5}$ The term media impressions generally refers to the number of people who may have seen or heard an article or story, whether on television, radio, in print, or on the Web. Number of impressions is often equated with listenership, viewership, number of subscribers, etc. It is a potential exposure estimate in that it assumes that all of these people saw the article or story, which is not likely. A subscriber or a usual viewer or listener may have been away or just missed the article. Still, in some cases, public relations people go beyond circulation or viewership by assuming that more than one targeted person was exposed. With newspapers, for example, a "pass along" or "multiplier" factor is sometimes used which assumes that more than one subscriber read an article before the paper was discarded.
} 
(Aurora); Teen Motor Vehicle Safety (Fort Collins); Colorado Association of School Resource Officers (CASRO); Mile-High RETAC (Denver); and Safe Kids Mesa County (Grand Junction).

Enforcement partners provided crashed vehicle and convincer displays and conducted demonstrations at various high schools. Several groups distributed educational materials regarding teen seat belt use at community events; some provided recognition to teens for being buckled up when involved in a crash; others distributed posters to local health care clinics, schools, libraries, post offices, and court houses. Schools and/or community organizations also placed Buckle Up signs at entrances and exits of school parking lots. Several partner groups contacted local news media and sent press releases to local newspapers, television, and radio stations. The Colorado State Patrol (CSP) was most prominent in this respect. CSP issued news releases prior to and after each wave. Paramedics and EMTs also created considerable media awareness for the need to buckle up. Other important products of outreach activities included: conducting Parent of Teen Driver educational classes; posting CIOT signs on Interstate 25; organizing campaigns to obtain teen pledges to buckle up; and encouraging students to write press releases. One organization supported a traveling billboard that logged nearly 2,400 miles across Colorado during Wave 4.

\subsubsection{Nevada}

In Nevada, OTS hired contractors to reach out to the community, particularly in the Latino community. One effort focused on the southern part of the State (Las Vegas) and the other focused on the northern part of the State (Reno). These efforts resulted in a variety of activities, some of the more prominent of which were kick-off events, high school assembly programs, posters placed in colleges and high schools, convincer demonstrations, etc.

Some of the organizations contacted and the resulting activities were fast food restaurants, such as Sonic, Wendy's, Taco Bell, McDonalds, and Burger King (rewards for teens who were buckled up as they passed through, rewards included free soft drinks and music download cards); Spanish-language media (conducted a special kick-off event); Big Brothers Big Sisters (distributed CIOT litter bags, clickers, fans, and Excuses postcards); Latino business organizations (distributed similar giveaways); youth groups (allowed for CIOT educational presentations); universities and colleges (displayed posters and distributed bracelets); shopping malls and vendors (displayed posters, distributed bracelets, etc.); high schools (displayed posters, announcements at sporting events, etc.); and various enforcement agencies (distributed information and download cards as part of enforcement). Again, while not totally quantifiable, there was evidence of considerable outreach activity, particularly in the northern part of the State (Reno). Some of the earned media described in the next section resulted from such activity. 


\subsubsection{Earned Media}

Prior to each wave, NHTSA, via its media and public relations contractors the Tombras Group and AkinsCrisp Public Strategies, provided earned media-related material to Colorado and Nevada, which then customized this material to be appropriate for their activities and calendars. This material included sample news releases, fact sheets, op-ed articles, letters-to-the-editor, morning announcements, etc.

In this section, we summarize the news stories or articles in print, Web, and television media as reported by media monitoring organizations and, in some cases, by a NHTSA clipping service. In addition, because some of the main stimuli for such stories are news releases, media advisories, or news events, we provide what evidence that we have of such events. In no case should it be assumed that the numbers provided here represent all of the earned media that was generated. However, by examining results from similar reports that presumably reflect similar monitoring procedures, we use these numbers as an index of the level of earned media achieved during each wave of activity (for print, Web, and television stories). Rather than listing the dates for all of the components of each wave (see Table 3) to reference the timing of articles and stories, we provide the dates of the enforcement activity associated with each wave.

\subsubsection{Colorado}

\section{Wave 1 (Enforcement conducted October 15-21, 2007)}

A news release from the CSP on October 15, 2007, announced that 11 of the State's most populous counties were involved in a CIOT program to increase seat belt use among all road users, but especially among teenagers. It discussed GDL; low seat belt use of teenagers relative to adults (72.9\% versus $81.1 \%$ ); the number of teens killed in 2006 (71) and the number of those fatalities who were unbuckled (50). The chief of the CSP was quoted regarding the need for teen drivers to make Smart Choices; that seat belts save lives; and that law enforcement will do its part to remind all motorists to buckle up. The release further pointed out that CSP and 35 law enforcement agencies (LEAs) will participate in the October CIOT effort under a \$600,000 grant from NHTSA and that the goal is to increase seat belt use and awareness among young Coloradans 16 to 20. In addition to this wave of activity, the release pointed out that additional enforcement will take place in January, March, and May 2008. It listed the components of the CIOT program: outreach, paid advertising, and education in the 11 identified counties. Additionally, the release announced that the program will involve the efforts of 11 high schools to obtain student pledges to buckle up. The press release closes with NHTSA statistics regarding teen drivers and passengers that account for $8.5 \%$ of the driving population but $14 \%$ of total traffic fatalities.

A follow-up news release was issued by CSP on October 25, 2007, reporting that 2,558 seat belt tickets were issued in the 11 participating counties during the week-long enforcement program, 296 of which were issued to teens. It also pointed out that CSP and 35 LEAs participated and listed the targeted counties. Citations issued during CIOT were broken down into adult non-use $(2,058)$, teen non-use (296), juvenile non-use (111), booster seat violations (29), and child safety seat violations (64). The release highlighted 8 agencies with the highest number of citations issued. Also listed were 11 high schools that were collecting teen pledges (about 1,500 pledges had been collected from 5 of the 11 schools at the time of the report). 
A print and Internet monitoring report was prepared by Robert Sharp and Associates (RSA) dated November 1, 2007. It found 13 news stories, 8 of which were Web-based and 5 of which were in the print media. Most were from the Denver or Fort Collins areas. Two were posted prior to the start of the CIOT wave; 5 ran while the program was ongoing; and 6 were printed just a little over a week after the end of the program, after citation statistics had been gathered. It was estimated that the Web-based articles resulted in a total of just under 2 million impressions; about 1.7 million (85\%) were associated with the Web articles and just over 300,000 impressions $(15 \%)$ were associated with newsprint articles.

With regard to the content of the stories run, most mentioned the issues highlighted in the initial news release. They included the seat belt use rate among adults $(81 \%)$ and the lower rate among teens (73\%); the participation of the CHP and the 35 local agencies; and the activity of 11 high schools to obtain teen pledges to buckle up. Some articles specifically mentioned the components of the program (outreach, enforcement, advertising, and education) and several mentioned the $\$ 600,000$ grant from NHTSA that helped to fund the program. Another frequently included fact was that 71 teens were killed in 2005 and that $50(70 \%)$ were unbuckled at the time of the crashes. The GDL law was also prominent in several articles, along with reference to recent teen fatalities in car crashes.

Articles run after completion of the program generally focused more on the number of participating LEAs and schools; the number of citations that had been issued (often by category); the number of pledges that had been collected; and the need for teens to buckle up. At least two mentioned that 7 teens had died during the period that the CIOT program was ongoing.

Video Monitoring Services (VMS) reports documented 39 television stories (with nearly 50 separate airings) run prior to and during CIOT (October 3-16, 2007) and two stories after CIOT (November 6-7, 2007). The stories that aired before and during the campaign included topics such as CIOT; participating LEAs and citations; participating schools and teen pledges to buckle up; teen seat belt use rates; Buckle Up Colorado; and 4 talked about seat belts on school buses. The 2 stories that aired after CIOT were in the Grand Junction media market and they focused on Fruita Monument High School and students' efforts to obtain teen pledges to buckle up.

Figure 3 shows the dates of these television stories, along with the dates of the print and Web stories documented by the RSA reports. It shows that the second largest number of television news stories ran on the day that the enforcement effort began (October 15). Thirty-one stories ran approximately 10 days earlier (October 3-4). Print and Web articles were more evenly distributed before, during, and after the enforcement period. 
Figure 3. Distribution of Web/Print and Television Stories in Colorado, Wave 1

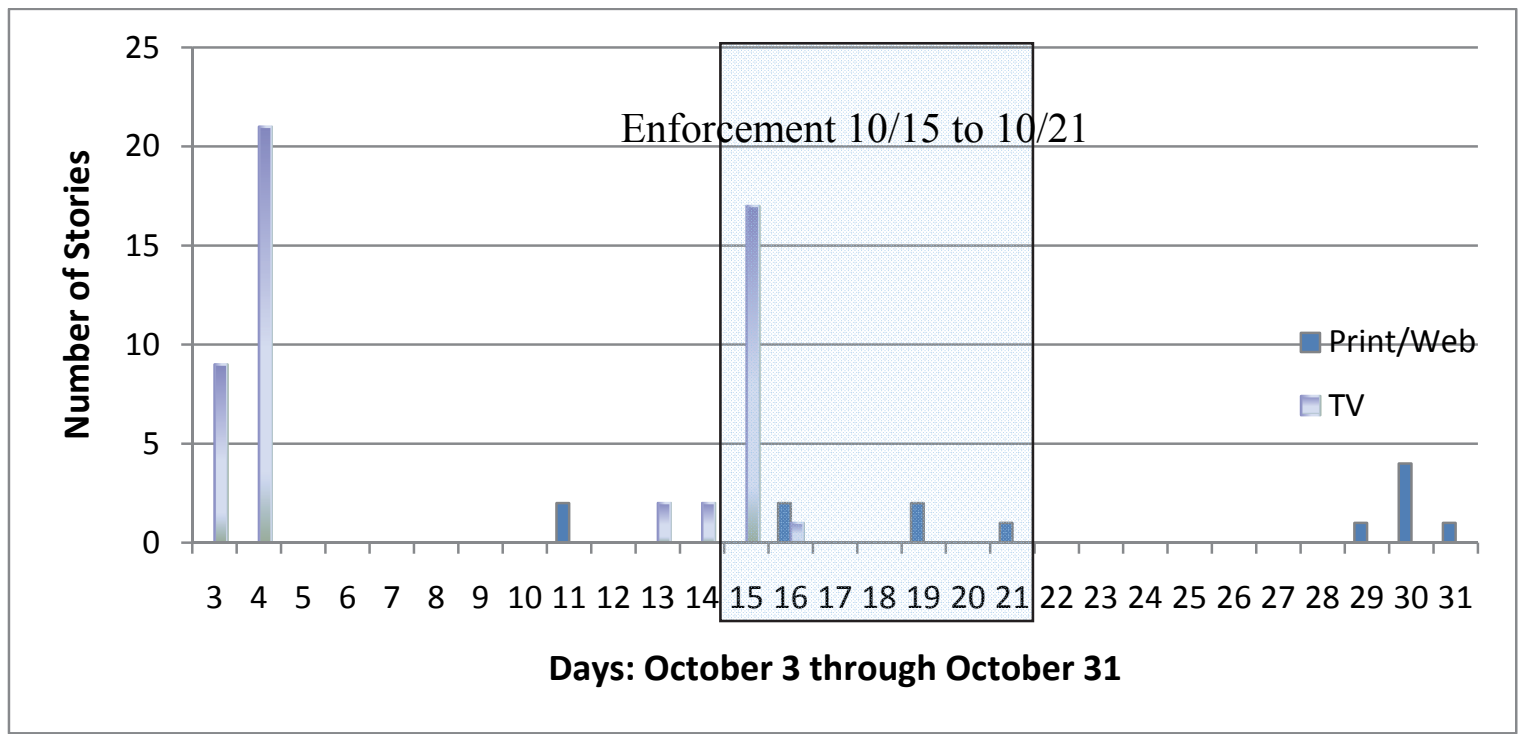

Wave 2 (Enforcement conducted January 14-20, 2008)

An initial press release was issued by CSP on January 10, 2008. It alerted the public that CSP and LEAs in the 11 most populous counties would be working overtime January 14-20 to enforce Colorado seat belt laws, especially among teenagers. It pointed out that 66 teens died in crashes in 2006, that $45(68 \%)$ of them were unbuckled, and that this unbuckled rate was higher than the national rate $(58 \%)$. This program announcement quoted the chief of the CSP regarding the need for teens to buckle up and for adults to set an example; it pointed out that, in addition to the CSP, 40 LEAs would be participating in enforcement and education activities, and that this was the result of a grant from NHTSA. It mentioned that the last CIOT wave, held in October 2007, resulted in 2,559 citations and that additional mobilizations would take place in March and May 2008. The release also identified the 11 high schools participating in the CIOT pledge drive to get teens to buckle up.

A second release was issued by CSP on January 18, 2008. This release, issued during the CIOT program, pointed out that CSP and LEAs in 11 counties continued to buckle down on those who don't buckle up. It reported preliminary data showing 1,839 seat belt-related citations being issued, which was expected to rise over the coming weekend. It conveyed particular concern regarding teenagers who do not buckle up; the number who died in 2006; and the 68\% who were not buckled up. The release listed local LEAs with the highest number of citations at the time; reported the results of the prior CIOT wave (October 2007); and pointed out that two additional CIOT waves would follow in March and May 2008.

A third release issued by the CSP on January 24 listed the final results of the January campaign, with 4,112 citations issued, 395 of which were issued to teens 16 to 20 . The chief of the CSP reminded readers that it takes only two seconds to buckle up; that it could change your life forever; and that it is not a matter of choice, it is the law. This release also identified other violations identified such as suspended licenses (283), outstanding warrants (27), DUI (34), and drug- 
related offenses (16). It pointed out that these mobilizations are not about writing tickets, they are about saving lives and it quoted the Colorado Governor's Highway Safety Representative's concern for teenagers who think they are invincible and do not buckle up.

Print and Web Articles. With regard to print or Web-related stories, an RSA report (March 18, 2008) listed 75 articles from January 5 through January 30, of which 72 (96\%) were in news print and $3(4 \%)$ were on the Web. It estimated that these stories resulted in about 1.7 million impressions, of which nearly 1.6 million $(94 \%)$ were in daily or weekly newspapers (1.4 million and 0.2 million, respectively) and 0.17 million impressions were on the Web.

Timing. Thirty-eight articles (51\% of the total) were printed prior to the start of enforcement (January 14); 31 of these 38 pre-enforcement stories $(82 \%)$ were run within one-day of the first news release issued by the CSP. Nineteen stories were printed during the CIOT enforcement effort (January 14-20) and 11 of these stories (58\%) were within one day of the January 18 news release. Finally, 18 stories (about $24 \%$ of the total) were printed after the enforcement effort was completed (January 20); 10 of these stories (56\%) were run within one day of the January 24 news release.

NHTSA Clips. As a supplement to the RSA report, 24 print articles were documented by NHTSA's news clipping service, few of which were found in the RSA report. The distribution of these articles over time was very similar to those in the RSA report: $14(58 \%)$ appeared prior to the start of enforcement, generally within one day of the first news release; $8(33 \%)$ appeared during the enforcement program, about half (4) within one day of the January 18 release; and 2 (8\%) appeared after the CIOT effort was completed, both appearing on the date of the final release.

Electronic Media. A VMS report covering the period January 13, 2008 to 25) identified 55 television stories about seat belts, nearly all of which were run during news or traffic reports. Multiple mentions of all or part of these stories resulted in an estimated 75 airings. These stories primarily mentioned the CIOT crackdown or teen buckle-up pledge programs in the high schools, and they ran primarily on major network affiliates.

Timing. The timing of the Web, print, and television stories documented by these reports is summarized in Figure 4. Sixty percent of the stories ran within one day of the start of the enforcement effort on January 14, just after the first news release. About 95\% of all stories ran in conjunction with enforcement and $4 \%$ ran after it was completed. Other than on the first day of enforcement, the largest number of stories ran on January 18 and 19, coincident with the second CSP news release. 
Figure 4. Distribution of Web/Print and Television Stories in Colorado, Wave 2

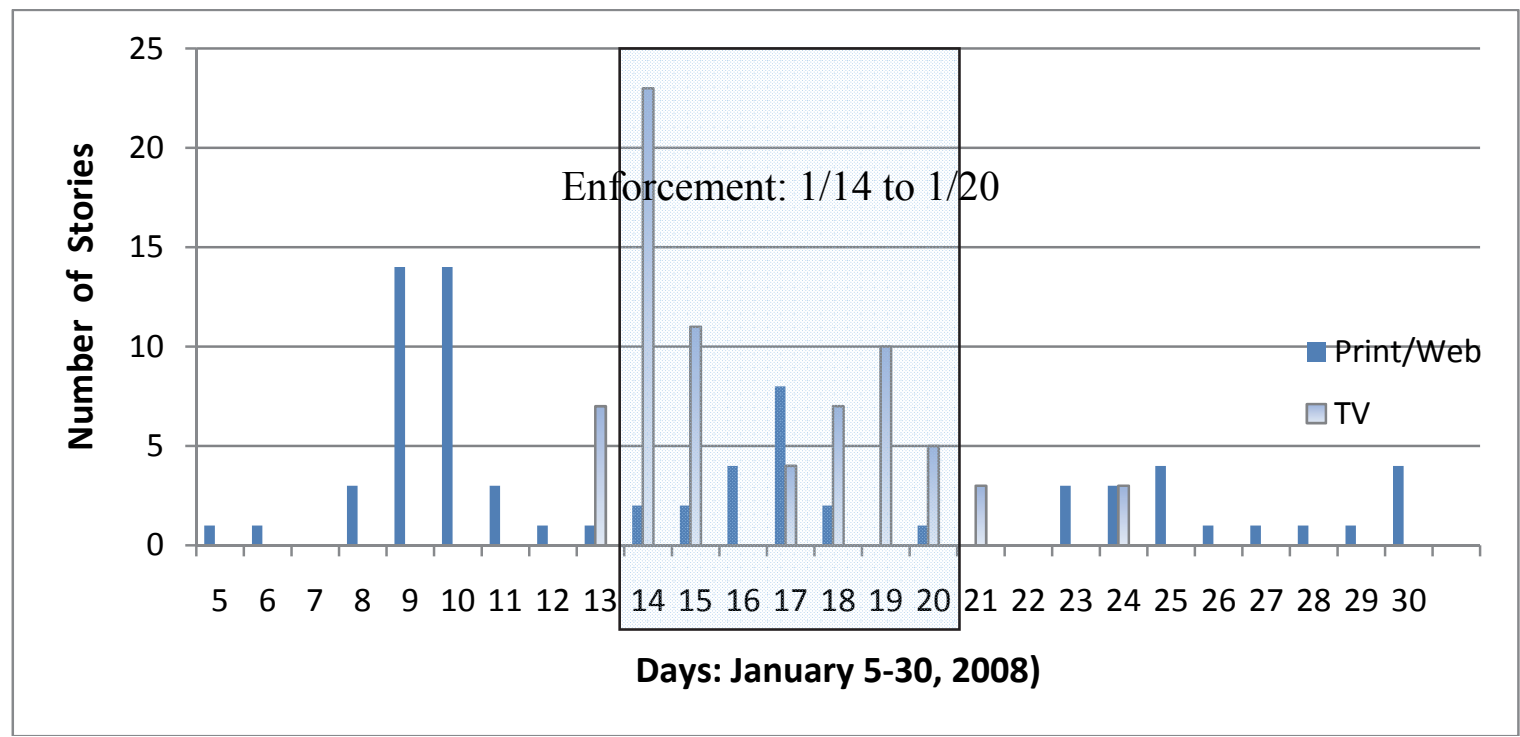

Variable Message Boards. Finally, while classified as advertising as well as earned media the Colorado Transportation Management Center reported that 56 variable message boards across the State carried the Click It or Ticket message during the January campaign. No estimate of exposures was provided.

Wave 3 (Enforcement conducted March 3-9, 2008)

CSP issued a news release on March 3 announcing that Colorado teen fatalities had declined by $34 \%$, from 66 in 2006 to 43 in 2007, and that the proportion of such teens who were not buckled up declined from $68 \%$ to $63 \%$. It suggested that these declines were likely associated with the Colorado GDL law, safe driving education programs, and enforcement of the seat belt law. While this was good news, the release indicated that many unbuckled teens continue to have their lives cut short because they were not wearing seat belts. Because of this, the CSP and 44 local LEAs in 11 counties would be participating in a third CIOT mobilization March 3-9. It also mentioned the grant from NHTSA to fund these teen CIOT efforts and that the last wave of activity (in January) resulted in 4,301 seat belt citations issued.

A second release was issued on March 13, about four days after completion of the enforcement effort, pointing out that the recent CIOT had sent a strong message regarding seat belt use by issuing 5,112 seat-belt-related tickets, 445 to teens. The head of CSP again pointed out that it takes only a couple of seconds to buckle up and that doing so would reduce the number of people needlessly killed on Colorado's highways. The release listed 10 agencies including 4 CSP troops that issued the largest number of tickets; pointed out that this was one of several waves of enforcement supported by an NHTSA grant; and that a final wave of CIOT enforcement would be conducted May12 to June 2.

Print and Web Articles. An RSA report dated April 11, 2008, documented 61 stories, 41 of which were in the print media and 20 on the Web, usually affiliated with a newspaper. This re- 
port estimated these articles were associated with approximately 8.7 million impressions, 5 million $(57 \%)$ of which were on the Web and 3.7 million $(43 \%)$ of which were attributed to print, mainly in daily newspapers.

Timing. Thirteen stories (21\%) were printed well in advance of the start of enforcement (March 3, 2008). Several stories reported on an apology from Miley Cyrus and her father for not wearing seat belts in a recent episode of their show, but most focused on the upcoming CIOT wave and on a reduction in teen fatalities from 2006 to 2007 . The majority of stories (64\%) were printed or posted during the enforcement period, usually within one day of the first news release. Nine stories (15\%) followed the completion of enforcement on March 9. Stories printed or posted during enforcement focused on the reduction in teen fatalities, CSP and local agency participation in the CIOT effort, and the number of unbuckled teens killed; they also mentioned a trooper-taught "Alive at 25" safety program and the GDL law. Articles written after enforcement included the number of citations written during this mobilization and as part of past teen mobilizations, and the dates of the next CIOT mobilization.

NHTSA clipping services showed a very similar distribution of print media stories with 36 total stories, 24 of which (67\%) were in print on March 3 or 4 and about 7 (19\%) in print on March 13 to 15 . Two articles ran prior to the mobilization and 3 ran during the middle of the mobilization.

Figure 5. Distribution of Web/Print and Television Stories in Colorado, Wave 3

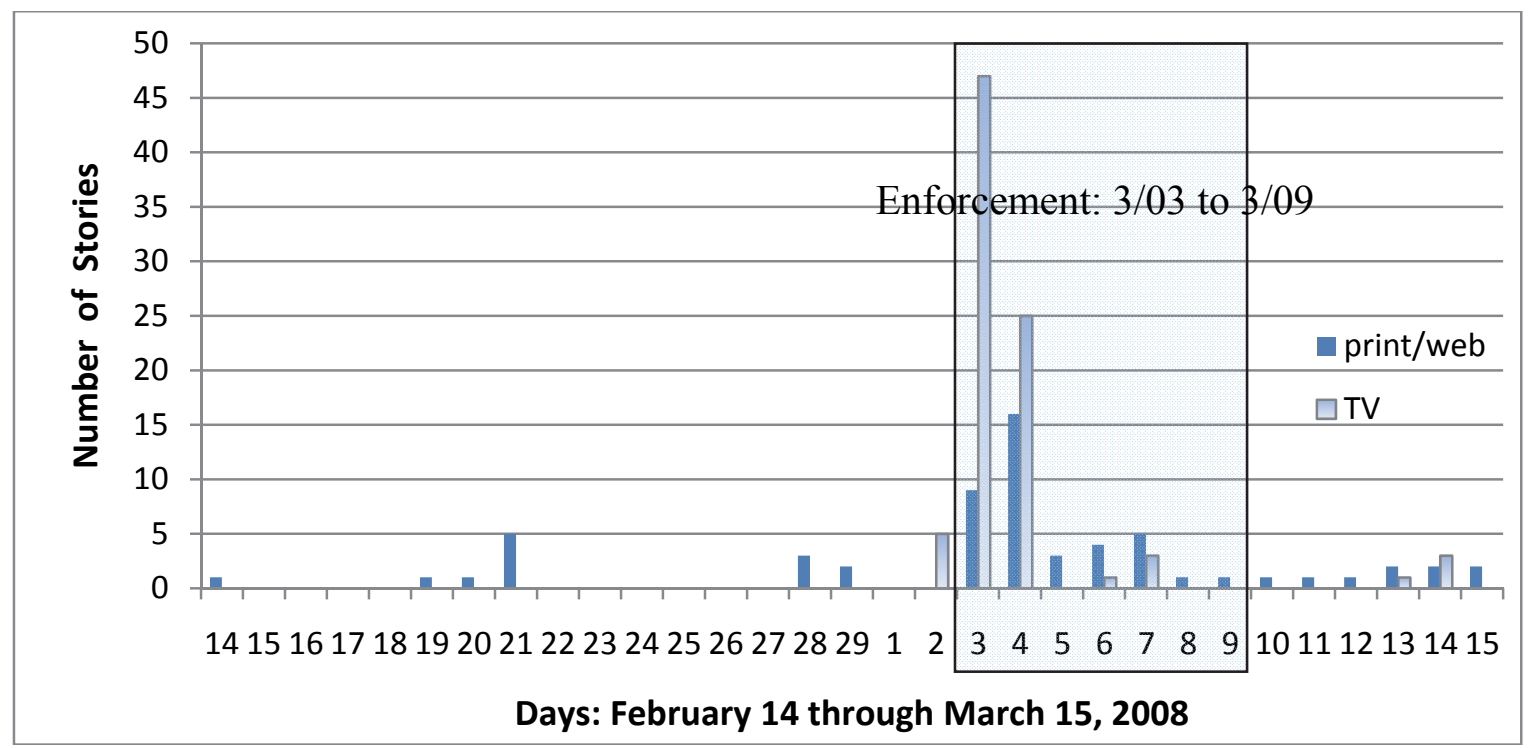

Electronic Media. A VMS report documented 53 television stories run by local ABC, CBS, Fox News, and NBC affiliates, with about 83 airings of all or a portion of such stories during various segments of the news. Nearly all dealt with the CIOT campaign, teen fatalities in crashes, reductions in such fatalities, lower belt use among teens, and an emphasis on no warnings. Most of these reports were aired on March 3 or 4, at the start of the enforcement effort, with a few on March 13 and 14, several days after the mobilization had been completed. Figure 5 shows the distribution of print/Web and television articles over time. 
Variable Message Boards. The Colorado Transportation Management Center reported that 24 message boards across the State carried the Click It or Ticket message during this wave of the teen campaign, compared with 54 during the previous wave.

\section{Wave 4 (Enforcement conducted May 12-18, 2008)}

An initial news release for Wave 4 of the Colorado teen program was issued on May 12 at the start of the enforcement component. It pointed out that the number of unbelted occupants killed in crashes was at an all-time low in 2007 and credited both education and high-visibility enforcement for recent reductions. The release announced the start of a stepped-up enforcement campaign in 11 counties on May 12 and a statewide expansion of that enforcement effort on May 19, with a total of three straight weeks of intensified enforcement. This release mentioned low belt use among nighttime road users and the fact that seat belt use costs you nothing. Lastly, it focused on the low use rate among teens and that this would be the fourth and final wave of a NHTSA-funded demonstration to increase use among teens.

A second release was issued on June 6, five days after completion of the statewide CIOT mobilizations. It reported that 15,043 tickets and warnings had been issued for the statewide campaign that began with the 11-county, teen-focused program. It listed the LEAs issuing the most tickets during the teen phase and pointed out that 5,286 citations were issued during that week alone. In addition to listing the schools that participated in the pledge drive, this release pointed out that more than 6,000 pledges to buckle up had been obtained. It also recognized the many local citizens and community organizations that aided the campaign by supplying crashed car displays, seat belt statistics, seat belt cutouts, and reminders at prom and graduation events. This final release recognized other safety programs that had supported the teen CIOT, including: Drive Smart, the Safe Kids Coalition, Alive at 25, and the Ft. Lupton Injury Free Coalition.

Print and Web Articles. An RSA report on July 14, 2008 documented 68 stories, 34 (50\%) of which appeared in newspapers and $34(50 \%)$ of which were posted on the Web The report estimated that these stories accounted for nearly 6.5 million impressions, of which 4.5 million (69\%) were on the Web and 2 million (31\%) were in newspapers, nearly all daily papers. Again, RSA estimated many more impressions on the Web than in print.

Timing. Twenty articles (29\% of the total) appeared prior to the start of the teen enforcement effort on May 12. Nineteen (28\%) were run while enforcement was ongoing; and about half appeared after enforcement had been completed but during the statewide CIOT enforcement phase. By far the greatest number of stories in any one day occurred on May 20 (23 stories), one day after the statewide enforcement effort began. There were only a modest number of stories (11) following the first news release and only one at the time of the June (post-CIOT) release. 
Figure 6. Distribution of Web/Print and Television Stories in Colorado, Wave 4

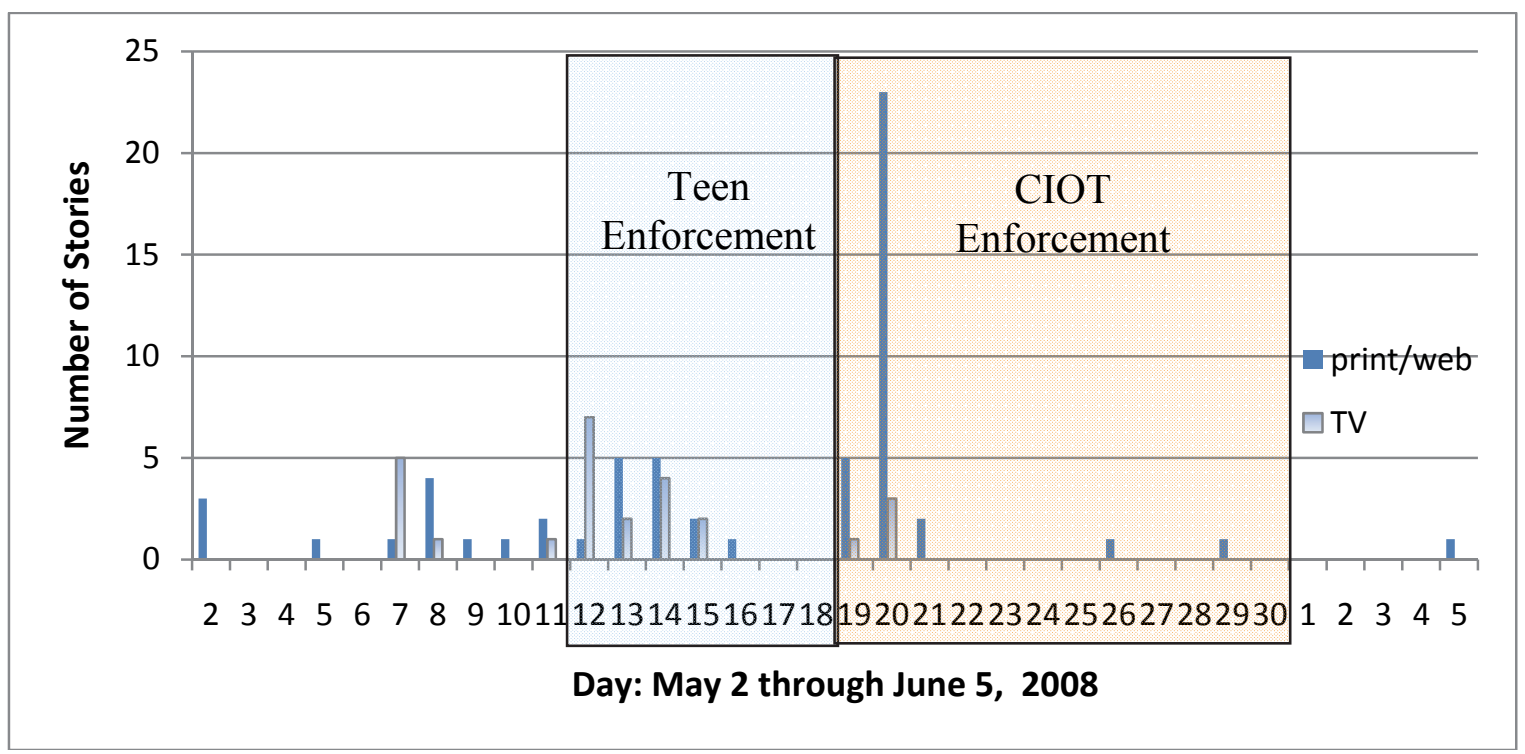

Electronic Media. With regard to television, VMS reports covering the period from May 7 through June 6 documented 23 stories that aired approximately 31 times. As in previous waves, these stories focused on CIOT enforcement, seat belt non-use, the issue of ejection, number LEAs participating, number of tickets issued to teens, and the recent decline in teen fatalities.

Other Earned Media. While PRG received no reports regarding the number of variable message signs displaying the CIOT message during this wave, we did receive information from the Colorado outreach report that a traveling billboard (semi-trailer truck) with the dual messages "Click It or Ticket: Get Belted, Not Busted" traveled continuously across the State during this wave of the campaign, logging approximately 2,400 miles. This vehicle was sponsored by the Center for Transportation Safety, one of CDOT's outreach partners.

\section{Summary of Four Waves of Earned Media in Colorado}

Table 4 summarizes the numbers of press releases, ads, airings, and impressions from the four waves. While none of these sources is likely to provide a complete number of such outcomes, it would be expected that, within each row or medium, the entries provide a rough index of the level of activity in that medium. If that is the case, the data in Table 4 indicate that Wave 2 and Wave 3 likely had the greatest amount of earned media associated with them, although Waves 3 and 4 may have had the greatest news exposure on the Web. It is not clear why a smaller number of print ads in Wave 3 (relative to Wave 2) resulted in twice as many impressions (in Wave 3).

While there was much variation across waves, a Web article appears to have resulted in an average of about 160,000 (potential) impressions, about 2.8 times as many as a print ad, which, on average resulted in about 58,000 (potential) impressions. Again, there was much variability in the reporting of these estimates. In the Awareness section, we examine awareness relative to 
messages received via print media and online. However, awareness is affected by earned media stories and by paid media ads, which are far more prevalent during a mobilization period.

Table 4. Summary of Earned Media Activity in Colorado

\begin{tabular}{|l|c|c|c|c|}
\hline \multicolumn{1}{|c|}{ Media } & W1 & W2 & W3 & W4 \\
\hline News Releases & 2 & 3 & 2 & 2 \\
\hline Web Articles $^{1}$ & 8 & 3 & 20 & 34 \\
\hline Web Impressions $^{1}$ & $1.6 \mathrm{~m}$ & $0.2 \mathrm{~m}$ & $5.0 \mathrm{~m}$ & $4.5 \mathrm{~m}$ \\
\hline Print Articles $^{1}$ & 5 & 72 & 41 & 34 \\
\hline Print Impressions $^{1}$ & $0.3 \mathrm{~m}$ & $1.6 \mathrm{~m}$ & $3.7 \mathrm{~m}$ & $2.0 \mathrm{~m}$ \\
\hline TV Stories/Airings $^{2}$ & $39 / 50$ & $55 / 75$ & $53 / 83$ & $23 / 31$ \\
\hline NHTSA Clippings & n/a & 24 & 36 & n/a \\
\hline Variable Message Boards & n/a & 56 & 24 & n/a \\
\hline Notes: ${ }^{1}$ From RSA Reports; ${ }^{2}$ From VMS Reports \\
\hline
\end{tabular}

\subsubsection{Nevada}

NHTSA media contractors Tombras Group and AkinsCrisp and the Nevada media contractor, (the Glenn Group, provided earned media material appropriate to each wave of the Teen Demonstration Project in Nevada. This material included sample news releases, news advisories, enforcement planners, sample letters-to-the-editor, fact sheets, talking points, Click It or Ticket morning announcements to be read in high schools, and a talking piece that described the Nevada CIOT program. This material along with various brochures and posters were distributed to partners including media and law enforcement to create news stories in addition to the ads purchased with media funds. As in Colorado, news articles were monitored primarily by RSA, which tracked both newsprint and Web articles. In Nevada, however, RSA also monitored television stories that appeared in the Las Vegas and Reno DMAs. Following is a summary of the information provided in those reports, as well as reports from the Glenn Group and NHTSA.

Press releases for each wave generally focused on the need for teens to buckle up, the upcoming enforcement activity, the number of police agencies participating in the program; media efforts that will accompany enforcement, recent fatal crashes involving teens, and school education programs. At least two press events were documented to kick off enforcement activity (Waves 1 and 3). These events were conducted by the Glenn Group at high schools on October 12, 2007, (Wave 1) and on April 30, 2008 (Wave 3). Media advisories were released prior to the start of each wave of activity, nearly always just prior to the start of enforcement.

\section{Wave 1 (Enforcement conducted October 20-November 9, 2007)}

Print and Web Articles. An RSA earned media report dated November 19, 2007, lists 11 Web and print articles on seat belt use that appeared from October 16 through November 9; 5 of the 11 articles (45\%) were posted on the Web, $6(55 \%)$ were found in the print media. The Sharp report estimated that the $5 \mathrm{Web}$ articles generated 0.5 million impressions $(83 \%$ of total impressions) and the 6 print articles, mostly from daily newspapers, generated just over 0.1 million impressions (17\%). In a final/overall RSA report (February 27, 2009), an additional 4 print articles were documented for the period from October 11 through November 27, for a total of 10 print 
articles $(67 \%$ of total) and 5 Web articles (33\%), generating an estimated 0.8 million impressions, 0.3 million from print $(37 \%)$ and 0.5 million on the Web $(63 \%)$.

Electronic Media. The February 2009 report also documented 72 television stories that ran from October 11 through October 25; 44 (61\%) of these stories originated in the Las Vegas area and $28(39 \%)$ originated in the Reno area. An independent television monitoring report found a nearly identical number of television stories over this period of time.

As Figure 7 shows, most of the television coverage was in advance of Wave 1 enforcement, which did not begin until October 20. In fact, much of it preceded the start of earned media efforts starting about October 16. Many of these stories covered issues such as recent crashes and fatalities involving unbuckled occupants, efforts of a judge to put teens through a defensive driving course, and teen driving safety week. However, several of these early stories also discussed the new grant to conduct a teen CIOT campaign in Nevada. Later stories focused on the \$67 fine that teens (and other drivers) will face if they don't buckle up. By October $20^{\text {th }}$, the stories focused almost exclusively on enforcement, including tickets given to teens for not buckling up and on free music download cards for teens who are wearing their seat belts.

Figure 7. Distribution of Web/Print and Television Stories in Nevada, Wave 1

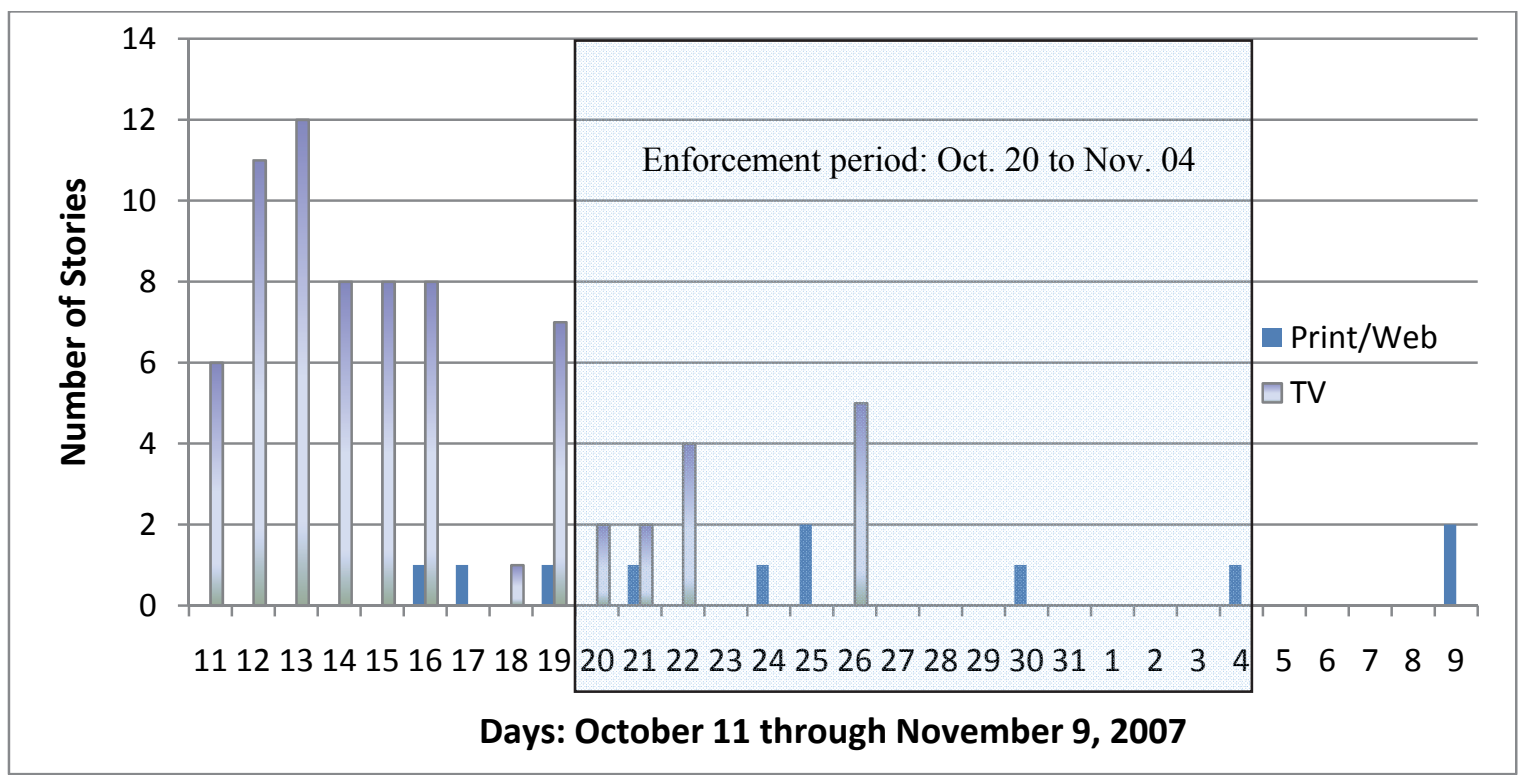

Wave 2 (Enforcement conducted January 4-20, 2008)

Print and Web Articles. During Wave 2, an RSA report dated March 3, 2008, identified only 3 Web or print articles associated with seat belts. All 3 articles originated in the Reno area (Carson City, Battle Mountain, and Reno). One was posted on January 6 on the Web, two days after the start of the enforcement effort. The remaining two articles were in the print media and were run on January 15 and 16, just prior to the end of the enforcement period. According to the RSA report, these articles generated an estimated 131,929 impressions, of which 62,611 (47\%) were on the Web and 69,318 (53\%) were in print. They focused nearly exclusively on the CIOT cam- 
paign, tickets being issued, tickets issued during Wave 1, NHTSA sponsorship of the program, and on various "giveaways" (download cards) to build awareness of the program. TheNHTSA clipping services found two additional print articles, both in the Reno DMA. These articles ran on January 13 in Sparks and January 16 in Reno.

Electronic Media. In addition to these Web and newsprint articles, the February 27 RSA report documented 14 television stories run from December 28, 2007, through January 20, 2008. All originated in the Reno DMA. Figure 8 shows the distribution of the Web/print and television stories associated with Wave 2.

Figure 8. Distribution of Web/Print and Television Stories in Nevada, Wave 2

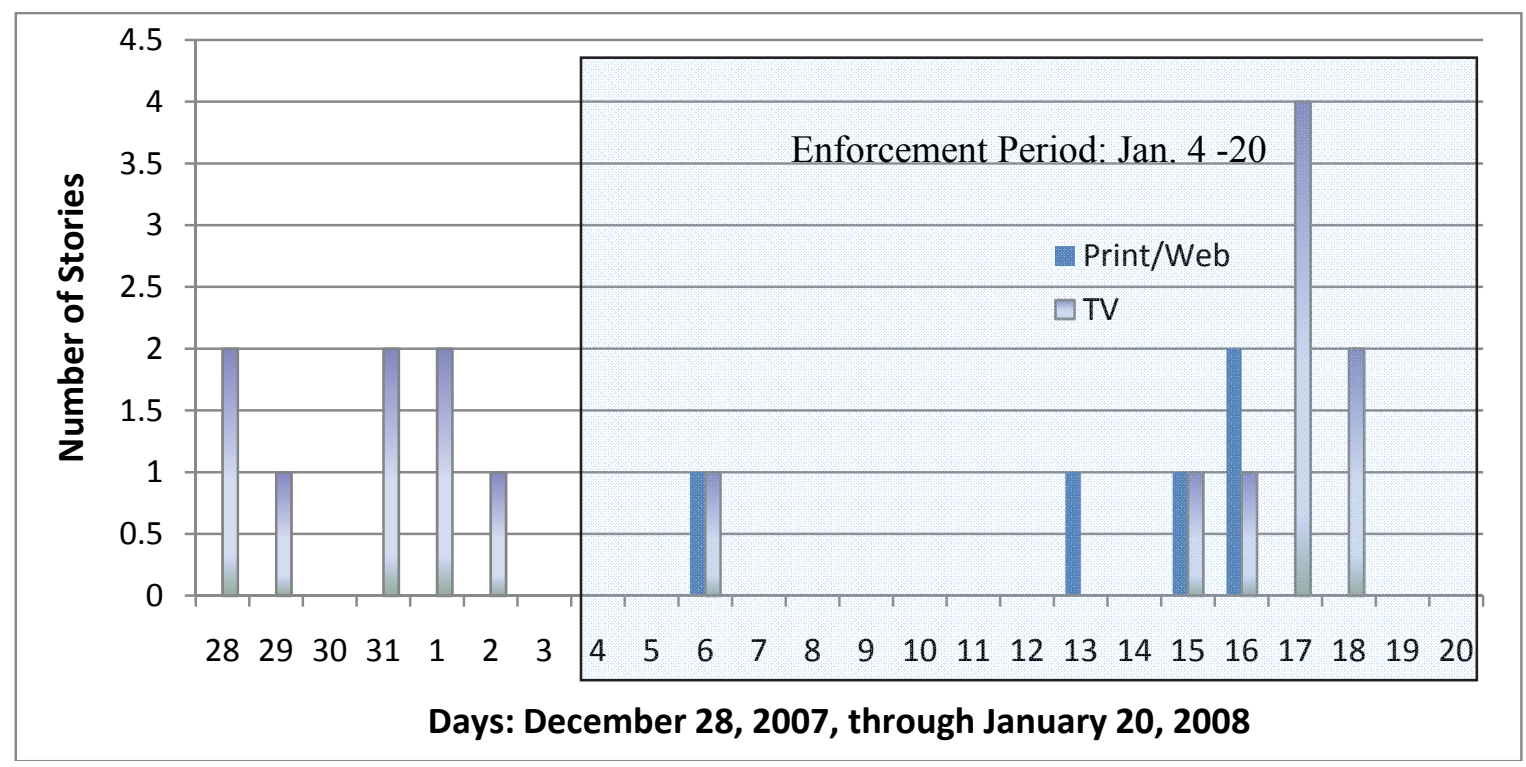

Wave 3 (Enforcement conducted May1-15, 2008)

Print and Web Articles. During Wave 3, an RSA report dated July 14, 2008, identified 15 articles associated with seat belts; $12(80 \%)$ were in newsprint; $3(20 \%)$ were found on the Web. Nine articles $(60 \%)$ originated in the Las Vegas area and $6(40 \%)$ originated in the Reno area. One article ran prior to the start of enforcement; 2 ran during enforcement; and $12(80 \%)$ ran after enforcement, but during the statewide CIOT mobilization. According to the RSA report, these articles generated an estimated 1.5 million impressions, of which 1 million $(67 \%)$ were from stories in daily newspapers and just under 0.5 million (33\%) were on the Web. In addition to the topics covered in other waves (i.e., the CIOT campaign, tickets being issued, NHTSA sponsorship of the program, etc.) these articles placed some emphasis on nighttime seat belt use.

Electronic Media. In addition to these Web and newsprint articles, the February 27 RSA report documented 23 television stories run from April 29 through May 31. All these stories originated in the Reno DMA. Figure 9 shows the distribution of the Web/print and television stories associated with Wave 3. 
Figure 9. Distribution of Web/Print and Television Stories in Nevada, Wave 3

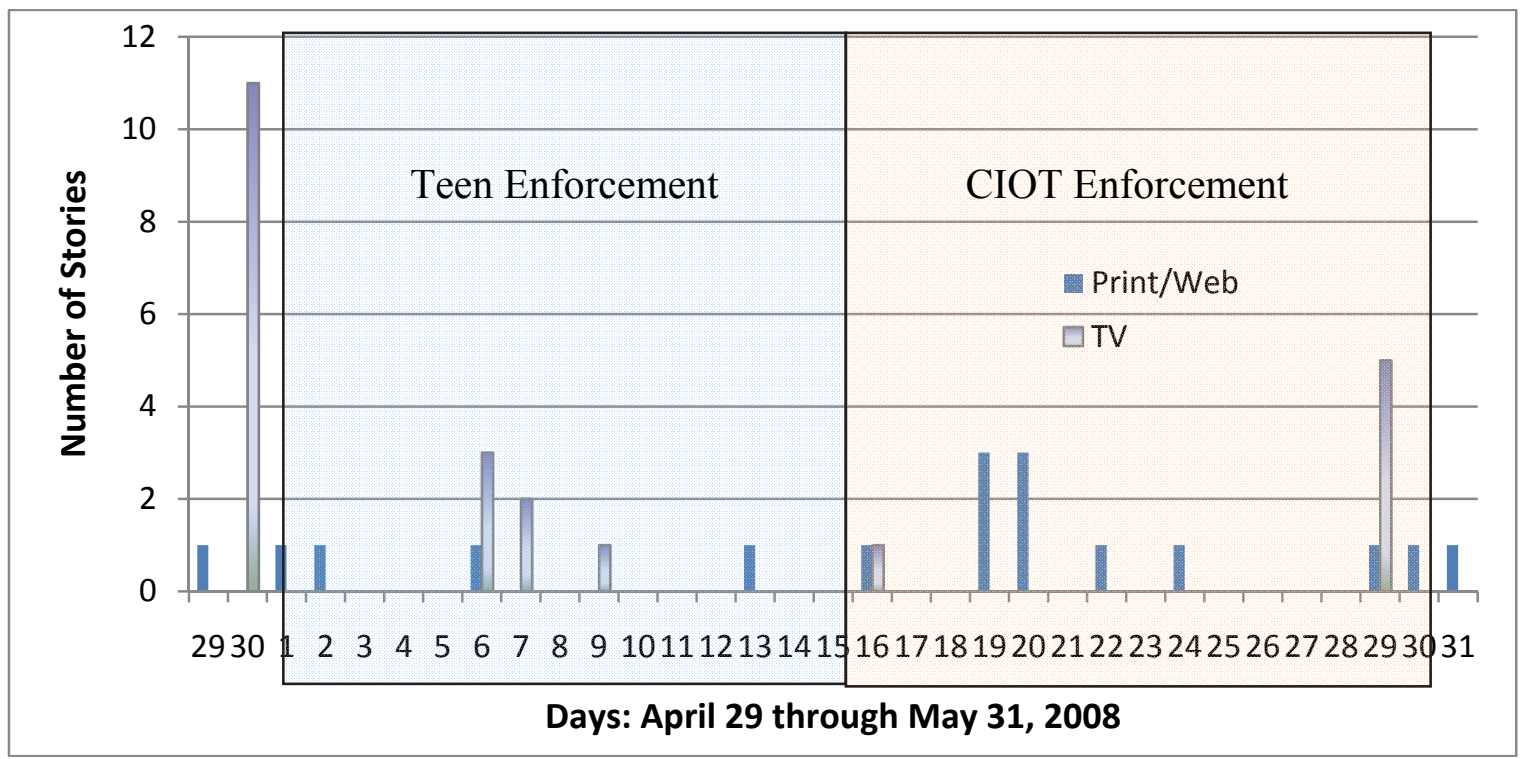

Wave 4 (Enforcement conducted September 10-24, 2008)

Figure 10. Distribution of Web/Print and Television Stories in Nevada, Wave 4

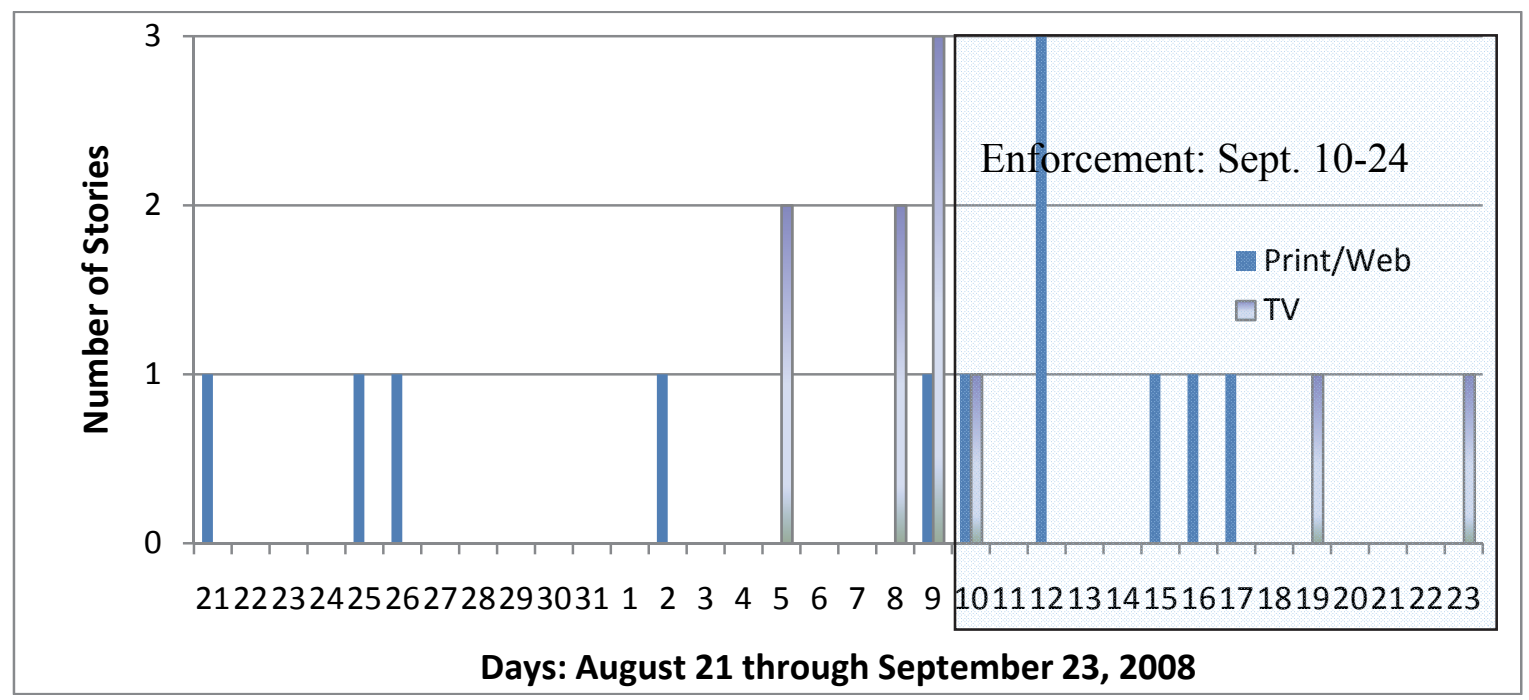

Print and Web Articles. The final wave of the Nevada Teen Demonstration Program was conducted in September 2008, early in the new school year. The RSA report dated October 2, 2008 that monitored earned media for this wave found 12 articles about this activity; $10(83 \%)$ were Web-based and 2 (17\%) were in newsprint (1 daily and 1 weekly). These articles generated an estimated 2.4 million impressions; 2.3 million (97\%) on the Web and about 0.06 million (3\%) in newsprint. Eight of these articles (67\%) originated in the Las Vegas DMA and 4 (33\%) originated in the Reno DMA. 
Electronic Media. In addition to the print/Web articles, the February 2009 RSA report identified 10 stories that aired on television, all in the Reno DMA. Figure 10 shows that 6 of 10 aired just prior to or at the start of the teen enforcement activity (September 10) and 2 stories aired toward the end of the period (September 24). ${ }^{6}$

\section{Summary of Four Waves of Earned Media in Nevada}

In summary, most documented television stories were associated with Wave 1, presumably generated by earned media efforts of the OTS, its contractors, and its partners. The greatest number of print articles was documented in conjunction with waves 1 and 3 , although these numbers were modest (10 and 12 articles, respectively). The greatest number of Web articles (and impressions) was reported for Wave 4. Nearly all of the documented television stories and the majority of Web and print stories (after Wave 1) were originated in the Reno DMA.

Table 5. Summary of Earned Media Activity in Nevada

\begin{tabular}{|c|c|c|c|c|}
\hline Media & W1 & W2 & W3 & W4 \\
\hline News Releases & $1+$ & $1+$ & $1+$ & $\mathrm{n} / \mathrm{a}$ \\
\hline Web Articles ${ }^{1}$ & 5 & 1 & 3 & 10 \\
\hline Web Impressions ${ }^{1}$ & $0.5 \mathrm{~m}$ & $0.06 \mathrm{~m}$ & $0.5 \mathrm{~m}$ & $2.3 \mathrm{~m}$ \\
\hline Print Articles ${ }^{1}$ & 10 & 2 & 12 & 2 \\
\hline Print Impressions ${ }^{1}$ & $0.3 \mathrm{~m}$ & $0.07 \mathrm{~m}$ & $1.0 \mathrm{~m}$ & $0.1 \mathrm{~m}$ \\
\hline TV Stories $^{1}$ & 72 & 14 & 23 & 10 \\
\hline
\end{tabular}

Because the RSA reports broke down the articles by DMA origination, we can compare the amount of earned media generated in the northern and southern areas of the State. Figure 11 shows a large amount of television news coverage in both areas at the start of the program in October. After Wave 1, however, all the television news stories documented by RSA originated in the Reno area, with Wave 3 (May 2008) receiving the next most coverage. With regard to print and Web articles, a modest number originated in both areas during waves 3 and 4.

\footnotetext{
${ }^{6}$ It should be pointed out that media monitoring services frequently do not capture all news stories in print or in the electronic media. Nevada OTS staff reported that television and radio stories ran in the Las Vegas DMA during waves 3 and 4 of the teen program. None were apparently captured the monitoring services.
} 
Figure 11. Distribution of Earned Media Stories in Nevada by Area

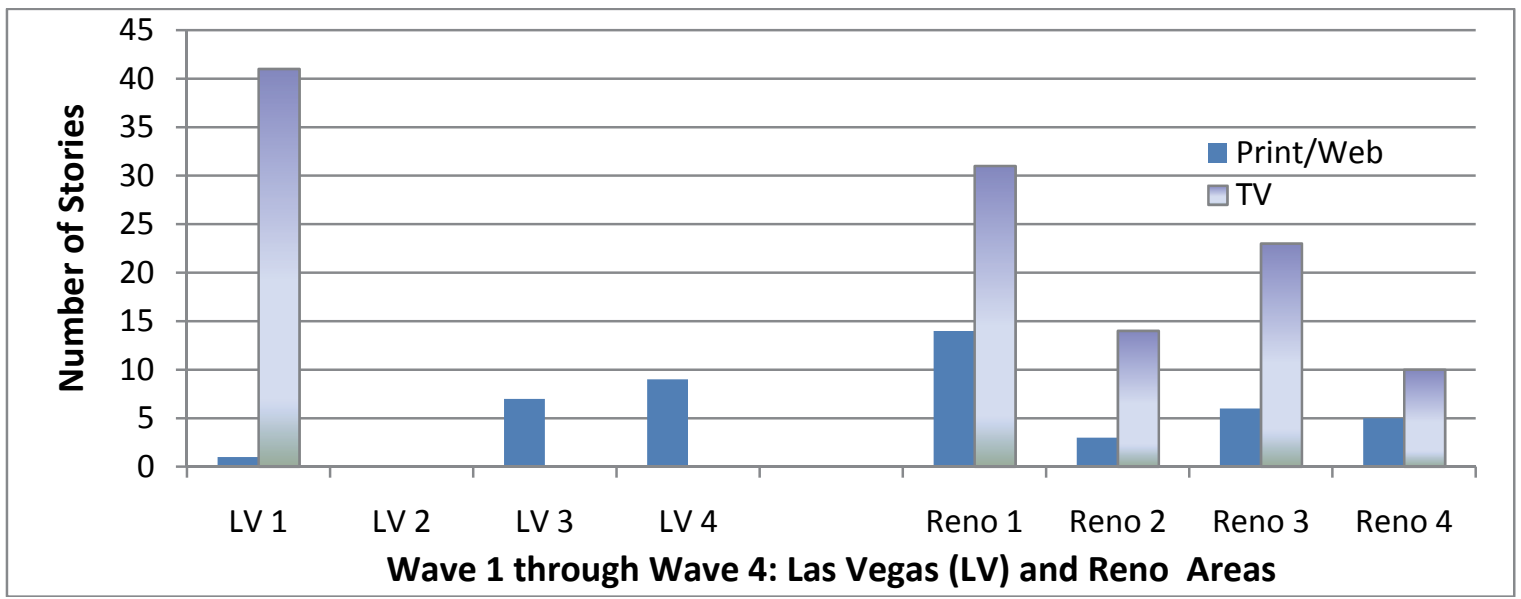

\subsection{Paid Media}

\subsubsection{Paid Media Plans}

Paid media plans were developed by NHTSA's media contractor, Tombras, for Colorado and Nevada. These plans specified many variables including:

(1) the target audience of teens 16 to 20 ;

(2) characteristics of the target audience (e.g., "Internet savvy," spend 6.5 hours per day with various media, extremely "tech savvy," spend time with parents and friends, socially conscious, "fast followers," etc.);

(3) the top five media used by teens (TV, radio, CD/tape/MP3, computers, and online);

(4) preferences of male teens (sports figures, driving trucks, action and sci-fi movies, video games, football, late-night television) and female teens (pop music, movie stars, music networks, social networking sites, not pro-football or late-night TV);

(5) campaign objectives to increase seat belt use by exposing teens to seat belt/enforcement messages 8 to 11 times per wave;

(6) media and messaging to be used (TV, radio, and Internet using an "out of nowhere" message in which a police officer appears "out of nowhere" when teens are unbuckled;

(7) advertising flight dates (shown below);

(8) media budgets (\$837,000 in Colorado; $\$ 524,000$ in Nevada - for all four media flights);

(9) households and number of teens by county; and

(10) media selection, primarily television and radio, but with some Internet advertising.

\subsubsection{Media Messaging}

Click It or Ticket was the primary branding for the teen program, just as it was for past statewide CIOT mobilizations. For the paid media portion of the teen campaign, however, a new enforcement-related ad for radio and for television was produced by Tombras. It was called "Out of Nowhere" and it was intended to send a message to teens that, if you are not buckled up, a po- 
liceman can appear out of nowhere to give you a ticket. The radio script can be found in Appen$\operatorname{dix} \mathrm{G}$. 


\subsubsection{Indices of Paid Media}

Based on the media plans and past experience with evaluations of CIOT and targeted demonstration programs, PRG monitored various indices associated with the paid media efforts. Some of the most objective and quantifiable of these measures were: (1) total expenditures per wave and per capita; (2) GRPs; and (3) planned versus actual GRPs achieved. Other data monitored included number of ads aired, including number of paid spots and number of "in-kind" spots; and expenditures for "alternative" media. Nearly all of these data were obtained via post-buy analyses conducted by the State media contractors in cooperation with Tombras.

GRPs provide an index of total exposure to paid media efforts. This measure is the percentage of the targeted audience reached by a particular advertisement, such as the "Out of Nowhere" ad, multiplied by the number of times the audience is exposed to the ad. GRPs are generally calculated per market, per week of a campaign. An example of a GRP calculation follows: if the "Out of Nowhere" ad is aired 10 times in one week, on broadcast television in a particular media market that reaches $50 \%$ of the target audience, the calculated GRP is 10 exposures $\times 50(\%$ reach $)=$ 500 GRPs. While objective, the GRP measure is not exact. As with impressions, there is no guarantee that $50 \%$ of targeted people in a particular medium are actually reached. Even among those with their televisions on, targeted individuals may be engaged in other activities and may not see the ad.

For this evaluation, PRG examined media plans, budgets, and post-buy reports and monitored quantitative criteria such as dollars spent, allocations by medium, ads aired, GRPs reported, and planned versus actual GRPs. Media data were provided by the States, their media contractors, and by Tombras. We used these data to provide comparisons between the States and to compare levels of activity with benchmarks from other HVE programs.

\subsubsection{Markets, Counties, and Population Sizes}

Table 6 provides a summary of targeted markets, counties, and population size for each State's teen campaign. Five DMAs were included in the media plans for the two States. Overall, about 7.5 million people and 475,000 teens 16 to 20 resided in these combined markets, where those teens were about $6.3 \%$ of the total population.

Table 6. Targeted Markets and Population

\begin{tabular}{|c|c|c|c|c|}
\hline State & $\begin{array}{c}\text { Media Markets } \\
\text { Targeted }\end{array}$ & \multicolumn{2}{|c|}{$\begin{array}{c}\text { Population Targeted } \\
\text { (millions) }\end{array}$} & $\begin{array}{c}\text { Teen (16-20) } \\
\text { \% of Total } \\
\text { Population }\end{array}$ \\
\cline { 3 - 4 } & & All Ages & Teens (16-20) & (16.5\% \\
\hline Colorado & 3 & 4.939 & 0.320 & $\mathbf{6 . 5 \%}$ \\
Nevada & 2 & 2.600 & 0.153 & $\mathbf{6 . 0 \%}$ \\
\hline Total & 5 & 7.539 & 0.473 & $\mathbf{6 . 3 \%}$ \\
\hline
\end{tabular}




\subsubsection{Paid Media Expenditures in Colorado and Nevada}

\subsubsection{Total and Per Capita Expenditures}

Table 7. Paid Media Expenditures in the Teen Belt Demonstration

\begin{tabular}{|c|c|c|c|c|c|}
\hline State & Wave 1 & Wave 2 & Wave 3 & Wave 4 & Total \\
\hline \multicolumn{7}{|c|}{ Expenditures: Colorado, Nevada, and Total } \\
\hline Colorado & $\$ 199 \mathrm{~K}$ & $\$ 173 \mathrm{~K}$ & $\$ 201 \mathrm{~K}$ & $\$ 210 \mathrm{~K}$ & $\mathbf{\$ 7 8 4 \mathrm { K }}$ \\
Nevada & $\$ 138 \mathrm{~K}$ & $\$ 110 \mathrm{~K}$ & $\$ 111 \mathrm{~K}$ & $\$ 130 \mathrm{~K}$ & $\$ 489 \mathrm{~K}$ \\
\hline Total & $\$ 337 \mathrm{~K}$ & $\$ 284 \mathrm{~K}$ & $\$ 312 \mathrm{~K}$ & $\$ 340 \mathrm{~K}$ & $\mathbf{\$ 1 , 2 7 3 \mathrm { K }}$ \\
\hline \multicolumn{7}{|c|}{ Per Capita Expenditures in Colorado } \\
\hline CO (all ages) & $\$ 0.04$ & $\$ 0.04$ & $\$ 0.04$ & $\$ 0.04$ & $\$ 0.16$ \\
CO (16-20) & $\$ 0.62$ & $\$ 0.54$ & $\$ 0.63$ & $\$ 0.66$ & $\$ 2.45$ \\
\hline \multicolumn{7}{|c|}{ Per Capita Expenditures in Nevada } \\
\hline NV (all ages) & $\$ 0.05$ & $\$ 0.04$ & $\$ 0.04$ & $\$ 0.05$ & $\$ 0.19$ \\
NV (16-20) & $\$ 0.90$ & $\$ 0.72$ & $\$ 0.73$ & $\$ 0.85$ & $\$ 3.20$ \\
\hline \multicolumn{7}{|c|}{ Total Per Capita Expenditures } \\
\hline Total (all ages) & $\$ 0.04$ & $\$ 0.04$ & $\$ 0.04$ & $\$ 0.05$ & $\$ 0.17$ \\
Total (16-20) & $\$ 0.71$ & $\$ 0.60$ & $\$ 0.66$ & $\$ 0.72$ & $\$ 2.69$ \\
\hline Expenditures are based on post-buy reports, not on planned budgets \\
\hline
\end{tabular}

An average of $\$ 195,878$ was spent on paid media (per wave) in Colorado and an average of $\$ 122,356$ was spent (per wave) in Nevada. Total expenditures, for four waves of activity, were $\$ 783,510$ in Colorado and $\$ 489,422$ in Nevada.

Relative to the total population, Colorado spent a total of $\$ 0.16$ per capita over the entire project, an average of $\$ 0.04$ per wave. Nevada spent about $\$ 0.19$ per capita over all four waves, an average of about $\$ .05$ per wave. Looking only at the teen 16-to-20 population, however, overall expenditures were about $\$ 2.45$ per capita in Colorado ( $\$ 0.61$ per wave) and $\$ 3.20$ per capita in Nevada (\$0.80 per wave).

Combining the expenditures and populations of the two States, a total of $\$ 1,272,932$ was spent on paid media over the four waves, an average of about $\$ 318,233$ per wave. This translated to a $\$ 0.17$ per capita (all ages) for the total program or about $\$ 0.04$ per wave. Looking only at the teen 16 -to-20 population, total per capita expenditures were $\$ 2.69$, or about $\$ 0.67$ per wave.

\subsubsection{Benchmarks and Comparisons}

As a possible frame of reference, each of the recent CIOT mobilizations has targeted young occupants, specifically young males. Thus, the expenditures in these areas may provide some context for the current expenditures. In the 2006 CIOT mobilization, it was reported that a total of about $\$ 27$ million was spent on paid media by the States and NHTSA (Tison, Solomon, \& Ni- 
chols, et. al., 2008). With about 300 million residents at the time, that translates to about $\$ 0.09$ per resident, about twice the per wave expenditures (for all ages) in the current program.

Narrowing the targeted group to 18 - to 34 -year-olds, about $25 \%$ of the total population, the $\$ 27$ million expenditure translates to about $\$ 0.36$ per capita. Further limiting the targeted group to males 18 to 34 (of which there were about 36,750,000 in 2006), the expenditure translates to $\$ 0.73$ per capita, which is just slightly greater than $\$ 0.67$ per capita, per wave, expended in Colorado and Nevada. These comparisons are provided only to show context for the current program. These comparisons are of similar, but not identical, programs and target groups.

\subsubsection{Paid Media Allocations by Medium in Colorado and Nevada}

Table 8 shows media expenditures by medium and by wave for Colorado and Nevada. Advertisements in four media were purchased in these two States: television (broadcast and cable), radio, theater screens, and the Internet. The Internet component consisted of advertising on online games (all waves), on Yahoo (Wave 1) and AOL (waves 2 to 4).

Television accounted for $73 \%$ of the total expenditures in Colorado and 63 per cent in Nevada. Radio accounted for $14 \%$ in Colorado and $19 \%$ in Nevada. Approximately $6 \%$ in Colorado to $8 \%$ in Nevada were spent on theater ads. About 7\% in Colorado to $10 \%$ in Nevada were spent on alternative media focused on Internet games, Yahoo, and AOL. Colorado placed a higher proportion of its total funds on television advertising (73\%) than Nevada (63\%), possibly due to more expensive television markets in Colorado. 
Table 8. Funding Allocations by Medium, by State and Wave

\begin{tabular}{|c|c|c|c|c|c|c|c|c|c|c|}
\hline \multirow[b]{2}{*}{ Media } & \multicolumn{5}{|c|}{ Colorado } & \multicolumn{5}{|c|}{ Nevada } \\
\hline & $\begin{array}{l}\mathbf{W 1} \\
\%\end{array}$ & $\begin{array}{l}\mathbf{W 2} \\
\%\end{array}$ & $\begin{array}{l}\text { W3 } \\
\%\end{array}$ & $\begin{array}{l}\mathbf{W 4} \\
\%\end{array}$ & $\begin{array}{c}\text { Total } \\
\%\end{array}$ & $\begin{array}{l}\text { W1 } \\
\%\end{array}$ & $\begin{array}{c}\mathbf{W} 2 \\
\%\end{array}$ & $\begin{array}{c}\text { W3 } \\
\%\end{array}$ & $\begin{array}{c}\text { W4 } \\
\%\end{array}$ & $\begin{array}{c}\text { Tota } \\
\%\end{array}$ \\
\hline TV & 75 & 71 & 75 & 69 & 73 & 63 & 66 & 65 & 60 & 63 \\
\hline Radio & 8 & 9 & 16 & 22 & 14 & 16 & 15 & 23 & 22 & 19 \\
\hline Cinema & 6 & 7 & 6 & 7 & 6 & 7 & 7 & 9 & 8 & 8 \\
\hline Internet & 11 & 13 & 3 & 1 & 7 & 14 & 12 & 3 & 10 & 10 \\
\hline $\begin{array}{c}\text { Total \$ } \\
(\times 1,000)\end{array}$ & $\$ 199$ & $\$ 173$ & $\$ 201$ & $\$ 210$ & $\$ 784$ & $\$ 138$ & $\$ 110$ & $\$ 111$ & $\$ 130$ & $\$ 489$ \\
\hline
\end{tabular}

\subsubsection{Number of Television and Radio Advertisements Aired}

Table 9 summarizes the number of ads shown on television and radio and the proportions allocated between these two media. Television accounted for a greater portion of total ads in Nevada $(75 \%$ on TV) than in Colorado ( $60 \%$ on TV).

Table 9. TV and Radio Ads, Total Number and Percentage of Total (purchased + added value ads)

\begin{tabular}{|c|c|c|c|c|c|c|c|c|c|c|}
\hline \multirow[b]{2}{*}{ Media } & \multicolumn{5}{|c|}{ Colorado } & \multicolumn{5}{|c|}{ Nevada } \\
\hline & W1 & W2 & W3 & W4 & Total & W1 & W2 & W3 & W4 & Total \\
\hline TV Ads & $62 \%$ & $62 \%$ & $61 \%$ & $53 \%$ & $60 \%$ & $75 \%$ & $79 \%$ & $71 \%$ & $75 \%$ & $75 \%$ \\
\hline Radio Ads & $38 \%$ & $38 \%$ & $39 \%$ & $47 \%$ & $40 \%$ & $25 \%$ & $21 \%$ & $29 \%$ & $25 \%$ & $25 \%$ \\
\hline $\begin{array}{c}\text { Total } \\
\text { Ads Aired }\end{array}$ & 3,470 & 2,101 & 2,965 & 2,227 & 10,763 & 2,339 & 2,432 & 2,515 & 2,429 & 9,715 \\
\hline & & te: $P$ & ges & of tot & $\mathrm{mb}$ & shov & botto & $\begin{array}{l}\text { OW. } \\
\text { ses. }\end{array}$ & & \\
\hline
\end{tabular}

The proportions spent on these two media were relatively consistent across all four waves within each State. From these data, it appears that, while proportionately more funds were spent on television in Colorado than in Nevada (73\% and 63\% of expenditures, respectively), proportionately fewer television ads were obtained in Colorado than in Nevada $(63 \%$ and $75 \%$ of total ads, respectively). That difference in proportions is likely due to the higher cost of television advertising in the Colorado market, particularly the Denver market.

\subsubsection{Theater (Cinema) Advertising}

On average, $13 \%$ of media funds in Colorado and 18\% of such funds in Nevada were spent on cinema ads and alternative media, including online gaming and advertisements placed on Yahoo (Wave 1) or AOL (Waves 2-4). Because cinema is quite different in terms of the number and type of exposures, we summarize it separately from the online gaming and advertising. Table 10 shows that expenditures of approximately $\$ 89,000$ in Colorado and Nevada (combined) resulted in a total of 2,624 theater screens (exposures) in these two States, about $\$ 34$ per screen. These costs were very similar in both States and across all four program waves. 
Table 10. Cinema Expenditures and Exposures in the Teen Demonstration Project

\begin{tabular}{|c|c|c|c|c|c|}
\hline State & Wave 1 & Wave 2 & Wave 3 & Wave 4 & Total \\
\hline \multicolumn{6}{|c|}{ Expenditures } \\
\hline Colorado & $\begin{array}{l}\$ 10.9 \mathrm{~K} \\
\$ 10.3 \mathrm{~K}\end{array}$ & $\begin{array}{c}\$ 11.7 \mathrm{~K} \\
\$ 82 \mathrm{~K}\end{array}$ & $\begin{array}{l}\$ 12.1 \mathrm{~K} \\
\$ 102 \mathrm{~K}\end{array}$ & $\begin{array}{l}\$ 15.4 \mathrm{~K} \\
\$ 103 \mathrm{~K}\end{array}$ & $\begin{array}{l}\$ 50.2 \mathrm{~K} \\
\$ 39.0 \mathrm{~K}\end{array}$ \\
\hline Total & $\$ 21.2 \mathrm{~K}$ & $\$ 19.9 \mathrm{~K}$ & $\$ 22.3 \mathrm{~K}$ & $\$ 25.7 \mathrm{~K}$ & $\$ 89.2 \mathrm{~K}$ \\
\hline \multicolumn{6}{|c|}{ Number of Screens Purchased } \\
\hline Colorado & 317 & 405 & 317 & 440 & 1,479 \\
\hline Nevada & 284 & 284 & 291 & 286 & 1,145 \\
\hline Total & 601 & 689 & 608 & 726 & 2,624 \\
\hline \multicolumn{6}{|c|}{ Cost per Screen } \\
\hline Colorado & $\$ 35$ & $\$ 29$ & $\$ 38$ & $\$ 35$ & $\$ 34$ \\
\hline Nevada & $\$ 36$ & $\$ 29$ & $\$ 35$ & $\$ 36$ & $\$ 34$ \\
\hline Total & $\$ 35$ & $\$ 29$ & $\$ 37$ & $\$ 35$ & $\$ 34$ \\
\hline
\end{tabular}

\subsubsection{Alternative Media: Online Gaming and Yahoo/AOL Advertising}

As more and more people, particularly teenagers, get their information from the Internet, it is important to attempt new, alternative media for reaching them. This section examines the expenditures and impressions associated with such media as they were reported in these two demonstration projects.

Table 11. Online Expenditures and Impressions in the Teen Demonstration Project

\begin{tabular}{|c|c|c|c|c|c|}
\hline State & Wave 1 & Wave 2 & Wave 3 & Wave 4 & Total \\
\hline \multicolumn{7}{|c|}{ Expenditures } \\
\hline $\begin{array}{c}\text { Colorado } \\
\text { Nevada }\end{array}$ & $\$ 21.5 \mathrm{~K}$ & $\$ 23.2 \mathrm{~K}$ & $\$ 6.2 \mathrm{~K}$ & $\$ 2.7 \mathrm{~K}$ & $\mathbf{\$ 5 3 . 6 \mathrm { K }}$ \\
\hline Total & $\$ 13.4 \mathrm{~K}$ & $\$ 2.9 \mathrm{~K}$ & $\$ 13.3 \mathrm{~K}$ & $\mathbf{\$ 4 8 . 3 \mathrm { K }}$ \\
\hline \multicolumn{7}{|c|}{$\mathbf{\$ 4 0 . 2 \mathrm { K }}$} & $\mathbf{\$ 3 6 . 6 \mathrm { K }}$ & $\mathbf{\$ 9 . 1 \mathrm { K }}$ & $\mathbf{\$ 1 6 . 0 \mathrm { K }}$ & $\mathbf{\$ 1 0 1 . 9 \mathrm { K }}$ \\
\hline $\begin{array}{c}\text { Colorado } \\
\text { Nevada }\end{array}$ & 3,537 & 995 & 3,031 & 2,968 & $\mathbf{1 0 , 5 3 1}$ \\
\hline Total & 6,016 & 1,498 & 4,770 & 4,030 & $\mathbf{1 6 , 3 1 4}$ \\
\hline \multicolumn{7}{|c|}{ Cost per Impression } \\
\hline $\begin{array}{c}\text { Colorado } \\
\text { Nevada }\end{array}$ & $\$ 0.006$ & $\$ 0.023$ & $\$ 0.002$ & $\$ 0.001$ & $\mathbf{\$ 0 . 0 0 5}$ \\
\hline Total & $\mathbf{\$ 0 . 0 0 7}$ & $\$ 0.027$ & $\$ 0.002$ & $\$ 0.013$ & $\mathbf{\$ 0 . 0 0 8}$ \\
\hline
\end{tabular}


Table 11 shows that just over $\$ 100,000$ was spent on Internet advertising over the four waves. These expenditures resulted in an estimated 16.3 million impressions, about 10.5 million in Colorado and 5.8 million in Nevada. There was some variability from wave to wave, with Wave 2 having the least number of impressions, although waves 3 and 4 had smaller expenditures. One constant was the low cost per impression, one-half of one cent in Colorado and 8-tenths of one cent in Nevada.

\subsubsection{Gross Rating Points}

As indicated earlier in this section, GRPs provide an important measure of the strength of a media campaign. Post-buy analyses were conducted by Tombras for each State following each wave of activity. In these analyses, Tombras examined the number of ads that were aired, by medium, along with factors such as the market shares of the programming during which the ads were run, the number of homes using television, etc. These post-buy reports focused almost exclusively on broadcast and cable television giving an index of reach and frequency of this medium for each campaign wave. Radio GRPs were not as readily available as ratings were available only twice per year. With radio, however, it was expected that purchased GRPs were achieved. These radio GRPs averaged about 360 per market per week in Colorado and about 270 per market per week in Nevada.

With regard to television, the goal was 300 GRPs per market during the first three waves in Colorado; the goal for Wave 4 was 235 GRPs per market. In Nevada, the goal was 300 GRPs for the first two waves, after which the goal was 250 per market. Table 12 below shows the actual number of television GRPs achieved during each wave in each of the five media markets where air time was purchased. The five columns on the right side of this table show the percentage of targeted GRPs actually delivered. According to Tombras, the acceptable range for broadcast television delivery is between $90 \%$ and $110 \%$ of the GRP goal.

Table 12. Television Gross Rating Points by State and Wave

\begin{tabular}{|c|c|c|c|c|c|c|c|c|c|c|}
\hline \multirow[b]{2}{*}{ Colorado } & \multicolumn{5}{|c|}{ Gross Rating Points (GRPs) } & \multicolumn{5}{|c|}{ Percent of Goals Achieved } \\
\hline & W1 & W2 & W3 & W4 & Average & W1 & W2 & W3 & W4 & Average \\
\hline TV Goal & 300 & 300 & 300 & 235 & 284 & - & - & - & - & - \\
\hline Denver & 269 & 219 & 317 & 265 & 268 & $90 \%$ & $73 \%$ & $106 \%$ & $113 \%$ & $95 \%$ \\
\hline Colorado Springs & 175 & 216 & 269 & 209 & 217 & $58 \%$ & $72 \%$ & $90 \%$ & $89 \%$ & $77 \%$ \\
\hline Grand Junction & 212 & 258 & 281 & 260 & 253 & $71 \%$ & $86 \%$ & $87 \%$ & $111 \%$ & $90 \%$ \\
\hline \multirow[t]{2}{*}{ TV Average } & 219 & 231 & 289 & 245 & 246 & $73 \%$ & $77 \%$ & $96 \%$ & $104 \%$ & $87 \%$ \\
\hline & \multicolumn{5}{|c|}{ Gross Rating Points (GRPs) } & \multicolumn{5}{|c|}{ Percent of Goal Achieved } \\
\hline Nevada & W1 & W2 & W3 & W4 & Average & W1 & W2 & W3 & W4 & Average \\
\hline TV Goal & 300 & 300 & 300 & 250 & 288 & - & - & - & - & - \\
\hline Las Vegas & 237 & 316 & 306 & 217 & 269 & $79 \%$ & $105 \%$ & $102 \%$ & $87 \%$ & $98 \%$ \\
\hline Reno & 322 & 260 & 219 & 202 & 251 & $107 \%$ & $87 \%$ & $73 \%$ & $81 \%$ & $91 \%$ \\
\hline TV Average & 280 & 288 & 263 & 210 & 260 & $93 \%$ & $96 \%$ & $88 \%$ & $84 \%$ & $90 \%$ \\
\hline
\end{tabular}


According to the post-buy reports, some waves required additional purchases of cable television to make up for under-delivered broadcast television (usually due to declines in market share of programs purchased or a reduction in homes using television). The top row for each State shows that the Nevada markets generally delivered better than the Colorado markets. Waves 1 and 2 generally were under-delivered in Colorado; Wave 4 was under-delivered in Nevada.

Overall, with the average number of radio GRPs included, the total number of GRPs per market in Colorado for each of the four waves was: 423 (W1), 435 (W2), 997 (W3), and 566 (W4), for an average of 605 total GRPs. In Nevada, the average number of television and radio GRPs was: 518 (W1), 488 (W2), 584 (W3), and 517 (W4), for an average of 527 GRPs.

Media guidelines call for 350 GRPs per market per week for a "strong" program; and 500 GRPs per market per week for a "very strong" program. Thus, with the radio component, the media programs for each wave, in both States, would be considered to be "strong" to "very strong." Television was the primary medium used by both States and the medium for which the most complete GRP data are available. Figures 12 and 13 show the number of GRPs achieved via television for each market and each wave within the two States.

Figure 12. Number of Television GRPs in Colorado

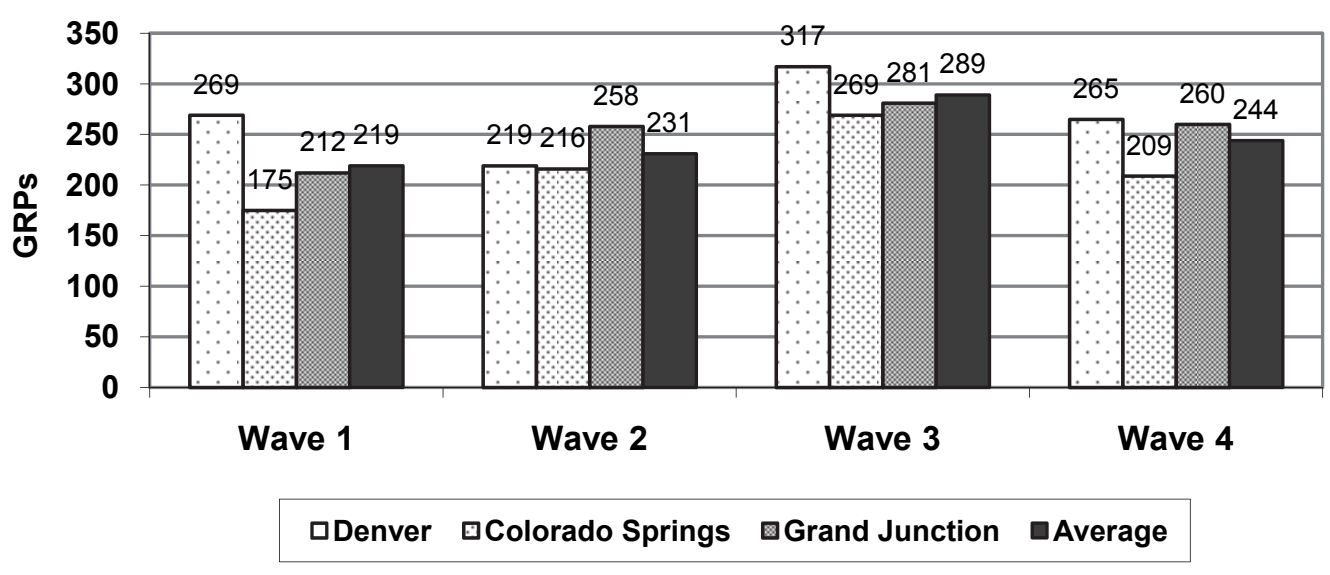

Figure 13. Number of Television GRPs in Nevada

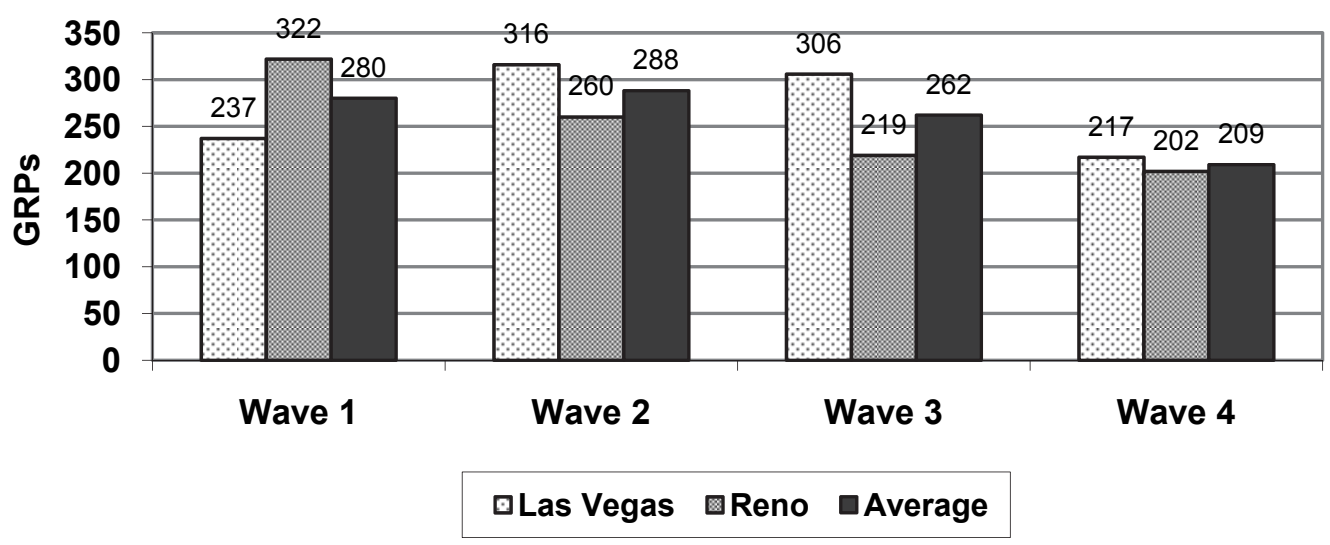




\subsubsection{May 2008 Statewide Click or Ticket Media Campaigns}

Another variable that must be considered when describing the intensity of the teen media campaigns is the May 2008 CIOT campaign, which immediately followed Wave 4 of the Colorado teen program and Wave 3 of the Nevada program. During the May 2008 CIOT mobilizations, Colorado spent an additional $\$ 169,827$ on paid ads: $\$ 145,548$ on television (86\%) and $\$ 24,279$ on radio (14\%). These expenditures resulted in just over 1,900 additional ads aired: 1,300 on television (68\%); and just over 600 on radio (32\%). The cost was $\$ 112$ per television ad and $\$ 40$ per radio ad. ${ }^{7}$

In Nevada, an additional $\$ 70,000$ was spent on paid advertising: $\$ 40,000$ for television (57\%); and $\$ 30,000$ for ads during traffic reporting (43\%). Just over 1,650 radio ads were reported (about $\$ 24$ per ad). The total number of mentions during traffic reports is not available although some of this may have been captured as part of news monitoring.

\subsection{Law Enforcement}

\subsubsection{Indices of Enforcement}

Several measures of enforcement have been used in the past to estimate the intensity of enforcement efforts in a HVE program. Some of the most common of these measures include: (1) number of enforcement agencies participating in the HVE program; (2) percentage of total enforcement agencies participating; (3) hours dedicated to special seat belt enforcement; (4) number of seat belt and child restraint citations issued; and (5) percentage of total traffic citations issued for seat belt violations.

Of these measures, citation-related indices have been most uniformly documented and, as such, have frequently been used in evaluations of HVE programs. Number and percentage of agencies participating is also used quite frequently, as is the seat belt percentage of total citations. Agency, officer, and time allocations to the seat belt enforcement program, while used in some evaluations, are often confounded by regular patrol activity. In some cases, reports include regular patrol activity. In others, they include only the agencies, officers, and/or hours identified for overtime activity and/or in special grants.

Again, the most frequently used index of enforcement level or intensity is the number of citations issued, normalized by the number of residents in the targeted area (e.g., citations per 10,000 residents). This measure has been used in most recent evaluations of HVE programs and, because of its frequent use, benchmarks have been established. In May CIOT mobilizations, for example, the benchmark is about 20 to 22 citations per 10,000 residents over a period of two weeks of enforcement (e.g., see Nichols \& Ledingham, 2008). No such benchmark exists for levels of en-

\footnotetext{
${ }^{7}$ In both States observational surveys were conducted immediately after the teen phase of the mobilization, not after the CIOT component. The reason for this was to survey before all schools were dismissed. While this avoided some of the impact of the additional media expenditures (and additional enforcement) associated with the statewide CIOT, it did not avoid all of it.
} 
forcement involving teens, however, and it is not known if the rate of citations issued to teens during CIOT mobilizations is similar to the rate for adult drivers and passengers.

\subsubsection{Enforcement Plans}

\subsubsection{Colorado}

Both States prepared enforcement plans that covered all four waves of activity. In Colorado, the plan specified enforcement to be conducted in nine counties within the three DMAs included in the media plan. Those counties, listed in the table below, accounted for a total of 4.1 million residents, about $83 \%$ of the population of the State. It was anticipated that, in addition to the Colorado State Patrol, a total of 77 enforcement agencies would be involved; and that just over 8,000 hours would be expended by these agencies over the four waves, about 2,000 hours per wave. Funding provided for enforcement was $\$ 545,000$ to support overtime activity for conducting enforcement zones and saturation patrols in areas and during times when teens were most likely to be driving. Data regarding enforcement activity (i.e., hours worked and citations issued) were reported after each wave to a CDOT Web-based database at www.dot.state.co.us/trafficsafety.

Table 13 summarizes the counties and population sizes that were included in the Colorado teen enforcement plan. It shows the areas that account for about $73 \%$ of the population of the State and are covered by the enforcement effort. Again, nearly $100 \%$ of the population of Colorado lies within the three DMAs covered by the media component.

Table 13. Counties, Population, Agencies, and Enforcement Hours Planned for Teen Seat Belt Enforcement in Colorado

\begin{tabular}{|c|c|c|}
\hline \multicolumn{3}{|c|}{ I. Markets, Counties, and Population Involved } \\
\hline DMA & County & Population \\
\hline Denver & $\begin{array}{c}\text { Adams } \\
\text { Arapahoe } \\
\text { Boulder } \\
\text { Denver } \\
\text { Douglas } \\
\text { Jefferson } \\
\text { Larimer } \\
\text { Weld }\end{array}$ & $\begin{array}{l}430,836 \\
554,282 \\
293,161 \\
598,707 \\
280,621 \\
533,339 \\
292,825 \\
249,775\end{array}$ \\
\hline Colorado Springs & $\begin{array}{l}\text { El Paso } \\
\text { Pueblo }\end{array}$ & $\begin{array}{l}596,053 \\
156,737 \\
\end{array}$ \\
\hline Grand Junction & Mesa & 143,171 \\
\hline \multicolumn{2}{|c|}{ Total Population in Enforcement Areas } & $4,129,507$ \\
\hline \multicolumn{2}{|c|}{ Percent of State Population $(4,939,456)$} & $83 \%$ \\
\hline \multicolumn{3}{|c|}{ II. Agencies and Proposed Hours } \\
\hline Agencies & Hours/Wave & Total \\
\hline Colorado State Patrol & 756 hours/wave & $3,024 \mathrm{hrs}$. \\
\hline 40 Local Agencies & 1250 hours /wave & 5,000 hrs. \\
\hline All Agencies & 2006 hrs/wave & 8,024 hrs. \\
\hline
\end{tabular}




\subsubsection{Nevada}

The Nevada enforcement plan described enforcement activities to be conducted primarily in Clark and Washoe counties in the Las Vegas and Reno DMAs. As Table 14 indicates, more than $90 \%$ of the population was covered within the areas targeted for enforcement. Key agencies involved were police departments in Las Vegas, North Las Vegas, Henderson, Reno, and Sparks. Key sheriff's offices were in Clark, Nye, and Washoe counties. During this initial planning period, it was anticipated that 12 to 15 agencies would be involved in each wave and that between 1,627 and 1,747 hours would be expended per wave for a total of that just over 6,700 hours expended over the four waves. The overall program coordination benefitted from the statewide Joining Forces program, an alliance of 30 enforcement agencies, 83\% of the 36 LEAs across the State. Each wave was scheduled for two weeks of enforcement, using enforcement zones and saturation patrols in areas and during times when teens were most likely to be driving (i.e., in areas surrounding high schools, colleges, and universities, as well as in malls, and around theaters and fast food restaurants). In addition to overtime grants, agency and officer recognition programs, and incentives (usually equipment incentives) were used to encourage agency participation.

Table 14. Counties, Population, Agencies, and Enforcement Hours Planned for Teen Seat Belt Enforcement in Nevada

\begin{tabular}{|c|c|c|}
\hline DMA & County & Population \\
\hline Las Vegas & $\begin{array}{l}\text { Clarke } \\
\text { Nye }\end{array}$ & $\begin{array}{c}1,865,746 \\
44,375\end{array}$ \\
\hline Reno & $\begin{array}{c}\text { Washoe } \\
\text { Carson City }\end{array}$ & $\begin{array}{c}410,443 \\
54,867\end{array}$ \\
\hline Nevada Highway Patrol & $\begin{array}{l}\text { North Command } \\
\text { Central Command } \\
\text { South Command }\end{array}$ & $\begin{array}{l}- \\
- \\
-\end{array}$ \\
\hline \multicolumn{2}{|c|}{ Total Population in Enforcement Areas } & $2,375,431$ \\
\hline \multicolumn{2}{|c|}{ Pct. of State Population $(2,600,167)$} & $91 \%$ \\
\hline Agencies & Total Hours/Wave & 4 Waves \\
\hline Nevada Highway Patrol & $235 \mathrm{hrs}$ & $940 \mathrm{hrs}$ \\
\hline 5 Local Agencies & $580 \mathrm{hrs}$ & $2320 \mathrm{hrs}$ \\
\hline 7 County Sheriffs & $812 \mathrm{hrs}$ & $3248 \mathrm{hrs}$ \\
\hline Other/ School PDs & 120 hrs (2 waves) & $240 \mathrm{hrs}$ \\
\hline Total Hours & 1,714 to $1,627 \mathrm{hrs}$. & $6,748 \mathrm{hrs}$ \\
\hline
\end{tabular}

Data regarding enforcement activity (i.e., hours worked and citations issued) were reported by each participating officer to the Joining Forces coordinator at the end of each overtime shift. The coordinator aggregated these data and reported them to the Joining Forces manager within 10 days after the end of each enforcement wave. Nearly all reporting was online. The online reporting form is posted at www.ots.state.nv.us/joining_forces_activity_report_f.shtml. Reported data included all seat belt citations issued and citations issued to teens, ages 16 to 20 . Table 14 summarizes the counties and population sizes included in the Nevada Teen Enforcement Plan. As indicated, more than $90 \%$ of the population of the State was covered by enforcement and a 
similar percentage was covered by media in the two DMAs identified in the Media Plan (i.e., the Las Vegas and Reno markets).

\subsubsection{Implementation of the Enforcement Programs}

\subsubsection{Colorado}

Data related to the implementation of enforcement in Colorado are summarized in Table 15. Each of the four waves of enforcement in Colorado was one week in duration. The number of agencies that actually participated increased from 36 in Wave 1 to 47 in Wave $4(+30 \%)$. The number of participating officers increased from 230 in Wave 1 to 318 in Wave $3(+38 \%)$; then declined to 303 in Wave 4 (a 32\% increase over Wave 1). Over time, the number of enforcement hours expended more than doubled, from 1,075 in Wave 1 (just over half the 2,006 hours planned) to 2,303 in Wave 4 (15\% more than the number of hours planned).

Table 15. Indices of Enforcement Activity, Colorado Teen Demonstration

\begin{tabular}{|c|c|c|c|c|}
\hline \multirow[b]{2}{*}{ Enforcement Participation Characteristics } & \multicolumn{4}{|c|}{ Enforcement Period } \\
\hline & Wave 1 & Wave 2 & Wave 3 & Wave 4 \\
\hline Dates (7-Day Duration): & $10 / 15-10 / 21$ & $1 / 14-1 / 20$ & $3 / 3-3 / 9$ & $5 / 12-5 / 18$ \\
\hline Number of Agencies Participating & 36 & 42 & 43 & 47 \\
\hline Number of Officers Participating & 230 & 314 & 318 & 303 \\
\hline Number of Hours of Enforcement Expended & 1,075 & 1,669 & 1,678 & 2,303 \\
\hline \multicolumn{5}{|c|}{ Seat belt Citations and Rates Relative to Total Population } \\
\hline State Population, $7 / 07$ and $7 / 08$ est. & $4,842,770$ & $4,842,770$ & $4,939,456$ & $4,939,456$ \\
\hline $\begin{array}{l}\text { Total Seat Belt Citations (All Ages/Teen Phase) } \\
\text { Total Seat Belt Citations (All Ages/CIOT Phase) }\end{array}$ & $\begin{array}{r}2,355 \\
\text { no CIOT }\end{array}$ & $\begin{array}{r}3,934 \\
\text { no ClOT }\end{array}$ & $\begin{array}{r}\mathbf{4 , 6 8 5} \\
\text { no ClOT }\end{array}$ & $\begin{array}{l}4,670 \\
9,604\end{array}$ \\
\hline $\begin{array}{l}\text { All Age Citation Rate (Teen Phase ) } \\
\text { All Age Citation Rate (ClOT Phase) }\end{array}$ & $\begin{array}{r}4.86 \\
\text { no } C / O T\end{array}$ & $\begin{array}{r}8.12 \\
\text { no CIOT }\end{array}$ & $\begin{array}{r}9.48 \\
\text { no } C / O T\end{array}$ & $\begin{array}{r}9.45 \\
19.44\end{array}$ \\
\hline Overall Rate, extrapolated to 14 days (Teen Phase) & 9.73 & 16.25 & 18.97 & 18.91 \\
\hline \multicolumn{5}{|c|}{ Seat belt Citations and Rates Relative to Teen Population } \\
\hline Teen Population, $7 / 07$ and 7/08 est. & 317,799 & 317,799 & 321,467 & 321,467 \\
\hline $\begin{array}{l}\text { Teen Seat Belt Citations (Teen Phase) } \\
\text { Teen Seat Belt Citations (CIOT Phase) }\end{array}$ & $\begin{array}{r}296 \\
\text { no CIOT }\end{array}$ & $\begin{array}{r}415 \\
\text { no } \mathrm{ClOT} \\
\end{array}$ & $\begin{array}{r}450 \\
\text { no CIOT }\end{array}$ & $\begin{array}{r}481 \\
\text { unknown }\end{array}$ \\
\hline $\begin{array}{l}\text { Teen Citation Rate (Teen Phase) } \\
\text { Teen Seat Belt Citations (CIOT Phase) }\end{array}$ & $\begin{array}{r}9.31 \\
\text { no CIOT }\end{array}$ & $\begin{array}{r}13.06 \\
\text { no } C I O T\end{array}$ & $\begin{array}{r}14.00 \\
\text { no ClOT }\end{array}$ & $\begin{array}{r}14.96 \\
\text { unknown }\end{array}$ \\
\hline Teen Rate, extrapolated to 14 days ${ }^{*}$ & 18.63 & 26.12 & 28.00 & 29.93 \\
\hline Teen Rate $\Delta$ from Standard Rate of 20 & -1.37 & 6.12 & 8.00 & 9.93 \\
\hline \multicolumn{5}{|l|}{ Enforcement Time Spent per SB Citation } \\
\hline Number of Hours of Enforcement Expended & 1,075 & 1,669 & 1,678 & 2,303 \\
\hline Minutes of Enforcement per Citation (all citations) & 27 & 25 & 21 & 30 \\
\hline Minutes of Enforcement per Teen Citation & 218 & 241 & 224 & 287 \\
\hline Hours of Enforcement per Teen Citation & (3.6 hrs) & $0 \mathrm{hrs})$ & (3.7 hrs) & (4.8 hrs) \\
\hline \multicolumn{5}{|c|}{ Teen Percentage of Total Citations and of Total Population } \\
\hline Teen Percentage of Total Citations & $12.57 \%$ & $10.55 \%$ & $9.61 \%$ & $10.30 \%$ \\
\hline Teen Percentage of Total Population & $6.56 \%$ & $6.56 \%$ & $6.51 \%$ & $6.51 \%$ \\
\hline
\end{tabular}




\section{Citations}

The rate of seat belt citations is calculated as the number of seat belt citations divided by the population, multiplied by 10,000. The citation rate for all ages increased from 4.9 to 9.5 (per 10,000 residents), a $94 \%$ increase for the one-week enforcement effort. This rate was still below the benchmark for a typical May CIOT mobilization (about 20 citations per 10,000 residents), but it is within the range of special demonstration programs described in the Background Section of this report. Citation rates in these specially targeted demonstrations ranged from about 12 to 27 citations per 10,000 residents. If the rate of citations had been sustained for two weeks in Colorado (which was not the case in three of the four waves), the population-based rate would have been very near the benchmark level during waves 3 and 4 (about 19 citations per 10,000 residents). In fact, the two-week enforcement effort during the May 2008 CIOT mobilization (following Wave 4), was 19 citations per 10,000 residents, very similar to benchmark levels.

Looking at teens, ages 16 to 20, the citation rate increased from just fewer than 10 citations (Wave 1) to about 15 citations (Wave 4$)$ per 10,000 teen residents $(+50 \%)$. As indicated, there is currently no benchmark for a teen-focused HVE program. Figure 14 shows the citation rates for all ages and for teens, by wave. An extrapolated rate for two weeks of enforcement at the same level of intensity would have resulted in a rate of 18 to 30 citations per 10,000 teens.

Figure 14. All-Age and Teen Citation Rates in Colorado Number of Citations per 10,000 Residents/Teens

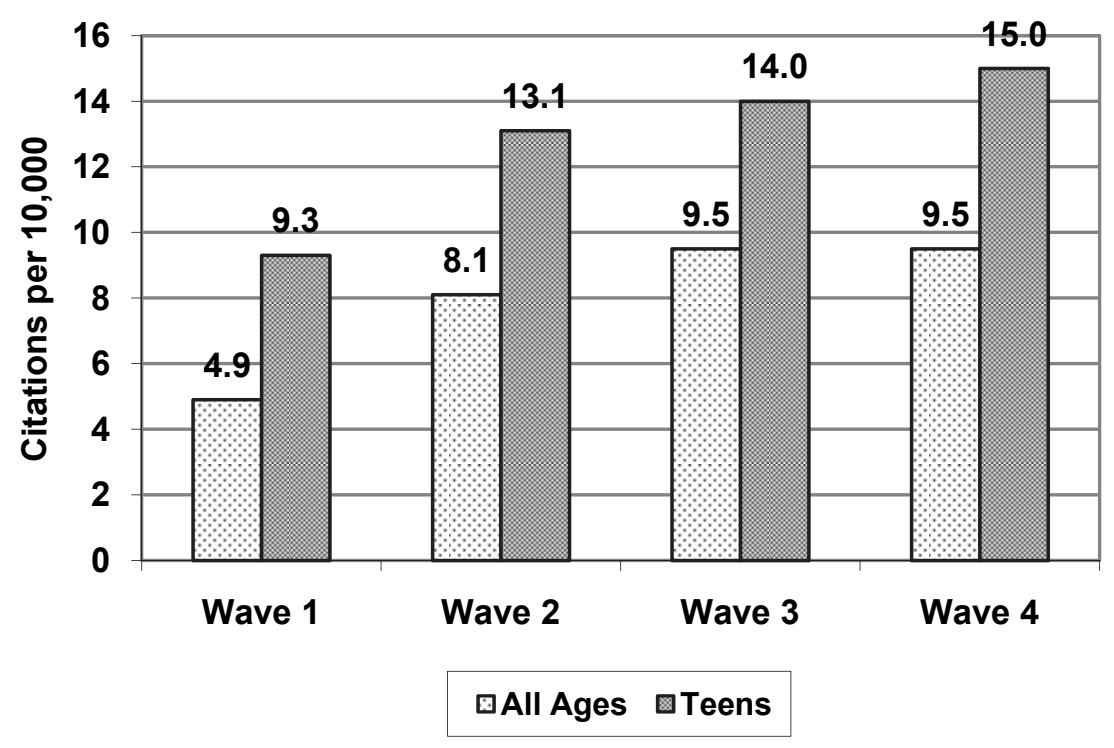

\section{Teen Percentage of Total Citations}

Another index of enforcement intensity is the teen percentage of total seat belt citations issued during each program wave, compared with citations issued to all ages, as shown above. Figure 15 shows that this measure was relatively consistent within $10-13 \%$ of total seat belt citations issued to teens, about twice the $6.5 \%$ of the total population accounted for by the 16 to 20 age group. This likely reflects the fact that enforcement was focused on areas and times when teens were most likely to be present. 
Figure 15. Teen Percent of Seat Belt Citations and Teen Percentage of Population in Colorado

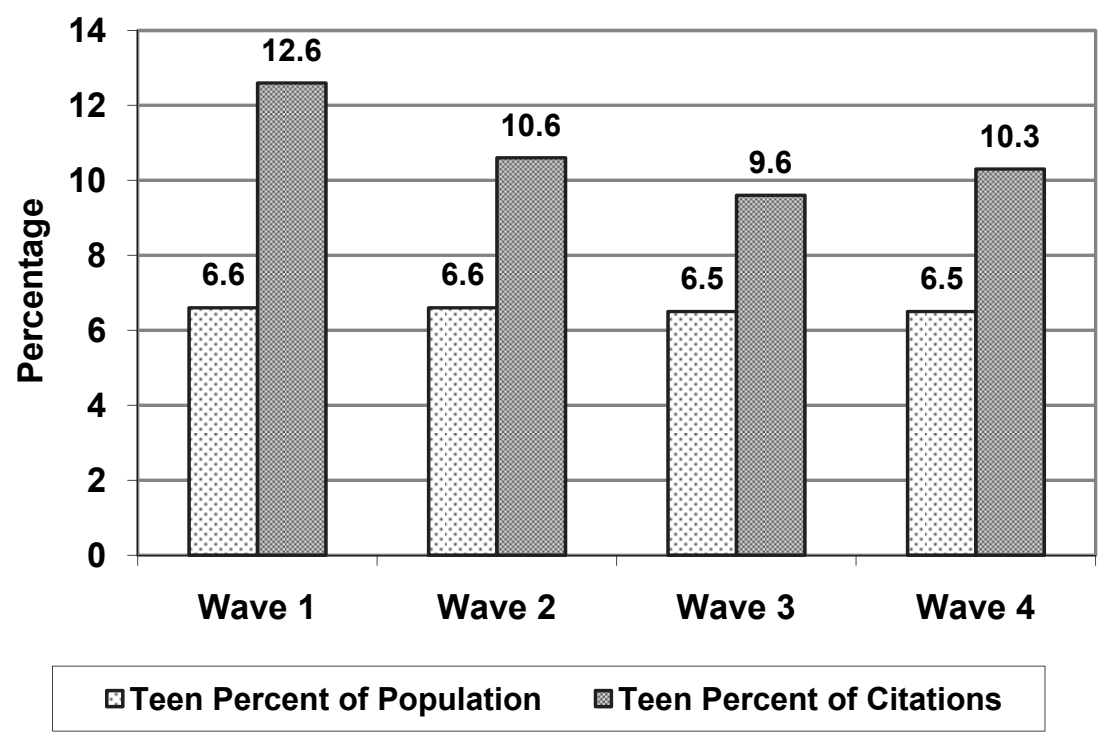

\subsubsection{Nevada}

Enforcement data for Nevada are summarized in Table 16. Here, each enforcement wave was two weeks in duration. The number of agencies that actually participated increased from 18 in Wave 1 to 30 in Wave $3(+67 \%)$, well over the planned level of 12-15 agencies per wave. Twenty-five agencies participated in Wave 4, a slight decline from Wave 3 but still about 40\% more than during Wave 1. The number of participating officers was highest during Wave 3, the wave involving the May CIOT mobilization. It was considerably lower during Waves 2 and 4. Over time, the number of enforcement hours nearly doubled, from 523 in Wave 1 to 1,024 in Wave 4, an increase of $96 \%$, but below the planned level of about 1,600 hours per wave.

\section{Citations}

With regard to citation rates, the number issued to motorists of all ages (per 10,000 residents) increased from 2.1 to $3.9(+86 \%)$ over the two weeks of enforcement. This is below the benchmark of about 20 citations per 10,000 residents for typical two-week CIOT mobilization and it is below the range of special demonstration programs described in the Background Section of this report. This likely reflects the fact that it was a teen-focused program that was conducted primarily at the times and locations when teens were present. However, the May CIOT mobilization, which immediately followed Wave 3, also resulted in a low citation rate of 2.3 seat belt tickets issued per 10,000 residents (all ages).

Looking at teens age 1616 to 20, the citation rate increased from about 10 citations (Wave 1) to about 16 citations (Wave 3) per 10,000 teens (+60\%), then declined to about 12 citations in Wave 4, about 20\% higher than the Wave 1 level. 
Table 16. Indices of Enforcement Activity, Nevada Teen Demonstration Project

\begin{tabular}{|c|c|c|c|c|}
\hline Enforcement Period & Wave 1 & Wave 2 & Wave 3 & Wave 4 \\
\hline Dates: 14-Day Duration & $10 / 20-11 / 04$ & $1 / 04-1 / 20$ & $5 / 01-5 / 15$ & $9 / 10-9 / 24$ \\
\hline Number of Agencies Participating & 18 & 28 & 30 & 25 \\
\hline Number of Officers Participating & unknown & 337 & 413 & 346 \\
\hline Number of Hours of Enforcement Expended & unknown & unknown & unknown & unknown \\
\hline \multicolumn{5}{|c|}{ Seat belt Citations and Rates for the Total Population } \\
\hline State Population, $7 / 07$ and $7 / 08$ est. & $2,554,344$ & $2,554,344$ & $2,600,167$ & $2,600,167$ \\
\hline $\begin{array}{l}\text { Total Seat Belt Citations (All Ages/Teen Phase) } \\
\text { Total Seat Belt Citations (All Ages/CIOT Phase) }\end{array}$ & $\begin{array}{r}523 \\
\text { no ClOT }\end{array}$ & $\begin{array}{r}1,116 \\
\text { no ClOT }\end{array}$ & $\begin{array}{r}998 \\
\text { no } \mathrm{ClOT}\end{array}$ & $\begin{array}{r}1,024 \\
599\end{array}$ \\
\hline $\begin{array}{l}\text { All Age Citation Rate (Teen Phase ) } \\
\text { All Age Citation Rate (CIOT Phase) }\end{array}$ & $\begin{array}{r}2.05 \\
\text { no ClOT }\end{array}$ & $\begin{array}{r}4.37 \\
\text { no CIOT }\end{array}$ & $\begin{array}{r}3.84 \\
\text { no CIOT }\end{array}$ & $\begin{array}{l}3.94 \\
2.30\end{array}$ \\
\hline \multicolumn{5}{|l|}{ Seat belt Citations and Rates for the Teen Population } \\
\hline Teen Population, $7 / 07$ and $7 / 08$ est. & 150,944 & 150,944 & 155,261 & 155,261 \\
\hline $\begin{array}{l}\text { Teen Seat Belt Citations (Teen Phase) } \\
\text { Teen Seat Belt Citations (CIOT Phase) }\end{array}$ & $\begin{array}{r}152 \\
\text { no } \mathrm{ClOT}\end{array}$ & $\begin{array}{r}204 \\
\text { no ClOT }\end{array}$ & $\begin{array}{r}246 \\
\text { no } C / O T\end{array}$ & $\begin{array}{r}185 \\
\text { Unknown }\end{array}$ \\
\hline $\begin{array}{l}\text { Teen Citation Rate* (Teen Phase) } \\
\text { Teen Seat Belt Citations (CIOT Phase) }\end{array}$ & $\begin{array}{r}10.07 \\
\text { no ClOT }\end{array}$ & $\begin{array}{r}13.51 \\
\text { no CIOT }\end{array}$ & $\begin{array}{r}15.84 \\
\text { no CIOT }\end{array}$ & $\begin{array}{r}11.92 \\
\text { Unknown }\end{array}$ \\
\hline \multicolumn{5}{|c|}{ Teen Percentage of Total Citations and of Total Population } \\
\hline $\begin{array}{l}\text { Teen Percentage of Total Citations } \\
\text { Teen Percentage of Total Population }\end{array}$ & $\begin{array}{r}29.06 \% \\
5.91 \%\end{array}$ & $\begin{array}{r}18.28 \% \\
5.91 \%\end{array}$ & $\begin{array}{r}24.65 \% \\
5.97 \%\end{array}$ & $\begin{array}{r}18.07 \% \\
5.97 \%\end{array}$ \\
\hline
\end{tabular}

Figure 16 shows the citation rates for all ages and for ages 16 to 20 in Nevada, by wave. The high rate for teens relative to the rate for all ages is consistent with a program that was highly focused on teens during each of the four waves. This figure suggests that, according to this index, Wave 3 was the most intense. 
Figure 16. All-Age and Teen Citation Rates in Nevada Number of Citations per 10,000 Residents/Teens

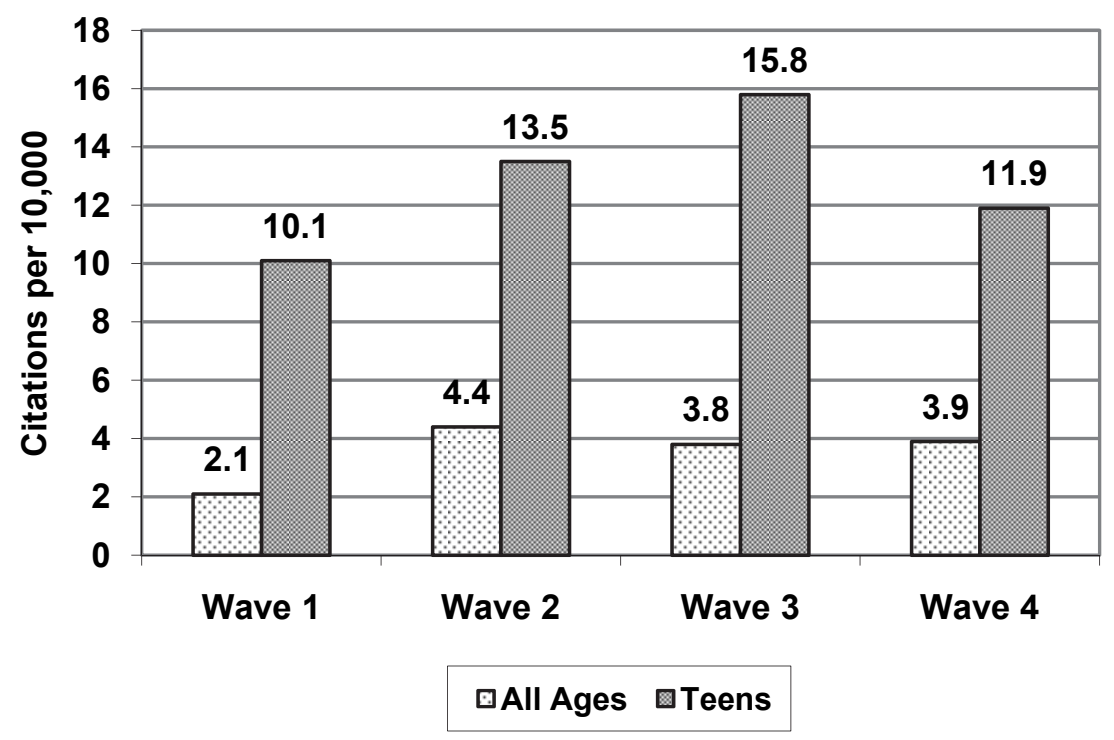

\section{Teen Percentage of Total Citations}

Similarly, the teen percentage of total seat belt citations issued during each wave was much higher than the teen proportion of the total population. As in Colorado, this likely reflects a program was implemented at times and in locations where teens were most likely to be present. The teen percentage of total citations varied considerably from a high of $29 \%$ during Wave 1 to lows of about 18\% during waves 2 and 4, suggesting that waves 1 and 3, by this index, were the more intense waves.

Figure 17. Teen Percentage of Seat Belt Citations and Teen Percentage of Population in Nevada

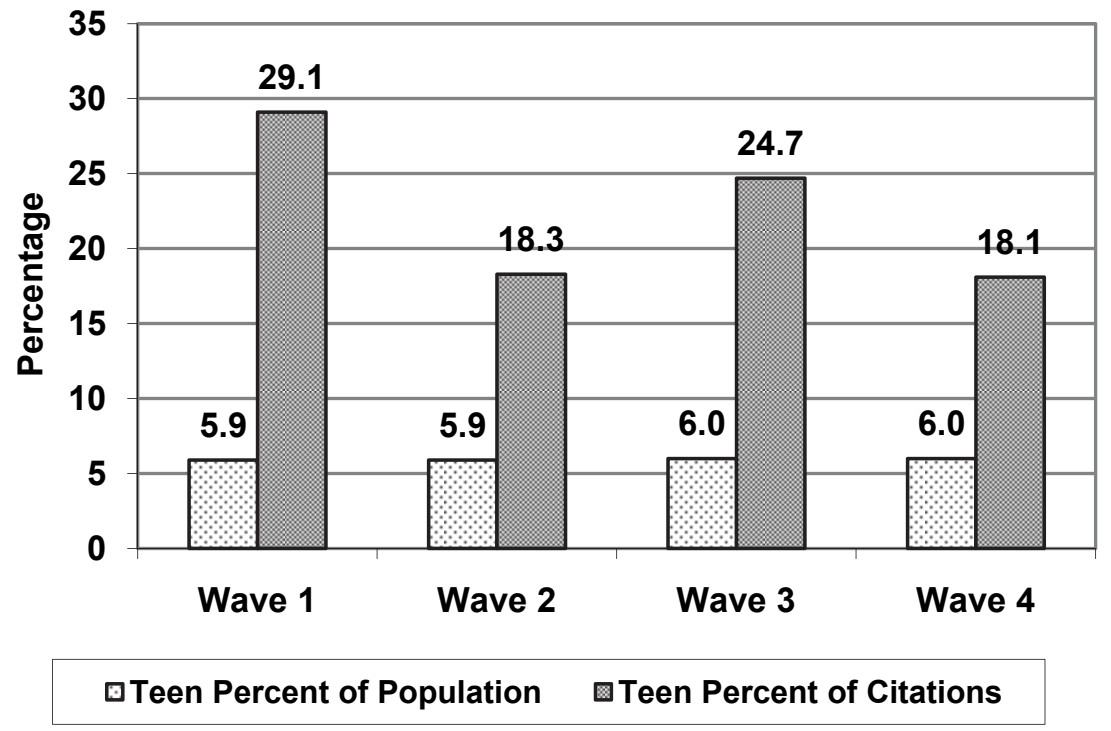


Based on the combination of a citation rate of 16 per 10,000 teens and the relatively high teen percentage of total citations in Wave 3, it appears to have been the most intense wave, from an enforcement perspective.

In summary, the above enforcement data suggest that both the Colorado and Nevada teen enforcement efforts were substantial, covering nearly $75 \%$ of the population of Colorado and more than $90 \%$ of the population of Nevada. All indices suggest a strong focus on teen seat belt use. Thus, it appears that officers were able to focus their enforcement efforts in a way that affected unbuckled teens to a greater extent than traditional approaches used in the past. This is suggested by both high teen citation rate and the high teen percentage of total citations.

Wave 1 had the lowest number of participating law enforcement agencies and officers (likely in both States), but this wave may have been boosted by additional officer enthusiasm associated with participation in a new/novel program. More agencies were on board for each successive wave of enforcement through May 2008 (Wave 4 in Colorado and Wave 3 in Nevada), but officers apparently had some difficulty identifying and citing teen occupants during Wave 2, which was winter vacation for most schools. Citations in both States were highest in May 2008, when the teen CIOT preceded the statewide CIOT. 


\section{Results}

\subsection{Awareness of Media and Law Enforcement Activity}

One key objective of the evaluation was to determine whether or not teens in the targeted areas were aware of the various aspects of the program, such as messages to buckle up, special enforcement efforts, the Click It or Ticket message, etc. The Colorado and Nevada Office of Highway Safety conducted awareness surveys to measure these perceptions. These questionnaires are provided in Appendices E and F. Sufficiently large samples of teens were surveyed during each wave and in each State.

\subsubsection{Messages to Buckle Up}

\subsubsection{Colorado}

A major component of the Teen Seat Belt Demonstration Project was to provide messaging to encourage teens to buckle up. The umbrella for such messages was Click It or Ticket. In order to assess the impact of the messaging component of the Colorado Teen Program, we asked:

In the past month, have you heard or seen any special messages regarding teenagers and young people wearing safety belts?

Responses to this question provided an index of the extent to which seat belt messages were perceived. In addition, teens that saw or heard a seat belt message were asked:

- $\quad$ where they saw or heard the message (i.e., from which media); and

- where they were when they saw or heard the message (i.e., at home, at school, at work, on the roadway, or in a social or recreational situation.

Since the umbrella for the Teen Program was Click It or Ticket, awareness of the specific CIOT message or slogan was important. In order to determine the recall level of CIOT as a message, we asked those who had seen or heard a seat belt message the open-ended question:

What did the message say?

Finally, in order to assess the recognition level of CIOT as a program, we asked all respondents:

Do you know the name of any safety belt programs in Colorado?

We provided a multiple choice list of various programs that had been in conducted in Colorado and asked respondents to check all that applied.

Table 17 shows that there was a steady increase in awareness of messages for teens to buckle up, with significant increases associated with each program wave, except Wave 2 (January 2008). Overall, there was a cumulative 16-point increase in awareness of seat belt messages for teens, from $51 \%$ to $68 \%$, with the largest increases were associated with waves 1 and 3 . There also was 
a large and significant increase in awareness of CIOT as a component of seat belt messages, particularly associated with Wave $1(+22.8$ percentage points) but also in conjunction with Wave 3 $(+5.4$ points). Cumulatively, there was a 29-point increase in recall awareness of CIOT as a message, from $32 \%$ to $61 \%$.

With regard to recognition as a program, Click It or Ticket was the most frequently selected of the several program options listed, with an average of $78 \%$ of respondents selecting it over the four waves. By comparison, multiple-wave averages for other mentioned programs were: Buckle Up Colorado (27\%); High School Seat Belt Challenge (3.9\%); Driver's Seat (2.5\%); Teen Seat belt Challenge (2.4\%); and Do the Twist (1\%).

Table 17. Awareness of Teen Seat Belt Messages and Recognition of Click It or Ticket in Colorado

\begin{tabular}{|c|c|c|c|c|c|}
\hline Indices & $\begin{array}{c}\text { Baseline } \\
4 / 16 / 07 \\
\end{array}$ & $\begin{array}{c}\text { Wave } 1 \\
10 / 22 / 07 \\
\end{array}$ & $\begin{array}{l}\text { Wave } 2 \\
1 / 22 / 08 \\
\end{array}$ & $\begin{array}{l}\text { Wave } 3 \\
3 / 10 / 08 \\
\end{array}$ & $\begin{array}{l}\text { Wave } 4 \\
5 / 19 / 08 \\
\end{array}$ \\
\hline $\begin{array}{l}\text { Saw/Heard Messages } \\
\text { For Teens to Buckle Up }\end{array}$ & $\begin{array}{c}\mathbf{5 1 . 3} \% \\
\mathrm{n}=581\end{array}$ & $\begin{array}{l}\mathbf{5 8 . 5} \% \\
n=764\end{array}$ & $\begin{array}{l}\mathbf{5 6 . 9} \% \\
n=915\end{array}$ & $\begin{array}{c}\mathbf{6 3 . 4} \% \\
n=1021\end{array}$ & $\begin{array}{r}67.7 \% \\
n=938\end{array}$ \\
\hline $\begin{array}{r}\text { Incremental Change (pct. pts.) } \\
\text { Significance } \\
\text { Cumulative Change (pct. pts.) } \\
\text { Significance }\end{array}$ & & $\begin{array}{c}+7.2 \\
* * \\
+7.2 \\
* *\end{array}$ & $\begin{array}{c}-1.6 \\
n s \\
+5.6 \\
*\end{array}$ & $\begin{array}{c}+6.4 \\
* * \\
+12.1 \\
* * *\end{array}$ & $\begin{array}{c}+4.3 \\
* \\
+16.4 \\
* * *\end{array}$ \\
\hline $\begin{array}{c}\text { Saw/Heard about } \\
\text { Click It or Ticket } \\
\text { (as part of SB message) }\end{array}$ & $\begin{array}{l}31.9 \% \\
n=204\end{array}$ & $\begin{array}{l}\mathbf{5 4 . 7} \% \\
n=331\end{array}$ & $\begin{array}{l}56.5 \% \\
N=407\end{array}$ & $\begin{array}{l}61.9 \% \\
n=470\end{array}$ & $\begin{array}{l}60.7 \% \\
n=507\end{array}$ \\
\hline $\begin{array}{r}\text { Incremental Change (pct. pts.) } \\
\text { Significance } \\
\text { Cumulative Change (pct. pts.) } \\
\text { Significance }\end{array}$ & & $\begin{array}{l}+22.8 \\
* * * \\
+22.8 \\
* * *\end{array}$ & $\begin{array}{c}+1.8 \\
n s \\
+24.6 \\
* * *\end{array}$ & $\begin{array}{c}+5.4 \\
n s \\
+30.1 \\
* * \star\end{array}$ & $\begin{array}{c}-1.2 \\
N s \\
+28.9 \\
\star * *\end{array}$ \\
\hline $\begin{array}{c}\text { Knew about } \\
\text { Click It or Ticket } \\
\text { (as a seat belt program) }\end{array}$ & $\begin{array}{l}82.7 \% \\
n=594\end{array}$ & $\begin{array}{l}74.8 \% \\
n=786\end{array}$ & $\begin{array}{l}79.1 \% \\
n=936\end{array}$ & $\begin{array}{c}79.8 \% \\
n=1041\end{array}$ & $\begin{array}{l}76.6 \% \\
n=957\end{array}$ \\
\hline $\begin{array}{r}\text { Incremental Change (pct. pts.) } \\
\text { Significance } \\
\text { Cumulative Change (pct. pts.) } \\
\text { Significance }\end{array}$ & & $\begin{array}{c}-7.9 \\
* * * \\
-7.9 \\
* * *\end{array}$ & $\begin{array}{c}+4.3 \\
* \\
-3.6 \\
n s\end{array}$ & $\begin{array}{c}+0.8 \\
n s \\
-2.8 \\
n s\end{array}$ & $\begin{array}{c}-3.2 \\
N s \\
-6.1 \\
\star *\end{array}$ \\
\hline
\end{tabular}

Legend: incremental change = wave-to-wave change; cumulative change = change relative to baseline; pct. pts. refers to percentage point (absolute) change; relative to significance, ${ }^{*}=p \leq 0.05 ;{ }^{* *}=p \leq 0.01$; ${ }^{* * *}=p \leq 0.001$; all dates (row 1 ) refer to start dates of awareness surveys. 
This recognition of the CIOT program did not increase over the four waves of activity. In fact, a decrease was measured after waves 1 and 4, typically the most powerful waves in terms of change. Particularly interesting was the decrease associated with Wave 4, which was measured prior to the completion of the statewide May CIOT mobilization. The high baseline (86\%), measured in April 2007, may have been a factor in the lack of increase in this index.

Figure 18 shows the changes in awareness/recognition for these three indices. The top (dashed) line shows changes in recognition of CIOT as a program, the bottom (dotted) line shows changes in recall of the CIOT message. In between, is awareness of any message regarding teen seat belt use (solid line). The highest level of awareness for this index was after Wave 4 (May 2008).

Figure 18. Awareness of Teen Seat Belt Messages and of CIOT Program and Message in Colorado

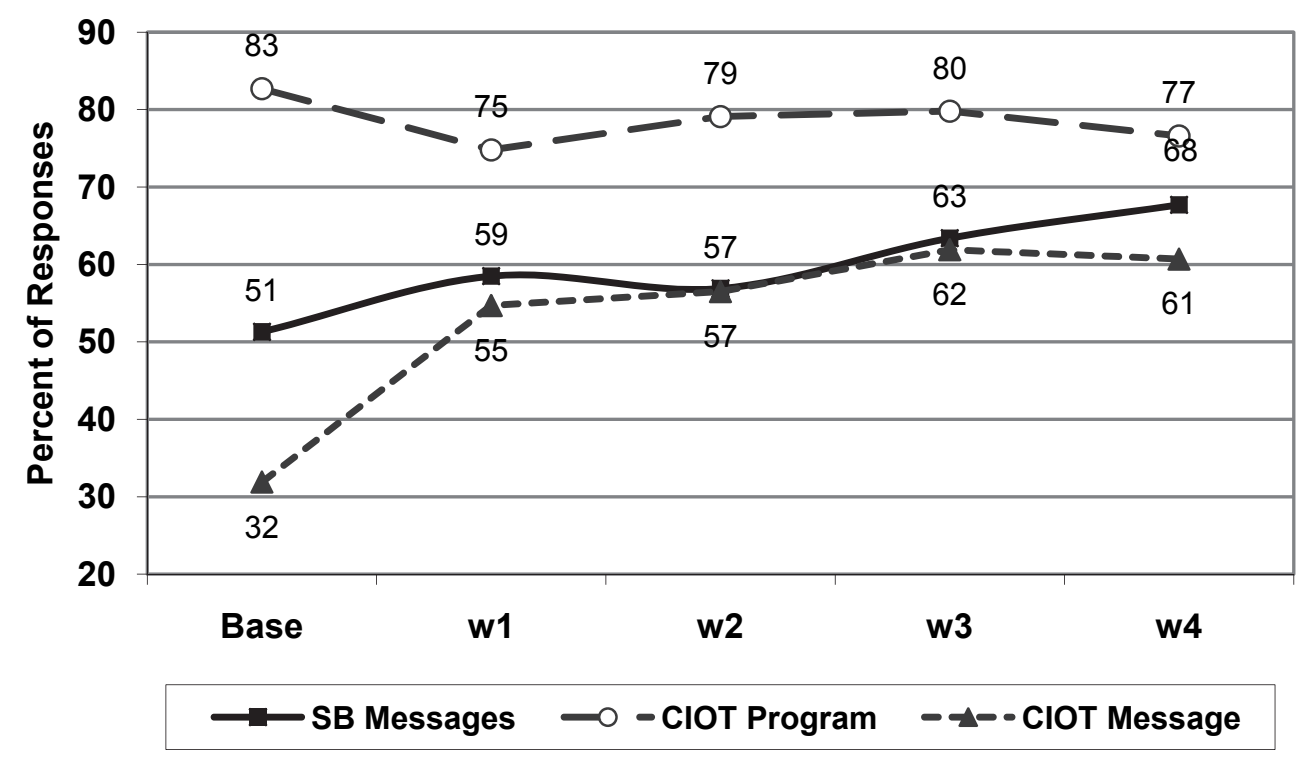

There were several sources of seat belt messages for teens. The paid media components were television, radio, theater screens, and the Internet (games and ads on Yahoo and AOL) but other media were present as well, including: newspapers (earned media), billboards, posters, and brochures. Figure 19 shows the baseline and change for each medium listed as a source of seat belt messages. The change shown is through Wave 4 (May 2008).

Television had the highest baseline as a source of seat belt messages (35\%); followed by radio and billboards (14\%); newspapers (10\%); enforcement posters (7\%); enforcement, theater ads, and the Internet (all about 4\%); and brochures (3\%). Television also was associated with the largest gains as a source of information ( +17 points); followed by radio ( +15 points); billboards ( +7 points); enforcement and newspapers $(+5$ points); Web sites $(+4$ points $)$; and posters, theater screens, and posters (all about 1\%).

It should be noted that the Internet, theater screens, and posters were not included on the baseline survey. Thus, the baselines for these media were likely lower than shown in Figure 19 and the change was likely greater than that shown. 
Figure 19. Sources of Awareness for Teen-Related Seat Belt Messages, Baseline Levels and Change Through Wave 4 in Colorado

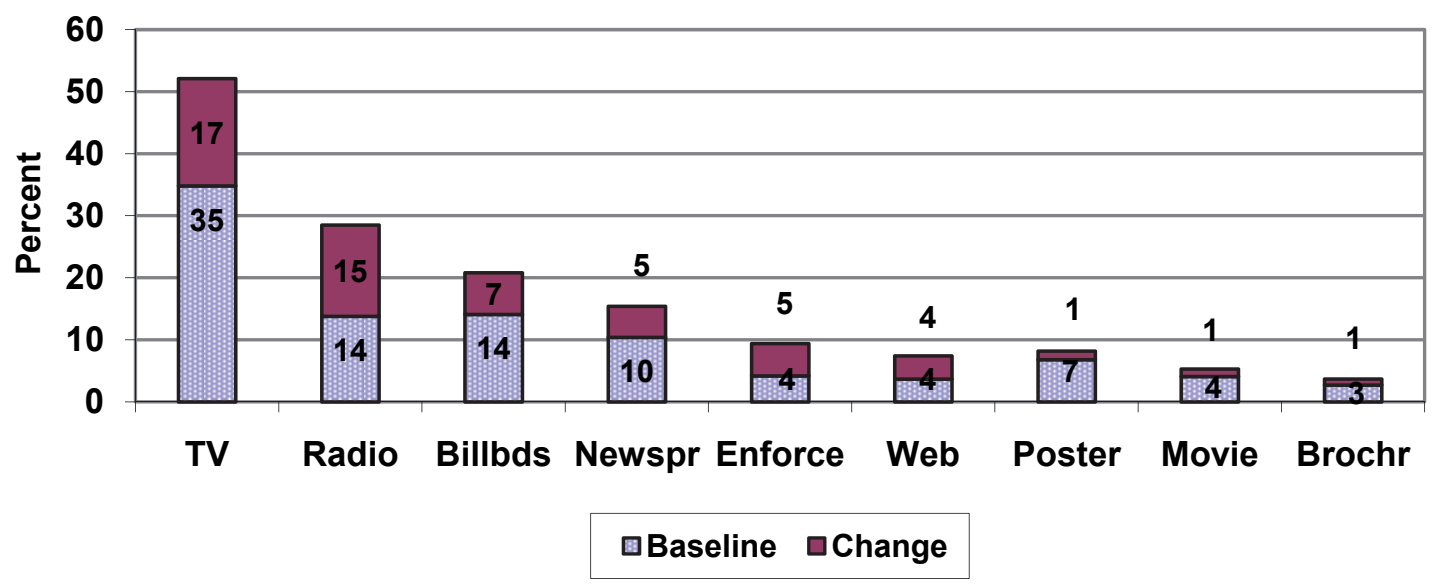

The surveys also asked where the respondents were when they received messages related to seat belt use. At baseline, most were at home (33\%); followed by school $(15 \%)$; on the roadway $(14 \%)$; at work $(4 \%)$; or in a social or recreational environment $(3 \%)$. In spite of having a much higher baseline, the greatest increases were at home $(+13$ points); followed by on the roadway $(+9)$; at school $(+6)$; in social and recreational situations $(+4)$; and at work $(+3)$.

Figure 20. Locations of Teen-Related Seat Belt Messages, Baseline Levels and Change Through Wave 4 in Colorado

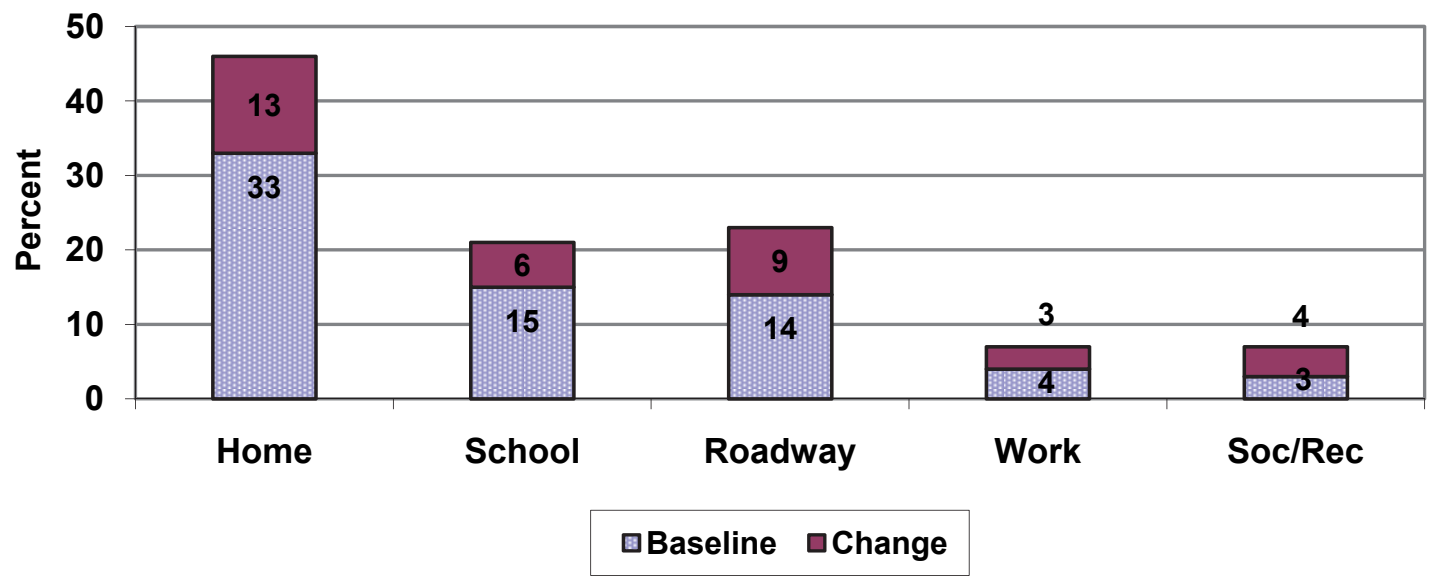

Based on where various media are available, it is likely that increases in messages received at home were associated with television, newspapers, and the Internet; increases on the road were likely associated with radio, billboards, and enforcement; increases at school, at work, and in social or recreational situations likely involved a combination of posters, brochures and other sources, such as demonstrations, educational programs, and social interactions. 


\subsubsection{Nevada}

The survey in Nevada generally asked the same questions as the survey in Colorado and Table 18 shows that there was a steady increase in awareness of messages for teens in Nevada to buckle up. This increase continued through Wave 3 (May 2008), after which there was a significant decline. The largest increases were associated with Wave 1 (October 2007) and Wave 3. There was a cumulative 28-point increase in awareness of seat belt-related messages, from $40 \%$ at baseline to $68 \%$ after Wave 3. An 11-point decline from Wave 3 to Wave 4 left awareness at $57 \%(+17$ points relative to baseline $)$.

As in Colorado, there was a significant increase in recall of CIOT, as a component of seat belt messages. Also as in Colorado, this increase was primarily associated with Wave $1(+25.9$ percentage points). There were no significant increases associated with any subsequent individual waves. Cumulatively, however, there was a 30 -point increase, from $36 \%$ at baseline to $66 \%$ after waves 3 and 4, very similar to the 29-point gain seen in Colorado.

With regard to recognition of CIOT as a program, Click It or Ticket was the most frequently selected option mentioned, with an average of $76 \%$ of respondents selecting the CIOT option as a seat belt program they knew of (compared with an average of $78 \%$ in Colorado). By comparison, multiple-wave averages for other programs options were: Buckle Up Nevada (30\%); Driver's Edge (20\%); Just Keep Thinking Safety (5\%); and PACE (3\%).

In Colorado there was a slight decrease in recognition of CIOT as a program. In Nevada, however, this recognition increased through Wave 2 and then remained stable at about $65 \%$. The substantial difference in baselines is relevant here. In Colorado, the baseline level of CIOT recognition was $86 \%$, compared with $36 \%$ in Nevada. Further, in both States, the May 2008 awareness survey began before the CIOT mobilization was completed (i.e., during Wave 4 in Colorado and Wave 3 in Nevada). Recognition of CIOT would likely have been higher after the completion of the statewide CIOT program.

Figure 21 shows the changes in awareness/recognition for these three indices. The top line represents changes in recognition of CIOT as a program, the bottom line represents changes in awareness of CIOT as a message. ${ }^{8}$ The solid line represents changes in awareness of any message regarding seat belt use and teens. It peaked after Wave 3 (May 2008).

\footnotetext{
${ }^{8}$ The percentage recognizing CIOT as a message represents a subset of those respondents who indicated that they had recently heard messages regarding seat belts.
} 
Table 18. Awareness of Teen-Related Seat Belt Messages and Recognition of CIOT in Nevada

\begin{tabular}{|c|c|c|c|c|c|}
\hline Indices & $\begin{array}{c}\text { Baseline } \\
4 / 16 / 07 \\
\end{array}$ & $\begin{array}{l}\text { Wave } 1 \\
11 / 05 / 07\end{array}$ & $\begin{array}{l}\text { Wave } 2 \\
1 / 22 / 08 \\
\end{array}$ & $\begin{array}{l}\text { Wave } 3 \\
5 / 19 / 08\end{array}$ & $\begin{array}{l}\text { Wave } 4 \\
9 / 25 / 08\end{array}$ \\
\hline $\begin{array}{l}\text { Saw/Heard Messages } \\
\text { For Teens to Buckle Up }\end{array}$ & $\begin{array}{l}39.8 \% \\
n=816\end{array}$ & $\begin{array}{l}58.5 \% \\
n=330\end{array}$ & $\begin{array}{l}56.4 \% \\
n=977\end{array}$ & $\begin{array}{l}67.8 \% \\
n=758\end{array}$ & $\begin{array}{l}56.5 \% \\
n=699\end{array}$ \\
\hline $\begin{array}{r}\text { Incremental Change (pct. pts.) } \\
\text { Significance } \\
\text { Cumulative Change (pct. pts.) } \\
\text { Significance }\end{array}$ & & $\begin{array}{c}+18.7 \\
* * * \\
+18.7 \\
\star \star * \star \\
\end{array}$ & $\begin{array}{c}-2.1 \\
n s \\
+16.6 \\
* \star \star\end{array}$ & $\begin{array}{l}+11.4 \\
* * * \\
+28.0 \\
* * * \\
\end{array}$ & $\begin{array}{c}-11.3 \\
* * * \\
+16.7 \\
* \star *\end{array}$ \\
\hline $\begin{array}{c}\text { Saw/Heard About } \\
\text { Click It or Ticket } \\
\text { (as part of SB message) }\end{array}$ & $\begin{array}{l}35.5 \% \\
n=276\end{array}$ & $61.4 \%$ & $65.3 \%$ & $65.9 \%$ & $65.5 \%$ \\
\hline $\begin{array}{r}\text { Incremental Change (pct. pts.) } \\
\text { Significance } \\
\text { Cumulative Change (pct. pts.) } \\
\text { Significance }\end{array}$ & & $\begin{array}{l}+25.9 \\
* * * \\
+\underset{* * *}{25.9} \\
\end{array}$ & $\begin{array}{c}+3.9 \\
n s \\
+29.8 \\
* * *\end{array}$ & $\begin{array}{c}+0.64 \\
n s \\
+30.4 \\
* * *\end{array}$ & $\begin{array}{l}-0.4 \\
n s \\
+30.0 \\
* * *\end{array}$ \\
\hline $\begin{array}{c}\text { Knew About } \\
\text { Click It or Ticket } \\
\text { (as a seat belt program) }\end{array}$ & $\begin{array}{l}67.4 \% \\
n=826\end{array}$ & $77.9 \%$ & $\begin{array}{l}77.2 \% \\
\mathrm{n}=977\end{array}$ & $\begin{array}{l}80.2 \% \\
n=758\end{array}$ & $n=699$ \\
\hline $\begin{array}{r}\text { Incremental Change (pct. pts.) } \\
\text { Significance } \\
\text { Cumulative Change (pct. pts.) } \\
\text { Significance }\end{array}$ & & $\begin{array}{l}+10.4 \\
\quad * * * \\
+10.4 \\
+* * \\
\end{array}$ & $\begin{array}{r}-0.7 \\
n s \\
+9.7 \\
* * *\end{array}$ & $\begin{array}{l}+3.0 \\
n s \\
+12.8 \\
* * *\end{array}$ & $\begin{array}{l}-0.7 \\
n s \\
+12.1 \\
* * *\end{array}$ \\
\hline \multicolumn{6}{|c|}{$\begin{array}{l}\text { Legend: incremental change }=\text { wave-to-wave change; cumulative change }=\text { change relative to base- } \\
\text { line; } \\
\text { pct. pts. refers to percentage point (absolute) change; relative to significance, }{ }^{*}=p \leq 0.05 ;{ }^{* *}=p \leq 0.01 \text {; } \\
{ }^{* * *}=p \leq 0.001 \text {; all dates (row 1) refer to start dates of awareness surveys. }\end{array}$} \\
\hline
\end{tabular}


Figure 21. Awareness of Teen Seat Belt Messages and CIOT in Nevada

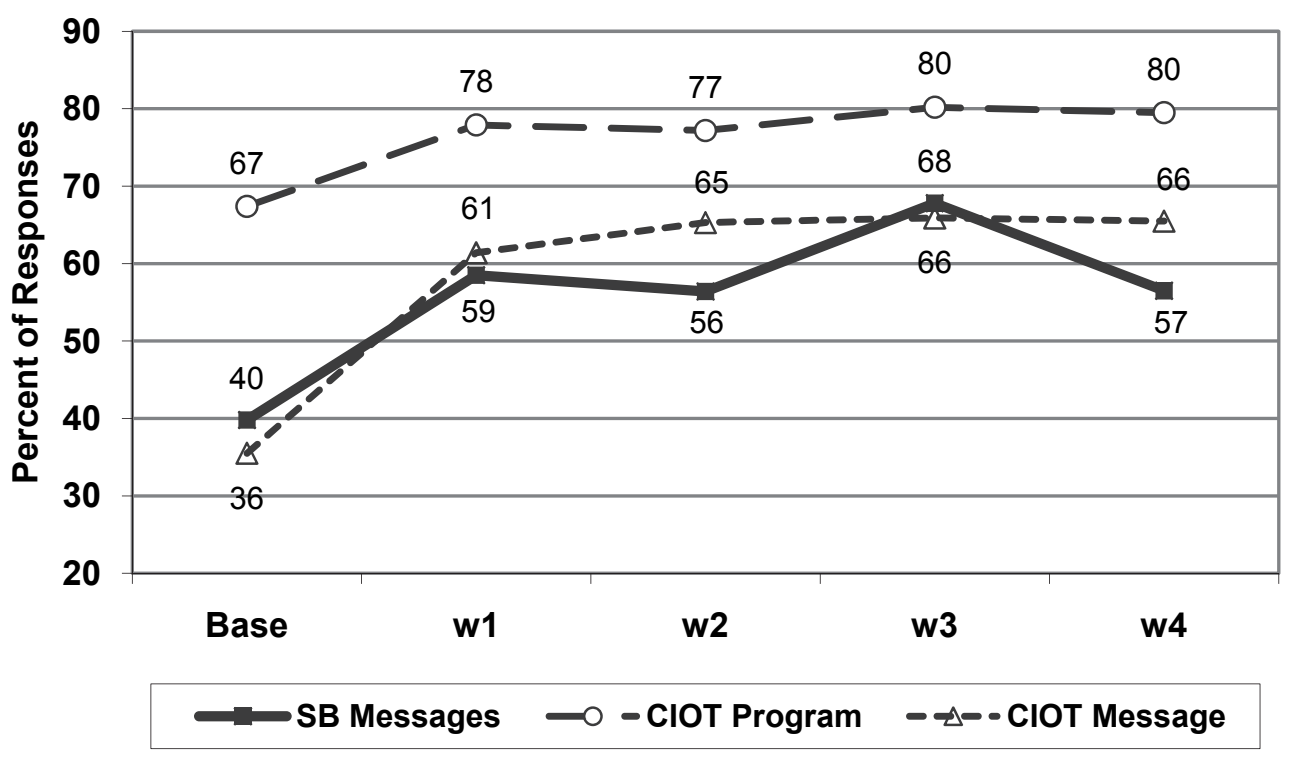


There were several sources of seat belt messages for teens. Figure 22 shows the baseline (and change) for each medium listed on the questionnaire. The change shown is through Wave 3 (May 2008). Television had the highest baseline as a source of seat belt messages (32\%); followed by radio $(10 \%)$, billboards $(9 \%)$; newspapers $(10 \%)$; enforcement posters $(7 \%)$; enforcement, theater ads, and the Internet (all about 4\%); and brochures (3\%).

\section{Figure 22. Sources of Awareness for Teen Seat Belt Messages,} Baseline Levels and Change Through Wave 3, in Nevada ${ }^{9}$

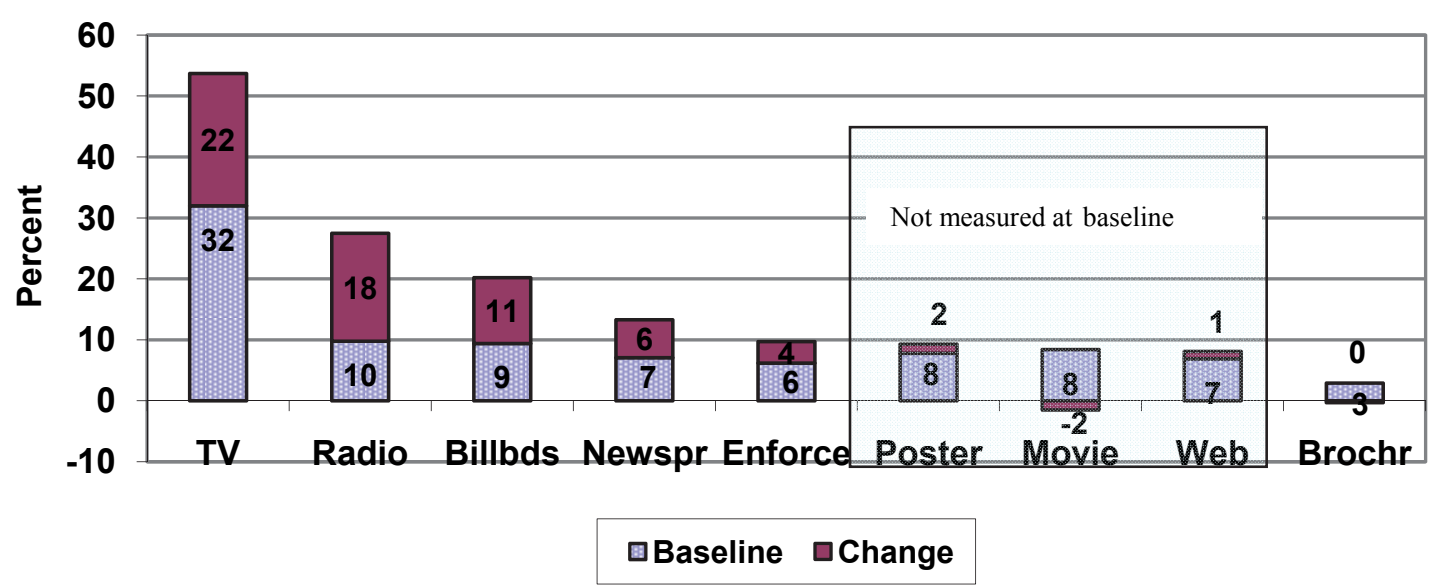

Television also was also associated with the largest gains as a source of information $(+17$ points); followed by radio ( +15 points); and billboards ( +7 points). The next highest baselines were likely newspaper and enforcement (7\% and 6\%, respectively) because posters, movie screens, and Web sites were not included in the baseline survey. Thus, the baselines for these media were likely lower and the change was likely greater than that shown in Figure 22.

The surveys also asked the respondents where they were when they saw or heard seat belt messages. At baseline, most were at home $(30 \%)$; at school $(13 \%)$; or on the roadway $(13 \%)$. Fewer said they were in a recreational or social situation $(5 \%)$ or at work $(3 \%)$. The greatest increases were: at home $(+19$ points); at school $(+17)$; on the road $(+9)$; at work $(+2)$; or in a social or recreational environment $(+1)$.

As in Colorado, it is likely that the increases in messages received at home were associated with television, newspapers, and the Internet; increases at school, at work, and in social or recreational situations likely involved a combination of posters, brochures and other sources, such as educational programs and social interactions; and increases in message awareness while driving were likely associated with radio, billboards, and enforcement.

\footnotetext{
${ }^{9}$ Changes are those measured through Wave 3 (May 2008) when awareness peaked. After Wave 4, change is slightly less than that shown in this Figure.
} 
Figure 23. Self-Reported Locations of Teen-Related Seat Belt Messages, Baseline Levels and Change Through Wave 3 in Nevada ${ }^{10}$

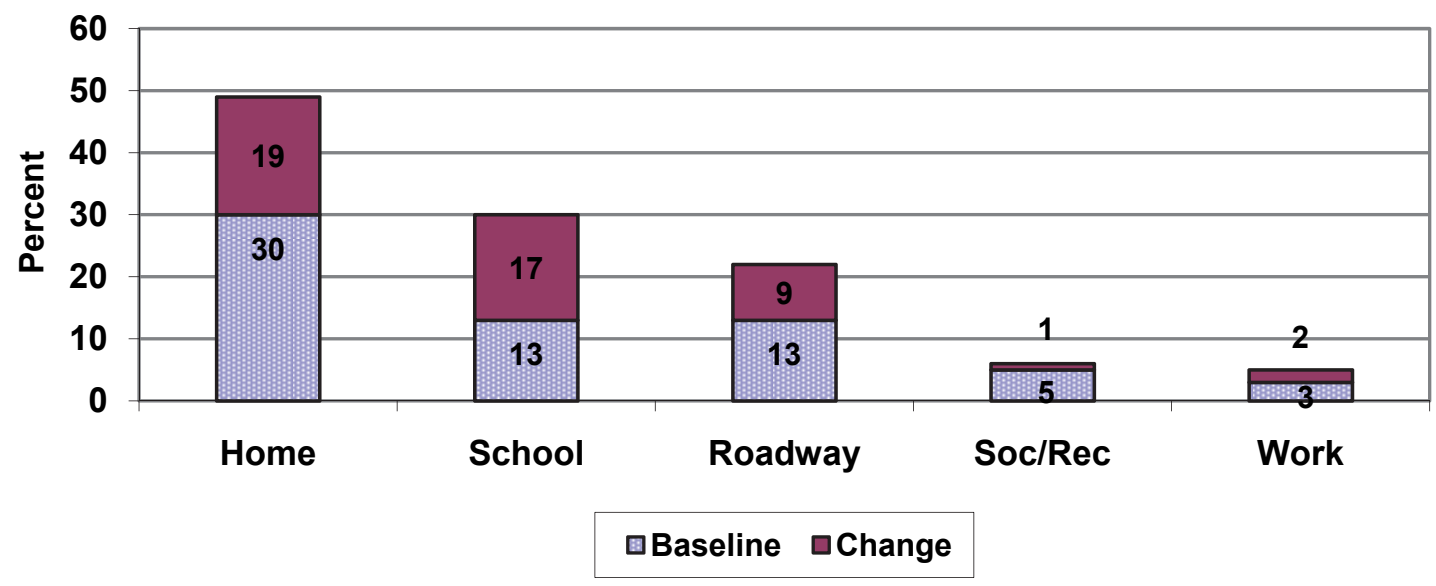

\subsubsection{Enforcement Related Questions}

\subsubsection{Colorado}

The foundation of the Teen Demonstration Project was high-visibility enforcement. Thus, one of the most important groups of questions examined teen awareness and perceptions regarding enforcement activity. Of these questions, three were of primary interest. They were:

- How strictly do you think the safety belt law in Colorado is enforced?

- In the past month, have you heard or seen special enforcement efforts regarding safety belt use that would affect teenagers and young people?

- What do you think the chances are of getting a ticket if you don't wear your safety belt?

There was an increase in the perception of strict enforcement through Wave 2, after which there was no statistically significant change. Relative to baseline, the proportion of respondents perceiving strict or very strict enforcement remained significantly higher through all four waves. Overall, there was a cumulative 7-percentage-point increase in this perception, from 58\% at baseline to $65 \%$ after the third and fourth program waves.

There also was a large and significant increase in awareness of special police efforts to enforce the seat belt law, particularly after Wave 1 but continuing through Wave 3. Awareness of special enforcement remained significantly elevated throughout the program, increasing from $32 \%$ at baseline to $52 \%$ after Wave 4 ( +20 points). Traditionally, this has been the most stable measure of enforcement awareness in CIOT and special demonstration programs.

\footnotetext{
${ }^{10}$ Changes are measured through Wave 3 (May 2008) when awareness peaked. If measured through Wave 4 , change is slightly less than that shown in this Figure.
} 
Finally, there was a large and significant increase in the perception that a ticket will always or nearly always be given if one rides unbuckled. That index increased by nearly 8 points from baseline to the post-Wave 1 survey and it remained significantly elevated throughout the program ( +6 points, from $34 \%$ at baseline to $40 \%$ after Wave 4 ).

Responses to these questions are summarized in Table 19 and shown graphically in Figure 24.

Table 19. Perceptions and Awareness Related to Seat Belt Enforcement in Colorado

\begin{tabular}{|c|c|c|c|c|c|}
\hline Indices & $\begin{array}{c}\text { Baseline } \\
4 / 16 / 07 \\
\end{array}$ & $\begin{array}{l}\text { Wave 1 } \\
10 / 22 / 07\end{array}$ & \begin{tabular}{|l|} 
Wave 2 \\
$1 / 22 / 08$ \\
\end{tabular} & $\begin{array}{l}\text { Wave } 3 \\
3 / 10 / 08\end{array}$ & \begin{tabular}{|l|} 
Wave 4 \\
$5 / 19 / 08$ \\
\end{tabular} \\
\hline $\begin{array}{l}\text { Perceive Strict/Very Strict } \\
\text { Enforcement of SB Laws }\end{array}$ & $\begin{array}{r}\mathbf{5 7 . 7 \%} \\
\mathrm{n}=588\end{array}$ & $\begin{array}{r}63.9 \% \\
\mathrm{n}=776\end{array}$ & $\begin{array}{l}68.2 \% \\
n=927\end{array}$ & $\begin{array}{c}65.1 \% \\
n=1023\end{array}$ & $\begin{array}{l}65.0 \% \\
n=952\end{array}$ \\
\hline $\begin{array}{r}\text { Incremental Change (pct. pts.) } \\
\text { Significance } \\
\text { Cumulative Change (pct. pts.) } \\
\text { Significance }\end{array}$ & & $\begin{array}{c}+6.3 \\
* \\
+6.3 \\
* \\
\end{array}$ & $\begin{array}{r}+4.3 \\
0.06 \\
+10.5 \\
* * *\end{array}$ & $\begin{array}{c}-3.1 \\
n s \\
+7.4 \\
* * *\end{array}$ & $\begin{array}{c}-0.1 \\
n s \\
+7.4 \\
* * * \\
\end{array}$ \\
\hline $\begin{array}{c}\text { Saw/Heard About } \\
\text { Special SB Enforcement }\end{array}$ & $\begin{array}{l}31.5 \% \\
n=588\end{array}$ & $\begin{array}{l}46.0 \% \\
n=778\end{array}$ & $\begin{array}{l}47.7 \% \\
n=930\end{array}$ & $\begin{array}{l}\mathbf{5 1 . 2} \% \\
\mathrm{n}=1030\end{array}$ & $\begin{array}{l}51.6 \% \\
n=954\end{array}$ \\
\hline $\begin{array}{r}\text { Incremental Change (pct. pts.) } \\
\text { Significance } \\
\text { Cumulative Change (pct. pts.) } \\
\text { Significance }\end{array}$ & & $\begin{array}{c}+14.6 \\
* * * \\
+14.6 \\
* * * \\
\end{array}$ & $\begin{array}{c}+1.7 \\
n s \\
+16.3 \\
* * * \\
\end{array}$ & $\begin{array}{c}+3.4 \\
n s \\
+19.7 \\
* * * \\
\end{array}$ & $\begin{array}{c}+0.4 \\
n s \\
+20.1 \\
* * *\end{array}$ \\
\hline $\begin{array}{l}\text { Perceived High Risk of } \\
\text { Getting a Ticket for Non-Use } \\
\text { (always or nearly always) }\end{array}$ & $\begin{array}{l}34.2 \% \\
n=591 \\
\end{array}$ & $\begin{array}{l}42.0 \% \\
n=776\end{array}$ & $\begin{array}{l}40.3 \% \\
n=929 \\
\end{array}$ & $\begin{array}{l}38.2 \% \\
n=1027\end{array}$ & $\begin{array}{l}39.9 \% \\
n=953\end{array}$ \\
\hline $\begin{array}{r}\text { Incremental Change (pct. pts.) } \\
\text { Significance } \\
\text { Cumulative Change (pct. pts.) } \\
\text { Significance }\end{array}$ & & $\begin{array}{l}+7.8 \\
* * \\
+7.8 \\
* *\end{array}$ & $\begin{array}{c}-1.8 \\
n s \\
+6.1 \\
\star\end{array}$ & $\begin{array}{c}-2.1 \\
n s \\
+4.0 \\
n s\end{array}$ & $\begin{array}{c}+1.7 \\
n s \\
+5.7 \\
\star\end{array}$ \\
\hline
\end{tabular}


Figure 24. Perceived Strictness of Enforcement, Awareness of Special Police Efforts, and Perceived Likelihood of Receiving a Ticket for Seat Belt Non-Use in Colorado

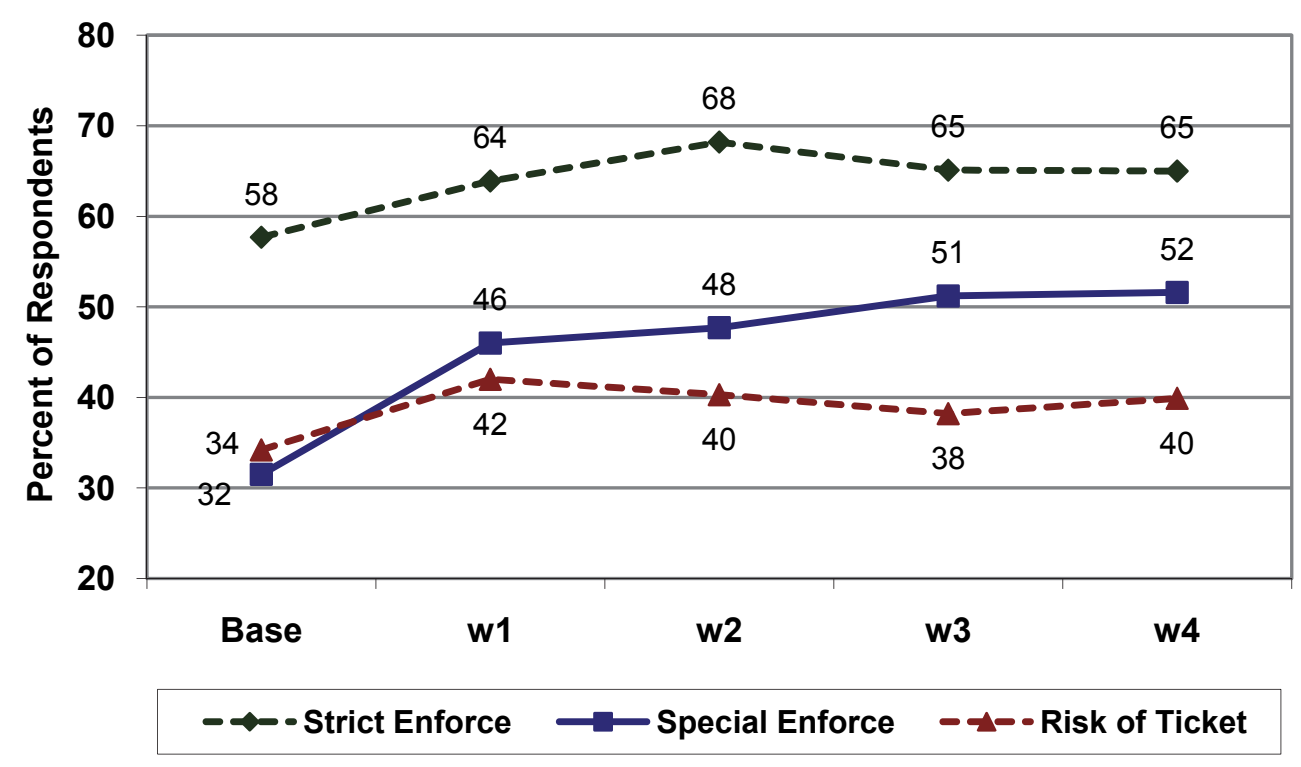

As with media message, the questionnaire also asked respondents were they were when they saw or heard messages related to special police efforts. The specific question was:

\section{Where did you learn about police enforcement (that would affect teenagers and young people)?}

Figure 25 shows that baseline levels of special enforcement awareness were generally lower than baseline levels of seat belt message awareness (shown in Figure 19) and that most respondents saw or heard about special enforcement at school (18\%), rather than at home $(12 \%)$. The third most frequent place was while on the roadway $(8 \%)$, followed by social or recreational situations $(4 \%)$, and at work (3\%). The greatest increases in awareness of special enforcement also came from school settings $(+12$ points), followed by on the road $(+11$ points $)$, at home $(+10$ points $)$, in social/recreational situations ( +3 points $)$, and at work $(+1$ point $)$.

Again, it seems logical that messages received at school came via educational events (not measured), peer-to-peer interactions (not measured), posters, contests (not measured directly), and possibly brochures. Information received at home would likely have come from television, the Internet, and possibly radio; and information received while on the road most likely would come from radio, billboards, or peer-to-peer interactions (not measured). The media through which special enforcement information was obtained were not addressed in the survey.

Figure 25 shows the baseline levels and changes for each location category. 
Figure 25. Self-Reported Locations of Enforcement Messages, Baseline Levels and Change Through Wave 4 in Colorado

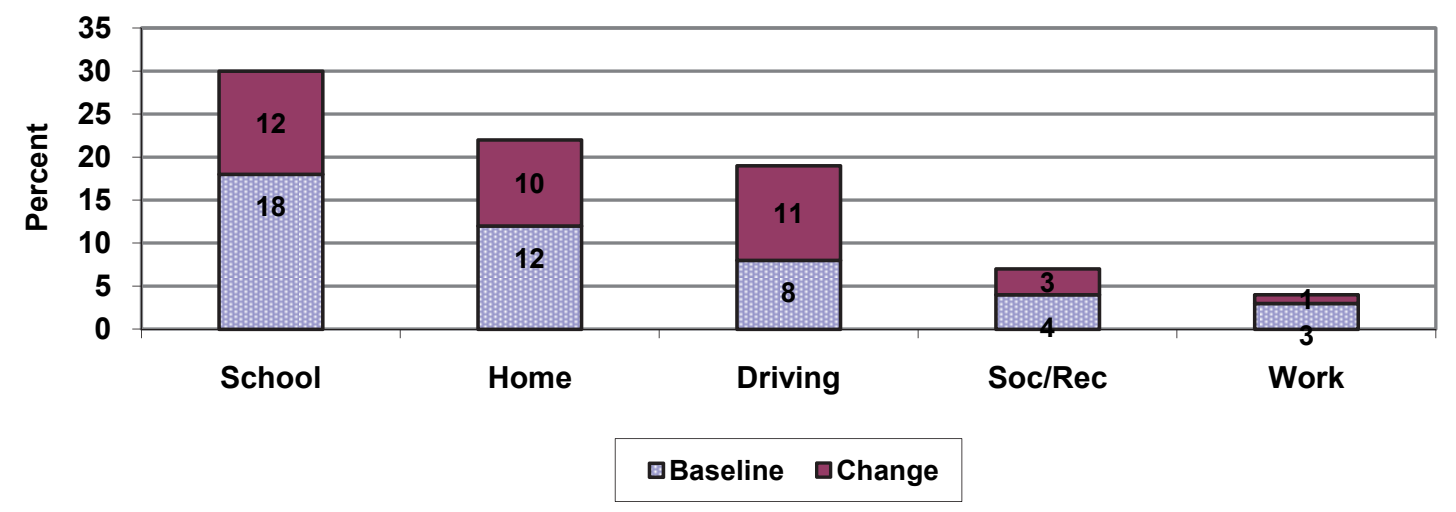

\subsubsection{Nevada}

As in Colorado, the key enforcement-related questions in Nevada were:

- How strictly do you think the safety belt law in Nevada is enforced?

- In the past month, have you heard or seen special enforcement efforts regarding safety belt use that would affect teenagers and young people?

- What do you think the chances are of getting a ticket if you don't wear your safety belt?

Responses to these questions, as well as wave-to-wave and cumulative changes, are summarized in Table 20. Trends are shown graphically in Figure 26.

There was a large and significant increase in the perception of strict enforcement associated with Wave 1 ( +12 points), after which there was a significant decline at Wave $2(-6$ points; $p=0.053)$, and then a slight increase through Wave 4. The proportion of respondents perceiving strict or very strict enforcement remained significantly higher than at baseline through all four waves, with an overall 8-point increase, from 50\% at baseline to $58 \%$ after waves 3 and 4.

There also was a large and significant increase in awareness of special police efforts to enforce seat belt laws after Wave 1; a decline after Wave 2, another increase after Wave 3; and a decline after Wave 4. In spite of these variations, awareness of special enforcement remained significantly higher than at baseline throughout the program, with a net increase from $31 \%$ at baseline to $43 \%$ after Wave 4 (+12 points). This measure has traditionally provided one of the most reliable indices of public awareness of CIOT and other HVE efforts.

Finally, there was an initial significant increase in the perception that a ticket will always or nearly always be given if one rides unbuckled. That index increased by nearly 8 percentage points from baseline to the post-Wave 1 survey. However, after a 3.5-point decline at Wave 2, this index was not significantly higher than at baseline. 
Table 20. Perceptions and Awareness Related to Seat Belt Enforcement in Colorado

\begin{tabular}{|c|c|c|c|c|c|}
\hline Indices & $\begin{array}{c}\text { Baseline } \\
4 / 16 / 07\end{array}$ & $\begin{array}{l}\text { Wave } 1 \\
11 / 05 / 07 \\
\end{array}$ & $\begin{array}{l}\text { Wave } 2 \\
1 / 22 / 08 \\
\end{array}$ & \begin{tabular}{|l|} 
Wave 3 \\
$5 / 19 / 08$ \\
\end{tabular} & $\begin{array}{l}\text { Wave } 4 \\
9 / 25 / 08 \\
\end{array}$ \\
\hline $\begin{array}{l}\text { Perceive Strict/Very Strict } \\
\text { Enforcement of SB Laws }\end{array}$ & $\begin{array}{r}49.5 \% \\
n=821\end{array}$ & $\begin{array}{r}61.6 \% \\
N=330\end{array}$ & $\begin{array}{c}55.4 \% \\
n=980\end{array}$ & $\begin{array}{l}\mathbf{5 8 . 4 \%} \\
\mathrm{n}=762\end{array}$ & $\begin{array}{l}57.9 \% \\
N=700\end{array}$ \\
\hline $\begin{array}{r}\text { Incremental Change (pct. pts.) } \\
\text { Significance } \\
\text { Cumulative Change (pct. pts.) } \\
\text { Significance }\end{array}$ & & $\begin{array}{c}+11.9 \\
* * * \\
+11.9 \\
* * * \\
\end{array}$ & $\begin{array}{l}-6.1 \\
0.053 \\
+5.8 \\
*\end{array}$ & $\begin{array}{c}+3.0 \\
n s \\
+8.8 \\
* * * \\
\end{array}$ & $\begin{array}{c}-0.5 \\
N s \\
+8.3 \\
* * \\
\end{array}$ \\
\hline $\begin{array}{c}\text { Saw/Heard About } \\
\text { Special SB Enforcement }\end{array}$ & $\begin{array}{l}30.5 \% \\
n=821\end{array}$ & $\begin{array}{l}44.4 \% \\
N=330\end{array}$ & $\begin{array}{l}38.2 \% \\
N=980\end{array}$ & $\begin{array}{l}50.1 \% \\
n=762\end{array}$ & $\begin{array}{l}42.8 \% \\
N=700\end{array}$ \\
\hline $\begin{array}{r}\text { Incremental Change (pct. pts.) } \\
\text { Significance } \\
\text { Cumulative Change (pct. pts.) } \\
\text { Significance }\end{array}$ & & $\begin{array}{c}+14.0 \\
* * * \\
+14.0 \\
* * * \\
\end{array}$ & $\begin{array}{c}-6.2 \\
* \\
+7.7 \\
* * * \\
\end{array}$ & $\begin{array}{c}+11.9 \\
* * * \\
+19.6 \\
* * * \\
\end{array}$ & $\begin{array}{c}-7.3 \\
* * \\
+12.3 \\
* * * \\
\end{array}$ \\
\hline $\begin{array}{l}\text { Perceived High Risk of } \\
\text { Getting a Ticket for Non-Use } \\
\text { (always or nearly always) }\end{array}$ & $\begin{array}{l}25.0 \% \\
n=816\end{array}$ & $\begin{array}{l}31.7 \% \\
n=331\end{array}$ & $\begin{array}{l}28.2 \% \\
n=983\end{array}$ & $\begin{array}{l}28.7 \% \\
N=764\end{array}$ & $\begin{array}{l}26.8 \% \\
n=702\end{array}$ \\
\hline $\begin{array}{r}\text { Incremental Change (pct. pts.) } \\
\text { Significance } \\
\text { Cumulative Change (pct. pts.) } \\
\text { Significance }\end{array}$ & & $\begin{array}{c}+6.7 \\
* \\
+6.7 \\
*\end{array}$ & $\begin{array}{c}-3.5 \\
n s \\
+3.2 \\
n s\end{array}$ & $\begin{array}{l}+0.5 \\
n s \\
+3.7 \\
n s\end{array}$ & $\begin{array}{l}-1.9 \\
N s \\
+1.8 \\
n s\end{array}$ \\
\hline
\end{tabular}

Figure 26 graphically illustrates the trends shown in Table 20. The significant increases following Wave 1 and Wave 3 are consistent with the enforcement indices that show these waves to have the greatest enforcement intensity. 
Figure 26. Perceived Strictness of Enforcement, Awareness of Special Police Efforts, and Perceived Likelihood of Receiving a Ticket for Seat Belt Non-Use in Nevada

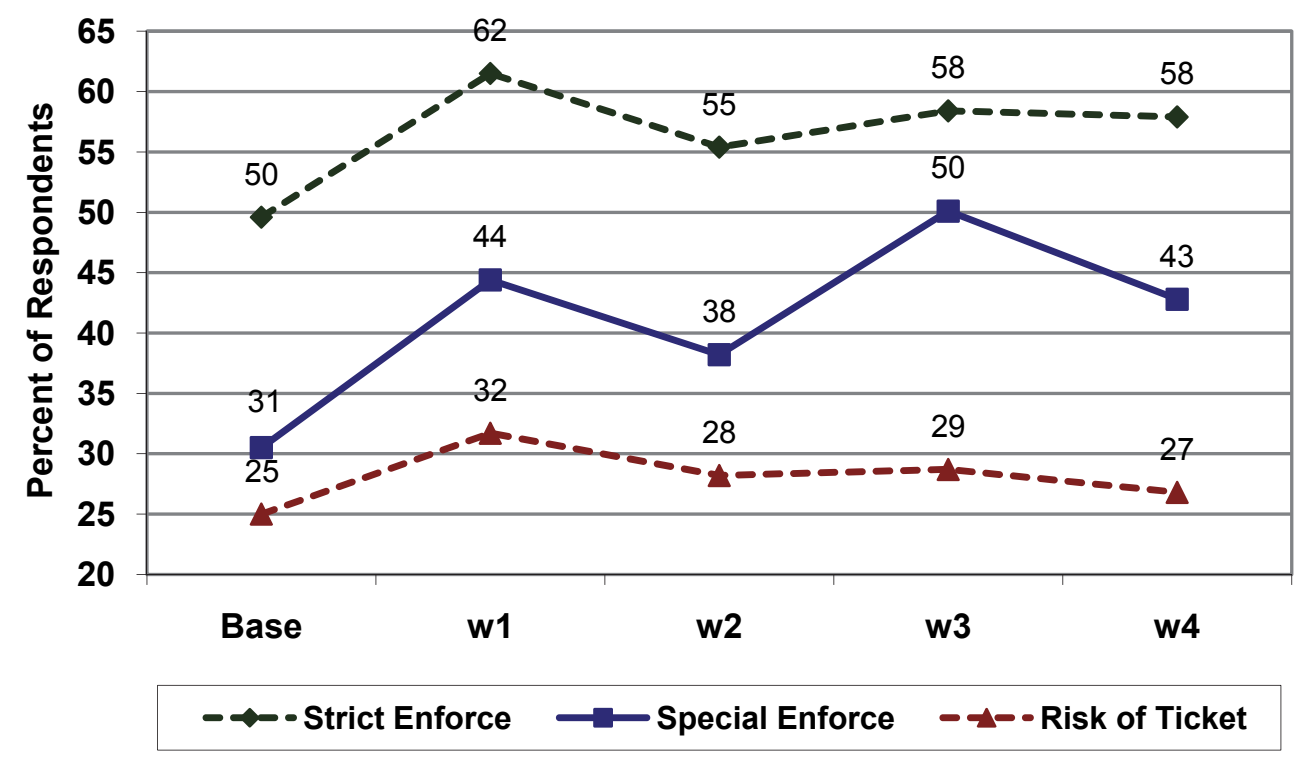

With regard to where respondents were when they saw or heard about special enforcement efforts, Figure 27 shows that most respondent said that they were at school $(15 \%)$ or at home $(14 \%)$; on the road was the next most frequent situation $(9 \%)$; followed by social or recreational locations (5\%); and at work (2\%).

Figure 27. Self-Reported Locations of Enforcement-Related Messages, Baseline Levels and Change Through Wave 4 in Nevada

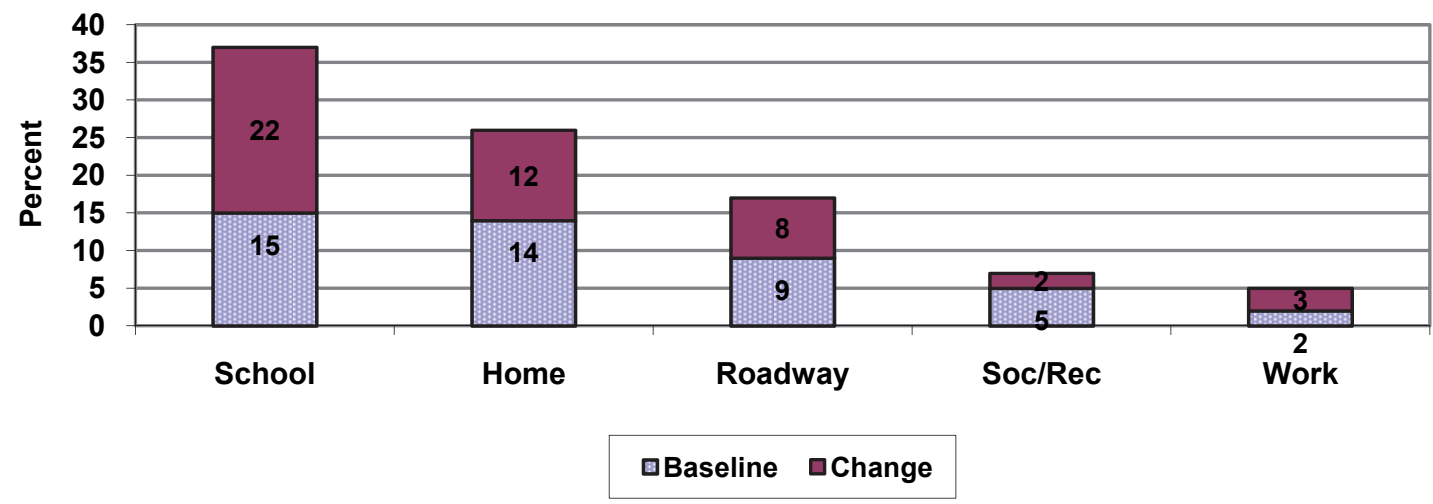

The greatest increases in awareness were after Wave 3 (May 2008) and in school situations $(+22$ points after Wave 3 and +13 points after Wave 4$)$. The next most frequent increases were associated with being at home ( +12 points and +8 points); on the road $(+8$ and +6$)$; at work $(+3$ and $+1)$; and in social or recreation situations $(+2$ and +3$)$. Consistently, school, home, and on the road were the locations most frequently indicated by teens when asked where they were when they saw or heard about special seat belt enforcement. 


\subsubsection{Comparison of Colorado and Nevada Awareness Results}

Figure 28 and Figure 29 show trends for three key indices in Colorado and Nevada, respectively. Colorado had a substantial initial wave effect, with gradual increases in awareness of seat belt messages and enforcement in subsequent waves, through Wave 4 (May 2008). Nevada also had a substantial initial wave effect but it also had a strong effect associated with Wave 3 (May 2008). Waves 2 and 4 generally were associated with declines in awareness.

Figure 28. Results of Key Awareness Indices in Colorado, by Wave

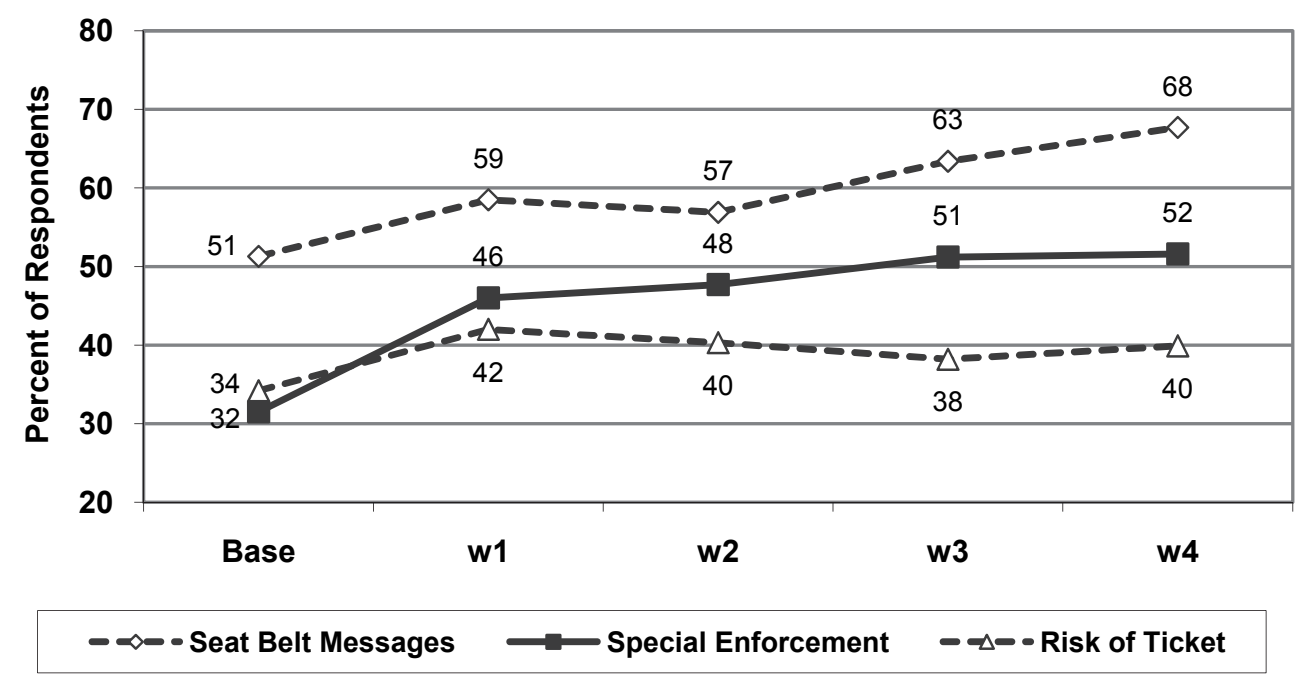

Figure 29. Results of Key Awareness Indices in Nevada, by Wave

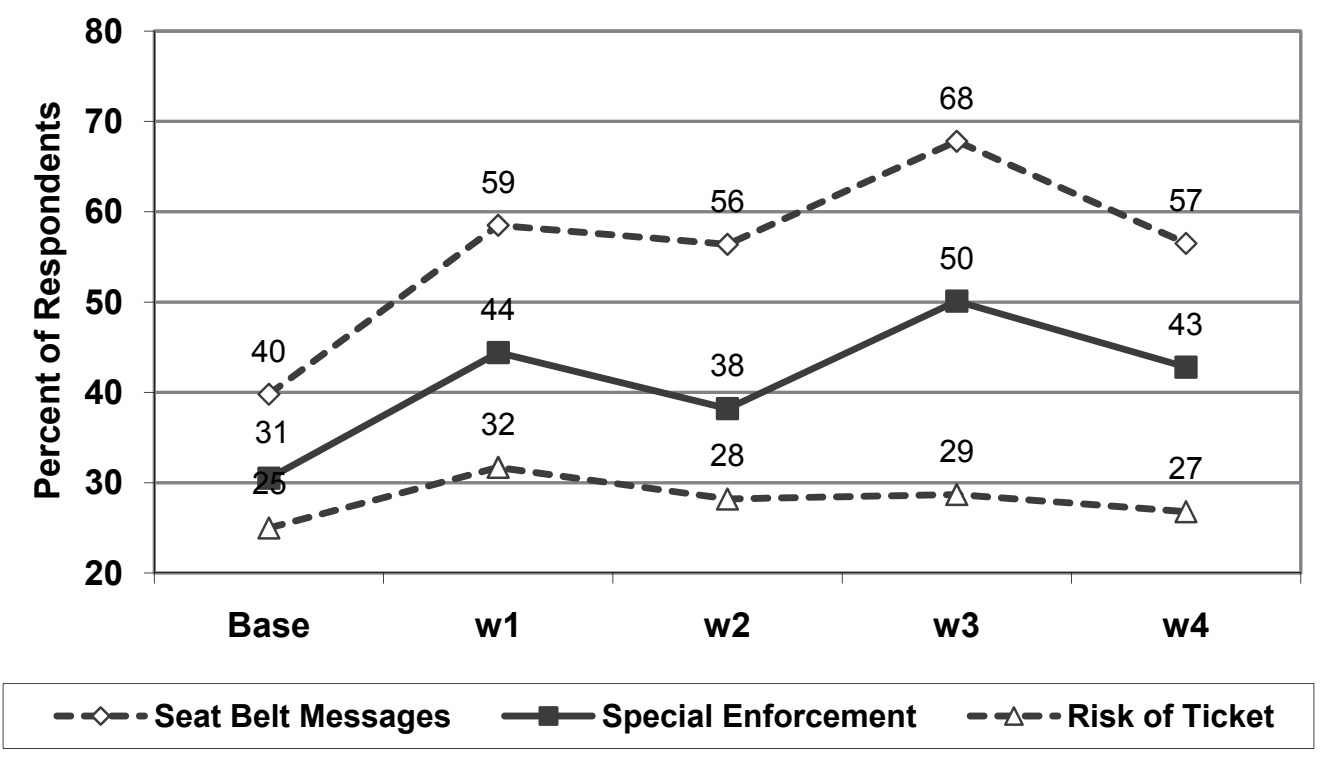


Looking at each measure individually, Figure 30 shows awareness of seat belt messages in both States. The trends are quite similar, particularly given that the Colorado surveys were conducted in DMV licensing centers and the Nevada surveys were conducted in participating schools.

Figure 30. Awareness of Seat Belt Messages in Colorado and Nevada, by Wave

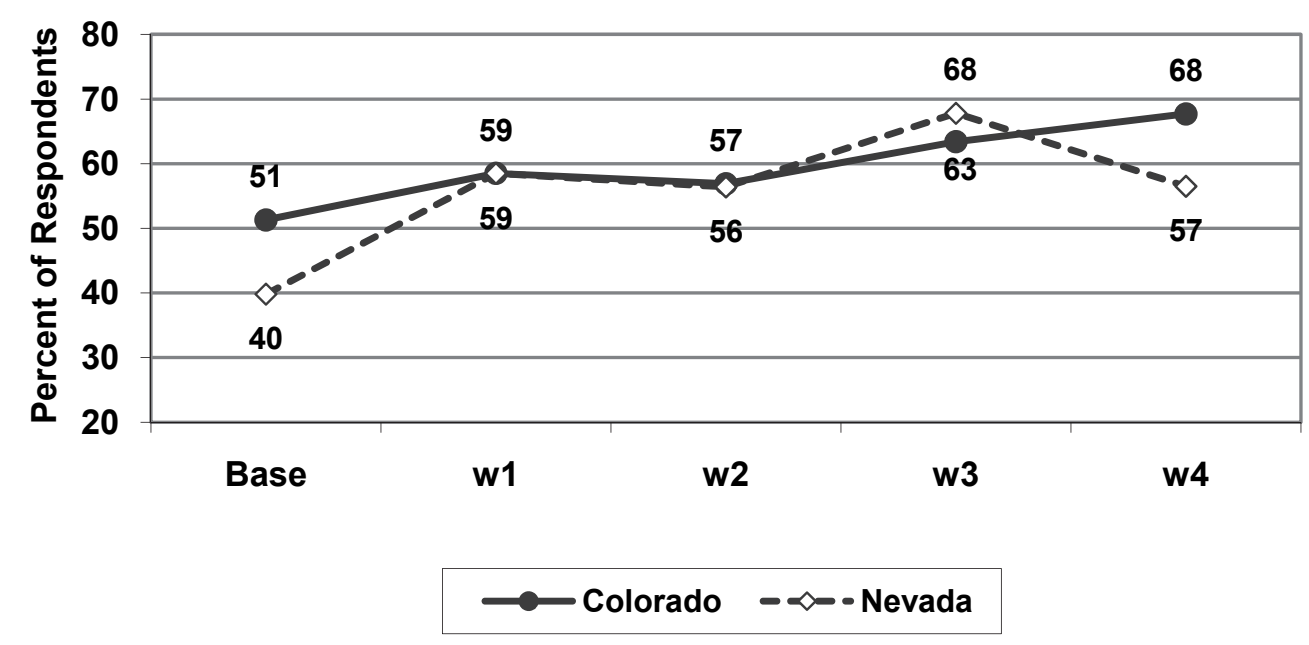

There is an initial wave effect in both States (particularly in Nevada) and a decline associated with Wave 2. The highest awareness levels were associated with Wave 4 in Colorado and Wave 3 in Nevada. Both of these measurements were conducted in May 2008. If the Wave 3 levels for Nevada were shifted forward so that they aligned with Wave 4 in Colorado, awareness would be identical in both States (68\% in Colorado, 16 points over baseline; and $68 \%$ in Nevada, 28 points over baseline). Both results are consistent with those of several previous demonstrations, where there were strong effects associated with the initial wave. In addition, the Nevada results for Wave 3 are consistent with frequent findings of an increased impact associated with special demonstrations that are followed by statewide CIOT mobilizations. ${ }^{11}$

With regard to awareness of enforcement efforts, Figure 31 also shows the initial wave effects and impact associated with the May 2008 wave (Wave 4 in Colorado and Wave 3 in Nevada). At this time, the levels and increases over baseline are nearly identical for the two States (52\% awareness in Colorado, +20 points; $50 \%$ in Nevada, +19 points). However, there were some differences, with considerable wave-to-wave variation in Nevada, compared with modest but steady increases over time in Colorado.

\footnotetext{
${ }^{11}$ It is important to reiterate at this point that these awareness surveys were conducted prior to completion of the May CIOT mobilizations in both States. Had they been conducted after the completion of the statewide CIOT program, awareness and gains in awareness likely would have been higher.
} 
Figure 31. Awareness of Special Enforcement Efforts, by Wave in Colorado and Nevada

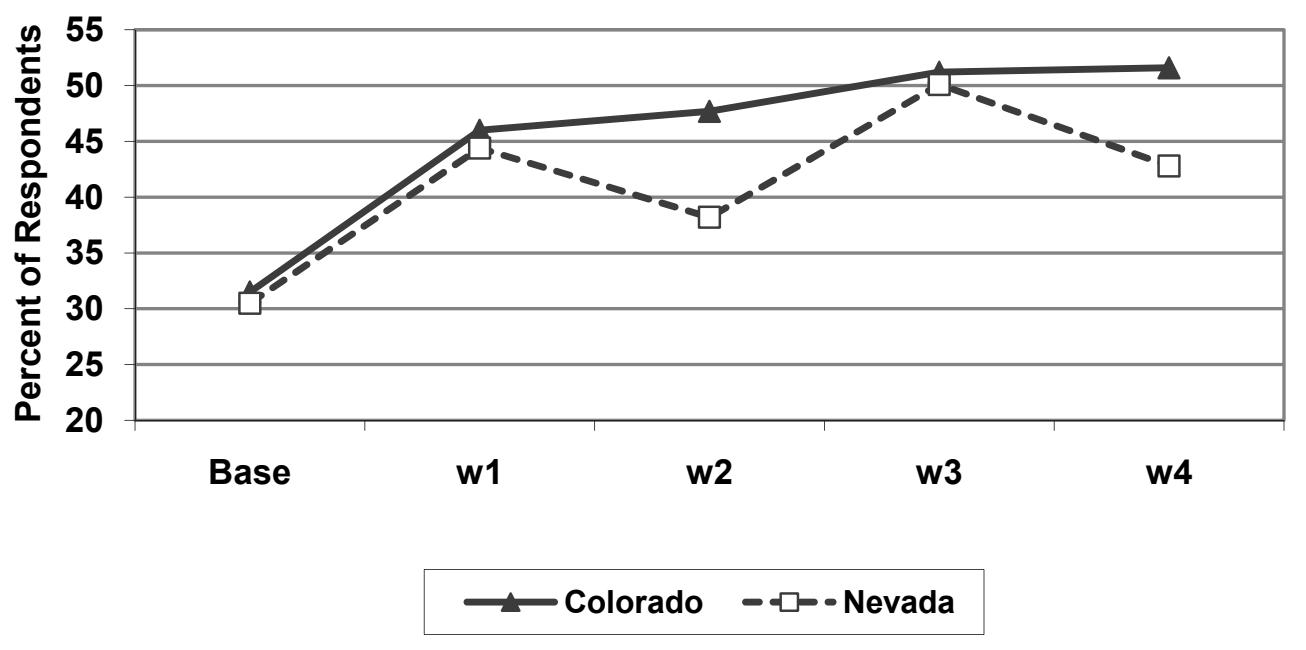

Figure 32 suggests that teens in Colorado are more likely to think that that they would get a ticket for not buckling up than teens in Nevada. In both States, there is an initial increase in this perception associated with Wave 1 of the teen program. In Colorado, this significantly higher perceived risk is maintained over time but, in Nevada, it declines to levels not significantly different from baseline.

Figure 32. Perceived Risk of Receiving a Ticket in Colorado and Nevada

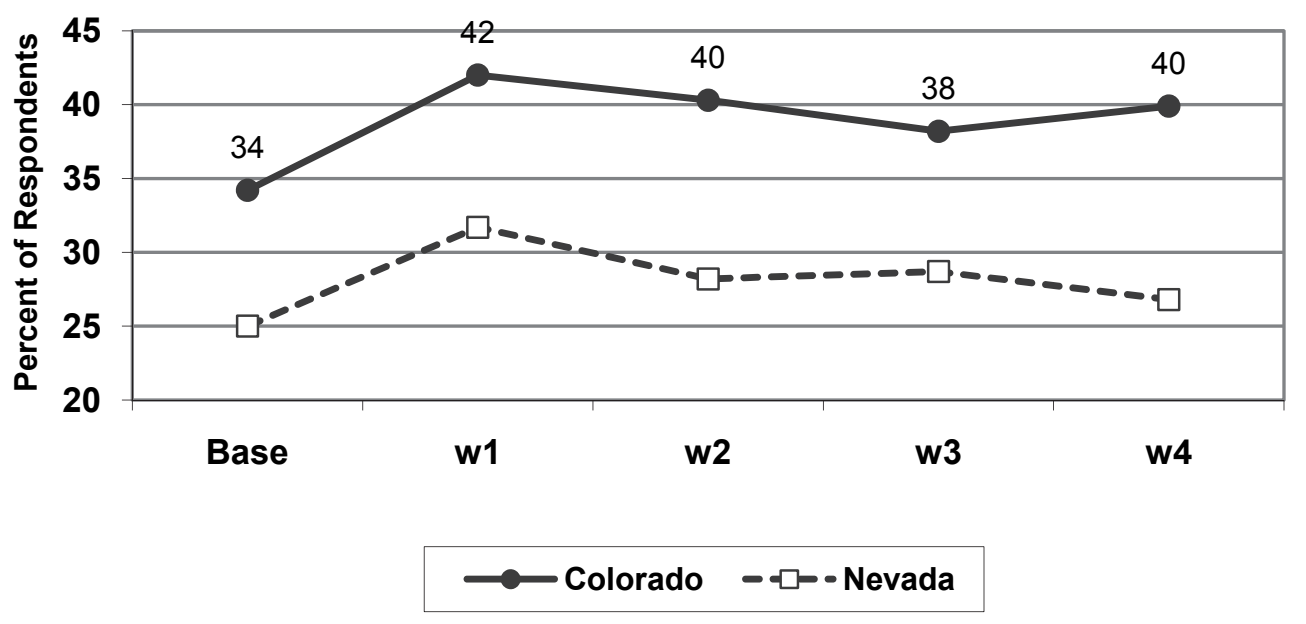

Finally, with regard to the sources of information, both States were remarkably similar with the highest baselines and largest increases associated with television (where most of the media funds were spent), followed by radio, billboards, newspapers, and enforcement itself. There was a larger increase associated with radio as a source of information in Nevada than in Colorado. Web-based and movie ads ranked relatively low (in both States) with regard to where teens said that they received their seat belt-related information. Most teens (in both States) said they were at home when they saw or heard messages to buckle up (likely from television, radio, newspa- 
pers, or the Internet). The next highest location was at school, followed by on the road. With regard to information regarding special enforcement efforts, most teens (in both States) indicated that they were at school when they read or heard about such activities, followed by at home and on the road, in that order. The patterns were remarkably similar in both States. The large proportion teens receiving information while at school suggests that some additional medium of information (e.g., an educational program or demonstration) may be a factor as well.

\subsection{Observed Seat Belt Use}

The key objective of this teen demonstration was to increase seat belt use, as measured by the observational surveys and procedures described in the Methods section. These surveys were conducted at baseline, prior to any program activity, in both States and after each program wave. In addition, in Colorado, statewide teen surveys were conducted in 2004, 2005, 2007, 2008, and 2009 and these results provide additional information with regard to change in teen belt use in that State. Following are the results of these observational surveys, beginning with Colorado.

\subsubsection{Colorado}

\subsubsection{Characteristics of Subsample (Mini) Surveys}

Numbers of Sites and Observations In Colorado, teen seat belt use data were available from 33 sites in the three media markets where the program was conducted. Twenty-eight sites were near high schools and 5 were near colleges or universities. Just over 52,600 observations of teen occupants were made at these 33 sites over the five measurement periods, which were at baseline, and after each of the four program waves (w1, w2, w3, and w4). On average there were about 10,500 observations made during each measurement period. The numbers and percentages of total observations for each measurement period are shown in Table 21.

Table 21. Colorado Teen Seat Belt Observation Frequencies, Driver and Passenger Combined

\begin{tabular}{|l|c|r|c|}
\hline Wave & Period & Frequency & Percent \\
\hline Baseline & Apr 2007 & 9,623 & 18.3 \\
\hline Wave 1 & Oct 2007 & 9,411 & 17.9 \\
\hline Wave 2 & Jan 2008 & 10,371 & 19.7 \\
\hline Wave 3 & Apr 2008 & 11,164 & 21.2 \\
\hline Wave 4 & May 2008 & 12,046 & 12.9 \\
\hline Total & & 52,615 & 100.0 \\
\hline
\end{tabular}

Sub-samples of the Statewide Teen Survey Observations were conducted at a subset of sites included in the Colorado statewide teen survey. For the baseline and wave 3 surveys, the sub-set of observations were made as part of full statewide surveys. For waves 1, 2, and 4, additional surveys were conducted using only this sub-sample of sites. To maintain consistency with the CDOT statewide survey methods, the additional surveys were restricted to the observations of teens, ages 16 through 19. 
Schools and Occupant Types Eighty-eight percent of all observations were conducted near high schools in the three targeted market areas; about $12 \%$ were conducted near colleges or universities. Seventy-three percent of all teens observed were drivers $(71 \%$ near high schools, $85 \%$ near colleges); $27 \%$ were passengers (29\% near high schools, $15 \%$ near colleges). Thus, the sample was predominantly composed of drivers in high school areas $(63 \%)$, followed by passengers in high school areas (25\%); drivers in college areas (10\%); and passengers in college areas $(2 \%)$. Younger teens, primarily 16 and 17 years old, were observed in and around high schools. Older teens 18 and 19 comprised the majority of the observations made near colleges and universities.

\subsubsection{Overall Impact}

We constructed an index of change in use in which larger volume sites were not overly represented in the sample. Thus, we weighted the results from each of the 33 sites, within each measurement period, so that each would count equally while maintaining the overall sample size. To do this, we calculated the rate of use for each site (within each wave) and multiplied that rated by the average number of observations per site (within that wave). We used these weighted data for the primary analysis of impact, using binary logistic regression. The results of this analysis are shown in Figure 33 and detailed in Table 22.

Figure 33. Weighted Teen Seat Belt Use Rates in Colorado

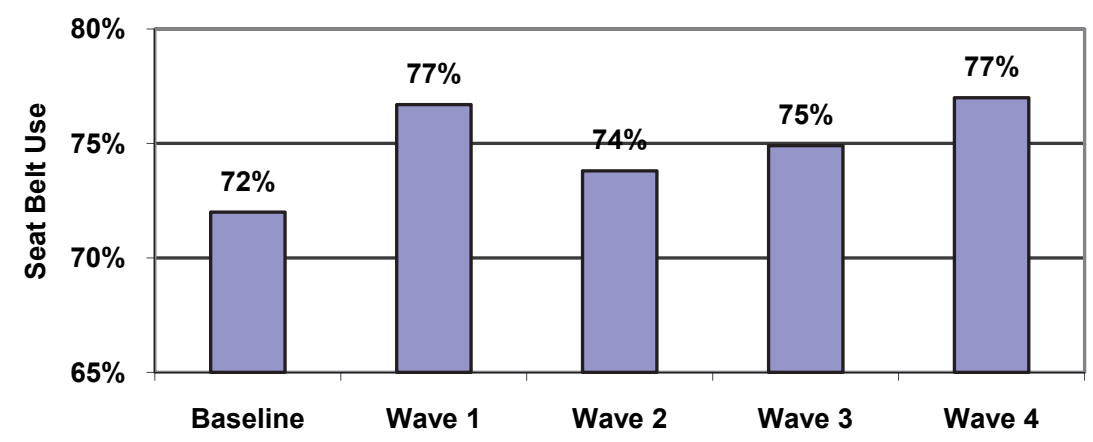

Table 22. Results of Binary Logistic Regression of Seat Belt Use Data in Colorado

\begin{tabular}{|c|c|c|c|c|c|c|c|c|c|}
\hline & \multirow[b]{2}{*}{ B } & \multirow[b]{2}{*}{ S.E. } & \multirow[b]{2}{*}{ Wald } & \multirow[b]{2}{*}{ df } & \multirow[b]{2}{*}{ Signif. } & \multirow{2}{*}{$\begin{array}{l}\text { Odds } \\
\text { Ratios }\end{array}$} & \multicolumn{2}{|c|}{ 95\% C.I. } \\
\hline & & & & & & & & Lower & Upper \\
\hline Overall Effect & & & & 91.69 & 4 & 0.000 & & & \\
\hline \multirow{5}{*}{$\begin{array}{l}\text { Effects } \\
\text { By Wave } \\
\text { (Versus } \\
\text { Baseline) }\end{array}$} & Wave 1 & 0.24 & 0.03 & 52.95 & 1 & $0.000^{*}$ & $1.27^{*}$ & 1.19 & 1.36 \\
\hline & Wave 2 & 0.09 & 0.03 & 8.05 & 1 & $0.005^{\star}$ & $1.09^{*}$ & 1.03 & 1.17 \\
\hline & Wave 3 & 0.02 & 0.03 & 22.41 & 1 & $0.000^{*}$ & $1.16^{*}$ & 1.09 & 1.23 \\
\hline & Wave 4 & 0.03 & 0.03 & 69.54 & 1 & $0.000^{*}$ & $1.30^{*}$ & 1.22 & 1.38 \\
\hline & Constant & 0.95 & 0.02 & 1736.50 & 1 & 0.000 & 2.58 & & \\
\hline
\end{tabular}

Overall, there was a significant 5-percentage-point increase in use, from $72 \%$ at baseline (in April 2007, when the most recent statewide survey was conducted) to $77 \%$ after the final program wave in May 2008. There was a strong initial effect associated with the first program wave (+6.7 points). While there was a decline from Wave 1 (October 2008) to Wave 2 (in January 
2008), use remained significantly higher than at baseline through waves 2 and 3; use then increased after Wave 4, reaching post-Wave 1 levels. As Table 22 shows, the odds ratios were significant after each program wave.

\subsubsection{Use at High School Sites, Overall and by Targeted Area}

We also examined changes in seat belt use at sites located near high schools, overall and within four designated program areas: the Denver metropolitan area (Area 1), which is served by the Denver media market; the Colorado Springs/Pueblo area (Area 2), which is south of Denver and is served by the Colorado Springs/Pueblo media market); north-central Colorado (Area 3), which is immediately north of the Denver metro area and is served by the Denver media market; and the Grand Junction/Mesa County area (Area 4), which is in far western Colorado and is served by the Grand Junction/Montrose media market.

\subsubsection{Overall (All Areas Combined)}

For these analyses, we weighted the results for each site within each wave (baseline through Wave 4), within occupant role (i.e., driver versus passenger), and within each area (1 through 4). Then, as with the overall high school analysis, we calculated the change in the odds of being buckled relative to baseline (odds ratios), and established $95 \%$ confidence intervals for these odds ratios (Wald 95\% CI).

Figure 34 shows the weighted use rates for all 28 high school sites, across each of the five waves. It shows driver use, passenger use, and combined driver and passenger use for each period. The overall rate closely follows the driver rate because drivers constituted more than $70 \%$ of the sample over the five measurement periods. Seat belt use at these sites increased significantly from baseline to Wave 1 (October 2007); declined modestly at Wave 2 (January 2008); changed little at Wave 3 (April 2008); and increased significantly at Wave 4 (May 2008). Overall, use increased by about 5 percentage points and, in spite of the decline after Wave 2, remained significantly higher after each program wave than at baseline.

Figure 34. Teen Seat Belt Use Rates Near High Schools in Colorado, By Occupant Type (weighted data)

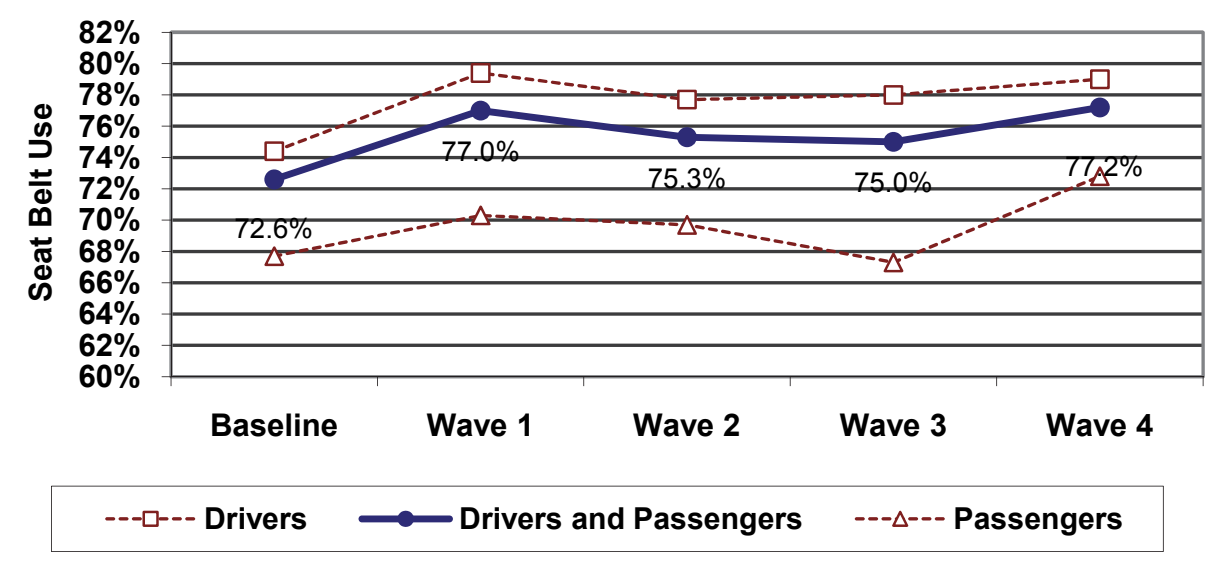


The odds of being buckled increased significantly for both teen drivers (odds ratio 1.292, 95\% $\mathrm{CI}: 1.193,1.399 ; \mathrm{p} \leq 0.05$ ) and teen passengers (odds ratio $1.279,95 \% \mathrm{CI}: 1.137,1.438 ; \mathrm{p} \leq$ 0.05). As Figure 34 shows, use among drivers was higher than among passengers throughout the program period. This gap, which averaged 8 percentage points, was greatest after Wave 3 (11 points). By the end of Wave 4, however, it was nearly the same as at baseline (6.2 points and 6.7 points, respectively). Table 23 shows the odds of seat belt use at each measurement period, odds ratios which reflect the change in odds relative to baseline, and confidence intervals for these odds ratios.

Table 23. Colorado Teen Seat Belt Use Near High Schools, Changes in the Odds of Use, Relative to Baseline After Each Program Wave

\begin{tabular}{|c|c|c|c|c|c|c|c|c|c|}
\hline & \multirow{2}{*}{$\begin{array}{c}\text { Measurement } \\
\text { Period }\end{array}$} & \multirow[b]{2}{*}{$\mathrm{n}$} & \multirow{2}{*}{$\begin{array}{c}\% \\
\text { Use }\end{array}$} & \multirow{2}{*}{$\begin{array}{l}\text { Odds } \\
\text { Of Use }\end{array}$} & \multirow{2}{*}{$\begin{array}{l}\text { Odds } \\
\text { Ratio }\end{array}$} & \multirow[b]{2}{*}{ df } & \multirow[b]{2}{*}{ S.E } & \multicolumn{2}{|c|}{ Wald $95 \%$ C.I. } \\
\hline & & & & & & & & Lower & Upper \\
\hline & Baseline & 8,226 & 72.6 & 2.654 & 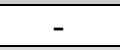 & - & - & - & - \\
\hline \multirow{4}{*}{$\begin{array}{c}\text { Effects } \\
\text { By Wave } \\
\text { Versus } \\
\text { Baseline }\end{array}$} & Wave 1 & 8,276 & 77.0 & 3.342 & $1.259^{*}$ & 1 & 0.045 & 1.173 & 1.351 \\
\hline & Wave 2 & 8,935 & 75.3 & 3.054 & $1.151^{*}$ & 1 & 0.040 & 1.075 & 1.232 \\
\hline & Wave 3 & 9,906 & 75.0 & 2.996 & $1.129^{*}$ & 1 & 0.038 & 1.056 & 1.206 \\
\hline & Wave 4 & 10,995 & 77.2 & 3.384 & $1.275^{*}$ & 1 & 0.043 & 1.194 & 1.362 \\
\hline
\end{tabular}

\subsubsection{Changes in Four Targeted Areas}

There were substantial variations in results from one program area to another and, although the sample sizes were smaller than when examining use at all 28 high school sites, the number of observations was still reasonably large, with total observations ranging from just over 1,000 per wave in Area 4 (Grand Junction) to nearly 3,500 per wave in Area 3 (North Central Colorado).

Area 1. Denver Metro Area Figure 35 shows seat belt use rates at high schools in the Denver metropolitan area. This sample consisted of 10 sites in 5 counties immediately surrounding Denver (Adams, Arapahoe, Denver, Douglas, and Jefferson). The average number of observations was just over 3,200 per wave. Here again, the overall rate closely followed the driver rate because the majority of observations were of drivers.

Figure 35. Colorado Teen Seat Belt Use Rates Near Denver Metro Area High School Sites, By Occupant Type (weighted data)

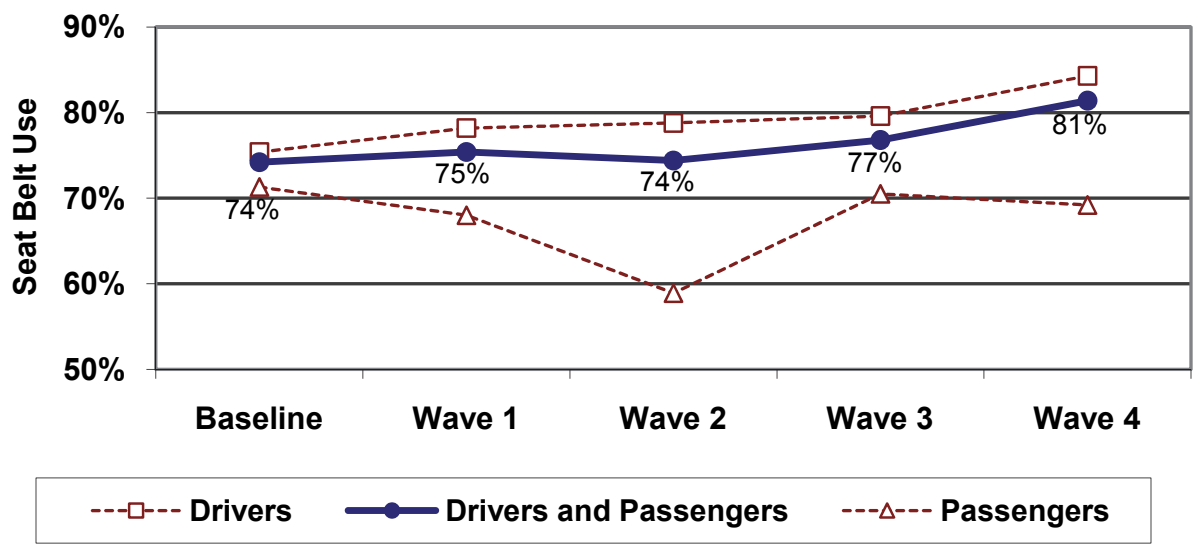


Use at these 10 sites did not increase significantly from baseline through Wave 1 or Wave 2. There was a modest but significant increase after Wave 3 that elevated use to about 3 points above the baseline rate; and there was a larger significant increase at Wave 4 that raised use to $81.4 \%$, more than 7 points above the baseline rate. Overall, the odds of being buckled up increased by about $52 \%$ from baseline to Wave 4 (from 2.87 to 4.37 ). For comparison purposes, we should note that baseline use in Area 1 was $74.2 \%$. Baseline is an important factor because it is more difficult to increase use from a higher baseline than from a lower one, and any given change in use (e.g., 5 percentage points) will result in a greater change in the odds of use from a higher baseline than from a lower one.

Seat belt use among teen drivers at these Denver-area high schools increased by about 9 percentage points, from baseline to the end of the program (odds ratio 1.754; 95\% CI: 1.524, 2.018; $\mathrm{p} \leq$ 0.05 ) and, on average, it was nearly 12 points higher than among teen passengers. This gap between driver and passenger use increased from about 4 points at baseline to nearly 20 points after Wave 2, when passenger use was measured at 59\%. Passenger use increased at Wave 3, but declined again after Wave 4, with no significant net increase over baseline levels. Had it not been for the lack of improvement in passenger use, overall increases would have been 1 - to 2 percentage points greater than those measured in this area. It should be noted that the sample sizes for passengers were quite small, especially after Wave 2, when many schools were on winter break and some of the variation in passenger use may have been influenced by the smaller number of passengers observed. Table 24 shows the odds of seat belt use, odds ratios, and the confidence intervals for these ratios following each program period.

Table 24. Colorado Teen Seat Belt Use Near High Schools in the Denver Metro Area, Changes in the Odds of Use Relative to Baseline After Each Program Wave

\begin{tabular}{|c|c|c|c|c|c|c|c|c|c|}
\hline & \multirow{2}{*}{$\begin{array}{c}\text { Measurement } \\
\text { Period }\end{array}$} & \multirow[b]{2}{*}{$\mathrm{N}$} & \multirow{2}{*}{$\begin{array}{c}\% \\
\text { Use }\end{array}$} & \multirow{2}{*}{$\begin{array}{l}\text { Odds } \\
\text { Of Use }\end{array}$} & \multirow{2}{*}{$\begin{array}{l}\text { Odds } \\
\text { Ratio }\end{array}$} & \multirow[b]{2}{*}{ df } & \multirow[b]{2}{*}{ S.E } & \multicolumn{2}{|c|}{ Wald $95 \%$ C.I. } \\
\hline & & & & & & & & Lower & Upper \\
\hline & Baseline & 3,513 & 74.2 & 2.873 & - & - & - & - & - \\
\hline \multirow{4}{*}{$\begin{array}{c}\text { Effects } \\
\text { By Wave } \\
\text { Versus } \\
\text { Baseline }\end{array}$} & Wave 1 & 2,535 & 75.4 & 3.069 & 1.068 & 1 & 0.064 & 0.949 & 1.202 \\
\hline & Wave 2 & 2,444 & 74.4 & 2.904 & 1.011 & 1 & 0.061 & 0.898 & 1.138 \\
\hline & Wave 3 & 4,578 & 76.8 & $3.319^{*}$ & 1.155 & 1 & 0.060 & 1.043 & 1.279 \\
\hline & Wave 4 & 3,249 & 81.4 & $4.370^{*}$ & 1.521 & 1 & 0.090 & 1.154 & 1.709 \\
\hline
\end{tabular}

Area 2. Colorado Springs/Pueblo Area Figure 36 shows seat belt use rates in Area 2. This sample consisted of 5 sites in El Paso and Pueblo counties. Relative to Area 1, this was a small number of sites, but the average number of observations was just over 3,200 per wave. Again, the overall (driver + passenger) use rate closely followed the driver rate. Although use increased from about $60 \%$ to $63 \%$, from baseline to Wave 1, this change was not statistically significant. As in the Denver area, use did not increase to levels that were significantly above baseline until Wave 3, when there was a large and significant 6-point increase in use and when the odds of being buckled increased by about $44 \%$.

The baseline use rate in this area (about 60\%) was substantially lower than in Area 1 (74\%). After peaking at Wave 3, use declined significantly ( -4 points) and the odds ratio from Wave 3 to Wave 4 was $0.831(95 \%$ CI: $0.725,0.952 ; \mathrm{p}<0.05)$, indicating that the odds of being buckled 
had declined by $17 \%$. In spite of this decline, Table 25 shows that the odds of use remained significantly (19\%) higher at Wave 4 than at baseline. Thus, as in Area 1, use was significantly elevated over the two final waves of the program.

Figure 36. Colorado Teen Seat Belt Use Rates Near Colorado Springs/Pueblo High Schools, by Occupant Type (weighted data)

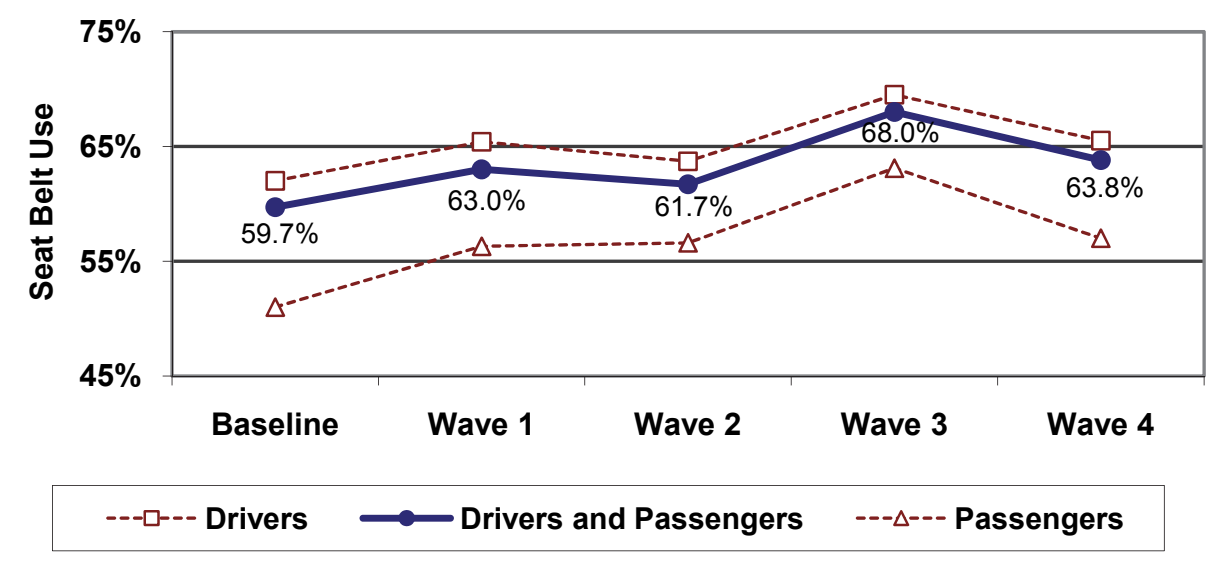

Driver use increased significantly, by about 8 percentage points, from baseline to Wave 3 (odds ratio $1.395 ; 95 \% \mathrm{CI}: 1.152,1.690 ; \mathrm{p} \leq 0.05)$. However, following a decline from Wave 3 to Wave 4, the ratio was no longer significantly different from baseline. Similarly, use among passengers increased significantly from baseline to Wave 3 (odds ratio 1.629; 95\% CI: 1.202, 2.208, $\mathrm{p}<0.05$ ) but, following a decline at Wave 4 , passenger use was no longer significantly different from baseline. The fact that the rate of the combined group was significantly higher at Wave 4 was due to the larger sample associated with this aggregate group.

On average, seat belt use among teen drivers in the Colorado Springs/Pueblo area was about 8.4 points higher than among teen passengers. This gap declined from about 11 points at baseline to about 6 points at Wave 3, before increasing slightly at the Wave 4 measurement. As Figure 36 shows, the gap between driver and passenger seat belt use generally decreased during the course of the program, particularly from baseline through Wave 3.

Table 25. Colorado Teen Seat Belt Use Near Colorado Springs/Pueblo High Schools, Changes in the Odds of Use Relative to Baseline After Each Program Wave

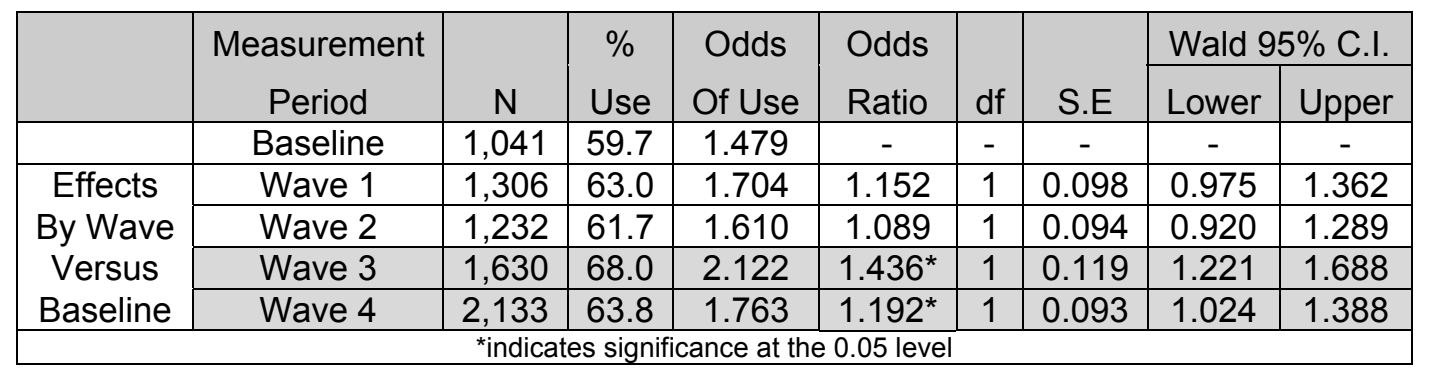


Area 3. North-Central Colorado Figure 37 shows seat belt use rates in Area 3. This sample consisted of 10 high school sites in Boulder, Broomfield, Larimer, and Weld counties. This area had the highest baseline use rate $(78 \%)$ and, in spite of this relatively high rate, it experienced a significant (6.4 point) increase in use associated with Wave 1. However, declines at the Wave 2 and Wave 3 measurement periods, left overall use at levels that were not significantly different from baseline during these two program periods. A two-point increase associated with the final wave increased seat belt use to a level that was again significantly greater than at baseline, although not quite as high as after the first program wave. Thus, there were significant gains associated with the first and the fourth program periods and it was only during these two periods that teen seat belt use was significantly higher than at baseline. However, use throughout the program period was high, relative to other areas, ranging from $77 \%$ (after Wave 3 ) to $85 \%$ (after Wave 1).

Figure 37. Colorado Teen Seat Belt Use Rates Near North Central Colorado High Schools, By Occupant Type (weighted data)

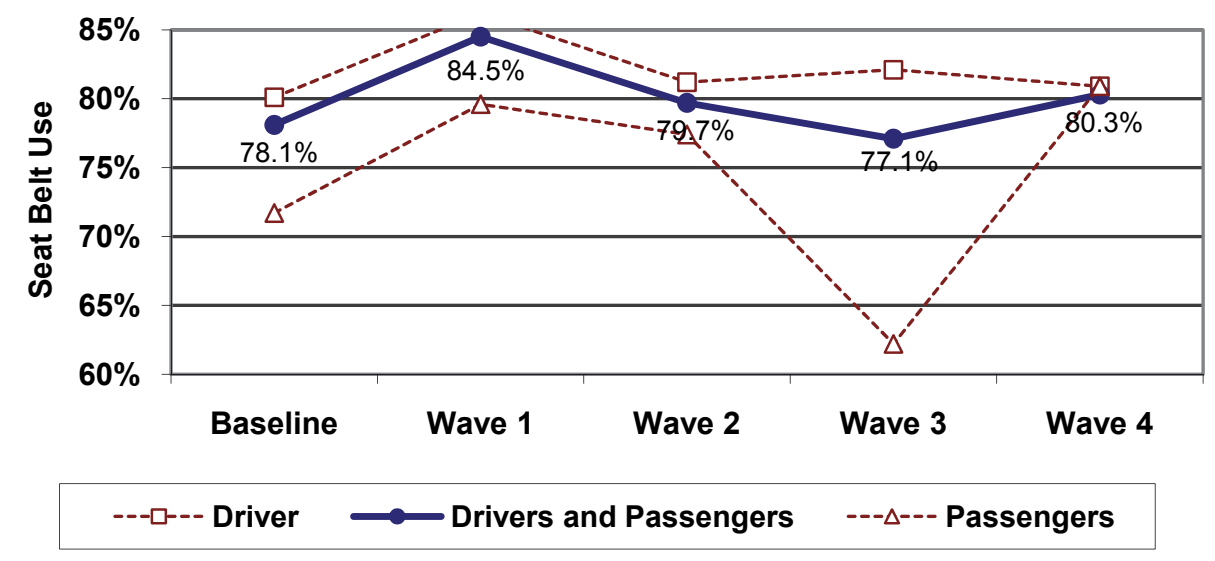

Driver use increased significantly, by about 6 points, from baseline to Wave 1 (odds ratio 1.547; 95\% CI: $1.316,1.819, \mathrm{p}<0.05$ ); then declined by about 5 points at Wave 2; and remained relatively unchanged (and not significantly different from baseline) throughout the remainder of the evaluation period. Similarly, passenger belt use increased significantly from baseline to Wave 1 (odds ratio 1.545; 95\% CI: $1.220,1.958 ; \mathrm{p}<0.05$ ); then declined modestly at Wave 2 and substantially at Wave 3, leaving passenger use far below baseline levels at that point. ${ }^{12}$ By the end of Wave 4 , however, passenger use had increased to over $80 \%$, equal to the driver rate.

On average, seat belt use among teen drivers in area 3 was about 8 points higher than among teen passengers. This average was highly influenced by the 20 -point difference at Wave 3 . Omitting that data point, Figure 37 shows that the gap between driver and passenger use declined steadily, from 8 points (at baseline), to 7 points (at Wave 1), to 4 points (at Wave 2), to zero (at Wave 4). This narrowing of the difference between driver and passenger use rates is similar to that seen in Area 2. It suggests that teen passengers, who typically use seat belts significantly less often than

\footnotetext{
${ }^{12}$ This very low rate was influenced by one site with " 0 " belt users and " 7 " non-users and this effect was magnified by the weighting procedure. However, even if that site is removed from the calculation, use declined from $77 \%$ (w2) to $69 \%$ (w3) for this group. Thus, the precipitous decline in passenger use at this measurement period was not simply the result of this anomaly.
} 
teen drivers, may have been affected more than teen drivers. Again, however, the dip in use at Wave 3 remains unexplained.

Table 26. Colorado Teen Seat Belt Use Near High Schools in North Central Colorado, Changes in the Odds of Use Relative to Baseline After Each Program Wave

\begin{tabular}{|c|c|c|c|c|c|c|c|c|c|}
\hline & \multirow{2}{*}{$\begin{array}{l}\text { Measurement } \\
\text { Period }\end{array}$} & \multirow[b]{2}{*}{$\mathrm{N}$} & \multirow{2}{*}{$\begin{array}{c}\% \\
\text { Use }\end{array}$} & \multirow{2}{*}{$\begin{array}{l}\text { Odds } \\
\text { Of Use }\end{array}$} & \multirow{2}{*}{$\begin{array}{l}\text { Odds } \\
\text { Ratio }\end{array}$} & \multirow[b]{2}{*}{ df } & \multirow[b]{2}{*}{ S.E } & \multicolumn{2}{|c|}{ Wald $95 \%$ C.I. } \\
\hline & & & & & & & & Lower & Uppe \\
\hline & Baseline & 2,604 & 78.1 & 3.568 & - & - & - & - & - \\
\hline \multirow{4}{*}{$\begin{array}{c}\text { Effects } \\
\text { By Wave } \\
\text { Versus } \\
\text { Baseline }\end{array}$} & Wave 1 & 3,188 & 84.5 & 5.467 & $1.532^{\star}$ & 1 & 0.104 & 1.340 & 1.751 \\
\hline & Wave 2 & 4,258 & 79.7 & 3.917 & 1.098 & 1 & 0.067 & 0.974 & 1.237 \\
\hline & Wave 3 & 2,655 & 77.1 & 3.374 & 0.949 & 1 & 0.063 & 0.831 & 1.077 \\
\hline & Wave 4 & 4,648 & 80.3 & 4.085 & $1.145^{*}$ & 1 & 0.069 & 1.018 & 1.288 \\
\hline
\end{tabular}

Area 4. Grand Junction/Mesa County Figure 38 shows seat belt use rates in Area 4. This sample consisted of three high school sites in Mesa County. Starting with the second lowest baseline rate, the Grand Junction/Mesa County sample provided the largest overall increase (10.6 points) associated largely with increases at Wave 1 and Wave 4. There were no significant increases or decreases associated with Wave 2 or Wave 3. As a result, use throughout the program period remained significantly higher than at baseline (see Table 27 ).

Figure 38. Colorado Teen Seat Belt Use Rates Near Grand Junction/Mesa County High Schools, by Occupant Type (weighted data)

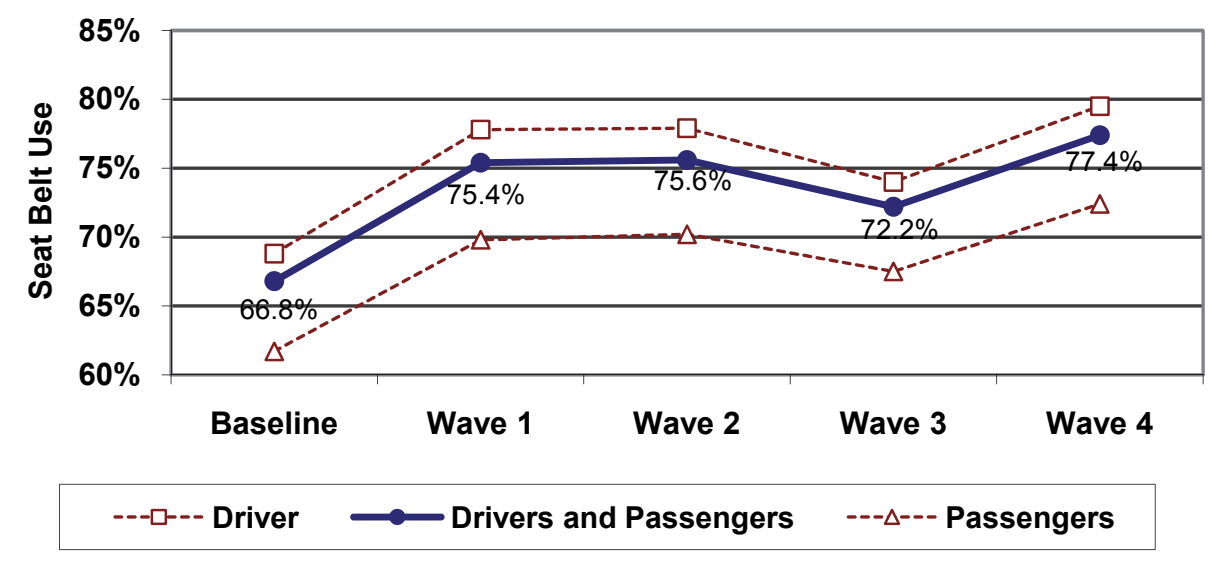

As Figure 38 shows, driver use was consistently higher than passenger use, by about 7 percentage points, throughout all four waves. Both rates increased or decreased in nearly a parallel fashion, suggesting that both groups were affected equally by the program. Overall, both driver and passenger use increased by 10.7 percentage points The odds of seat belt use among drivers increased by $75 \%$ (odds ratio $1.750 ; 95 \% \mathrm{CI}: 1.375,2.226 ; \mathrm{p}<0.05$ ) and the odds of seat belt use among passengers increased by $63 \%$ (odds ratio $1.63 ; 95 \% \mathrm{CI}: 1.151,2.310 ; \mathrm{p}<0.05$ ). This area, which had the fewest number of sites, produced the largest and most consistent effects, overall and among the driver and passenger sub-samples. 
Table 27. Colorado Teen Seat Belt Use Near Grand Junction/Mesa County High Schools, Changes in the Odds of Use Relative to Baseline After Each Program Wave

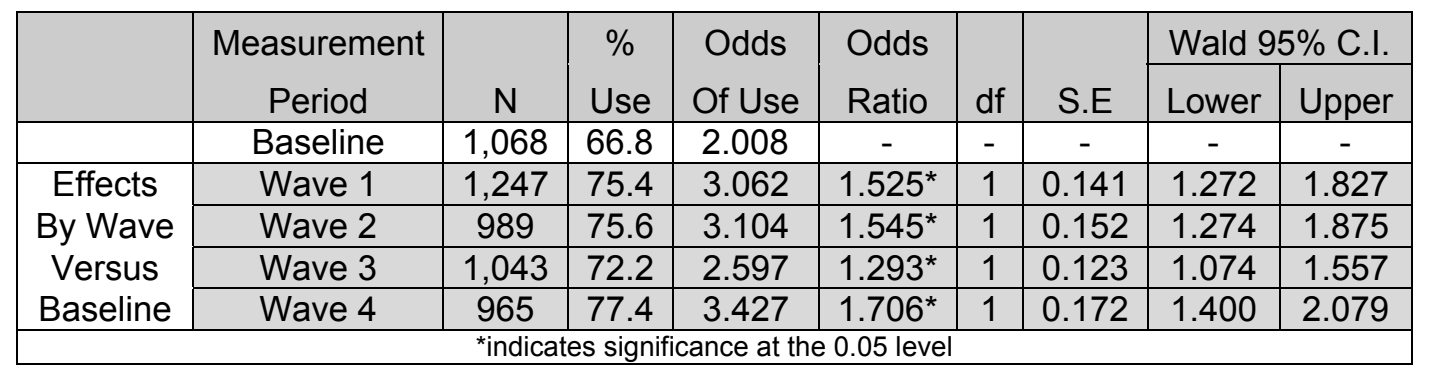

In summary of use at high-school-related sites, Figure 39 shows the increases relative to baseline after each program wave, within each targeted area. Based on this figure, the greatest impact in Area 1 (Denver area) was associated with Wave 4, followed by Wave 3. In Area 2 (Colorado Springs), the greatest impact was associated with Wave 3, followed by Wave 4 and then Wave 1. In Area 3 (North Central Colorado), the greatest impact was associated with Wave 1, followed by Wave 4 and Wave 2). Finally, in Area 4 (Grand Junction), the greatest impact was associated with Wave 4, followed by Wave 2 and Wave 1. Over all areas, the greatest average impact (i.e., the sum of changes at each wave divided by 4) was associated with Wave 4, followed by Wave 1 , Wave 3, and Wave 2, in that order.

Figure 39. Percentage-Point Increases in Colorado Teen Seat Belt Use, Relative to Baseline Levels by Program Area

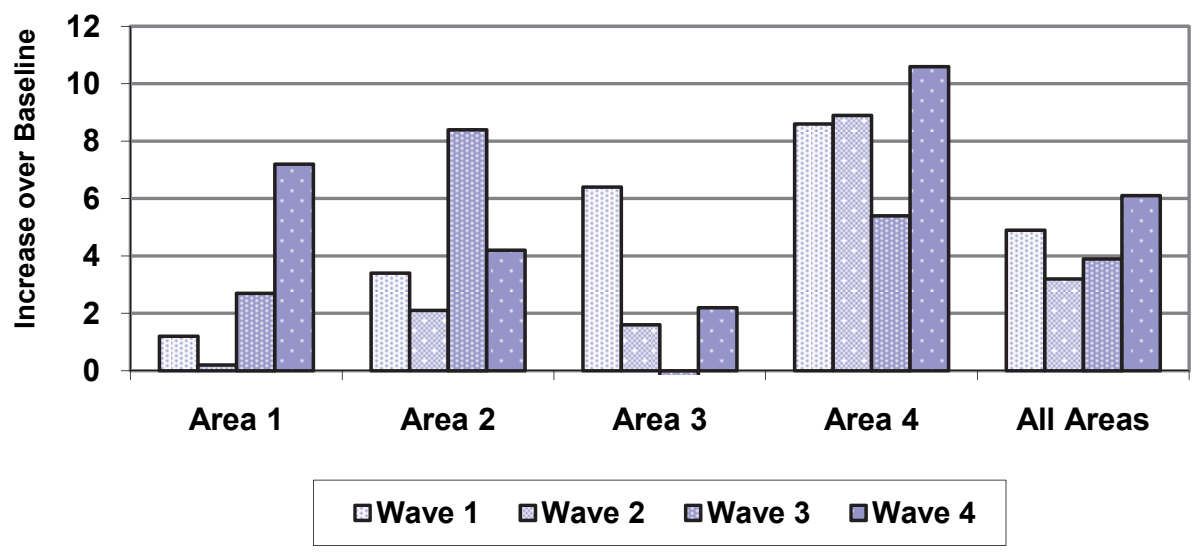


Figure 40. Overall Seat Belt Use Rates of Colorado Teens, By Program Area (percentage use)

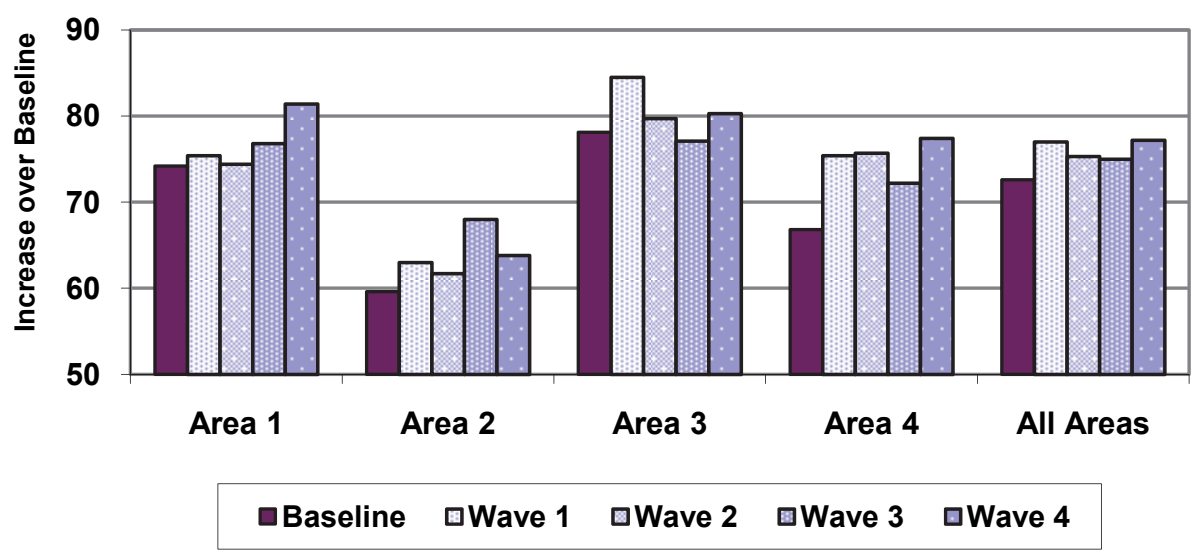

The above figure shows the change for each area in terms of actual use rates. In Area 1, baseline use was just over 74\% and it did not increase significantly until Wave 3, when it reached 77\% and then $81 \%$ after Wave 4 . Baseline use in the Colorado Springs area was lower, at about $60 \%$. There was an increase at Wave 1 to about 63\%; the first significant gain was at Wave 3, when use reached 68\%. Baseline use was highest in the North Central Region (78\%), increasing significantly to $85 \%$ at Wave 1 ; then settling down to levels that were very close to baseline. In the Grand Junction area, baseline use was a modest $67 \%$, significantly increasing to $75 \%$ at Wave 1 , $76 \%$ at Wave 2 , and $77 \%$ at Wave 4 . Overall, high school use increased from about $73 \%$ at baseline to $77 \%$ at Wave $1,75 \%$ at Wave 2 and Wave 3, and $77 \%$ at Wave 4 . Waves 2 and 4 , on average, had the highest use rates.

\subsubsection{Use at Colleges and Universities}

Five college or university sites were included in the sample. These sites were located in Area 1 (1 site), Area 2 (2 sites), Area 3 (1 site) and Area 4 (1 site). All of these sites were combined for analysis and weighted by the average number of observations per wave. This sample of college versus high school sites is the only source of information with regard to the impact of the Teen Seat Belt Demonstration Project on older teens (likely to be predominantly 18 to 20 years old). ${ }^{13}$

Baseline use at the 5 college and university sites was about $71 \%$, midway between the various high school area averages (60\% in Area 2, 67\% in Area 4, 74\% in Area 1, and 78\% in Area 3) and just slightly lower than the overall high school average of $73 \%$. As with use in high school areas, use around colleges was largely driven by use among drivers who constituted the majority $(85 \%)$ of the sample.

\footnotetext{
${ }^{13}$ This was also the case in Nevada, where 5 sites that were located near colleges or universities provided an index of use among older teens.
} 
Figure 41. Colorado Teen Seat Belt Use Rates Near Colleges or Universities, By Occupant Type (weighted data)

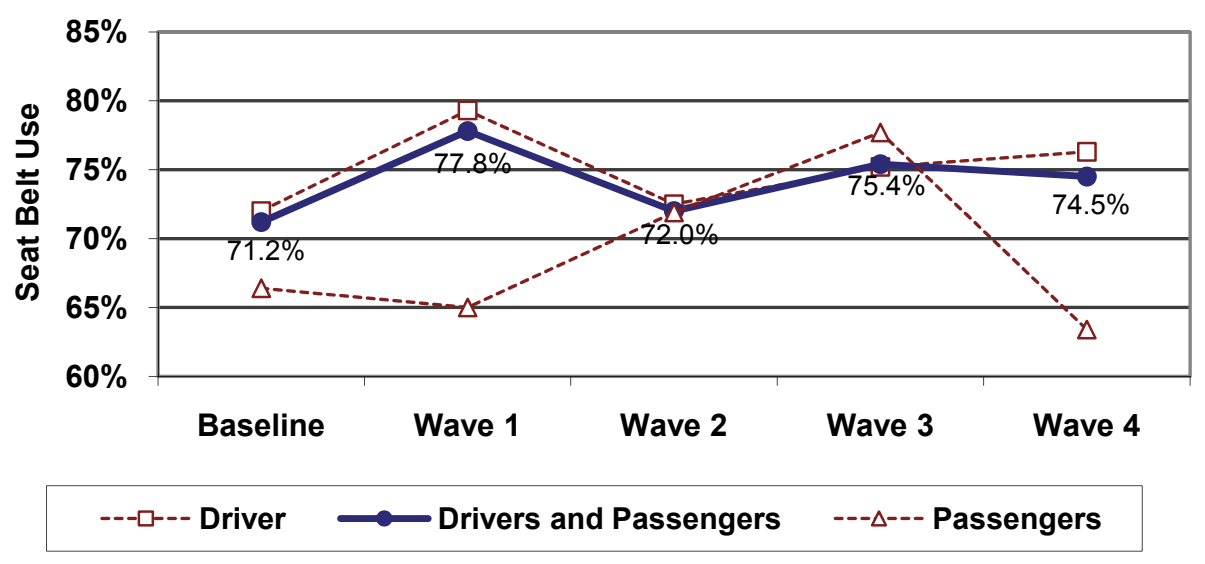

Figure 41 shows that there was a large initial effect associated with Wave 1; a decline measured after Wave 2 (January 2008); another increase measured after Wave 3 (March 2008); and little change after Wave $4 .{ }^{14}$ Post-wave measurements that showed seat belt use to be significantly higher than at baseline were at Wave 1 and Wave 3, although the Wave 4 level was near significant (see Table 28). The odds of being buckled up, relative to the baseline period, were increased by $42 \%$ higher after Wave 1 and by $24 \%$ higher after Wave 3 .

Driver use and trends were nearly identical to overall use and trends, while passenger use varied. Passenger use was very similar to driver use at baseline, Wave 2, and Wave 3. However, it reflected no impact at Wave 1, apparently the most powerful wave among drivers, and it declined precipitously at Wave 4 (when most students had likely left the campus at the end of the school year). The number of passenger observations at each wave averaged about 200. This small size, combined with the exodus of students at the end of school year provides some rationale for the drop in passenger use after Wave 4 (although it is not clear why the driver rate remained unchanged). It is not clear why passengers showed no increase in use after Wave 1. Variation due to a small sample provides one possible explanation. The possibility that passengers simply were not affected by the program at that point is another possibility.

Table 28. Colorado Teen Seat Belt Use Near Colleges and Universities by Occupant Type, Changes in the Odds of Use Relative to Baseline After Each Program Wave

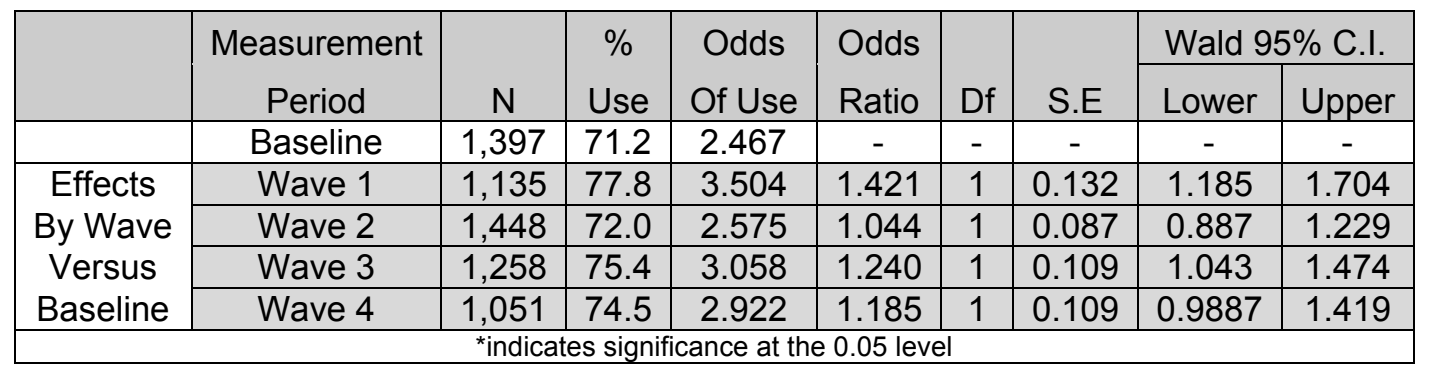

\footnotetext{
${ }^{14}$ As with all of the high school analyses, we cannot estimate the actual impact of any wave after Wave 1 . That is because, without pre-wave baseline surveys, we have no estimate of use just before the wave began. Thus, we can only estimate post-wave to post-wave changes.
} 


\subsubsection{A Comparison of Results From High Schools and Colleges}

Figure 42 shows the use rate trends in the 28 sites located near high schools and in the 5 sites located near colleges and universities in Colorado. Because each of these sites was observed in a consistent manner throughout the program period, they provide an index of change in these two environments.

\section{Figure 42. Colorado Teen Seat Belt Use Rates, High Schools} Versus Colleges and Universities

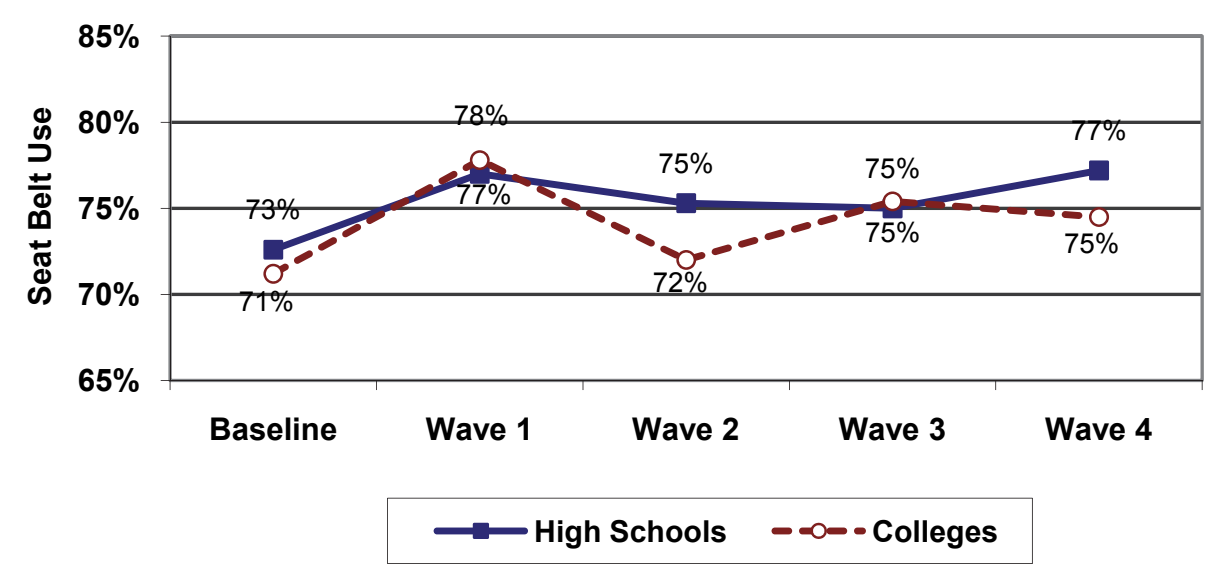

Use at college sites varied slightly more than at high school sites, increasing more (from a slightly lower baseline) at Wave 1; declining more at Wave 2 (immediately following winter break at most schools); experiencing nearly identical rates as high schools at Wave 3 (March 2008); and showing no gains in May 2008 (when many students had left their campuses at the end of the academic year). ${ }^{15}$ Meanwhile, use at high schools increased significantly with the first program activity; maintained most gains through waves 2 and 3; and then increased again with the final wave in May 2008.

Both high school and college students increased their use during the nine-month program period. As indicated, the greatest impact on high school students (primarily younger teens) was in conjunction with Wave $1(+4.3$ points) and Wave $4(+4.6$ points); the greatest impact on college students (primarily older teens) appears to have been in conjunction with Wave $1(+6.6$ points) and Wave 3 ( +4.2 points), with near-significant impact at Wave 4 ( +3.3 points). Each of these gains is relative to baseline levels.

Thus, at the end of the program, use at high school sites was 4.6 points greater than at baseline and use at college sites was 3.3 points greater than at baseline. Over all four waves of the program, however, the average increases over baseline were very similar $(+3.5$ points at the 28 high school sites and +3.8 points at the 5 college sites).

\footnotetext{
${ }^{15}$ Media and enforcement occurred January 11 to 20; observational surveys were conducted January 22 to February 5. High schools resumed classes on Monday, January 5; most colleges and universities resumed classes on January 12.
} 
Figure 43. Increases in Colorado Teen Seat Belt Use Relative to Baseline Levels Near 28 High School Sites and 5 College and University Sites

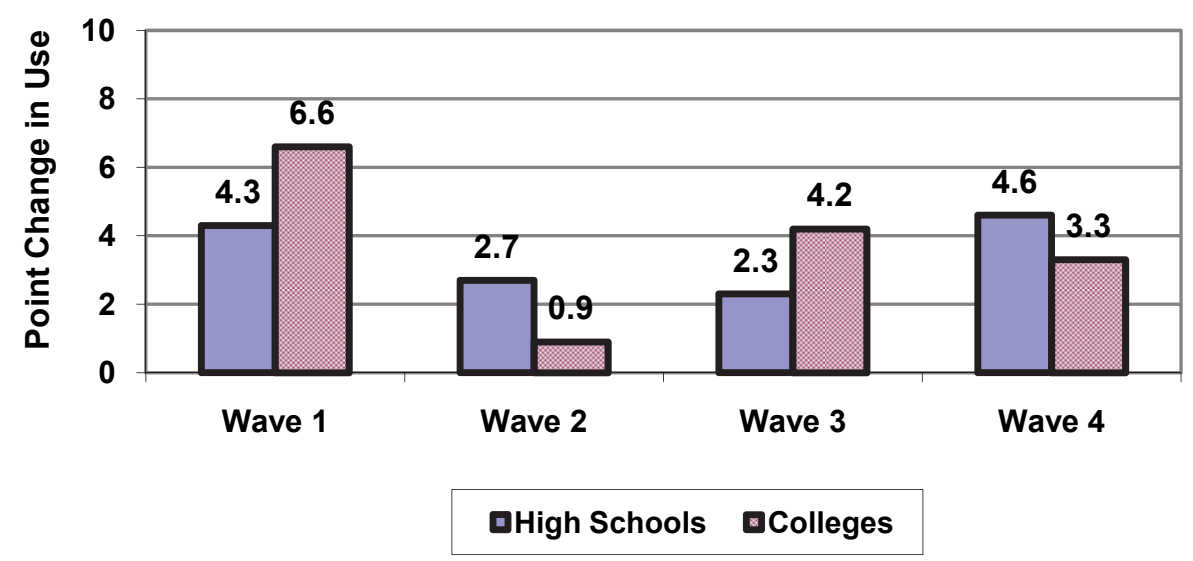

\subsubsection{Changes in Use by Vehicle Type}

We also examined changes in use rates by vehicle type. For this analysis, we combined all 33 sites and weighted them within each measurement period (baseline and waves 1 through 4). Passenger cars constituted $58.1 \%$ of the sample; sport utility vehicles (SUVs) accounted for $25 \%$; pickup trucks accounted for 11\%; and vans accounted for about 5\%. Seat belt use for all vehicle types is shown in Figure 44. Passenger cars are in bold font because they constitute the majority of vehicles. Odds ratios are provided in Table 29.

Figure 44. Colorado Teen Seat Belt Use Rates in Cars and Pickup Trucks

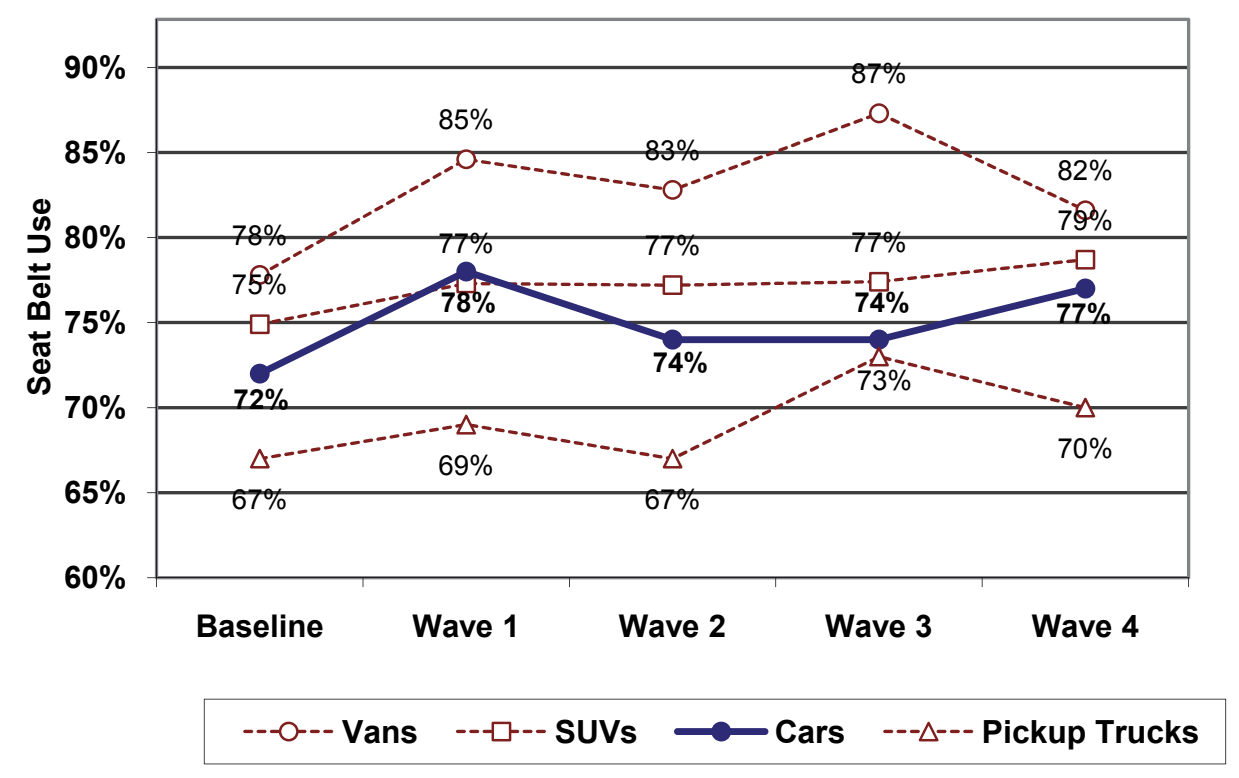


Passenger Cars Use among occupants of cars increased significantly after Wave 1 (odds ratio $1.318 ; 95 \%$ CI: $1.210,1.437 ; \mathrm{p}<0.05)$ and remained significantly elevated throughout the evaluation period (in spite of a decline immediately after Wave 2).

Sport Utility Vehicles Use in SUVs was similar to use in passenger cars, although there was a slightly higher baseline rate for SUVs (75\% versus 72\%); a smaller increase after Wave $1(+2$ points versus +6 points); and little change associated with subsequent waves. Usage was significantly elevated after every wave of activity. After Wave 4, for example, usage was 78.7\%, compared with $74.9 \%$ at baseline (odds ratio 1.240; 95\% CI: 1.095, 1.405; $\mathrm{p}<0.05$ ).

Pickup Trucks Use in pickups was lower than for any other vehicle type and such use did not change significantly until Wave 3, when there was a large and significant increase from $67.4 \%$ to $73.3 \%$ (odds ratio 1.353 ; $95 \% \mathrm{CI}: 1.131,1.618$; $\mathrm{p}<0.05$ ). That increase was followed by a nearsignificant decline measured after Wave 4 . Thus, the only period when use in pickups was significantly above baseline was immediately after Wave 3.

Vans Occupants of vans had the highest seat belt use rate at baseline and throughout the program period although there was a decline from post-Wave 3 to post-Wave 4 . The highest rate (after Wave 3) was 87.3\%, compared with $77.8 \%$ at baseline (odds ratio $1.963 ; 95 \%$ CI: 1.441 , $2.674 ; \mathrm{p}<0.05)$

Table 29. Colorado Teen Seat Belt Use in Passenger Vehicles, Relative to Baseline and Program Wave

\begin{tabular}{|c|c|c|c|c|c|c|c|c|c|}
\hline & \multirow{2}{*}{$\begin{array}{c}\text { Measurement } \\
\text { Period }\end{array}$} & \multirow[b]{2}{*}{$\mathrm{N}$} & \multirow{2}{*}{$\begin{array}{c}\% \\
\text { Use }\end{array}$} & \multirow{2}{*}{$\begin{array}{l}\text { Odds } \\
\text { Of Use }\end{array}$} & \multirow{2}{*}{$\begin{array}{l}\text { Odds } \\
\text { Ratio }\end{array}$} & \multirow[b]{2}{*}{ df } & \multirow[b]{2}{*}{ S.E. } & \multicolumn{2}{|c|}{ Wald $95 \%$ C.I. } \\
\hline & & & & & & & & Lower & Upper \\
\hline \multirow{5}{*}{$\begin{array}{c}\text { Cars } \\
\text { Effects } \\
\text { By Wave } \\
\text { Versus } \\
\text { Baseline } \\
\end{array}$} & Baseline & 5,608 & 72.4 & 2.618 & 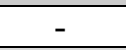 & - & - & - & - \\
\hline & Wave 1 & 5,551 & 77.5 & 3.451 & $1.318^{*}$ & 1 & 0.058 & 1.210 & 1.437 \\
\hline & Wave 2 & 6,019 & 74.1 & 2.858 & $1.092^{*}$ & 1 & 0.046 & 1.006 & 1.185 \\
\hline & Wave 3 & 6,413 & 74.4 & 2.901 & $1.108^{*}$ & 1 & 0.046 & 1.022 & 1.202 \\
\hline & Wave 4 & 6,941 & 76.8 & 3.311 & $1.265^{*}$ & 1 & 0.052 & 1.167 & 1.371 \\
\hline \multirow{5}{*}{$\begin{array}{c}\text { SUVs } \\
\text { Effects } \\
\text { By Wave } \\
\text { Versus } \\
\text { Baseline } \\
\end{array}$} & Baseline & 2,437 & 74.9 & 2.982 & - & - & - & - & - \\
\hline & Wave 1 & 2,390 & 77.3 & 3.410 & $1.143^{*}$ & 1 & 0.077 & 1.002 & 1.305 \\
\hline & Wave 2 & 2,715 & 77.2 & 3.386 & $1.136^{n}$ & 1 & 0.074 & 0.999 & 1.291 \\
\hline & Wave 3 & 2,822 & 77.4 & 3.430 & $1.150^{*}$ & 1 & 0.075 & 1.013 & 1.308 \\
\hline & Wave 4 & 3,162 & 78.7 & 3.698 & $1.240^{*}$ & 1 & 0.079 & 1.095 & 1.405 \\
\hline \multirow{5}{*}{$\begin{array}{c}\text { Trucks } \\
\text { Effects } \\
\text { By Wave } \\
\text { Versus } \\
\text { Baseline } \\
\end{array}$} & Baseline & 1,089 & 66.9 & 2.025 & - & - & - & - & - \\
\hline & Wave 1 & 971 & 69.1 & 2.237 & $1.105^{*}$ & 1 & 0.105 & 0.917 & 1.330 \\
\hline & Wave 2 & 1,050 & 67.4 & 2.070 & 1.022 & 1 & 0.094 & 0.853 & 1.225 \\
\hline & Wave 3 & 1,219 & 73.3 & 2.739 & $1.365^{*}$ & 1 & 0.124 & 1.131 & 1.618 \\
\hline & Wave 4 & 1,279 & 70.1 & 2.348 & 1.160 & 1 & 0.103 & 0.974 & 1.380 \\
\hline \multirow{5}{*}{$\begin{array}{c}\text { Vans } \\
\text { Effects } \\
\text { By Wave } \\
\text { Versus } \\
\text { Baseline }\end{array}$} & Baseline & 478 & 77.8 & 3.509 & - & - & - & - & - \\
\hline & Wave 1 & 442 & 84.6 & 5.500 & $1.567^{*}$ & 1 & 0.269 & 1.119 & 2.195 \\
\hline & Wave 2 & 587 & 82.8 & 4.812 & $1.371^{*}$ & 1 & 0.213 & 1.012 & 1.859 \\
\hline & Wave 3 & 710 & 87.3 & 6.889 & $1.963^{*}$ & 1 & 0.309 & 1.441 & 2.674 \\
\hline & Wave 4 & 636 & 81.6 & 4.436 & 1.264 & 1 & 0.190 & 0.941 & 1.697 \\
\hline
\end{tabular}


In summary of use and changes in use by vehicle type, the Colorado teen program was associated with significant increases in use in all four vehicle types, although not similarly throughout the program period. Use in cars and SUVs was consistently higher than at baseline (i.e., during all program periods); ${ }^{16}$ the largest wave-to-wave gain was among occupants of vans $(+9.5$ points at Wave 3 ) and occupants of pickup trucks (+6.3 points at Wave 3$)$.

Wave 1 was associated with significant gains among occupants of cars, SUVs, and vans, but not among occupants of pickup trucks. Wave 2 was associated with declines in use in all vehicle types; Wave 3 was associated with the greatest increases among occupants of vans and trucks; and Wave 4 was followed by declines in use in vans and pickups, but modest increases in cars and SUVs. Table 30 provides a summary of use levels and changes, by vehicle type and by program wave. Key outcomes, such as the highest use rates for each vehicle type, greatest wave-towave changes and cumulative changes in use, are highlighted. Also included in the upper-right corner of Table 30 are final change from baseline at Wave 4 and maximum change from baseline regardless of wave, along with the wave when the maximum change occurred.

Table 30. Summary of Teen Seat Belt Use Rate and Change in Colorado by Vehicle Type

\begin{tabular}{|c|c|c|c|c|c|c|c|c|}
\hline $\begin{array}{c}\text { Vehicle } \\
\text { Type }\end{array}$ & B & w1 & w2 & W3 & w4 & \multicolumn{3}{|c|}{$\begin{array}{l}\text { Final and Max. Gains } \\
\text { Relative to Baseline }\end{array}$} \\
\hline & \multicolumn{5}{|c|}{ Observed Use Rate } & W4 & Max. & Wave \\
\hline Cars & $72.4 \%$ & $77.5 \%$ & $74.1 \%$ & $74.4 \%$ & $76.8 \%$ & +4.4 & +5.2 & w1 \\
\hline SUVs & $77.8 \%$ & $84.6 \%$ & $82.8 \%$ & $87.3 \%$ & $81.6 \%$ & +3.8 & +3.8 & w4 \\
\hline Trucks & $66.9 \%$ & $69.1 \%$ & $67.4 \%$ & $73.3 \%$ & $70.1 \%$ & +3.2 & +6.3 & w3 \\
\hline Vans & $77.8 \%$ & $84.6 \%$ & $82.8 \%$ & $87.3 \%$ & $81.6 \%$ & +3.8 & +9.5 & w3 \\
\hline \multicolumn{9}{|c|}{ Wave-to-Wave Change (percentage points) } \\
\hline Cars & \multirow{4}{*}{$\mathrm{n} / \mathrm{a}$} & $+5.2^{*}$ & $-3.5^{*}$ & +0.3 & $+2.4^{*}$ & \multirow{4}{*}{\multicolumn{3}{|c|}{$\mathrm{n} / \mathrm{a}$}} \\
\hline SUVs & & $+2.4^{*}$ & -0.1 & +0.2 & +1.3 & & & \\
\hline Trucks & & +2.2 & -1.7 & $+5.8^{*}$ & -3.1 & & & \\
\hline Vans & & $+6.8^{*}$ & -1.8 & $+4.5^{*}$ & $-5.7^{*}$ & & & \\
\hline \multicolumn{6}{|c|}{ Cumulative Change Relative to Baseline } & Ave. & \multirow{5}{*}{\multicolumn{2}{|c|}{$\mathrm{n} / \mathrm{a}$}} \\
\hline Cars & \multirow{4}{*}{$\mathrm{n} / \mathrm{a}$} & $+5.2^{*}$ & $+1.7^{*}$ & $+2.0^{*}$ & $+4.4^{*}$ & +3.3 & & \\
\hline SUVs & & $+2.4^{*}$ & +2.3 & $+2.5^{*}$ & $+3.8^{*}$ & +2.8 & & \\
\hline Trucks & & +2.2 & +0.5 & $+6.3^{*}$ & +3.2 & +3.0 & & \\
\hline Vans & & $+6.8^{*}$ & $+5.0^{*}$ & $+9.5^{*}$ & +3.8 & +6.3 & & \\
\hline \multicolumn{9}{|c|}{$\begin{array}{l}\text { Notes: "Final" refers to change at Wave 4, relative to baseline; "Max." refers to maximum } \\
\text { gain relative to baseline (regardless of wave); "*” designates a significant result ( } \leq \leq \\
0.05) \text {; "Wave-to-Wave Change" refers to change from one wave to the next; "Cumulative } \\
\text { Change" refers to change at any wave, relative to baseline; shaded cells represent } \\
\text { highest rate or greatest gain. }\end{array}$} \\
\hline
\end{tabular}

\subsubsection{Colorado Statewide Teen Seat Belt Use Surveys}

The Institute of Transportation Management at the Colorado State University (CSU) conducted six statewide surveys of teen seat belt use from 2004 through 2009 (Institute of Transportation Management (2004, 2005, 2007, 2008, and 2009). While PRG did not collect or analyze these data, NHTSA and CDOT stipulated at the start of the demonstration project that the results of

\footnotetext{
${ }^{16}$ Significant increases $(p \leq 0.05)$ for cars and SUVs at all waves, except SUVs at Wave where $p=0.052$.
} 
these surveys would be made available to PRG to be incorporated into the program evaluation. CSU cooperated with PRG in several ways: (1) by providing raw data for specific sites included in a sub-sample sites taken from the statewide survey to serve as the Baseline and Wave 3; (2) by conducting additional sub-sample surveys at the identified sites for Waves, 1, 2, and 4; and (3) by providing PRG with reports from previous and subsequent statewide surveys. In this section we describe the overall results of the five statewide surveys that were conducted and reported to CDOT in comparison with the timing and results that we have already reported in this evaluation of the Teen Demonstration Project.

Figure 45 shows the overall results of five statewide surveys conducted by CSU from 2004 through 2009, with an overlay that shows the period during which the teen demonstration program was implemented. The timing of the statewide increase shown in this figure is consistent with an impact associated with the teen program.

Figure 45. Results of the Colorado Statewide Teen Seat Belt Surveys, Relative to the Timing of the Teen Seat Belt Demonstration Project

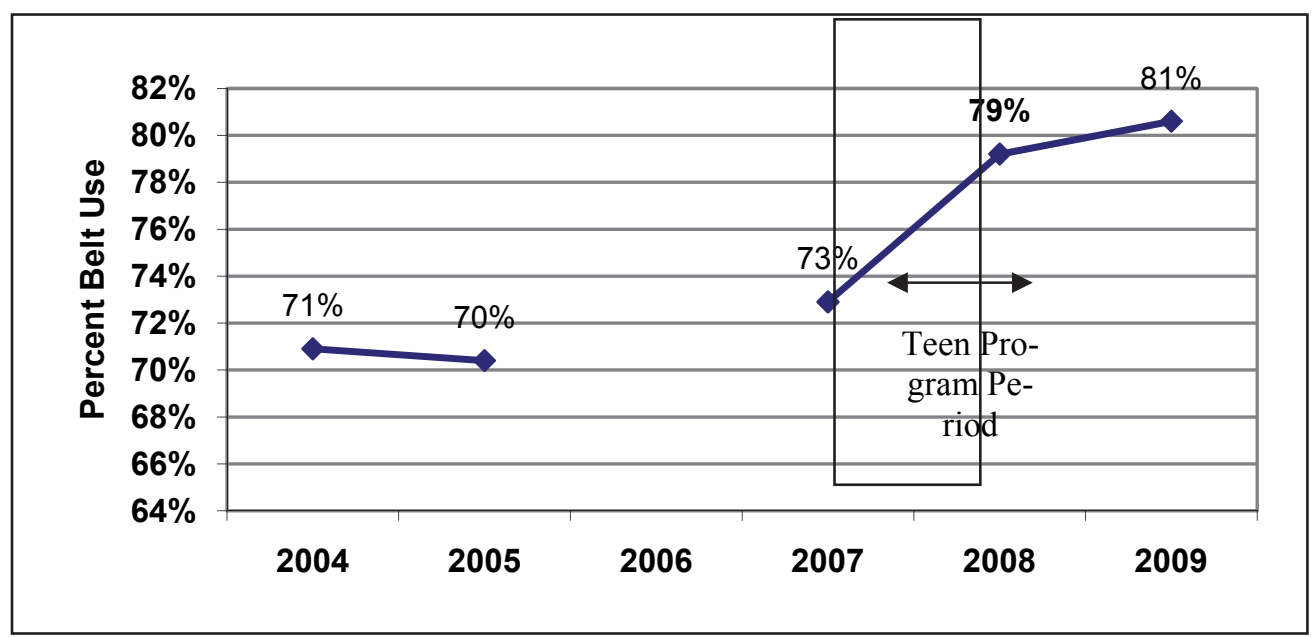

Relationship Between Two Survey Systems The 2007 survey was conducted in April of that year and, as described earlier, a sub-sample of that survey served as the baseline for the teen program evaluation. The seat belt use rate derived from the sub-sample was $72 \%$, very similar to the $73 \%$ statewide rate reported by CSU. The 2008 statewide survey was conducted after Wave 3 of the demonstration was completed (March 2008) and just prior to Wave 4 being implemented (May 2008). The same sub-sample of sites that was identified from the 2007 survey was extracted from the 2008 survey data to serve as the Wave 3 measure of seat belt use. That sub-sample estimate of use in the targeted areas was $75 \%, 44$ percentage points lower than the $79 \%$ statewide estimate reported in the 2008 statewide report, but well within the $95 \%$ confidence interval for that estimate (95\% CI: $73.9 \%$ to $84.5 \%$ ).

Similarities in Outcomes There were many similarities in the findings of these two survey systems. With regard to use by vehicle type, for example, the statewide survey found vans to have the highest use rates, followed by SUVs, cars, and trucks; identical to the order found in this study. In addition, the 2008 statewide survey found the largest gains among trucks and vans, 
similar to the findings (at Wave 3) for the sub-sample. The 2009 survey found a decline in use among occupants of trucks and vans. This was also suggested in Wave 4 of our surveys.

Differences in Outcomes There were some important differences in the results of the two survey systems. While the baseline rates for counties included in our Areas 1, 3, and 4 were very similar in both surveys, the average baseline rates for counties in Area 2 were quite different. This area contained El Paso County, with a relatively high use rate $(77 \%)$ and Pueblo County with a relatively low rate $(66 \%)$. Although our sample included sites from both counties, our average baseline for Area 2 was much closer to the Pueblo rate than to the El Paso rate.

Finally, with regard to changes in use, our index of change in Mesa County (Area 4), from baseline through Wave 3, was nearly identical to the average for sites included in the statewide estimate, but our indices for Denver and the North Central area were lower than those suggested by comparing results from the 2007 and 2008 statewide surveys. In Area 2 (Colorado Springs/Pueblo), our index of change at Wave 3 was greater than the statewide estimate, possibly influenced by the lower baseline in our sample.

Bottom Line In general, the indices of change from our sub-samples were more conservative than those suggested by comparing the results of the 2007 and 2008 statewide surveys, but both survey systems found evidence of increases in usage between April 2007 (Baseline) and March 2008 (Wave 3). In our analysis, there was a 3-point increase from baseline through Wave 3 (odds ratio $1.16 ; 95 \% \mathrm{CI}: 1.09,1.23 ; \mathrm{p}<0.05$ ). In the CSU statewide surveys there was a 9.2point increase during roughly the same period of time, from 70.4\% in March 2007 (9; 95\% CI: $66.4 \%$ to $74.5 \%$ ) to $72.9 \%$ in April 2008 (95\% CI: $73.9 \%$ to $84.5 \%$ ).

The changes in statewide use shown in Figure 45 clearly show an upward trend in statewide teen seat belt use during the period of the teen demonstration program but the survey results for 2009 , suggest that progress may have slowed after the teen demonstration was completed.

\subsubsection{Nevada}

\subsubsection{Characteristics of Subsample (Mini) Surveys}

Number of Sites and Observations Observations of teen seat belt use were made at 30 sites in the two media markets: 18 sites were in the Las Vegas DMA in southern Nevada; and 12 sites were in the Reno DMA in northern Nevada. Twenty-one sites were near high schools (12 sites in Las Vegas; 9 in Reno); 5 sites were near colleges or universities (3 sites in Las Vegas; 2 in Reno); and 4 sites were in non-school situations, including a shopping mall, a theater, and 2 skate parks (3 non-school sites in Las Vegas; 1 in Reno).

A total of 23,519 observations were made at these 30 sites over the five measurement periods, an average of about 4,700 observations during each period. The number and percentage of total observations by wave and by subgroup are shown in Table 31. Observations were relatively evenly distributed across the five measurement periods, between drivers and passengers, and between the two media markets. However, many more observations were made at high schools sites than at colleges or non-school locations and more observations involved cars than all other types of vehicles combined. 
Table 31. Nevada Teen Seat Belt Observation Frequencies, by Wave and Subgroup

\begin{tabular}{|c|c|c|}
\hline Wave & Observations & $\%$ of Total \\
\hline Baseline & 4,644 & $20 \%$ \\
\hline Wave 1 & 5,246 & $22 \%$ \\
\hline Wave 2 & 4,436 & $19 \%$ \\
\hline Wave 3 & 4,761 & $20 \%$ \\
\hline Wave 4 & 4,432 & $19 \%$ \\
\hline Total & 23,519 & $100 \%$ \\
\hline Subgroup & Observations & Percent \\
\hline Drivers & 11,117 & $48 \%$ \\
\hline Passengers & 12,342 & $52 \%$ \\
\hline Total & 23,519 & $100 \%$ \\
\hline Las Vegas Area & 11,465 & $49 \%$ \\
\hline Reno Area & 12,054 & $51 \%$ \\
\hline Total & 23,519 & $100 \%$ \\
\hline High Schools & 19,326 & $82 \%$ \\
\hline Colleges & 2,292 & $10 \%$ \\
\hline Non-School & 1,901 & $8 \%$ \\
\hline Total & 23,519 & $100 \%$ \\
\hline Cars and Wagons & 13,225 & $56 \%$ \\
\hline Pickup Trucks & 2,986 & $13 \%$ \\
\hline Vans and SUVs & 7,308 & $31 \%$ \\
\hline Total & 23,519 & $100 \%$ \\
\hline
\end{tabular}

As Table 31 shows, $82 \%$ of all observations were conducted near high schools; about $10 \%$ were conducted near colleges or universities (referred to as "colleges"). Forty-eight percent of all teens observed were drivers and 51\% were passengers. Younger teens 16 and 17 were observed in and around high schools; older teens 18 to 20 were observed primarily near colleges. A mixture of younger and older teens was observed at non-school sites.

\subsubsection{Overall Impact}

As in Colorado, we constructed an index of Nevada teen belt use for each wave in which larger volume sites were not overly represented in the sample. We did this by weighting the observations at each of the 30 sites, within each measurement period, so that each site would count equally toward the use rate for that wave. ${ }^{17}$ We used these weighted data for the primary analysis of impact, using binary logistic regression. The results of this analysis are shown in Figure 46, with additional detail provided in Table 32.

\footnotetext{
${ }^{17}$ This involved calculating the average number of observations at each site, within each measurement period, then multiplying the raw use rate by that average number of observations.
} 
Figure 46. Nevada Teen Seat Belt Use Rates (weighted data)

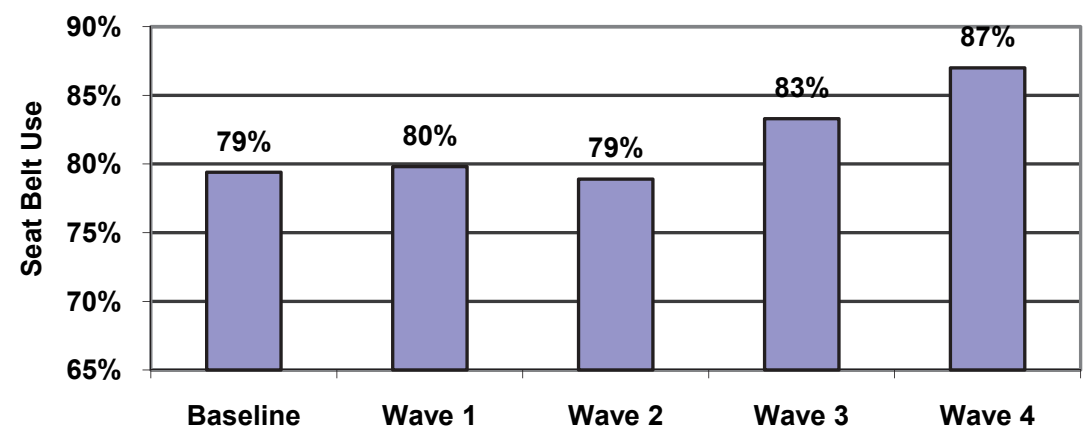

Table 32. Results of Binary Logistic Regression of Teen Seat Belt Use Data in Nevada

\begin{tabular}{|c|c|c|c|c|c|c|c|c|c|}
\hline & \multirow[b]{2}{*}{ B } & \multirow[b]{2}{*}{ S.E. } & \multirow[b]{2}{*}{ Wald } & \multirow[b]{2}{*}{ df } & \multirow[b]{2}{*}{ Signif. } & \multirow{2}{*}{$\begin{array}{l}\text { Odds } \\
\text { Ratios }\end{array}$} & \multicolumn{2}{|c|}{ 95\% C.I. } \\
\hline & & & & & & & & Lower & Upper \\
\hline Overall Effect & & - & - & 142.798 & 4 & 0.000 & - & - & - \\
\hline \multirow{5}{*}{$\begin{array}{c}\text { Effects } \\
\text { by Wave } \\
\text { Compared } \\
\text { With Baseline }\end{array}$} & Wave 1 & .027 & .050 & .281 & 1 & 0.596 & 1.027 & 0.931 & 1.133 \\
\hline & Wave 2 & -.030 & .052 & .346 & 1 & 0.557 & 0.970 & 0.877 & 1.073 \\
\hline & Wave 3 & .260 & .053 & 23.934 & 1 & 0.000 & 1.297 & 1.169 & 1.439 \\
\hline & Wave 4 & .556 & .058 & 93.201 & 1 & 0.000 & 1.743 & 1.557 & 1.951 \\
\hline & Constant & 1.347 & .036 & 1380.546 & 1 & 0.000 & 3.848 & - & - \\
\hline
\end{tabular}

Overall, there was a significant 7.6-percentage-point increase in use, from baseline (79.4\%) through Wave $4(87 \%)$. The odds of seat belt use increased by $74 \%$, from 3.848 at baseline to 6.708 at Wave 4 (odds ratio $=1.743)$.

The overall change in the index of use was slightly greater in Nevada than in Colorado (7.6 points and 5.0 points, respectively). Unlike the results in Colorado, however, there was no initial effect associated with the first program wave. In fact, the first significant impact was measured after Wave 3 (May 2008), with an additional significant increase associated with Wave 4 (September 2008). As in Colorado, there was a slight decline in measured use from Wave 1 to Wave 2 (January 2008), which immediately followed winter break for most colleges and high schools. This decline was not statistically significant in Nevada.

\subsubsection{Driver and Passenger Use}

We also examined changes in seat belt use by occupant role. For these analyses, we weighted the results for each site, within each role (i.e., within drivers and passengers), within each measurement period. We then examined changes in use rates and in the odds of being buckled from one wave to another and for each wave relative to baseline. Significance was determined by establishing 95\% confidence intervals for the odds ratios. 
Figure 47. Nevada Teen Driver and Passenger Seat Belt Use, by Wave

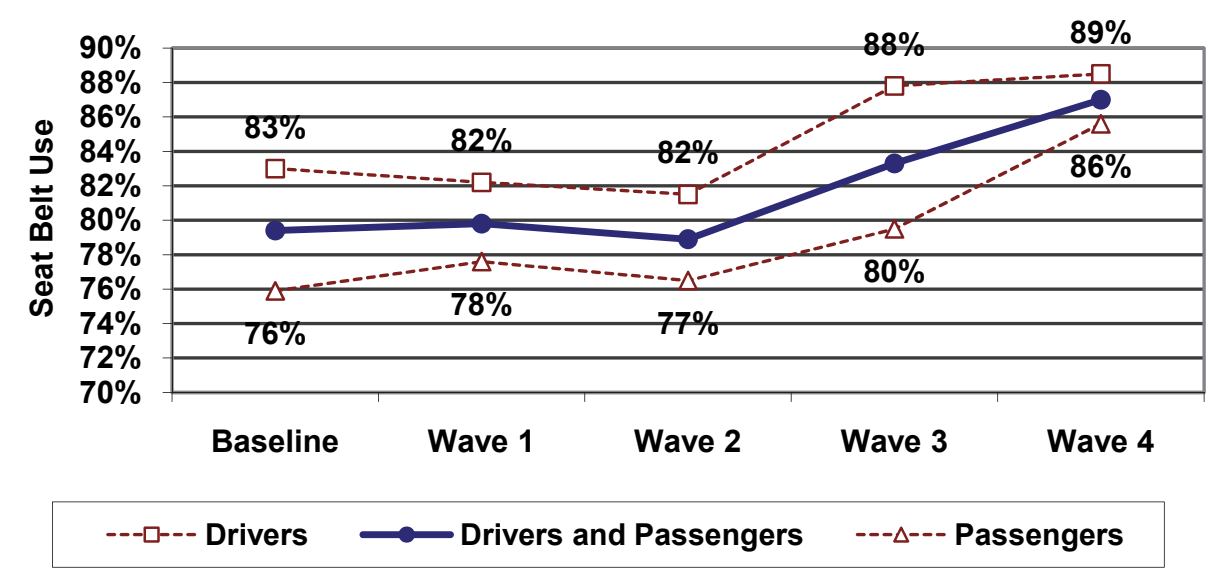

Figure 47 shows the use rates for drivers, passengers, and combined drivers and passengers, by wave. There were no significant changes for any group prior to wave 3 . From Wave 2 to Wave 3 , driver use increased by 6 percentage points (odds ratio $1.636,95 \% \mathrm{CI}: 1.381,1.937 ; \mathrm{p}<0.05$ ) and passenger use increased by 3 points (odds ratio 1.194, 95\% CI: 1.043, 1.367; p < 0.05). From Wave 3 to Wave 4, passenger use increased by 6 points, (odds ratio 1.529, 95\% CI: 1.314 , $1.779 ; \mathrm{p}<0.05)$. This increase drove overall use upward as well but driver use increased only slightly during this period (odds ratio 1.072, 95\% CI: 0.892, 1.289; $\mathrm{p}>0.05$ ).

Use rates and the odds of buckling up (for all three groups) were significantly higher after Wave 3 and Wave 4 than at baseline. There was an overall 5.5-percentage-point increase in use among drivers, increasing the odds of being buckled by $58 \%$ (odds ratio $1.579,95 \% \mathrm{CI}: 1.330,1.875 ; \mathrm{p}$ $<0.05$ ) and a cumulative 9.7-point increase in the use rate among passengers, increasing their odds of being buckled by $89 \%$ (odds ratio $1.889,95 \% \mathrm{CI}: 1.626,2.195 ; \mathrm{p} \leq 0.05$ ). Except for the Wave 3 measurement, when driver use increased more than passenger use, the gap between driver and passenger use generally declined throughout the program period, from 7 percentage points at baseline to 3 points after Wave 4. Still, the odds of drivers buckling up remained significantly higher than the odds of passengers buckling up (odds ratio 1.295, 95\% CI: 1.085, 1.545; p < $0.05)$.

\subsubsection{Use at High Schools, Colleges, and Non-School Sites}

Figure 48 shows use at high school sites, college sites, and non-school sites. Because the number of sites and observations was much larger in and around high schools than at other locations, the index of use is much more stable for high schools. Baseline use at college sites (85\%) was higher than at high schools $(77 \%)$ or at non-school sites $(74 \%)$, but use at colleges did not increase significantly, even at its peak at Wave 3. Use at high school and non-school sites increased significantly at Waves 3 and 4 . 
Figure 48. Nevada Teen Seat Belt Use Rates Near High School, College/University, and Non-School Sites

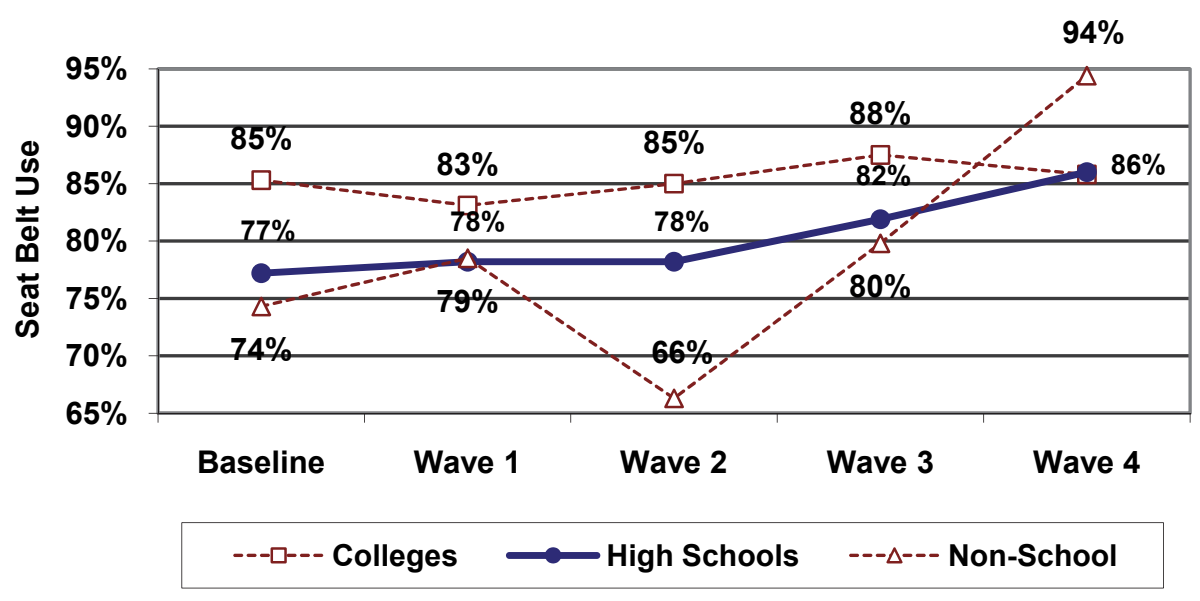

Figure 48 shows the increases in seat belt use at high schools that were associated with Wave 3 and Wave 4; the odds of seat belt use increased by $26 \%$ and $36 \%$ at those measurement periods, respectively (odds ratios 1.264 and 1.360 , respectively, $p<0.05$ ). Compared with baseline, the cumulative increases in use were also significant after each of these final program periods, with the odds of seat belt use elevated by $34 \%$ after Wave 3 and by $82 \%$ after Wave 4 (i.e., odds ratios of 1.34 and 1.82 , respectively, $\mathrm{p}<0.05$ for both).

High School Versus College Sites Over the course of the program, seat belt use at sites near high schools trended upward at a greater rate than use near colleges. After the final wave, use rates (and the odds of use) were nearly identical for these two school conditions. The overall trends show a greater increase among high school students (younger teens; +9 points) than among college students (older teens; +1 point). At least two factors likely contributed to this greater increase: a lower baseline rate of use at high school sites (77\% versus $85 \%$ at college sites); and an increase in use at high school sites at Wave 4 (September 2008), with no corresponding increase at college sites.

Figure 49. Change in Teen Seat Belt Use at High School and College Sites in Nevada

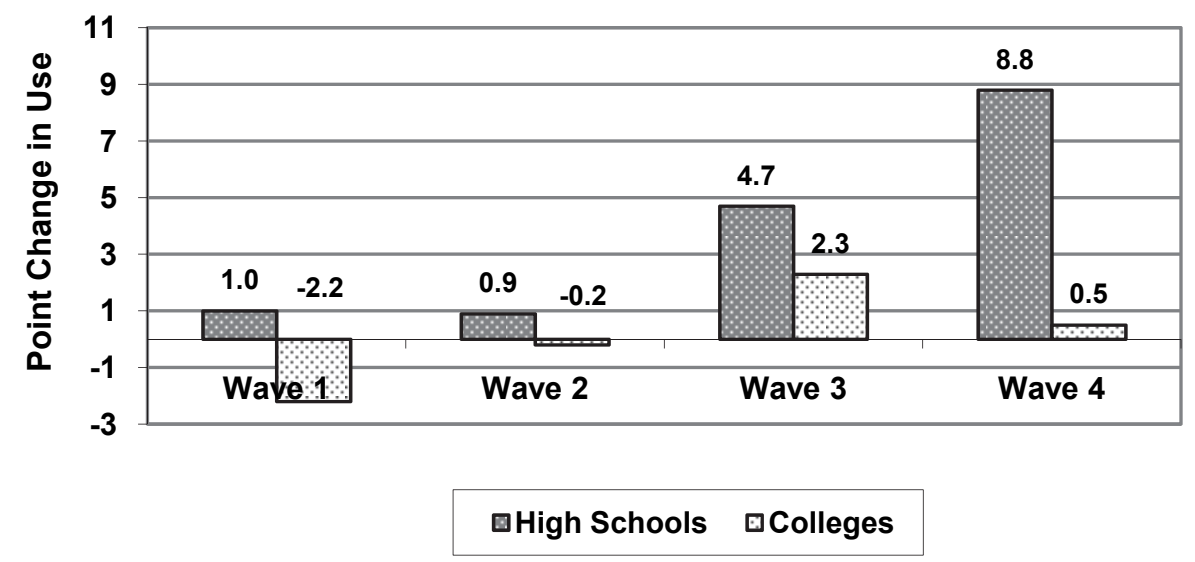


Table 33. Teen Seat Belt Use Percentages, Odds of Use, and Odds Ratios Relative to Baseline Levels near High Schools, College/University, and Non-School Locations

\begin{tabular}{|c|c|c|c|c|c|c|c|c|c|}
\hline & \multirow{2}{*}{$\begin{array}{c}\text { Measurement } \\
\text { Period }\end{array}$} & \multirow[b]{2}{*}{$\mathrm{N}$} & \multirow{2}{*}{$\begin{array}{c}\% \\
\text { Use }\end{array}$} & \multirow{2}{*}{$\begin{array}{l}\text { Odds } \\
\text { of Use }\end{array}$} & \multirow{2}{*}{$\begin{array}{l}\text { Odds } \\
\text { Ratio }\end{array}$} & \multirow[b]{2}{*}{ df } & \multirow[b]{2}{*}{ S.E } & \multicolumn{2}{|c|}{ Wald $95 \%$ C.I. } \\
\hline & & & & & & & & Lower & Upper \\
\hline High Schools & Baseline & 3,674 & 77.2 & 3.389 & - & - & - & - & - \\
\hline \multirow{4}{*}{$\begin{array}{l}\text { Effects } \\
\text { By Wave } \\
\text { Versus } \\
\text { Baseline }\end{array}$} & Wave 1 & 4,309 & 78.2 & 3.589 & 1.059 & 1 & 0.057 & 0.953 & 1.177 \\
\hline & Wave 2 & 3,522 & 78.2 & 3.580 & 1.056 & 1 & 0.990 & 0.945 & 1.180 \\
\hline & Wave 3 & 4,122 & 81.9 & 4.525 & $1.335^{*}$ & 1 & 0.075 & 1.195 & 1.491 \\
\hline & Wave 4 & 3,699 & 86.0 & 6.155 & $1.816^{*}$ & 1 & 0.112 & 1.609 & 2.049 \\
\hline Colleges & Baseline & 530 & 85.3 & 5.795 & - & - & - & - & - \\
\hline Effects & Wave 1 & 533 & 83.1 & 4.922 & 0.849 & 1 & 0.143 & 0.611 & 1.182 \\
\hline By Wave & Wave 2 & 528 & 85.0 & 5.684 & 0.981 & 1 & 0.170 & 0.699 & 1.377 \\
\hline Versus & Wave 3 & 273 & 87.5 & 7.026 & 1.213 & 1 & 0.268 & 0.787 & 1.869 \\
\hline Baseline & Wave 4 & 429 & 85.8 & 6.033 & 1.041 & 1 & 0.192 & 0.725 & 1.495 \\
\hline Non-School & Baseline & 440 & 79.8 & 3.944 & - & - & - & - & - \\
\hline Effects & Wave 1 & 404 & 79.2 & 3.810 & 0.966 & 1 & 0.165 & 0.691 & 1.350 \\
\hline By Wave & Wave 2 & 386 & 73.6 & 2.784 & 0.706 & 1 & 0.117 & 0.510 & 0.977 \\
\hline Versus & Wave 3 & 367 & 82.3 & 4.646 & 1.178 & 1 & 0.213 & 0.826 & 1.680 \\
\hline Baseline & Wave 4 & 304 & 86.5 & 6.415 & $1.627^{*}$ & 1 & 0.334 & 1.087 & 2.434 \\
\hline
\end{tabular}

Use at non-school sites was highly variable due to the fact that there were only four such sites and less than $10 \%$ of the total observations were made at those sites. Figure 48 shows a significant decline at Wave 2, but there were significant wave-to-wave increases associated with waves 3 and 4. Relative to baseline, there was a near-significant 5.5-percentage-point increase in the use rate after Wave 3 (odds ratio 1.368, 95\% CI: 0.981, 1.909; p 0.06) and there was a significant 20-point increase in use (relative to baseline) after Wave 4 (odds ratio 5.834, 95\% CI: 3.420, $9.951 ; \mathrm{p}<.05)$. Table 33 shows the number of observations, the odds of use, odds ratios, standard errors, and 95\% confidence intervals for each of these school and non-school conditions, by wave. All odds ratios and confidence intervals are relative to baseline.

\subsubsection{A Comparison of Changes in Use in the Las Vegas and Reno Areas}

Baseline rates and changes in use between the Reno and Las Vegas areas resemble baselines and changes in colleges versus high schools. As with use near colleges, baseline rates in the Reno area were higher and use did not change as much as in the Las Vegas area. Thus, there was a decreasing gap in use between the two groups over time. Figure 49 shows the convergence of use rates in these two DMAs.

In the Reno area, the only significant wave-to-wave change was measured from Wave 2 to Wave 3 (+4.4 points, odds ratio 1.371, 95\% CI: 1.181, 1.592; $\mathrm{p}<0.05$ ). Because of decreases at waves 1 and 2, however, use never increased to levels that were significantly greater than at baseline, not even after Wave 4 ( +1.7 points; odds ratio 1.147 ; 95\% CI: 0.971 to $1.356 ; \mathrm{p}>0.05)$.

In the Las Vegas area, an initial increase at Wave 1 was near significant $(+2$ points; odds ratio 1.116, 95\% CI: $0.979,1.271 ; \mathrm{p} \sim 0.07)$; there was virtually no change at Wave 2 ; then use increased significantly at Wave $3(+4.2$ points, odds ratio $1.300 ; 95 \%$ CI: 1.118 to $1.511 ; \mathrm{p}<0.05)$ 
and again at Wave $4(+5.4$ points, odds ratio $1.523 ; 95 \%$ CI: 1.290 to $1.797 ; \mathrm{p}<0.05)$. As Table 34 shows, this resulted in cumulative increases that were near significant after Wave 1 and Wave 2 and highly significant after Wave 3 and Wave 4. Overall, there was a highly significant 11.6point increase in use.

Figure 50. Overall Teen Seat Belt Use Rates in the Reno and Las Vegas Areas
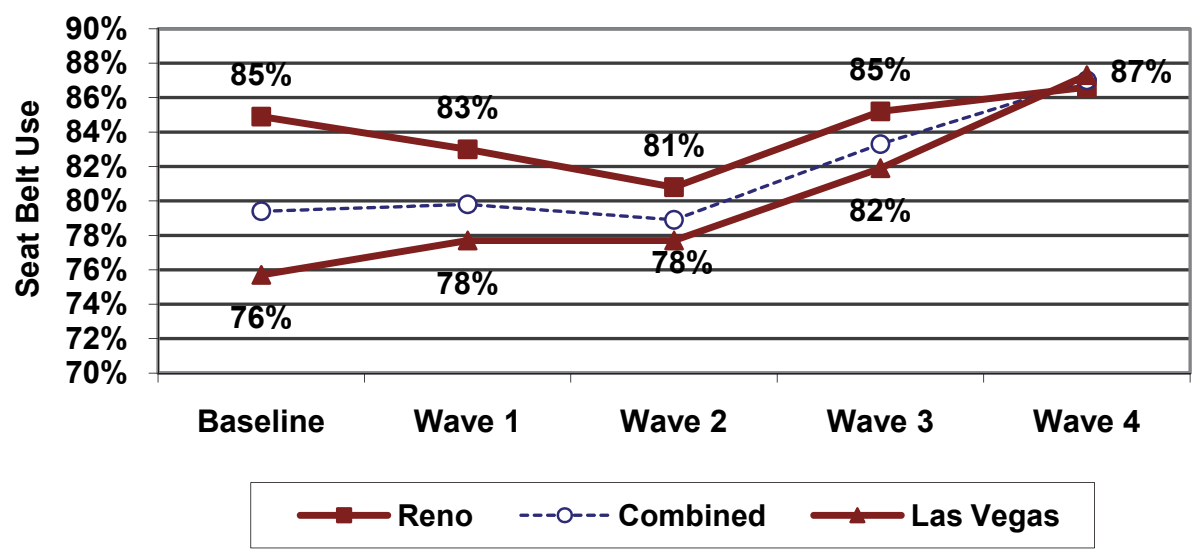

Table 34. Teen Seat Belt Use Percentages, Odds of Use, and Odds Ratios Relative to Baseline Levels in the Reno and Las Vegas DMAs

\begin{tabular}{|c|c|c|c|c|c|c|c|c|c|}
\hline & \multirow{2}{*}{$\begin{array}{c}\text { Measurement } \\
\text { Period }\end{array}$} & \multirow[b]{2}{*}{$\mathrm{N}$} & \multirow{2}{*}{$\begin{array}{c}\% \\
\text { Use }\end{array}$} & \multirow{2}{*}{$\begin{array}{l}\text { Odds } \\
\text { of Use }\end{array}$} & \multirow{2}{*}{$\begin{array}{l}\text { Odds } \\
\text { Ratio }\end{array}$} & \multirow[b]{2}{*}{ df } & \multirow[b]{2}{*}{ S.E } & \multicolumn{2}{|c|}{ Wald $95 \%$ C.I. } \\
\hline & & & & & & & & Lower & Upper \\
\hline Reno & Baseline & 2,232 & 84.9 & 5.623 & - & - & - & - & - \\
\hline \multirow{4}{*}{$\begin{array}{l}\text { Effects } \\
\text { By Wave } \\
\text { Versus } \\
\text { Baseline }\end{array}$} & Wave 1 & 2,596 & 83.0 & 4.873 & 0.867 & 1 & 0.068 & 0.743 & 1.012 \\
\hline & Wave 2 & 2,471 & 80.8 & 4.202 & $0.747^{*}$ & 1 & 0.058 & 0.641 & 0.871 \\
\hline & Wave 3 & 2,482 & 85.2 & 5.763 & 1.025 & 1 & 0.084 & 0.873 & 1.203 \\
\hline & Wave 4 & 2,273 & 86.6 & 6.452 & $1.147^{n}$ & 1 & 0.098 & 0.971 & 1.356 \\
\hline Las Vegas & Baseline & 2,412 & 75.7 & 3.123 & - & - & - & - & - \\
\hline Effects & Wave 1 & 2,650 & 77.7 & 3.484 & $1.116^{n}$ & 1 & 0.074 & 0.979 & 1.271 \\
\hline By Wave & Wave 2 & 1,965 & 77.7 & 3.476 & $1.113^{n}$ & 1 & 0.080 & 0.967 & 1.282 \\
\hline Versus & Wave 3 & 2,279 & 81.9 & 4.518 & $1.447^{*}$ & 1 & 1.105 & 1.256 & 1.667 \\
\hline Baseline & Wave 4 & 2,159 & 87.3 & 6.880 & $2.203^{*}$ & 1 & 0.177 & 1.882 & 2.578 \\
\hline
\end{tabular}

Changes by School Type in Reno and Las Vegas. Figure 51 shows seat belt use rates at high school, college, and non-school sites in the Reno area. Observations at sites near Reno high schools (about 1,900 per wave) showed a reasonably high use rate, ranging from $82 \%$ to $86 \%$, among these younger teens. There was very little evidence of an increase until waves 3 and 4 . After Wave 4, the odds of seat belt use were significantly greater than at baseline for the first time since the program began (+3.2 percentage points) (odds ratio 1.274; 95\% CI: $1.064,1.525$; $\mathrm{p}<0.05)$. 
The number of observations at college and non-school sites was small relative to the number of observations at high schools, generally between 240 and 270 per wave. On average, there was higher use at college sites (older teens) than at high school sites (younger teens). Use at nonschool sites was generally about the same as at high schools. There were significant declines in use at college and non-school sites associated with Wave 2, followed by significant increases associated with Wave $3 .^{18}$

Figure 51. Teen Seat Belt Use Rate at High School, College, and Non-School Sites in Reno Area

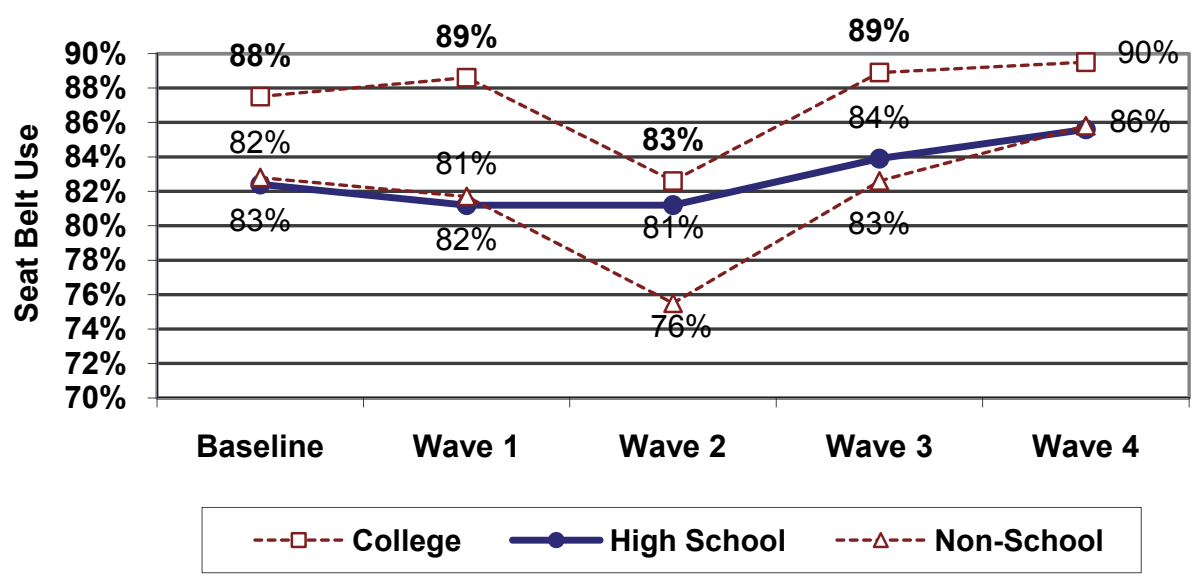

Figure 52 shows use at high school, college, and non-schools sites in the Las Vegas area. With regard to high schools, the trend is similar to that in Reno, with a significant increase at Wave 3. Unlike Reno, there also was a significant increase at Wave 4. Use at non-school sites was similar to use at high schools, except for Wave 2, when there was a significant decline (as in Reno). However, there was a different pattern of use at Las Vegas college sites, with a decline at Wave 1 and an increase at Wave 2. After Wave 4, there was little difference in use between the three (school/non-school) categories.

\footnotetext{
${ }^{18}$ The Wave 2 program occurred while most Nevada colleges were on holiday break; data collection took place the week that residence halls re-opened at UNLV and UNR. High schools were in session during most of the program and during all of the data collection period.
} 
Figure 52. Teen Seat Belt Use Rates at High School, College, and Non-School Sites in Las Vegas

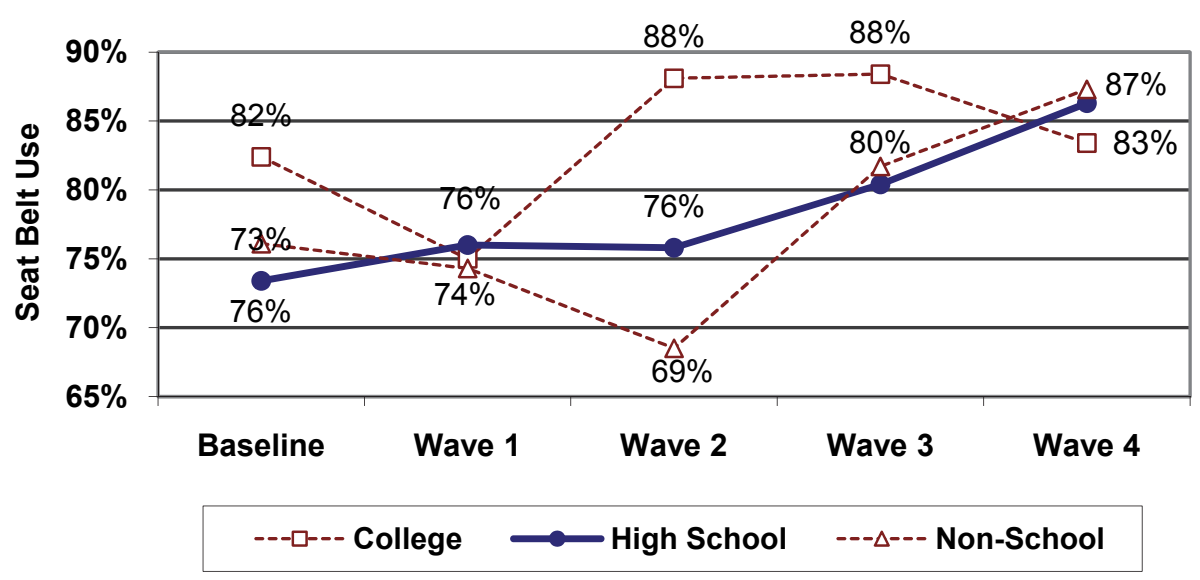

\subsubsection{Changes in Use by Vehicle Type}

Figure 53 shows changes in seat belt use by vehicle type. Unlike Colorado, where the highest teen seat belt use was found in vans and SUVs, teen occupants of cars and station wagons in Nevada had very similar rates as those riding in vans and SUVs. There were increases in both vehicle categories toward the end of the program period.

Figure 53. Nevada Teen Seat Belt Use Rates by Vehicle Type, All 30 Sites

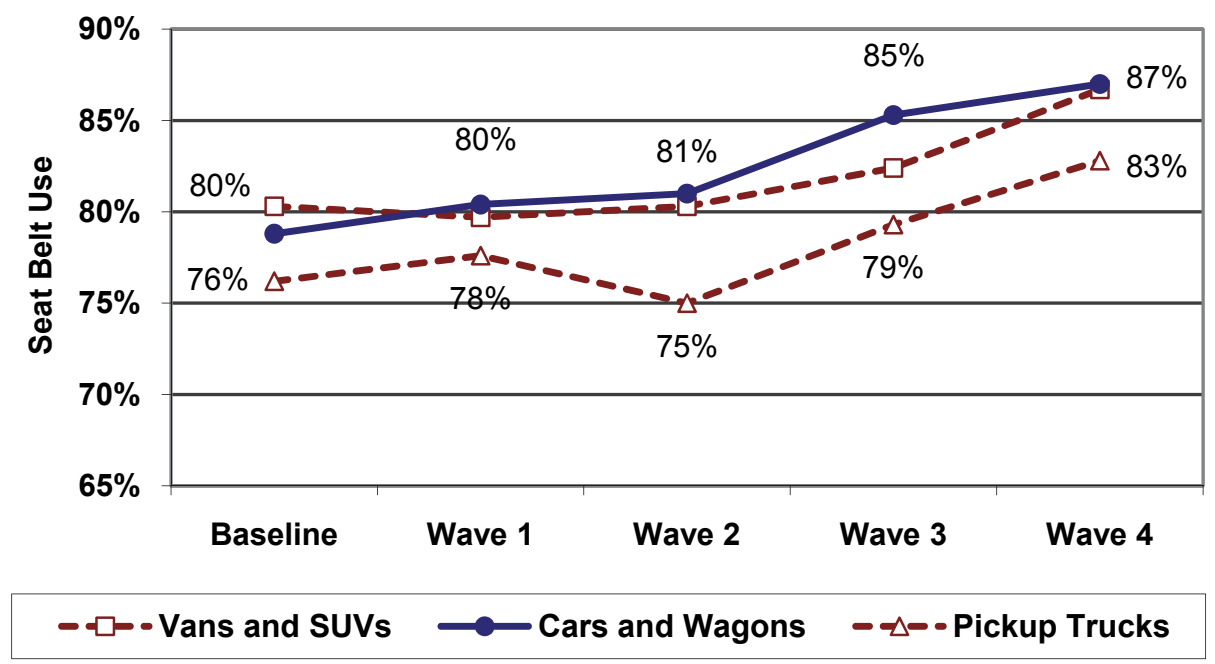


Table 35. Teen Seat Belt Use Percentages, Odds of Use, and Odds Ratios Relative to Baseline Levels at High Schools, Colleges/Universities, and Non-School Locations

\begin{tabular}{|c|c|c|c|c|c|c|c|c|c|}
\hline & \multirow{2}{*}{$\begin{array}{c}\text { Measurement } \\
\text { Period }\end{array}$} & \multirow[b]{2}{*}{$n$} & \multirow{2}{*}{$\begin{array}{l}\% \\
\text { Use }\end{array}$} & \multirow{2}{*}{$\begin{array}{l}\text { Odds } \\
\text { of Use }\end{array}$} & \multirow{2}{*}{$\begin{array}{l}\text { Odds } \\
\text { Ratio }\end{array}$} & \multirow[b]{2}{*}{ df } & \multirow[b]{2}{*}{ S.E } & \multicolumn{2}{|c|}{ Wald $95 \%$ C.I. } \\
\hline & & & & & & & & Lower & Upper \\
\hline Cars & Baseline & 2,583 & 78.8 & 3.714 & - & - & - & 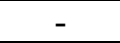 & - \\
\hline \multirow{4}{*}{$\begin{array}{l}\text { Effects } \\
\text { By Wave } \\
\text { Versus } \\
\text { Baseline }\end{array}$} & Wave 1 & 2,952 & 80.4 & 4.107 & 1.106 & 1 & 0.074 & 0.970 & 1.261 \\
\hline & Wave 2 & 2,458 & 81.0 & 4.275 & $1.151^{*}$ & 1 & 0.081 & 1.003 & 1.322 \\
\hline & Wave 3 & 2,770 & 85.3 & 5.823 & $1.568^{*}$ & 1 & 0.113 & 1.361 & 1.806 \\
\hline & Wave 4 & 2,462 & 87.0 & 6.718 & $1.809^{*}$ & 1 & 0.139 & 1.556 & 2.103 \\
\hline Vans/SUVs & Baseline & 1,485 & 80.3 & 4.086 & - & - & - & - & - \\
\hline Effects & Wave 1 & 1,602 & 79.7 & 3.929 & 0.962 & 1 & 0.087 & 0.806 & 1.148 \\
\hline By Wave & Wave 2 & 1,382 & 80.3 & 4.081 & 0.999 & 1 & 0.094 & 0.831 & 1.201 \\
\hline Versus & Wave 3 & 1,415 & 82.4 & 4.683 & 1.146 & 1 & 0.110 & 0.950 & 1.382 \\
\hline Baseline & Wave 4 & 1,424 & 86.7 & 6.534 & $1.599^{*}$ & 1 & 0.163 & 1.310 & 1.953 \\
\hline Trucks & Baseline & 576 & 76.2 & 3.204 & - & - & - & - & - \\
\hline Effects & Wave 1 & 692 & 77.6 & 3.465 & 1.081 & 1 & 0.145 & 0.832 & 1.405 \\
\hline By Wave & Wave 2 & 596 & 75.0 & 3.000 & 0.936 & 1 & 0.127 & 0.717 & 1.223 \\
\hline Versus & Wave 3 & 576 & 79.3 & 3.840 & 1.198 & 1 & 0.170 & 0.907 & 1.583 \\
\hline Baseline & Wave 4 & 546 & 82.8 & 4.809 & $1.501^{*}$ & 1 & 0.225 & 1.119 & 2.013 \\
\hline
\end{tabular}

Cars and Station Wagons There was a significant 4.3-point increase in cars and wagons from Wave 2 to Wave 3 (odds ratio 1.362; 95\% CI: 1.177, 1.576; $\mathrm{p}<0.05$ ). Another increase from Wave 3 to Wave $4(+1.7$ points) did not reach significance $(\mathrm{p} \sim 0.08)$. However, because of combined increases associated with waves 1 and 2, the use rate at Wave 2 was significantly higher than at baseline and there were additional increases with each subsequent wave (see Table $35)$.

Vans and SUVs Use did not increase significantly among occupants of vans and SUVs until Wave 4, when the rate increased by 4.3 percentage points relative to the Wave 3 level (odds ratio 1.395; $95 \% \mathrm{CI}: 1.136,1.714 ; \mathrm{p}<0.05$ ) and by 6.4 points relative to baseline (odds ratio 1.599 ; 95\% CI: $1.131,1.953 ; \mathrm{p}<0.05)$.

Pickup Trucks Use was lowest among occupants of pickup trucks and no significant wave-towave increases were observed. By the end of the fourth program wave, however, use among occupants of pickup trucks was significantly higher than at baseline ( +6.6 points) and the odds of use were $50 \%$ higher than at baseline (odds ratio 1.501; 95\% CI: 1.310, 1.953; $\mathrm{p}<0.05$ ).

Table 36 summarizes the use rates and changes in such rates from wave to wave and from baseline to each wave. For all vehicle types, the highest use rates (and the greatest odds of use) were at Wave 4. Thus, the maximum gains relative to baseline were also at Wave 4. For cars and pickup trucks, the largest wave-to-wave change occurred at Wave 3 ( +4.3 points) but that increase was significant only for cars, due to the smaller number of pickups observed. For vans and SUVs, the largest wave-to-wave gain occurred at Wave 4 (also +4.3 points). By Wave 4 , use in all three groups was significantly greater than at baseline. In cars, that was the case after Wave 2, Wave 3, and Wave 4. 
Table 36. Summary of Nevada Teen Seat Belt Use Rates and Change, by Vehicle Type

\begin{tabular}{|c|c|c|c|c|c|c|c|c|}
\hline $\begin{array}{l}\text { Vehicle } \\
\text { Type }\end{array}$ & B & w1 & w2 & w3 & w4 & \multicolumn{3}{|c|}{$\begin{array}{l}\text { Final and Max. Gains } \\
\text { Relative to Baseline }\end{array}$} \\
\hline \multicolumn{6}{|c|}{ Observed Use Rate } & $\begin{array}{c}\text { Gain } \\
\text { at } \\
\text { w4 }\end{array}$ & $\begin{array}{l}\text { Max } \\
\text { Gain }\end{array}$ & Wave \\
\hline Cars & $78.8 \%$ & $80.4 \%$ & $81.0 \%$ & $84.3 \%$ & $87.0 \%$ & +8.3 & +8.3 & w4 \\
\hline Vans/SUVs & $80.3 \%$ & $79.7 \%$ & $80.3 \%$ & $82.4 \%$ & $86.7 \%$ & +6.4 & +6.4 & w4 \\
\hline Trucks & $76.2 \%$ & $77.6 \%$ & $75.0 \%$ & $79.3 \%$ & $82.8 \%$ & +6.6 & +6.6 & w4 \\
\hline \multicolumn{9}{|c|}{ Wave-to-Wave Change (percentage points) } \\
\hline Cars & \multirow{3}{*}{$\mathrm{n} / \mathrm{a}$} & +1.6 & +0.6 & $+4.3^{*}$ & +1.7 & \multirow{3}{*}{\multicolumn{3}{|c|}{$\mathrm{n} / \mathrm{a}$}} \\
\hline Vans/SUVs & & -0.6 & +0.6 & +2.1 & $+4.3^{*}$ & & & \\
\hline Trucks & & +1.4 & -2.6 & +4.3 & +3.4 & & & \\
\hline \multicolumn{6}{|c|}{ Cumulative Change Relative to Baseline } & $\begin{array}{l}\text { Ave } \\
\text { Gain }\end{array}$ & \multirow{4}{*}{\multicolumn{2}{|c|}{$\mathrm{n} / \mathrm{a}$}} \\
\hline Cars & \multirow{3}{*}{$\mathrm{n} / \mathrm{a}$} & +1.6 & $+2.3^{*}$ & $+6.6^{*}$ & $+8.3^{*}$ & +4.7 & & \\
\hline Vans/SUVs & & -0.6 & 0.0 & +2.1 & $+6.4^{*}$ & +2.0 & & \\
\hline Trucks & & +1.4 & -1.2 & +3.1 & $+6.6^{*}$ & +2.5 & & \\
\hline
\end{tabular}

\subsubsection{A Comparison of Colorado and Nevada Results}

Although the teen seat belt programs implemented in Colorado and Nevada were similar, there were some important differences in their results and, while it involves some repetition of results, the following sections compare the results in these two States: overall, by school type, among drivers and passengers, and by vehicle type.

\subsubsection{Overall Impact}

Figure 54 shows that the baseline rate among teens in Colorado was lower than in Nevada (72\% versus 79\%). There was a significant initial impact associated with Wave 1 in Colorado, but no such impact was observed in Nevada. Use declined significantly following the holiday break in Colorado and, while such a decline was not apparent in the overall Nevada use rate, it did appear in the data from college and non-school sites in Reno. There was a modest increase in use associated with Wave 3 (March 2008) and Wave 4 (May 2008) in Colorado but use after Wave 4 was about the same as after the significant increase at Wave 1. In Nevada, by contrast, there were significant increases in use associated with both Wave 3 (May 2008) and Wave 4 (September 2008).

Based on our sub-sample surveys, Colorado use during the program period averaged about 4 percentage points over baseline, with a final rate that was about 5 points over baseline. Results from Colorado's statewide teen survey showed a slightly larger 6-percentage-point increase, from April 2007 through April 2008, just prior to the fourth and final wave of the Colorado program. 
Nevada's teen rate was, on average, about 3 percentage points higher than at baseline over the year-long program. In spite of a relatively high baseline rate, a surge at the end of the program left teen use nearly 8 points higher than the baseline rate.

Figure 54. Teen Seat Belt Use Rates in Colorado and Nevada, by Wave

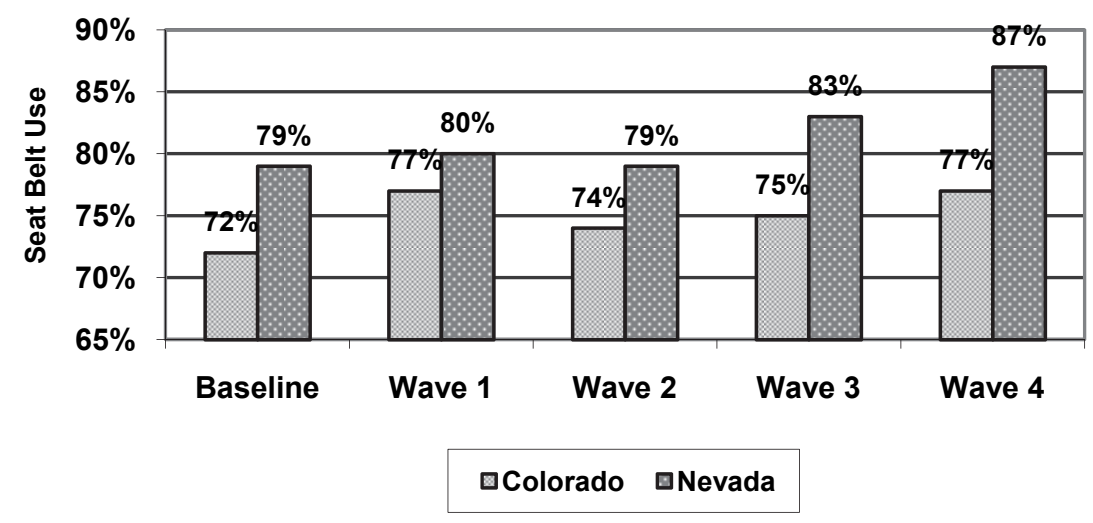

Table 37. Summary of Teen Seat Belt Use Rates and Change in Colorado and Nevada, by Wave

\begin{tabular}{|c|c|c|c|c|c|c|c|c|}
\hline State & B & w1 & w2 & w3 & w4 & \multicolumn{3}{|c|}{$\begin{array}{c}\text { Final and Maximum Gains } \\
\text { Relative to Baseline }\end{array}$} \\
\hline \multicolumn{6}{|c|}{ Observed Use Rate } & $\begin{array}{l}\text { Gain } \\
\text { at w4 }\end{array}$ & $\begin{array}{l}\text { Max } \\
\text { Gain }\end{array}$ & Wave \\
\hline Colorado & $72.0 \%$ & $76.7 \%$ & $73.8 \%$ & $74.9 \%$ & $77.0 \%$ & $+5.0^{*}$ & $+5.0^{*}$ & W4 \\
\hline Nevada & $79.4 \%$ & $79.8 \%$ & $78.9 \%$ & $83.3 \%$ & $87.0 \%$ & $+7.7^{*}$ & $+7.7^{*}$ & w4 \\
\hline \multicolumn{9}{|c|}{ Wave-to-Wave Change (percentage points) } \\
\hline Colorado & \multirow[b]{2}{*}{$\mathrm{n} / \mathrm{a}$} & $+4.7^{*}$ & $-2.9^{*}$ & +1.1 & +2.1 & \multirow{2}{*}{\multicolumn{3}{|c|}{$\mathrm{n} / \mathrm{a}$}} \\
\hline Nevada & & +0.4 & -0.9 & $+4.4^{*}$ & $+3.7^{*}$ & & & \\
\hline \multicolumn{6}{|c|}{ Cumulative Change Relative to Baseline } & $\begin{array}{l}\text { Ave } \\
\text { Gain }\end{array}$ & \multirow{3}{*}{\multicolumn{2}{|c|}{$\mathrm{n} / \mathrm{a}$}} \\
\hline Colorado & \multirow[b]{2}{*}{$\mathrm{n} / \mathrm{a}$} & $+4.7^{*}$ & $+2.5^{*}$ & $+2.6^{*}$ & $+5.0^{*}$ & +3.6 & & \\
\hline Nevada & & +0.4 & -0.5 & $+3.9^{*}$ & $+7.6^{*}$ & +2.9 & & \\
\hline \multicolumn{9}{|c|}{$\begin{array}{l}\text { Notes: Maximum gain refers to maximum gain relative to baseline (regardless of wave); "*" designates a } \\
\text { significant result ( } p \leq 0.05) \text {; "Wave-to-Wave Change" refers to change from one wave to the next; "Cu- } \\
\text { mulative Change" refers to change at any wave, relative to baseline; shaded cells are used to highlight } \\
\text { highest rates and greatest gains. }\end{array}$} \\
\hline
\end{tabular}

Table 37 summarizes the observed use rates and gains for each wave, relative to the preceding wave and relative to baseline. The highest use rates were recorded immediately after Wave 4 in both States (77\% in Colorado and $87 \%$ in Nevada).

Based on wave-to wave changes, the greatest single wave gain in Colorado was associated with Wave 1 , followed by Wave 4 . In Nevada, the greatest gain was associated with Wave $3(+4.4$ points), followed by Wave 4 ( +3.7 points). 
Looking at cumulative change, relative to baseline, there was a 5-point (maximum and overall) gain in Colorado and a 7.7-point (maximum and overall) gain in Nevada.

\subsubsection{High School Versus College Sites}

Figure 55 shows changes in teen seat belt use at high school sites (primarily younger teens) and at college sites (primarily older teens) for both States. In Nevada, baseline use among college students was substantially higher than among high school students ( $85 \%$ and $77 \%$, respectively). In Colorado, there was very little difference in the baseline rates of high school and college students.

Increases in use were greater at high schools than at colleges in both States, with increases at Colorado high schools occurring at Wave 1 and Wave 4 and increases at Nevada high schools occurring at Wave 3 and Wave 4.

Use among college students did not increase significantly in Nevada but did increase by approximately 4 percentage points in Colorado, which was significant at Wave 3 . However, use among college students in Colorado remained about 11 points lower than in Nevada. Further, such use either declined (in Nevada) or remained the same (in Colorado) from Wave 3 to Wave 4, while use among high school students increased significantly (in both States). In Colorado, most students had already left the campus (May 2008) and in Nevada, students were just arriving for the new school year (September 2008).

\section{Figure 55. Teen Seat Belt Use Rates Near High School and College/University Sites in Colorado} and Nevada

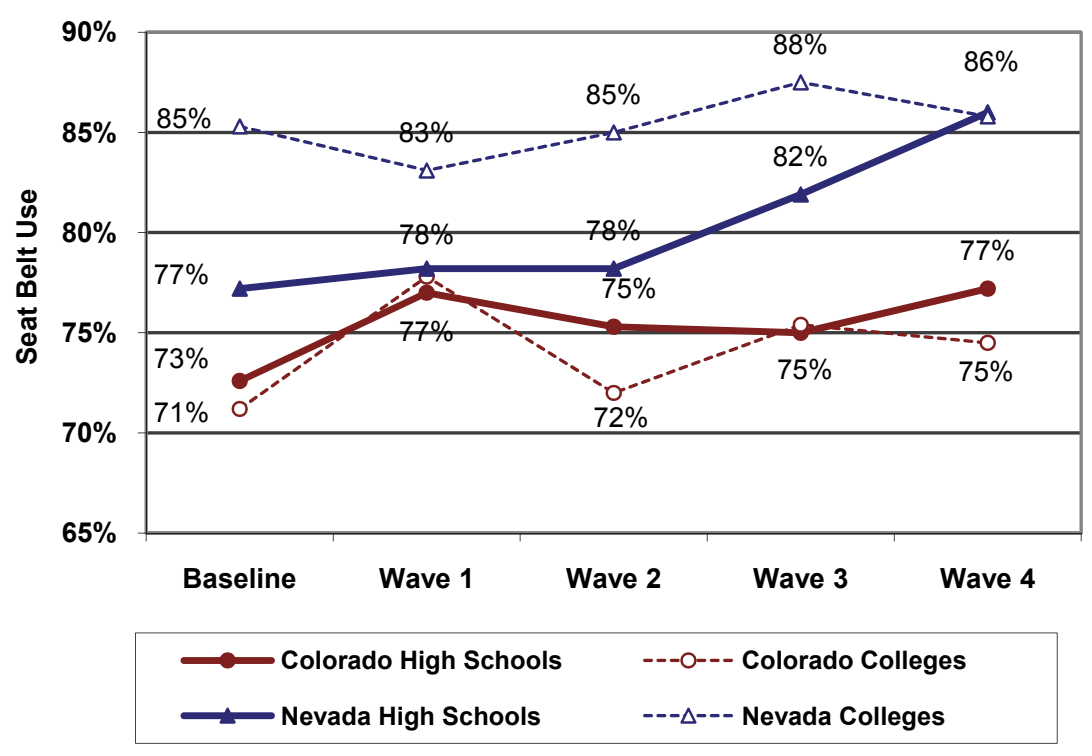

\subsubsection{Drivers Versus Passengers}

Drivers had higher seat belt use rates than passengers in both Colorado and Nevada: $83 \%$ versus $76 \%$ at baseline in Nevada; $74 \%$ versus $68 \%$ at baseline in Colorado. Baseline rates were higher for both groups in Nevada (83\% for drivers and $76 \%$ for passengers) than in Colorado (74\% for drivers and $68 \%$ for passengers). 
In Nevada, there was little impact on either drivers or passengers through Wave 2. Use appears to have been affected more among drivers than among passengers at Wave 3 (May 2008) but less so at Wave 4 (September 2008), when passenger use increased by about 6 percentage points. Overall, driver use increased by about 6 points and passenger use increased by about 10 points. These results suggest that teen passengers may have been affected more than teen drivers in Nevada.

In Colorado, drivers may have been impacted more than passengers by Wave 1, the most powerful program wave. However, there was little difference in the overall impact on drivers and passengers; use increased by about 5 percentage points in both groups.

Figure 56. Teen Seat Belt Use Rates Among Teen Drivers and Passengers in Colorado and Nevada, by Wave ${ }^{19}$

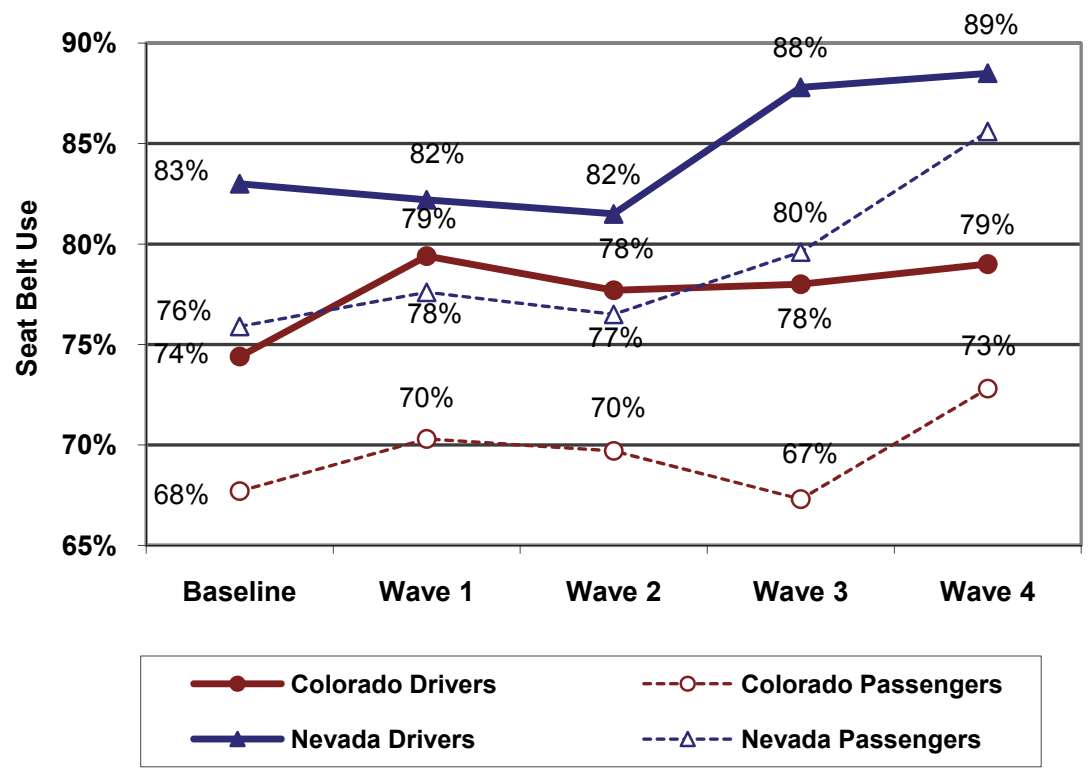

\subsubsection{Cars Versus Pickup Trucks}

Occupants of passenger cars had higher use rates than occupants of pickup trucks. This was the case in Colorado and in Nevada (79\% in cars versus $76 \%$ in pickups at baseline in Nevada; $72 \%$ versus $67 \%$ at baseline in Colorado) and baseline use rates for both vehicle types were higher in Nevada than in Colorado.

In Nevada, use among occupants of cars was significantly elevated, relative to baseline, at Wave 2 and at each subsequent wave. Use in pickups was not significantly higher than baseline until after Wave 4, although increases in these vehicles were as great as (or greater than) increases in

${ }^{19}$ Use rates for drivers and passengers were calculated from weighted overall data in Nevada and from weighted high school data in Colorado. Since there was very little difference between high school and college use in Colorado, the driver and passenger rates (when weighted and calculated for both school groups combined) would be nearly identical to the rates for Colorado shown in this Figure. 
cars at waves 3 and 4 . A smaller sample, plus a slight decline at Wave 2 resulted in nonsignificant increases in pickups at Wave 3. Overall, use increased by about 8.3 points and 6.6 points in cars and trucks, respectively.

In Colorado, occupants of cars were affected more than occupants of pickups by the initial program wave $(+6$ points versus +2 points). Over all four waves, use in cars increased by about 5 points and use in pickups increased by about 3 points. Greater variation in rates among occupants of pickup trucks may have resulted from the relatively smaller numbers of such occupants observed (compared with occupants of cars). A range of 1,000 to 1,200 occupants of pickup trucks were observed at each measurement period, compared with 5,500 to 7,000 occupants of passenger cars.

Based upon the results shown in Figure 57, it is likely that occupants of both vehicle types were affected by the teen program. In Nevada, the increases relative to baseline were significant among occupants of cars from Wave 2 through Wave 4 and among occupants of pickup trucks at Wave 4. In Colorado, increases among occupants of cars were significant at every wave and among occupants of pickups at Wave 3.

Figure 57. Teen Seat Belt Use Rates Among Occupants of Cars and Pickup Trucks in Colorado and Nevada, by Wave

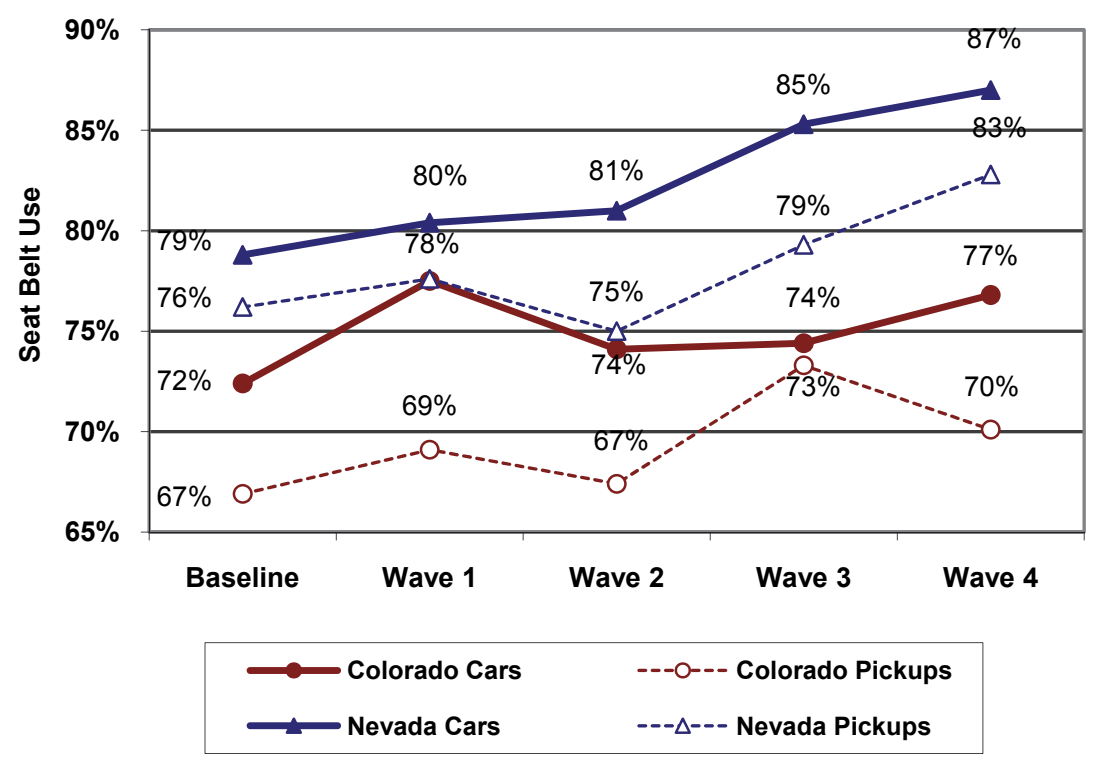

Vans and SUVs Compared with baseline rates, use in vans and SUVs (combined) increased by 6.4 percentage points in Nevada, about the same as increases among occupants of pickup trucks ( +6.6 points), but less than among occupants of cars and station wagons ( +8.4 points). All of these increases were significant $(\mathrm{p} \leq 0.05)$. Figure 58 shows that the largest increases were associated with program Wave 3 and Wave 4.

In Colorado, baseline seat belt use was higher in vans than in any other vehicle type and increases (through Wave 3 ) were greater in any other vehicle type (+9.5 points). These increases resulted in a use rate of $87 \%$ at Wave 3, significantly higher than at baseline. However, there was 
a large and significant decline in use among van occupants at Wave 4 (May 2008) and there is no immediate explanation for that decline.

Baseline use for SUVs in Colorado was just slightly greater than for passenger cars (75\% versus $72 \%)$. Increases associated with Wave 1 were modest $(+2.4$ points $)$, but significant $(\mathrm{p}<0.05)$ and use then remained unchanged until Wave 4 , when there was another modest increase $(+1.3$ points). Overall, use among Colorado teens in SUVs increased by about 4 percentage points, from baseline through Wave $4(\mathrm{p}<0.05)$. Figure 58. Teen Seat Belt Use Rates Among Occupants of Vans and SUVs in Colorado and
Nevada, by Wave

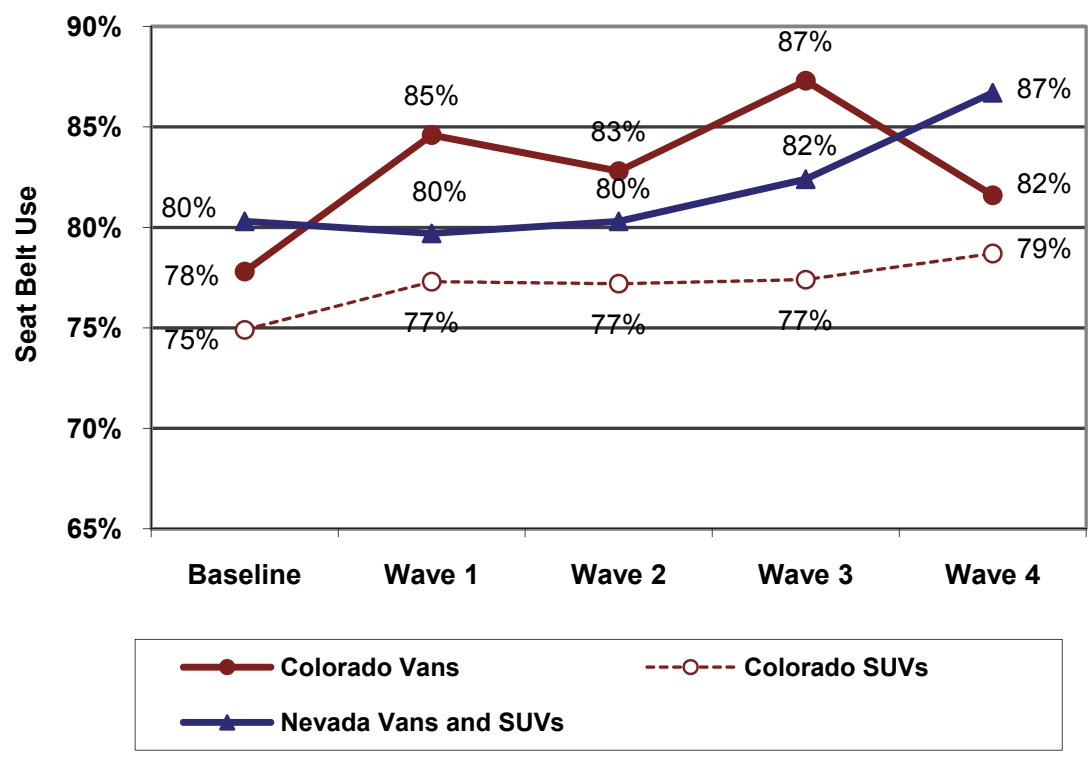

\subsubsection{Seat Belt Use Among Teens Killed in Fatal Crashes}

An examination of data from the Fatality Analysis Reporting System (FARS) for the years 2005 through 2008 found that the unbuckled percentage of teens age 16 to 20 killed in Colorado increased from 2005 to 2006; declined in 2007, from 70\% to 64\%; and declined again in 2008, from $64 \%$ to $56 \%{ }^{20}$ Due to the small numbers involved, however, these declines were not statistically significant, neither alone nor combined. Also, although teen fatalities declined in 2007 , there was an increase in such teen fatalities in 2008. Assuming a Poisson distribution, this increase $(+10$ fatalities) was not statistically significant.

In Nevada, the unbuckled percentage of teen victims 16 to 20 increased from 2005 through 2006; remained at that level (69\%) through 2007; then declined by 10 percentage points (to 59\%) in 2008. Here again, due to small numbers, this substantial decline in the unbuckled percentage of teen victims was not statistically significant. In 2008, there also was a substantial decline in the number of teen fatalities, from 39 to 17 , which was significant $(Z=-2.94 ; 95 \% \mathrm{CI}:-36,-7 ; \mathrm{p}=$ $.003)$. Figure 59 shows the decline in the unbuckled percentage of teen fatalities in Colorado and Nevada, from 2005 through 2008. The trends suggest that there may have been an impact on

\footnotetext{
${ }^{20}$ In 2007,3 of the restrained victims were "improperly restrained." If these victims were classified as unrestrained, the 2007 unrestrained rate would have been $71 \%$ and the decline to $56 \%$ would have been 15 percentage points.
} 
belt use among teens killed in crashes in both States, although other factors (e.g., GDL law improvements, parental participation) may also have contributed to this decline

Figure 59. Unbelted Percentage of Teen Fatalities in Colorado and Nevada, 2005-2008 Source: FARS
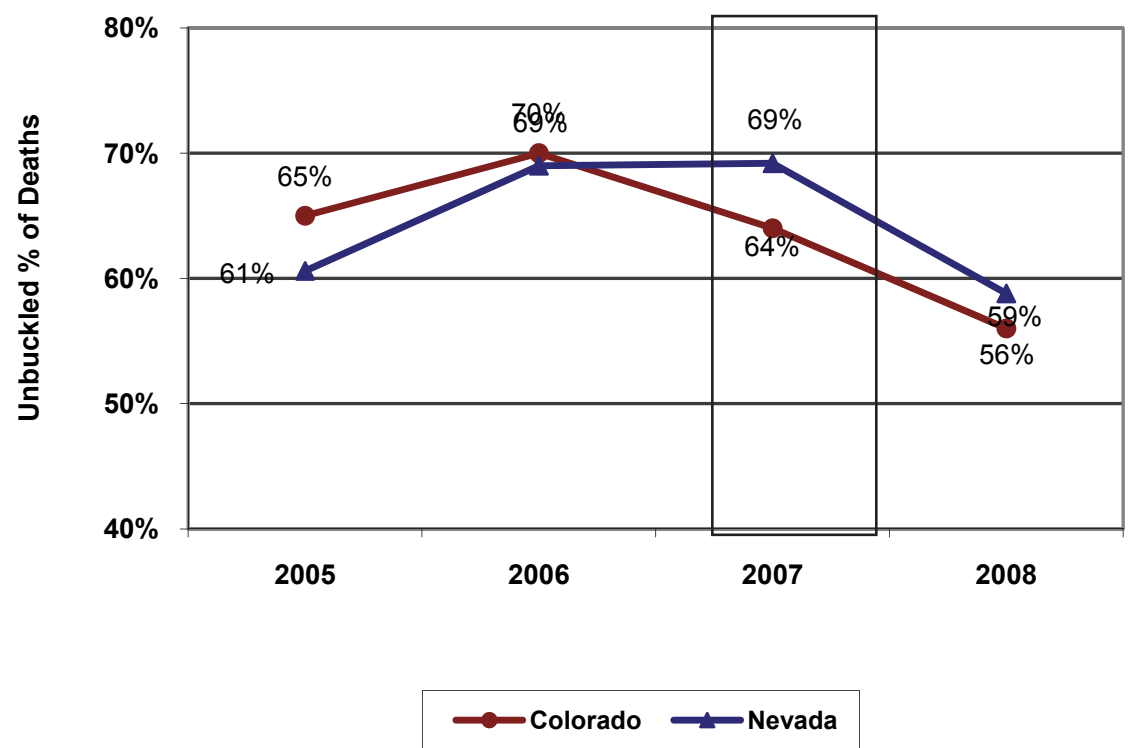
Evaluation of Teen Seat Belt Demonstration Projects in Colorado and Nevada

\section{Summary and Discussion}

\subsection{Summary}

Program-related data suggest that the teen demonstration programs implemented in Colorado and Nevada were "strong" programs. Paid media expenditures peaked at about $\$ 0.66$ per teen in Colorado and about $\$ 0.90$ per teen in Nevada (i.e., dollars spent/teen population size). With regard to enforcement, teen citations for seat belt violations peaked at about 15 per 10,000 teens in Colorado and at about 16 per 10,000 teens in Nevada. Expenditures and citations were strongest at Wave 4 in Colorado and at Waves 3 and 4 in Nevada. Presumably related to these media and enforcement activities, awareness of seat belt and enforcement messages peaked at Wave 4 in Colorado (68\% and 52\%, respectively). In Colorado, these indices peaked at Wave 3 (at $68 \%$ and $50 \%$, respectively). Thus, the highest awareness of messages and enforcement occurred in association with the May 2008 wave.

Increases in Teen Seat Belt Use. Teen seat belt use increased significantly in both States. In Nevada, increases were greater among passengers than among drivers; in Colorado, gains were similar among both occupant categories. Increases were observed among all vehicle types, in both States. The largest increases were among occupants of vans (at Wave 3 in Colorado), followed by occupants of cars and pickups (at Wave 4 in Nevada). The first and last program waves appeared to have the greatest impact in Colorado; the last two waves had the greatest impact in Nevada. Generally speaking, use at high schools (among younger teens) increased more than use at colleges (among older teens); and baselines were substantially higher among college students than among high school students (in Nevada). Baselines were also substantially higher in Nevada than in Colorado.

Within State Variations Mesa County, located in far western Colorado, had the greatest overall impact ( +10 points), benefitting from large increases in use at Wave 1 and Wave 4 . The next greatest impact was in the Denver metropolitan area ( +7 points), a much more complex media market that experienced significant impact at Wave 3 and Wave 4. The Colorado Springs/Pueblo area, located south of Denver, had a large and significant impact through Wave 3 (+8 points), but a decline at Wave 4 left use modestly, but significantly, higher than at baseline ( +4 points). There was little gain experienced in the north central (Boulder/Greeley) area which, however, had the highest baseline use rate. In Nevada, where increases were limited primarily to Wave 3 and Wave 4, the greatest increase was in the Las Vegas area ( +9 points), located in southern Nevada. The Reno area experienced only a two-point gain but it had had a substantially higher baseline rate than Las Vegas (85\% versus 76\%).

\subsection{Discussion}

Measurement Issues. At least two factors make comparable measurement of teen seat belt use difficult. The most important of these is the difficulty of measuring use among teens during the month of May, which is when States implement their statewide CIOT mobilizations and when many specially targeted demonstrations have had their greatest visibility and impact. The problem posed for teen demonstration programs is that nearly all colleges end classes very early in May (sometimes during the last week in April) and many high schools have ended regular class 
activity by the middle of May. Thus, it is difficult to obtain a measure of belt use at this time that would be comparable to measures taken earlier in the school year.

The second problem, one which likely affected the Wave 2 results in the Colorado and Nevada, was the fact that this post-holiday wave was implemented during the first two weeks of January when most colleges were still on break and immediately after most high schools returned from their holiday break. Awareness and observational surveys, which began during the third week of January caught college students just as they were returning to their campuses. This situation likely was associated with the generally lower use rates measured at Wave 2.

In addition to problems involved with implementing and evaluating teen programs implemented in May and January, teen program planners must also be mindful of spring break schedules of high school and colleges, the start of which varies from mid-March through early April. The bottom line is that planners of teen programs must look very closely at school calendars in their targeted areas.

Factors Which Could Potentially Enhance Impact The overall gains of 5 percentage points in Colorado and 8 points in Nevada represent substantial impacts, particularly given the fact that both States have secondary enforcement laws and low fine levels (\$20 in Colorado; \$25 in Nevada). It is likely that greater gains could be made with passage of a primary law upgrade and/or an increase in fine levels in either or both of these States.

Sub-Group Comparisons Because there were only a limited number of sites within the various sub-areas examined (e.g., Denver versus Colorado Springs), these intra-state comparisons were somewhat tenuous. The purpose of examining outcomes at these regional levels was to determine whether or not there was evidence of differences in impact and, if so, to determine whether or not there were program factors or other circumstances that could account for such differences. We did find evidence that suggested variations in the timing and magnitude of outcome. However, other than factors such as school calendars and variations in baseline rates, we did not find evidence that would account for such differences. Perhaps local programmers will have additional insights when reviewing these results and, of course, it may be that some of these subgroup variations were spurious, owing to the small number of observation sites involved.

Finally, it should be reiterated that the program-related data collected for this evaluation suggest that these were two well-structured and well-implemented programs. All program components, ranging from outreach, to earned and paid media, to enforcement appeared to be strong and effectively targeted toward the teen population, particularly in high schools in the targeted areas. 


\section{References}

Fell, J. C., Baker, T. K., McKnight, A. S., Brainard, K., Langston, E., Rider, R., Levy, D., \& Grube, J. (2005, September). Increasing Teen Safety Belt Use: A Program and Literature Review. (DOT HS 809 899). Washington, DC: National Highway Traffic Safety Administration. Available at www.nhtsa.gov/people/injury/newdriver/teenbeltuse/index.htm.

Glassbrenner, G. \& Ye, T. J. (2007, July). Traffic Safety Facts: Driver Cell Phone Use in 2006 - Overall Results. (DOT HS 810 790). Washington, DC: National Highway Traffic Safety Administration. Available at www-nrd.nhtsa.dot.gov/Pubs/810790.pdf.

Hedlund, J., Shults, R., \& Compton, R. (2003). What we know, what we don't know, and what we need to know about graduated driver licensing. Journal of Safety Research, 34, $107-$ 115. Available at http://downloads.nsc.org/pdf/HedlundShultsCompton.pdf.

Institute of Transportation Management [at Colorado State University]. (2004). 2004 Colorado 16 to 20 Year Old Youth Seat Belt Survey. Denver: Colorado Department of Transportation.

-----. (2005). 2005 Colorado 16 to 20 Year Old Youth Seat Belt Survey. Denver: Colorado Department of Transportation.

-----. (2007). 2007 Colorado 16 to 20 Year Old Youth Seat Belt Survey. Denver: Colorado Department of Transportation.

-----. (2008). 2008 Colorado 16 to 20 Year Old Youth Seat Belt Survey. Denver: Colorado Department of Transportation.

-----. (2009). 2009 State of Colorado Teen Seat Belt Survey. Denver: Colorado Department of Transportation.

Lin, M-L., \& Fearn, K. T. (2003). The provisional license: nighttime and passenger restrictions, a literature review. Journal of Safety Research, 34, 51-61.

NHTSA. (2007). Traffic Safety Facts 2006: A Compilation of Motor Vehicle Crash Data from the Fatality Analysis Reporting System and the General Estimates System. NHTSA. DOT HS 810 818. Washington, DC: National Center for Statistics and Analysis, U.S. Department of Transportation. Available at www-nrd.nhtsa.dot.gov/pubs/tsf2006fe.pdf.

-----. (2008, March). Traffic Safety Facts: Young Drivers 2006 Data. (DOT HS 810 817). Washington, DC: National Highway Traffic Safety Administration. Available at wwwnrd.nhtsa.dot.gov/pubs/810817.pdf. 
----. (2009). Traffic Safety Facts: 2008 Data. Occupant Protection. (DOT HS 811 160). Washington, DC: National Highway Traffic Safety Administration. Available at wwwnrd.nhtsa.dot.gov/Pubs/811160.pdf.

----. (2010). Traffic Safety Facts: 2009 Data. Occupant Protection DOT HS 811 390. Washington, DC: National Highway Traffic Safety Administration. Available at wwwnrd.nhtsa.dot.gov/Pubs/811390.pdf.

Nichols, J. L., \& Ledingham, K. A. (2008). The Impact of Legislation, Enforcement, and Sanctions on Safety Belt use. (NCHRP Report 601). Washington, DC: National Cooperative Highway Research Program, Transportation Research Board. Available at http://onlinepubs.trb.org/onlinepubs/nchrp/nchrp_rpt_601.pdf.

Tison, J., Solomon, M. G., Nichols, J. L., Gilbert, S. H., Siegler, J. N., \& Cosgrove, L. A. (2008, June). May 2006 Click It or Ticket Mobilization Evaluation: Final Report. DOT HS 810 979. Washington DC: National Highway Traffic Safety Administration. Available at www.nhtsa.gov/DOT/NHTSA/Traffic\%20Injury\%20Control/Articles/Associated\%20File s/810979.pdf.

Williams, A. F. (2003). Teenage drivers: patterns of risk. Journal of Safety Research, 34, 5-15.

-----. (2006). Young driver risk factors: successful and unsuccessful approaches for dealing with them and an agenda for the future. Injury Prevention, 12 (Suppl 1), 14-18.

Williams, A. F., McCartt, A. T., \& Geary, L. (2003). Seatbelt use by high school students. Injury Prevention, 9:25-28.

Williams, A. F., \& Shabanova, V. I. (2002). Situational factors in seat belt use by teenage drivers and passengers. Traffic Injury Prevention, 3:201-04. 
Appendices 


\section{A. Colorado Designated Market Areas \\ Courtesy of The Tombras Group}

\section{COLORADO}

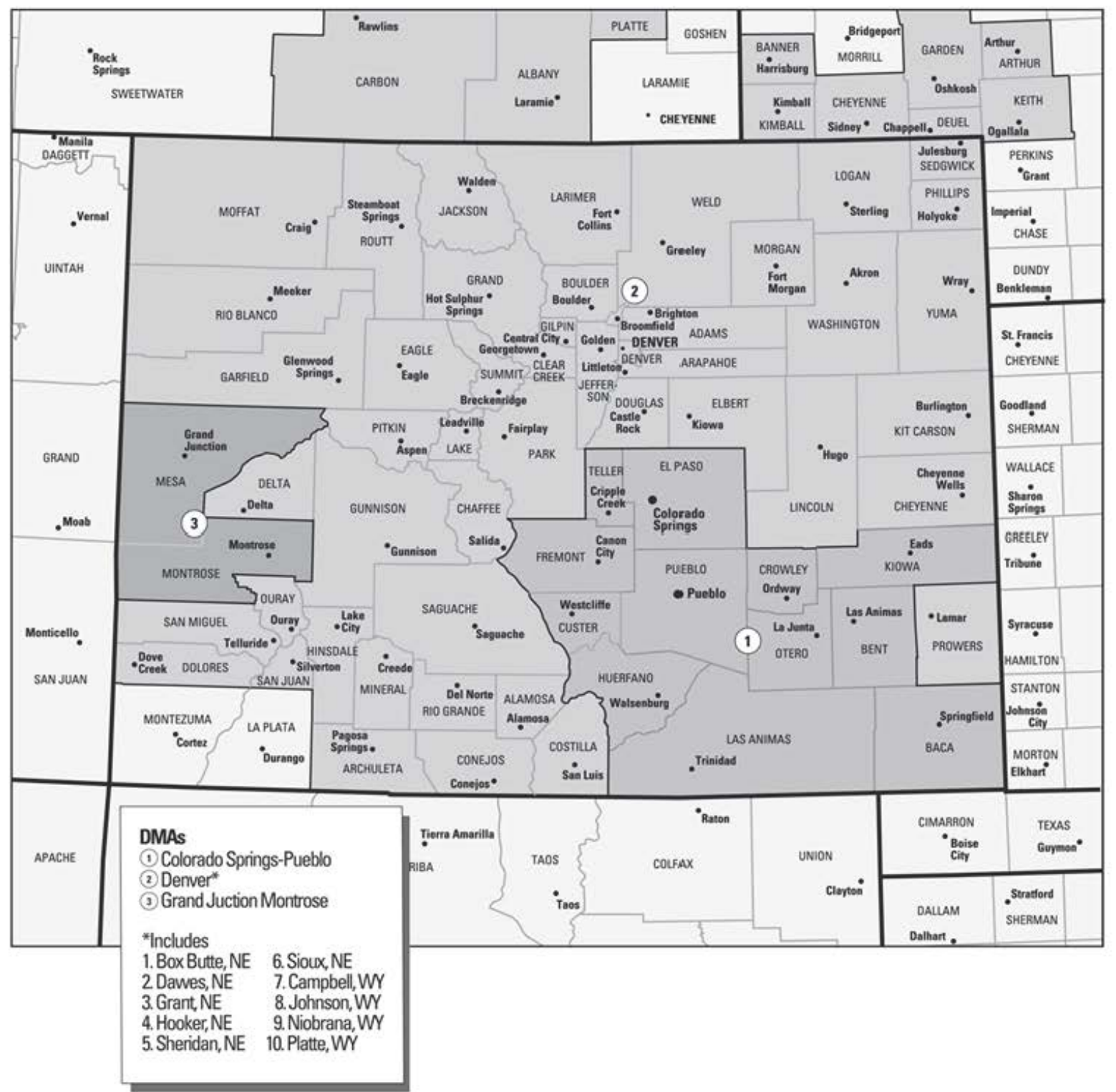




\section{B. Nevada Designated Market Areas \\ Courtesy of The Tombras Group}

\section{NEVADA}

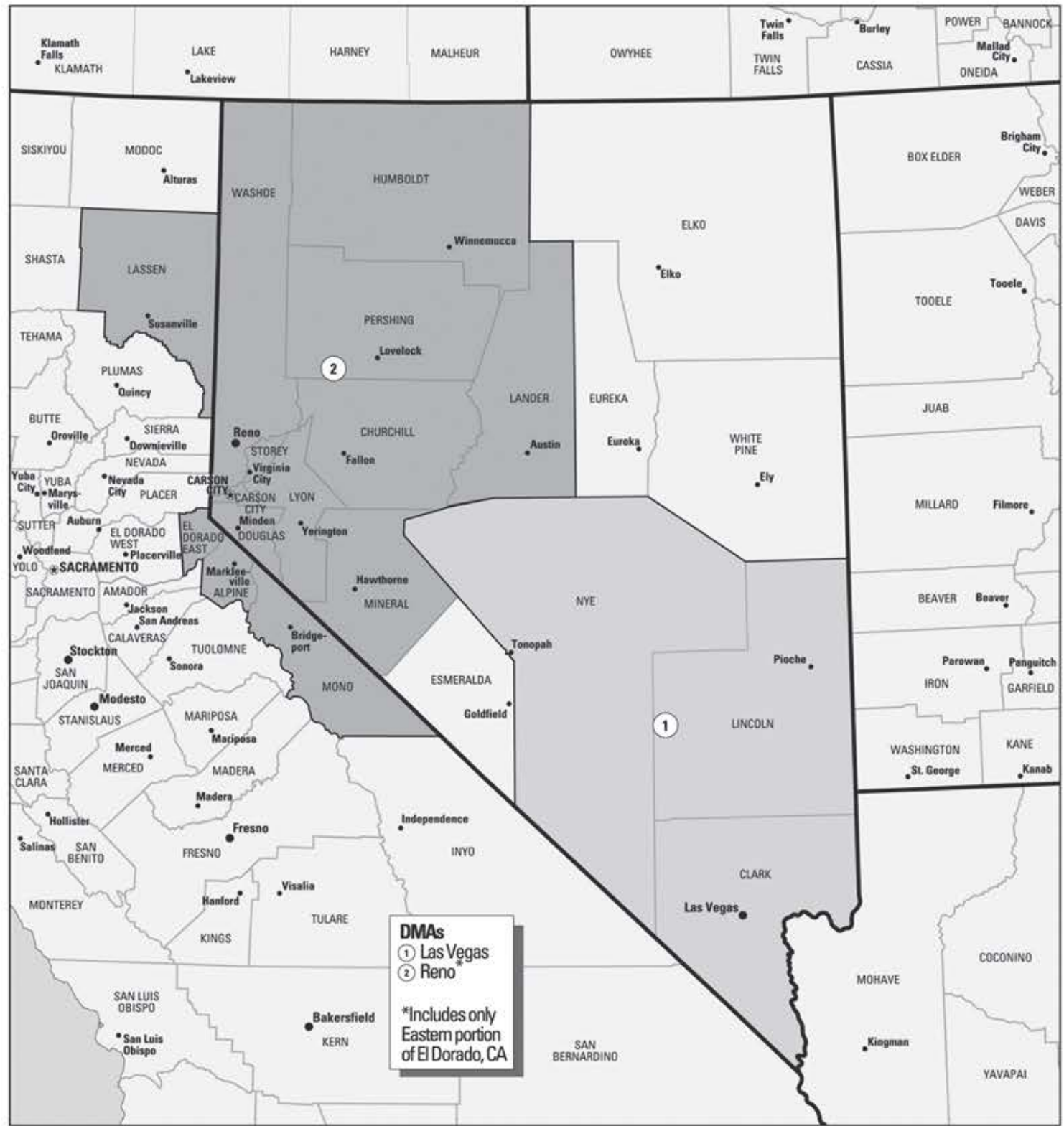




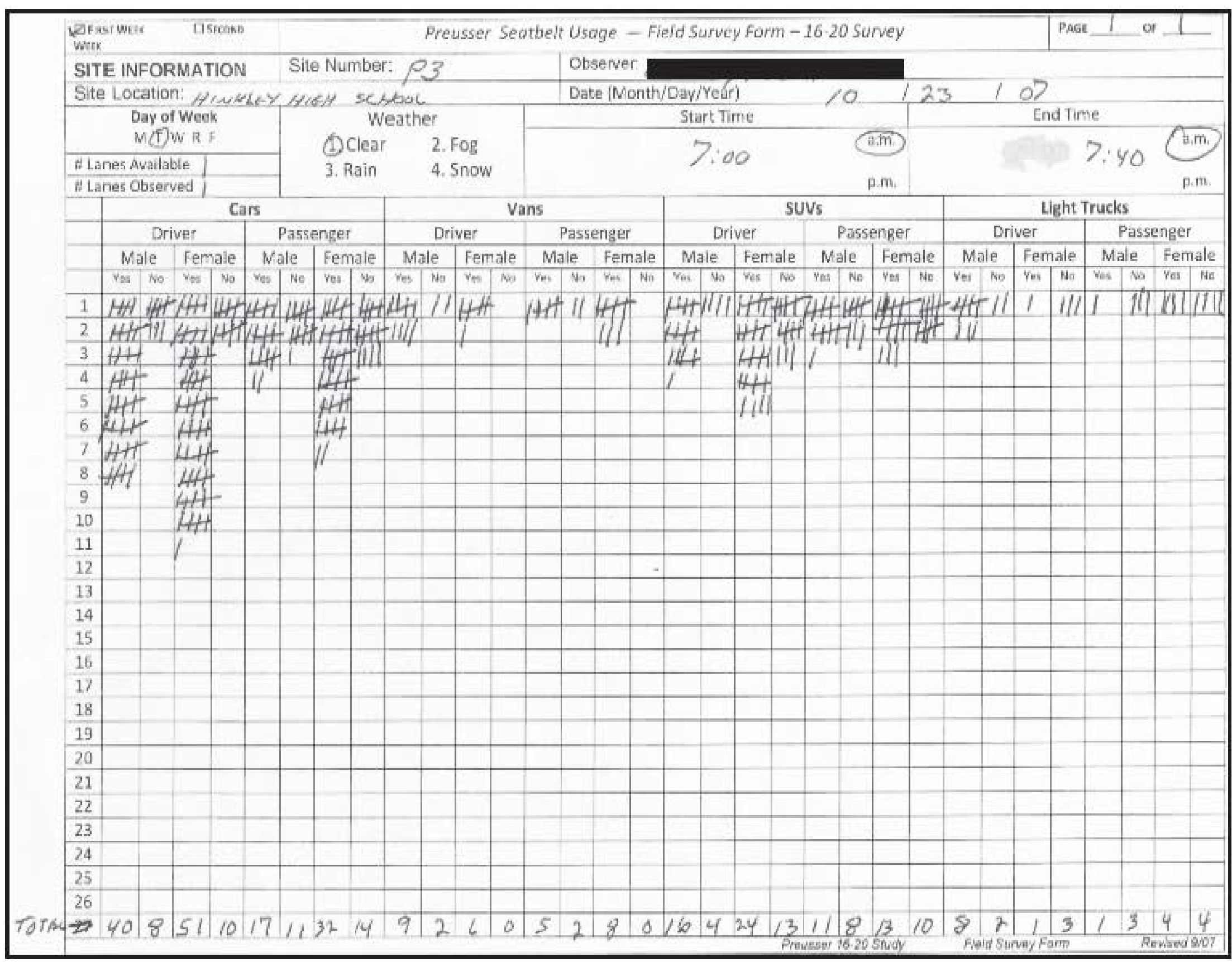




\section{Nevada Observational Survey Form \\ Vehicle-Level, front}

\section{Nevada Seat Belt Observation Data Form}

SITE NUMBer:- \# CIT: Reno location descripmon: Woster High School DATE: $05 \cdot 22 \cdot 08$ DAY OF WEEK: Thurs day START TME: $\quad 0$ ) $=0.0 \mathrm{am}$ ENDTIME: $08.00 \mathrm{am}$ WEATHER CONDITION (circie one): 1 Clear / Sunny Zuight Rain

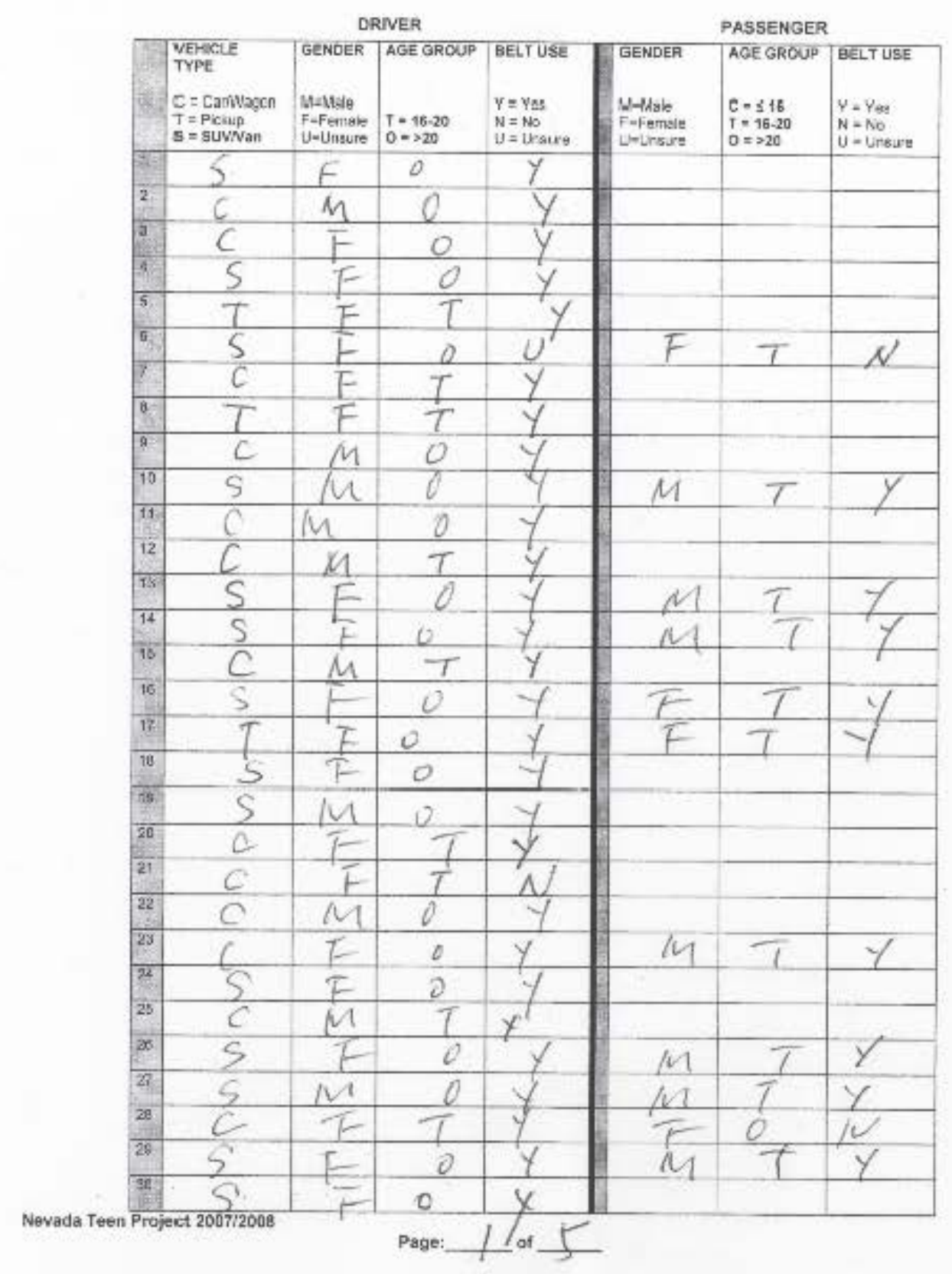


D. Nevada Observational Survey Form

Vehicle-Level, back

USE THIS FORM IF :

- THIS IS THE FIRST TIME THE OBSERVATION SITE IS VISITED

OR

- THE OBSERVATION SITE IS BEING COMPROMISED/CHANGED

PROVIDE BELOW:

- A BRIEF DESCRIPTION OF WHERE YOU ARE STANDING

- DIRECTION OF TRAFFIC YOU ARE OBSERVING AND

- LANES OF TRAFFIC YOU ARE OBSERVING.

OBSERVATION SITE DESCRIPTION: 


\section{E. Colorado DMV Awareness Survey}

The Highway Safety Program of the Colorado Department of Transportation is collecting information about safety belt use. Your answers to the following questions are voluntary and anonymous. Thank you.

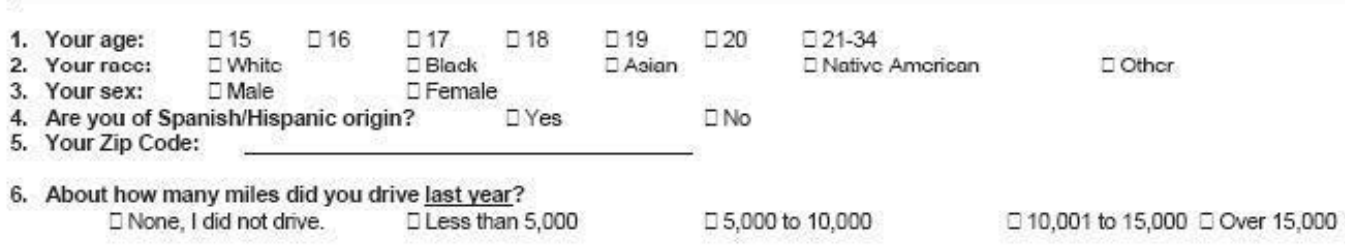

7. What type of vehicle do you drive most often?

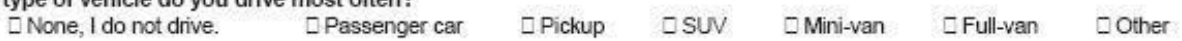

8. How often do you use safety belts when you drive or ride in a (answer for each of the following):

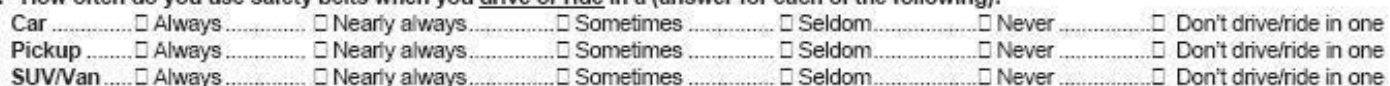

9. Do you think that it is important for police to enforce the safety belt law?

$$
\square \text { Yes } \quad \square \text { No }
$$

10. What do you think the chances are of getting a ticket if you don't wear your safety belt?

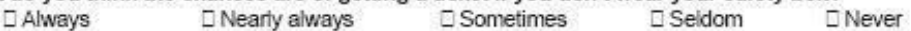

11. How strictly do you think the safety belt law in Colorado is enforced?
avery strictly
$\square$ Somewhat strictly $\square$ Not very strictly
¿Rarely
INot at al

12. In the past month, have you heard about or seen special police enforcement efforts regarding safety belt use that would affect teenagers and young people?

$$
\square \text { YNes } \quad \text { № }
$$

If yes, where did you learn about police enforcement regarding safety belt use that would affect teenagers and young people? (Check all that apply.)

¿Home ¿School ¿Work ¿Social or Recreational Area $\quad$ Driving on a roadway

13. In the past month, have you read, seen or heard any messages regarding teenagers and young people wearing safety belts?

QYes $\quad$ No

If yes, how did you see or hear about these safety belt messages? (Check all that apply.)

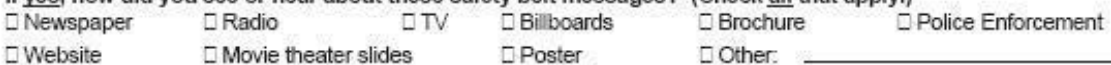

If yes, what did the messages say?

If yes, where were you when you saw or heard these safety belt messages? (Check all that apply.)

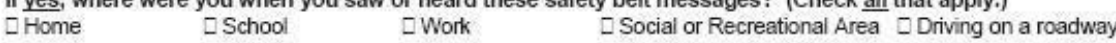

14. Do you know the name of any safety belt programs in Colorado? (Check all that apply.)

$\square$ Click It or Ticket $\square$ High School Safety Belt Challenge ¿Other $\quad$ ¿None

15. In the past month, have you read, seen or heard anything about police working at night to enforce the safety belt law?

IYes $\quad$ INo

16. In Colorado, when can a law enforcement officer stop a driver for not using a safety belt?

If the driver is 18 and older, officers can stop the driver

Z anytime the driver operates a vehicle without wearing a safety belt ¿ only if the driver has violated another traffic law

If the driver is 17 and younger, officers can stop the drive

Zanytime the driver operates a vehicle without wearing a safety belt ¿ only if the driver has violated another traffic law

17. For what age group is safety belt use mandatory for the driver?
- All eligible driving ages
¿ Under 21
च Under 18
प Safety belt use is not mandatory in the State of Colorado

18. For what age group is safety belt use mandatory for front seat passengers?
$\square$ All ages 6 and up
口under 21
-Under 18
口 Safety belt use is not mandatory in the State of Colorado

19. Do your parents/guardians require that everyone in your vehicle buckle up?

aYes aNo

If yes, how do your parents/guardians enforce the requirement that everyone in your vehicle buckle up? 


\section{F. Nevada Awareness Survey Form}

The Nevada Office of Traffic Safety in the Department of Public Safety is collecting information about safety belt use. Your answers to the following questions are voluntary and anonymous. Thank you.
1. Your age:
$\square 16 \quad \square 17$
$\square 18$
$\square 19 \square \square 20$
2. Your race:
$\square$ White $\square$ Black
$\square$ Asian
$\square$ Native American $\square$ Other
3. Your sex:
$\square$ Male $\square$ Female
4. Are you of Spanish/Hispanic origin?
$\square$ Yes $\square$ No
5. Your Zip Code:
6. About how many miles did you drive last year?

$$
\square \text { None, I did not drive. ¿ Less than } 5,000 \quad \square 5,000 \text { to } 10,000 \quad \square 10,001 \text { to } 15,000 \text { प Over } 15,000
$$
7. What type of vehicle do you drive most often?

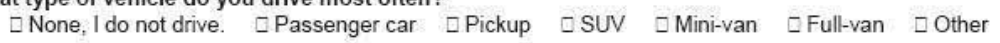

8. How often do you use safety belts when you drive or ride in a (answer for each of the following vehicles):

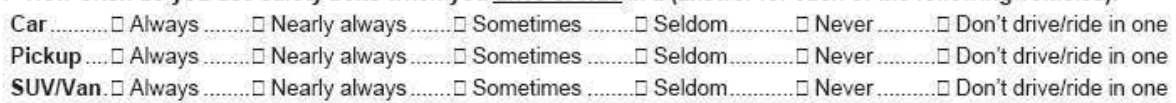

9. Do you think that it is important for police to enforce the safety belt law?

$$
\square \text { Yes } \square \text { No }
$$

10. What do you think the chances are of getting a ticket if you don't wear your safety belt?

$$
\square \text { Always } \square \text { Nearly always } \square \text { Sometimes } \square \text { Seldom Never }
$$

11. How strictly do you think the satety belt law in Nevada is entorced?

$$
\square \text { Very strictly } \square \text { Somewhat strictly } \square \text { Not very strictly } \square \text { Rarely } \square \text { Not at all }
$$

12. In the past month, have you heard about or seen special police enforcement efforts regarding safety belt use that would affect teenagers and young people?

$$
\square \text { Yes } \quad \text { No }
$$

If yes, where did you learn about police enforcement regarding safety belt use that would affect teenagers and young people? (Check all that apply.)

$\square$ Home $\quad$ School $\quad$ Work Social or Recreational Area $\quad$ Driving on a roadway

13. In the past month, have you read, seen or heard any messages regarding teenagers and young people wearing safety belts?

$\square$ Yes

$\square$ No

If yes, how did you see or hear about these safety belt messages? (Check all that apply.)

$\square$ Newspaper $\square$ Radio $\square$ TV $\square$ Billboards $\square$ Brochure $\square$ Police Enforcement

$\square$ Website $\quad$ Movie theater slides $\square$ Poster $\square$ Other:

If yes, what did the messages say?

If yes, where were you when you saw or heard these safety belt messages? (Check all that apply.)

$\square$ Home $\square$ School $\square$ Work $\square$ Social or Recreational Area $\square$ Driving on a roadway

14. Do you know the name of any safety belt safety programs in Nevada? (Check all that apply.) $\square$ Buckle Up Nevada $\square$ Driver's Edge $\square$ Just Keep Thinking Safety
$\checkmark$ Click It or Ticket
$\square$ PACE
$\square$ Other
- None

15. In the past month, have you read, seen or heard anything about police enforcing the safety belt law at night? $\square$ Yes $\square$ No

16. In Nevada, when can a law enforcement officer stop a driver for not using a safety belt? $\square$ anytime the driver operates a vehicle without wearing a safety belt $\square$ only if the driver has violated another traffic law

17. For what age group is safety belt use mandatory for the driver? $\square$ All eligible driving ages $\square$ Under $21 \quad \square$ Under $18 \quad \square$ Safety belt use is not mandatory in the State of Nevada.

18. For what age group is safety belt use mandatory for passengers?

$$
\square \text { All ages } \square \text { Under } 21 \quad \square \text { Ages } 6 \text { and up } \quad \square \text { Safety belt use is not mandatory in the State of Nevada. }
$$

19. Do your parents/guardians require that everyone in your vehicle buckle up?

$$
\square \text { Yes } \quad \text { No }
$$

If yes, how do your parents/guardians enforce the requirement that everyone in your vehicle buckle up? 


\section{G. Radio Script}

OUT OF NOWHERE :30 Radio

NOTE: $\quad$ This spot uses sound effects to create the impression that the teens are talking about UFOs. It will also have music that suggests the old $X$-files theme. The read by the teens is nervous and intense.

TEEN 1: I was just driving around minding my own business ...

TEEN 2: $\quad$ When it came out of nowhere ...

TEEN 3: Suddenly, there were lights all around me ...

SFX: $\quad$ Sound effects and music build in intensity.

TEEN 2: l'm like "They're coming for me!"

TEEN 3: Yeah, it was crazy.

TEEN 1: I just never thought they'd find me. Not out here.

SFX: SIREN WHOOP!

TEEN 2: Next thing I know, a cop's giving me a ticket for not wearing a seat belt. I couldn't believe it.

ANNCR: In [State], anyone can get pulled over for not using a seat belt. If you don't buckle up, you will get caught. Cops are cracking down all across the state. Click it or ticket. Paid for by ... [State supplied]. 

DOT HS 811518

September 2011

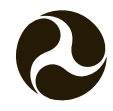

U.S. Department of Transportation

National Highway

Traffic Safety

Administration

.

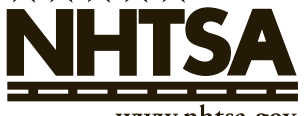

www.nhtsa.gov 